\section{BUILDINGA CONTINUUM} GERSTEN JONKER
Competence development from student to medical specialist

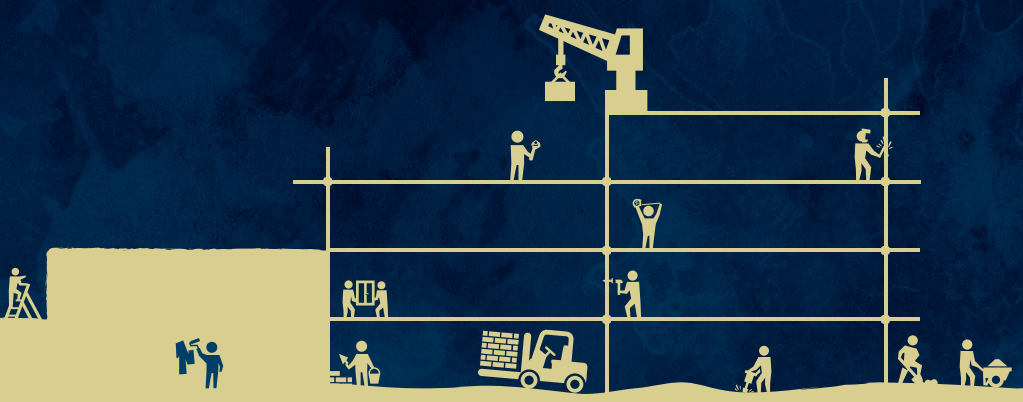





\section{GERSTEN \\ JONKER}




\section{COLOPHON}

Cover design: $\quad$ James Jardine | www.jamesjardine.nl

Layout: $\quad$ James Jardine | www.jamesjardine.nl

Print: $\quad$ Ridderprint | www.ridderprint.nl

ISBN: $\quad$ 978-94-6416-488-6

De uitgave van dit proefschrift is mede ondersteund door de Nederlandse Vereniging voor Medisch Onderwijs en de Divisie Vitale Functies, UMC Utrecht.

Copyright @ 2021 by Gersten Jonker. All rights reserved. Any unauthorized reprint or use of this material is prohibited. No part of this thesis may be reproduced, stored or transmitted in any form or by any means, without written permission of the author or, when appropriate, of the publishers of the publications. 


\title{
Building a continuum \\ Competence development from student to medical specialist
}

\author{
Bouwen aan een continuüm \\ Competentieontwikkeling van student tot medisch specialist
}

(met een samenvatting in het Nederlands)

Proefschrift

ter verkrijging van de graad van doctor

aan de Universiteit Utrecht

op gezag van de rector magnificus, prof.dr. H.R.B.M. Kummeling,

ingevolge het besluit van het college voor promoties

in het openbaar te verdedigen op donderdag 22 april 2021 des middags te 4.15 uur

door

Gersten Jonker

geboren op 4 november 1976

te Leek 
Promotoren:

Prof.dr. Th.J. ten Cate

Prof.dr. R.G. Hoff 



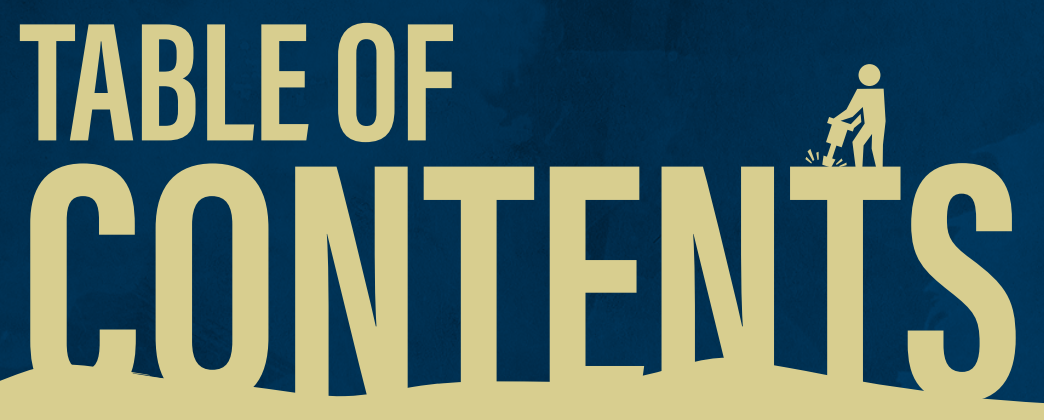


Chapter 2 Connecting undergraduate and postgraduate medical education through an elective EPA-based transitional year in acute care: an early project report

Chapter 3 An elective EPA-based thematic final medical school year. An appreciative inquiry study among students, graduates and supervisors

Chapter 4 Simulation at the frontier of the Zone of proximal development: a test in acute care for inexperienced learners

Chapter 5 In pursuit of a better transition to selected residencies: a final year of medical school dedicated to the acute care domain

Chapter 6 Variations in assessment and certification in postgraduate anesthesiology training: a European survey

Chapter 7 Would you trust your loved ones to this trainee? Certification decisions in postgraduate anesthesia training

Chapter 8 A case for competency-based anesthesiology training with entrustable professional activities. An agenda for development and research.

Chapter 9 General discussion

$\begin{array}{lll}\text { Appendices Summary } & 207\end{array}$

$\begin{array}{ll}\text { Samenvatting in het Nederlands } & 213\end{array}$

$\begin{array}{ll}\text { Dankwoord } & 221\end{array}$

$\begin{array}{ll}\text { Curriculum vitae } & 225\end{array}$ 


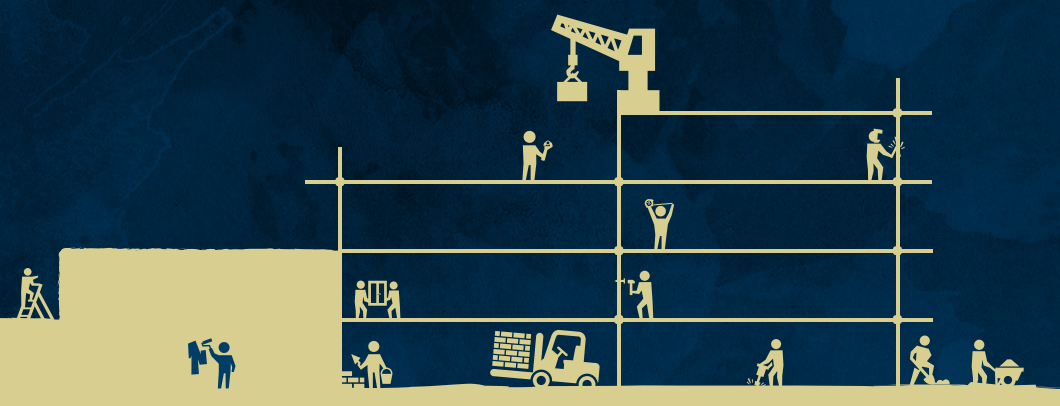


GENERAL INTRODUCTION 



\section{MEDICAL EDUCATION: A SERIES OF STAGES}

In medical education, learners develop through a series of stages to become doctors [1]. In medical school, students move from classroom education to workplace learning in clinical clerkships. A phase of increased responsibilities follows graduation from medical school in several countries to lay the foundation of practicing as a physician [1]. In other countries, graduates move directly into postgraduate specialty training (residency)'. After completion of postgraduate training and certification as a medical specialist, doctors may move into fellowship training or into unsupervised practice.

The move from one educational stage to another comes with challenges and difficulties and is referred to as a transition. A transition is defined as the (process of) change, passage, or development from one form, state, or stage to another (Cambridge Dictionary, dictionary.cambridge.org, and Merriam-Webster Dictionary, merriamwebster.com). Applied to medical education, a transition is a period of change, in which individuals experience some form of discontinuity forcing a response to cope with the new situation [2].

Because of the associated challenges, transitions have attracted considerable attention in the medical education literature $[3,4]$. In general terms, learners struggle to adapt to the expectations of the role in the new stage [5-9]. For example, students, who transition to the junior clerkship phase, experience difficulties in participating and learning in the workplace, due to lack of practical skills, unfamiliarity with clinical routines and incongruous learning strategies $[5,7]$. The transition from student to doctor has received ample attention. In several studies, students, graduates, and faculty perceive this significant transition as problematic and they identify gaps in graduates' preparedness to carry patient care responsibility at the start of postgraduate training [10-13]. Also after postgraduate training, newly certified specialists entering subspecialty fellowship training are reported to have insufficient expertise and skill for autonomous work $[8,14]$ and fresh specialists are suboptimally prepared for managerial, financial and teaching tasks that belong to their new role $[9,15]$.

Taken together, rather than a continuum, the educational trajectory to medical specialist is a series of stages, in which one stage does not seamlessly prepare for the next. The trajectory may be continuous in time and arrangement, but it is deficient in representing

\footnotetext{
${ }^{1}$ The stage of medical school, with graduation leading to licensure as a doctor is in this thesis referred to as undergraduate medical education. The stage after medical school leading to certification as a medical specialist is referred to as postgraduate (specialty) training.
} 
a "coherent whole" that typifies a continuum [16]. Put differently, the stages do not have an overarching single goal - to train doctors fit for healthcare needs -, but instead each stage has its own goals.

A better alignment of stages could lead to a developmental pathway of learning across the continuum from undergraduate medical education to postgraduate training and into practice $[17,18]$. It would strengthen the connection between the basic sciences and clinical medicine, between medical education and patient care, and the pathway would facilitate transitions and foster the progression of a learner's professional and personal development [17]. Ultimately, this could lead to an effective and efficient trajectory to train competent doctors that provide safe and high quality patient care.

\section{IMPROVING CONNECTIONS BETWEEN STAGES}

\section{Prior to postgraduate training: a spectrum of initiatives}

Around the globe, at all stages of education and training, programs make efforts to facilitate transitions and to align one stage with the next. In undergraduate medical education, curricula combine teaching basic sciences with clinical application and reasoning, as well as with skills and communication training, followed by early clerkships in a vertically integrated curriculum $[19,20]$. Some clerkship programs introduced longitudinal, integrated clinical experiences [21]. Another approach emphasizes the role of electives to support and monitor development [22], with specialty streaming, i.e. undergraduate pre-residency training within a specialty being a marked example [23]. In addition, medical educators advocated to improve final year design to optimize graduate readiness [10, 11, 24-26]. After graduation, the United Kingdom has two foundation years, in which the recent graduates obtain full licensure after one year. In the United States of America and Canada all graduates proceed through an internship year, sometimes preceded by rigorously focused preparatory bootcamp courses [6, 27], before starting specialty training [28].

\section{In postgraduate training: competency-based medical education}

Whereas many different initiatives aimed to improve the undergraduate part of the trajectory, in postgraduate training all initiatives were dwarfed by one dominant force that has been making an advance over the last two decades: competency-based medical education (CBME). This theoretical framework has induced a major shift in thinking about specialty training. 
The idea of CBME originated in the late seventies of the twentieth century when a World Health Organization report suggested that the output of medical training be doctors who are able to practice at a defined level of proficiency to meet local health care needs [29]. It initiated an educational evolution toward curricula that are derived from doctors' current or future role in society and that aim to license or certify learners based on demonstrable proficiency in aspects of that role [30].

Presently, CBME is defined as "an approach to preparing physicians for practice that is fundamentally oriented to graduate outcome abilities and organized around competencies derived from an analysis of societal and patient needs. It de-emphasizes time-based training and promises greater accountability, flexibility, and learnercenteredness" [31].

In CBME, the self-regulating medical profession acknowledges the obligation to society to focus on outcome, i.e. to deliver able graduates who consistently provide safe and effective, patient-centered care [3, 32-36]. CBME "starts with the end in mind" - desired outcomes of physicians that must demonstrate to meet society's needs [16]. Instead of concentrating (only) on knowledge, CBME emphasizes the attainment of the required abilities, framed as observable competencies synthesized from necessary technical and interpersonal skills and attitudes [34].

CBME can improve the connection between stages of education, as it builds a curriculum around the end-product it promises to deliver.

Learners do not necessarily take the same amount of time to master the required competencies. Therefore, in CBME, the learner is central. With a transparent path towards clear goals, a learner should be able to complete a personally tailored program in which time and the process are secondary to the development of learner competence [34].

Assessment is important in establishing that graduates have met the outcomes. However, competencies are difficult to assess separately [37, 38]. Also, atomizing medicine into too many competencies, detached from context, is not meaningful [18]. It may reduce assessment to a check box exercise [37]. Competence, as a holistic integrated model of competencies, is not necessarily directly assessable, but can be inferred from performance [39]. Workplace assessments with a variety of tools provide subjective low-stakes data on single encounters, with the main goal of supporting learner progress. When aggregated, the data points should paint a complete, valid, and reliable picture of learner performance that can be used for high-stakes decisions. This approach to assessment is called programmatic assessment [40-42]. 


\section{The role of entrustable professional activities}

CBME can be strongly anchored in clinical work with entrustable professional activities $[43,44]$. Entrustable professional activities (EPAs) relocate competencies from theory to clinical practice $[45,46]$.

An EPA is defined as an essential task of a discipline (profession, specialty, or subspecialty) that an individual can be trusted to perform without direct supervision in a given health care context, once sufficient competence has been demonstrated $[43,44,47]$.

An EPA can be executed as a discrete, observable and assessable entity in the workplace. EPAs display the training opportunities in clinical practice and direct the attention of assessing supervisors [43]. An EPA requires competencies from different competency domains and observing EPA performance allows inferences to be made about these competencies $[43,44,48]$.

A set of EPAs clarify the learning objectives of a program [43] and thus what a program graduate is expected to be able to do; i.e. in postgraduate training a set of EPAs describes what a medical specialist can be expected to do.

Learners develop their competence gradually toward the level of a medical specialist. Supervisors can entrust an EPA to a learner to execute that task without direct supervision, once the learner attained an adequate level of performance in the EPA [43, $44,48]$. This constitutes a formal summative decision, a certificate to execute a part of the work of the specialty.

The granting of responsibility, through entrustment, requires an assessment system consisting of several tools to construe a robust view on the trainees level of performance. In addition, entrustment is dependent on the degree of trust the supervisor has in the trainee, the trustworthiness of the trainee, the relationship that the supervisor and trainee have, task factors, and contextual factors [44, 45, 49-51]. During the development toward medical specialist, trainees attain competence, grow trust, and get progressive responsibility when increasing numbers of EPAs of increasing complexity are entrusted to them. This process may commence prior to entering residency and this puts CBME with EPAs in the position to improve the connection between stages and forge a continuum $[3,36]$. 


\section{THE DEVELOPMENT OF COMPETENCE}

A central construct in this thesis is competence. Competence is defined as the possession of the integrated range of interpersonal and technical competencies and abilities, across multiple aspects of performance, synthesized from relevant knowledge, skills, and attitudes, that are needed and habitually and judiciously used to perform tasks within the scope of professional practice [34, 39, 52].

An individual's competence may develop further with continuing practice and learning or recede with disuse. Competence is to a certain extent context-dependent and may vary between situations, settings or environments, depending on factors and resources outside the individual $[34,48]$. It includes expertise, professional judgments, and discernment of limits [39]. Societal, professional, and educational opinions on what the constituents of competence and being competent are is subject to change over time and culturally dependent [35]. As such, it does not only describe what is expected of a trained doctor, but also serves as a barrier to entry, progression, graduation, licensure, and certification [35].

\section{Models, theoretical frameworks, and theories}

To understand how competence develops, we have to consult educational models, theoretical frameworks, and theories.

One way to describe the development of competence is the model of Dreyfus \& Dreyfus $[53,54]$. It recognizes five stages from novice to expert and competence is not an endpoint but the middle stage of the spectrum. Reaching the competence state signifies the permission for unsupervised practice [48]. The expert state implies adaptive expertise, meaning that the professional can adapt her performance to the demands of a situation [54].

Ericsson emphasizes the importance of deliberate practice in his theoretical framework for the development of expertise [55]. It stresses the significance of continuing practice of a complex skill or activity over time. Moreover, engaging in the activity should be deliberate, i.e. the practitioner should counteract automaticity and stay aware of possibilities to keep improving performance at challenging levels. Building expertise on experience with the activity requires the practitioner to actively monitor and evaluate her execution of that activity. 
Translated to learning and to competence development, this would mean that a learner engages with specific tasks, receives detailed direct feedback, and has opportunities to improve the execution of the activity. This approach is analogous to the mastery learning model [56].

For the development of competence in medicine, clinical experience is key. Experiential learning, is learning elicited by authentic experiences in practice [57, 58]. Experiential learning, or its phenotype of Workplace learning, stems from the grand theory of Socio-cultural learning. This grand theory, i.e. a group of theories, holds that learning is situated in a social context and takes place in interactions between the learner and the social environment [57]. Workplace learning theory states that the quality and quantity of the participatory interactions determine the richness of learning [59]. The relation between workplace affordances and learner agency define the extent of learner participation. Workplace affordances are contextual factors that promote or hinder learner participation, such as rules of conduct, practice culture, and kinds of activities, whereas learner agency relates to the degree of proactivity and engagement [59].

Also rooted in Socio-cultural learning theory, and related to Workplace learning theory, is the theory of Communities of practice [60], which resonates significantly with medical education [57]. From this perspective, learning is situated in a community of practice in which the learner participates. The community has a common goal and possesses the required knowledge and language to strive for this goal. The learner starts to work and learn at the periphery of the practice, while participating in and contributing to part of the work of the community; this is referred to as legitimate peripheral participation. As a result of learning, the learner moves toward the center of the community, where the qualified members are situated. At the same time, the formation of professional identity is stimulated.

Both Workplace learning and Communities of practice theories emphasize that learner development is not to be left to chance, but happens best when supported by choosing and staging participatory learning activities in a curriculum.

Developing from novice to expert [53], building expertise by deliberately engaging in challenging activities [55], actively participating within the social context of a community of clinical practice $[59,60]$, requires that a learner is supported to develop.

Vygotsky, one of the founders of Socio-cultural learning theory, addressed this in the theory of the Zone of proximal development [61], which originally concerned agerelated cognitive child development stages. The zone of proximal development refers 
to the virtual and variable space between the current developmental level and the level of potential development. Independent problem solving characterizes the actual developmental level, whereas in the zone of proximal development adequate guidance by an experienced person (e.g. teacher) is required for adequate performance [61, 62]. The zone also refers to the steps needed to get to the next level of capability.

A final theory mentioned here in relation to competence development is Selfdetermination theory [63]. It is a major theory of motivation from experimental educational psychology and consists of a set of psychological mechanisms relating to the self [64]. Self-determination theory asserts that an individual's natural propensity for development is stimulated when three psychological needs are satisfied. These are the needs for competence, for autonomy, and for relatedness. Competence refers here, in this theory, to the need to feel confident and effective, or - psychologically phrased - the perception of effectance. Autonomy relates to the perception of volition, participating in useful interactions out of free will. Relatedness reflects belonging to a social group or community $[63,64]$. Satisfaction of the needs boosts intrinsic motivation, social development, and well-being, facilitating learning [63].

The abovementioned models, frameworks and theories regarding competence development play a role in thinking about shaping a continuum in medical education. For that reason, they will be applied in the research of this thesis.

\section{BUILDING AN EDUCATIONAL CONTINUUM}

Despite initiatives at the undergraduate and postgraduate levels of the educational trajectory to medical specialist, a misalignment of curricula across transitions still exists [16] and the trajectory can be seen as a series of linked but independent silos "haphazardly pieced together" [65]. Continuity within stages and integration of experiences across stages would reinforce learning and foster a seamless formation across the continuum $[16,66]$.

CBME offers a solid starting point to forge an educational continuum [3, 16, 18, 65-67]. It provides us with a common framework and language that could be used across the continuum [65], which fits well with the model of a novice-to-expert trajectory [53]. CBME puts the learner central and thus requires an active role of the learner to self-direct her progression toward competence in sequenced learning experiences $[17,65]$, which matches the theoretical framework of Deliberate practice [55]. It requires supervision and coaching to assist the learner in efficiently navigating the zone of proximal development to reach the next developmental level $[61,62,64,65]$. Appropriate supervision has to 
balance safe and effective patient care with robust experiential, workplace learning [17, $57,65]$. This is the task of the community of practice in which the learner participates in working and learning [57].

A CBME curriculum to construct a continuum "starts with the end in mind": physicians who consistently provide safe effective patient-centered care to the population they serve $[3,18]$. That requires the delineation of the requisite competencies of specialists and the design of a developmental assessment system to observe and evaluate learners across the continuum in meeting the competencies $[3,18]$. Subsequently, the expected outcomes for a phase, such as undergraduate medical education, in the continuum can be reverse engineered.

\section{PURPOSE OF THE THESIS}

Forging the transition to an education continuum is an evolutionary and iterative process [65]. The objects of study of this thesis take a place in this evolution. The overall aim of the thesis is to explore the role of competency-based medical education and entrustable professional activities in creating an educational continuum that fosters the development of competence.

\section{Final year of medical school}

The first part of the thesis regards the final year of medical school and the role of competency-based education in the transition from student to doctor.

Graduation from medical school has become an intermediate station in a long educational trajectory, rather than an end point [68]. Most doctors continue the educational trajectory in some form of postgraduate training. This transition could be eased by explicit preparation for tasks in the next stage; not only for general tasks of a doctor, but specifically for the direction the student is aspiring to continue in $[25,69-71]$.

In the Netherlands, undergraduate medical education is a six year vertically integrated curriculum $[19,20]$. In the first stage, a three-year bachelor phase, the emphasis is on basic sciences, but these are integrated with clinical application and reasoning, as well as with skills and communication training. Clinical rotations start in the third year of the bachelor. In the subsequent three-year master phase, clinical rotations are combined with preparatory courses $[19,20]$. The sixth and final year of undergraduate 
medical education prepares for work as a doctor by a graded increase in clinical care responsibilities during an individually assembled set of electives. It is referred to as a transitional year [19, 72-74].

The object of study in the first part of the thesis is an innovative approach to the transitional year at the University Medical Center Utrecht that students can elect to follow. It applies horizontal integration by offering a multidisciplinary track around the theme of acute care, with interdisciplinary learning outcomes. The track aims to enhance competence development and improved preparedness for work in this area. The students commence the track by taking a multimodal pre-test in acute care that includes managing critically ill patients in a high-fidelity simulator. Simulation can be stressful, all the more when it involves medical emergencies $[75,76]$. On the other hand, a formative pre-test may clarify learning objectives and may be very valuable and motivating to students [77].

The overarching research question is: is an elective transitional year track dedicated to acute care helpful in easing the transition from student to doctor and in building an education continuum in a specialty where acute care is relevant?

Contributing research questions are:

- Does such an elective final year, focused on acute care, have a beneficial effect on the development of competence and preparedness for the next stage, i.e. working as a doctor in an acute care specialty?

- If the innovation has effect, can its effect be understood by looking at learning theory, like Communities of practice, and motivational theory, such as Selfdetermination theory? And if the innovation does not sort effects, do these theories require adaptation?

- What is the psychosocial and educational effect on students of simulation pretesting beyond the competence level of graduates?

\section{Postgraduate anesthesiology training}

The second part of the thesis aims to establish what current postgraduate anesthesiology training in Europe looks like and to gauge the progression to CBME. In addition, it explores the role of EPAs in operationalizing CBME in postgraduate anesthesiology training. 
At the start of the research project leading to this thesis (late 2013), EPAs began to emerge around the globe as curricular building blocks in postgraduate specialty training in obstetrics \& gynecology [78], psychiatry [79], family medicine [80], and internal medicine [81].

Within anesthesiology, there is an important lack of clarity what the current approaches to training and in particular assessment and certification are. In the European Union, member states have to mutually acknowledge equivalent diplomas, making migration of professionals, including doctors, possible. This assumes comparability of training outcomes, but whether training outcomes or competence levels are equivalent is unknown. The studies in this thesis aim to map the present state and to explore whether we can be content with the level of competence of the specialists we have trained and how we ascertain this level.

The research questions are:

- What is the structure, or are the structures, of European postgraduate anesthesiology training and to what degree have training programs transitioned to CBME and to EPAs?

- What is the foundation or justification of the ultimate entrustment decision of certification ${ }^{2}$ granted to trainees at completion of training in anesthesiology in Europe?

- How can CBME, operationalized with EPAs, be applied to postgraduate anesthesiology training, and what research is required to assist competency-based anesthesiology training with EPAs?

\footnotetext{
${ }^{2}$ certification is defined as the process of all steps in meeting requirements and in decision making that eventually leads to the completion of training and access to registration as a medical specialist.
} 


\section{OUTLINE OF THIS THESIS}

We will address the research questions as follows.

The first part of the thesis focuses on the final year of undergraduate medical education and the role of competency-based education in the transition from student to doctor.

Chapter 2 presents the idea of the multidisciplinary elective final year dedicated to acute care. The descriptive study discusses the design and establishment of the track. It links the theory of Communities of practice to the thinking behind the track. It also coins the idea of elective profile EPAs as advanced level and specific objectives, offering targeted preparation for postgraduate training in a range of specialties.

After implementation of the acute care final year elective track, an explorative qualitative study looks at strengths and challenges of the track and how it produces effect (Chapter 3). The study uses appreciative inquiry as a method for interviews and focus groups with end-users of the track. It uses Self-determination theory as an interpretive lens.

Chapter 4 zooms in on the use of simulations in the pre-test at the start of the elective final year focused on acute care. The study aims to provide understanding of the psychosocial and educational effect that high-fidelity simulations of critically ill patients has on students. Such overly challenging scenarios happen at the student's far edge of the zone of proximal development. The findings of this phenomenological study are to be linked to Vygotsky's Zone of proximal development theory.

Chapter 5 evaluates the effect of the elective final year focused on acute care on learning and preparedness for practice, measured as performance of students in a multimodal assessment. The quasi-experimental study uses a pre-test \& post-test design and compares track students' performance with that of non-track students - with an interest in acute care - and with junior doctors working in acute care specialties.

The second part of the thesis relates to postgraduate anesthesiology training.

Chapter 6 seeks to establish the current state of affairs in European postgraduate anesthesiology training. A survey study, with quantitative and qualitative data, compares national programs with regards to assessment and certification processes to evaluate the current place of CBME.

Chapter 7 aims to provide a better understanding of the foundation and justification of certification decisions in European postgraduate anesthesiology training. In an 
interview study using a constructivist grounded theory approach the focus is on how decision-makers ascertain that trainees have reached the competence level of a medical specialist.

Chapter 8 explores the possible role of EPAs in postgraduate anesthesiology training and sets an agenda for curriculum development and research.

The thesis concludes with a General discussion in Chapter 9 that highlights findings from each study in the thesis and puts them into perspective of the literature. It describes implications of the research for clinical educational practice and suggests avenues for further research.

Note: The thesis is a collection of research articles, written as stand-alone papers. A degree of repetition and overlap across chapters is therefore inevitable. 


\section{REFERENCES}

1. Wijnen-Meijer M, Burdick W, Alofs L, Burgers C, ten Cate O. Stages and transitions in medical education around the world: clarifying structures and terminology. Med Teach 2013; 35(4):301-7.

2. Westerman M. Mind the gap. The transition to hospital consultant [thesis]. 2012, Vrije Universiteit Amsterdam.

3. Aschenbrener CA, Ast C, and Kirch DG. Graduate medical education: its role in achieving a true medical education continuum. Acad Med 2015; 90(9):1203-9.

4. Custers $\mathrm{E}$, ten Cate O. The history of medical education in Europe and the United States, with respect to time and proficiency. Acad Med 2018; 93(3S Competency-Based, Time-Variable Education in the Health Professions):S49-54.

5. O'Brien B, Poncelet AN. Transition to clerkship courses: preparing students to enter the workplace. Acad Med 2010; 85(12):1862-9.

6. Cohen ER, Barsuk JH, Moazed F, et al. Making July safer: simulation-based mastery learning during intern boot camp. Acad Med 2013; 88(2):233-9.

7. Teunissen PW, Westerman M. Junior doctors caught in the clash: the transition from learning to working explored. Med Educ 2011; 45(10):968-70.

8. Mattar SG, Alseidi AA, Jones DB, et al. General surgery residency inadequately prepares trainees for fellowship: results of a survey of fellowship program directors. Ann Surg 2013; 258(3):440-9.

9. Westerman M, Teunissen PW, Fokkema JP, et al. The transition to hospital consultant and the influence of preparedness, social support, and perception: A structural equation modelling approach. Med Teach 2013; 35(4):320-7.

10. Lyss-Lerman P, Teherani A, Aagaard E, et al. What training is needed in the fourth year of medical school? Views of Residency Program Directors. Acad Med 2009; 84(77):823-9.

11. Walling $A$, Merando $A$, The fourth year of medical education: a literature review. Acad Med 2010; 85(11):1698-704.

12. Wolf SJ, Lockspeiser TM, Gong J, Guiton G. Students' perspectives on the fourth year of medical school: a mixed-methods analysis. Acad Med 2014; 89(4):602-7.

13. Lindeman BM, Sacks BC, Lipsett PA, Graduating students' and surgery program directors' views of the Association of American Medical Colleges Core Entrustable Professional Activities for Entering Residency: where are the gaps? J Surg Educ 2015; 72(6):e184-92.

14. Halpern SD, Detsky AS, Becoming a physician. Graded autonomy in medical education Managing things that go bump in the night. N Engl J Med 2014; 370(12):1086-9.

15. Morrow G, Burford B, Redfern N, Briel R, Illing J. Does specialty training prepare doctors for senior roles? A questionnaire study of new UK consultants. Postgrad Med J 2012;88(1044):55865.

16. Englander $\mathrm{R}$, Carraccio $C$. A lack of continuity in education, training, and practice violates the "Do no harm" principle. Acad Med 2018; 93(3S Competency-Based, Time-Variable Education in the Health Professions):S12-6. 
17. Hirsh D, Ogur B, Thibault GE, Cox M. "Continuity" as an organizing principle for clinical education reform. N Engl J Med 2007; 356(8):858-66.

18. Carraccio C, Englander R, Gilhooly J, et al. Building a framework of entrustable professional activities, supported by competencies and milestones, to bridge the educational continuum. Acad Med 2017; 92(3):324-30.

19. Ten Cate O, Medical education in The Netherlands. Med Teach 2007; 29(8):752-7.

20. Wijnen-Meijer $M$, ten Cate $O$, van der Schaaf $M$, et al. Vertically integrated medical education and the readiness for practice of graduates. BMC Med Educ 2015; 15: 229.

21. Hirsh D, Walters $L$, Poncelet AN, Better learning, better doctors, better delivery system: possibilities from a case study of longitudinal integrated clerkships. Med Teach 2012; 34(7):548-54.

22. Lumb A, Murdoch-Eaton D. Electives in undergraduate medical education: AMEE Guide No. 88. Med Teach 2014; 36(7):557-72.

23. Andrews JS, Bale JF, Soep JB, et al. Education in pediatrics across the continuum (EPAC): first steps toward realizing the dream of competency-based education. Acad Med 2018; 93(3):414-20.

24. Reddy ST, Chao J, Carter JL, et al. Alliance for clinical education perspective paper: recommendations for redesigning the "final year" of medical school. Teach Learn Med 2014; 26(4):420-7.

25. Aagaard E, Abaza M. The residency application process - burden and consequences. N Engl J Med 2016; 374(4):303-5.

26. Dewan M, Norcini J. A purpose-driven fourth year of medical school. Acad Med 2018; 93(4):581-5.

27. Minter RM, Amos KD, Bentz ML, et al. Transition to surgical residency: a multi-institutional study of perceived intern preparedness and the effect of a formal residency preparatory course in the fourth year of medical school. Acad Med 2015; 90(8):1116-24.

28. O'Brien BC, Forrest K, Wijnen-Meijer M, ten Cate O. A global view of structures and trends in medical education, in Understanding Medical Education, Swanwick T, Forrest K, and O'Brien BC, Editors. 2019, Wiley-Blackwell: Hoboken, NJ, USA.

29. McGaghie WC, Miller GE, Sajid AW, Telder TV. Competency-based curriculum development on medical education: an introduction. 1978, Geneva: World Health Organization.

30. Hodges BD, Lingard L. The question of competence. Reconsidering medical education in the twenty-first century. 2012, Ithaca, NY: Cornell University Press.

31. Frank JR, Mungroo R, Ahmad Y, et al. Toward a definition of competency-based education in medicine: a systematic review of published definitions. Med Teach 2010; 32(8):631-7.

32. lobst WF, Sherbino J, ten Cate O, et al. Competency-based medical education in postgraduate medical education. Med Teach 2010; 32(8):651-6.

33. Holmboe ES, Sherbino J, Long DM, Swing SR, Frank JR. The role of assessment in competencybased medical education. Med Teach 2010; 32(8):676-82.

34. Frank JR, Snell LS, ten Cate O, et al. Competency-based medical education: theory to practice. Med Teach 2010; 32(8):638-45. 
35. Hodges BD. The shifting discourses of competence, in The question of competence. Reconsidering medical education in the twenty-first century, B.D. Hodges and L. Lingard, Editors. 2012, Cornell University Press: Ithaca, NY. 14-41.

36. Nasca TJ, Philibert I, Brigham T, Flynn TC. The next GME accreditation system - Rationale and benefits. N Engl J Med 2012; 366(11):1051-6.

37. Lurie SJ, Mooney CJ, Lyness JM. Measurement of the general competencies of the Accreditation Council for Graduate Medical Education: a systematic review. Acad Med 2009; 84(3):301-9.

38. Lurie SJ, Mooney CJ, Lyness JM. Commentary: pitfalls in assessment of competency-based educational objectives. Acad Med 2011; 86(4):412-4.

39. Wojtczak A. Glossary of medical education terms: part 3. Med Teach 2002; 24(4):450-3.

40. Schuwirth LW, van der Vleuten CP. Programmatic assessment: from assessment of learning to assessment for learning. Med Teach 2011; 33(6):478-85.

41. Van der Vleuten CP, Schuwirth LW, Driessen EW, et al. A model for programmatic assessment fit for purpose. Med Teach 2012; 34(3):205-14.

42. Bok HGJ, Teunissen PW, Favier RP, et al. Programmatic assessment of competency-based workplace learning: when theory meets practice. BMC Med Educ 2013; 13:123.

43. Ten Cate O. Entrustability of professional activities and competency-based training. Med Educ 2005; 39(12):1176-7.

44. Ten Cate O, Scheele F. Competency-based postgraduate training: can we bridge the gap between theory and clinical practice? Acad Med 2007; 82(6):542-7.

45. Jones MD, Rosenberg AA, Gilhooly JT, Carraccio CL. Perspective: Competencies, outcomes, and controversy - linking professional activities to competencies to improve resident education and practice. Acad Med 2011; 86(2):161-5.

46. Carraccio $\mathrm{C}$, Burke AE. Beyond competencies and milestones: adding meaning through context. J Grad Med Educ 2010; 2(3):419-22.

47. Englander R, Frank JR, Carraccio C, et al. Toward a shared language for competency-based medical education. Med Teach 2017; 39(6):582-7.

48. Ten Cate O, Snell L, Carraccio C. Medical competence: the interplay between individual ability and the health care environment. Med Teach 2010; 32(8):669-75.

49. Kennedy TJT, Regehr G, Baker GR, Lingard L. Point-of-care assessment of medical trainee competence for independent clinical work. Acad Med 2008; 83(10S):S89-92.

50. Sterkenburg A, Barach P, Kalkman C, Gielen M, ten Cate O. When do supervising physicians decide to entrust residents with unsupervised tasks? Acad Med 2010; 85(9):1408-17.

51. Hauer KE, ten Cate O, Boscardin C, et al. Understanding trust as an essential element of trainee supervision and learning in the workplace. Adv Health Sci Educ Theory Pract 2014; 19(3):435-56.

52. Epstein RM, Hundert EM. Defining and assessing professional competence. JAMA 2002; 287(2):226-35.

53. Dreyfus HL, Dreyfus SE. Mind over machine. The power of human intuition and expertise in the era of the computer. 1988, New York, NY: Free Press. 
54. Dreyfus SE. The five-stage model of adult skill acquisition. Bull Sci Technol Soc 2004; 24(3):17781.

55. Ericsson A. Deliberate practice and the acquisition and maintenance of expert performance in medicine and related domains. Acad Med 2004; 79(10S):S70-81.

56. McGaghie WC. Mastery learning: it is time for medical education to join the 21 st century. Acad Med 2015; 90(11):1438-41.

57. Yardley S, Teunissen PW, Dornan T. Experiential learning: AMEE Guide No. 63. Med Teach 2012; 34(2):e102-15.

58. Yardley S, Teunissen PW, Dornan T. Experiential learning: transforming theory into practice. Med Teach 2012; 34(2):161-4.

59. Billett S. Workplace participatory practices. J Workp/ Learning 2004; 16(6):312-24.

60. Lave J, Wenger E. Situated Learning: Legitimate Peripheral Participation. 1991, Cambridge: Cambridge University Press.

61. Vygotsky L. Mind in society. The development of higher psychological processes. 1978, Cambridge, MA: Harvard University Press.

62. Chaiklin S. The Zone of proximal development in Vygotsky's analysis of learning and instruction, in Vygotsky's educational theory in cultural context, A. Kozulin, et al., Editors. 2003, Cambridge University Press: Cambridge UK. 39-64.

63. Ryan RM, Deci EL. Self-determination theory and the facilitation of intrinsic motivation, social development, and well-being. Am Psychol 2000; 55(1):68-78.

64. Ten Cate O, Kusurkar RA, Williams GC. How self-determination theory can assist our understanding of the teaching and learning processes in medical education. AMEE guide No. 59. Med Teach 2011; 33(12):961-73.

65. lobst WF, Holmboe ES, Building the continuum of competency-based medical education. Perspect Med Educ 2015; 4(4):165-7.

66. Sklar DP. Creating a medical education continuum with competencies and entrustable professional activities. Acad Med 2019; 94(9):1257-60.

67. Ten Cate O, Carraccio C. Envisioning a true continuum of competency-based medical education, training, and practice. Acad Med 2019; 94(9):1283-8.

68. Ten Cate O. What is a 21st-century doctor? Rethinking the significance of the medical degree. Acad Med 2014; 89(7):966-9.

69. Lower TK. The continuum of pediatric medical education and life-long learning. $J$ Pediatr 2011; 159(1):1-2.

70. Benbassat J, Baumal R. Expected benefits of streamlining undergraduate medical education by early commitment to specific medical specialties. Adv Health Sci Educ Theory Pract 2012; 17(1):145-55.

71. Andrew SE, Oswald A, Stobart K. Bridging the continuum: Analysis of the alignment of undergraduate and postgraduate accreditation standards. Med Teach 2014; 36(9):804-11.

72. Wijnen-Meijer M, ten Cate O, Rademakers JJ, van der Schaaf M, Borleffs JC. The influence of a vertically integrated curriculum on the transition to postgraduate training. Med Teach 2009; 31(11):e528-32. 
73. Van den Broek WES, Wijnen-Meijer M, ten Cate O, van Dijk M. Medical students'preparation for the transition tot postgraduate training through final year elective rotations. GMS J Med Educ 2017; 34(5):Doc65.

74. Weggemans MM, van Dijk B, van Dooijeweert B, Veenendaal AG, ten Cate O. The postgraduate medical education pathway: an international comparison. GMS J Med Educ 2017; 34(5):Doc63.

75. Clarke S, Horeczko T, Cotton D, Bair A. Heart rate, anxiety and performance of residents during a simulated critical clinical encounter: a pilot study. BMC Med Educ 2014; 14:153.

76. Hunziker S, Laschinger L, Portmann-Schwarz S, et al. Perceived stress and team performance during a simulated resuscitation. Intensive Care Med 2011; 37(9):1473-9.

77. Takayesu J, Evans AJ, Sullivan JE, Pawlowski JB, Gordon JA. How do clinical clerkship students experience simulator-based teaching? A qualitative analysis. Simul Healthc 2006; 1(4):215-9.

78. Scheele F, Teunissen $P$, van Luijk $S$, et al. Introducing competency-based postgraduate medical education in the Netherlands. Med Teach 2008; 30(3):248-53.

79. Boyce P, Spratt C, Davies M, McEvoy P. Using entrustable professional activities to guide curriculum development in psychiatry training. BMC Med Educ 2011; 11:96.

80. Shaughnessy AF, Sparks J, Cohen-Osher M, et al. Entrustable professional activities in family medicine. J Grad Med Educ 2013; 5(1):112-8.

81. Hauer KE, Kohlwes J, Cornett $\mathrm{P}$, et al. Identifying entrustable professional activities in internal medicine training. J Grad Med Educ 2013; 5(1):54-9. 


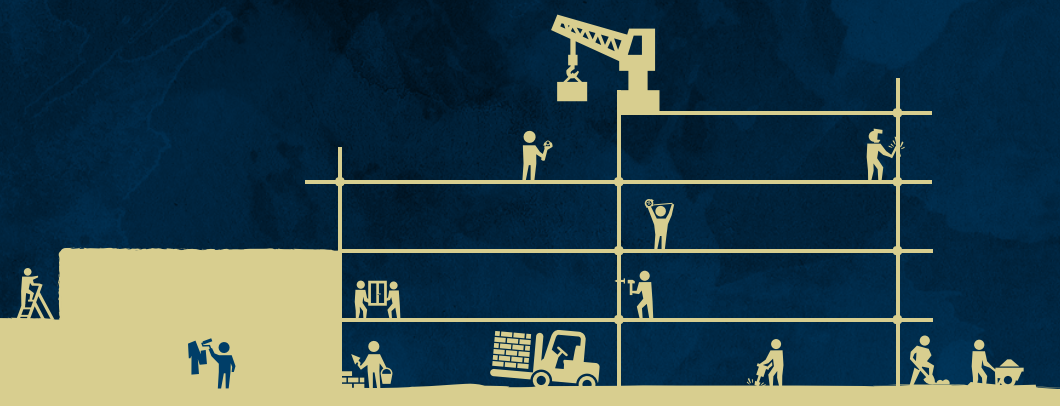




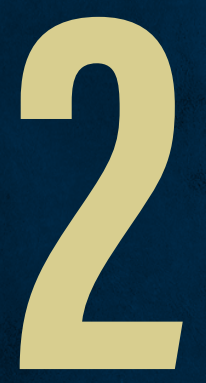

\section{CONNECTING UNDERGRADUATE AND POSTGRADUATE MEDICAL EDUCATION THROUGH AN ELECTIVE EPA-BASED TRANSTIIONAL YEAR INACUTE CARE}

\section{AN EARLY PROJECT REPORT}

\section{Published as:}

Jonker G, Hoff RG, Max S, Kalkman CJ, ten Cate O.

Connecting undergraduate and postgraduate medical education through an elective EPA-based transitional year in acute care: an early project report.

GMS J Med Educ. 2017;34(5):Doc64. doi: 10.3205/zma001141. 


\section{ABSTRACT}

Objective A well-designed final year may ease the transition from medical school to postgraduate training, if it has enough depth to enable the acquisition of early specialty expertise, while keeping enough breadth to support the graduation as all-round physician. Aim of this article is to describe the design of a multidisciplinary dedicated transitional year (DTY) around the theme of recognition and initial treatment of vitally threatened patients.

Methods Undergraduate and postgraduate training directors from the departments of Anesthesiology, Cardiology, Emergency Medicine, Intensive Care Medicine and Respiratory Medicine at UMC Utrecht and partnering hospitals have collaboratively developed and implemented a curriculum for a final year focusing on three entrustable professional activities (EPAs) in the domain of acute care. These EPAs represent authentic tasks of starting residents in each of the participating specialties, align student training objectives with postgraduate expectations, and are the primary focus of learning, teaching, and assessment throughout the year. Students are developmentally supported by a mentor and educationally supported by monthly academic half days.

Results Since October 2014, 47 students chose the Acute Care Transitional Year (ACTY). The set-up of the ACTY is inspiring other specialties to develop multidisciplinary DTYs. Attainment of clinical competence, experience of students and staff, and exploration of graduates' early careers are subjects of current research projects.

Conclusion This multidisciplinary dedicated transitional year aims to graduate students with profile-specific competence in acute care. It prepares for residency in a range of specialties. 


\section{INTRODUCTION}

The goal of undergraduate medical training is to deliver doctors who are ready to practice within a postgraduate training program [1].

Students, graduates and program directors have identified gaps in the preparedness for postgraduate training in areas such as carrying responsibility and working at near intern-level, attributed to lack of educational focus in the final year of medical school [4-6]. A well-designed final year can bridge these gaps and facilitate the transition to residency $[5,7]$. In the Netherlands, following the Bologna declaration [2], medical education consists of a three year Bachelor phase, which is mainly theoretical in nature, and a three year Master phase, which is largely devoted to clinical rotations [3]. Master years one and two comprise compulsory rotations in a wide range of disciplines. In the third and final year of the Master phase, all medical students at University Medical Center (UMC) Utrecht, follow a transitional year. This is a composite of one to three clinical electives and a research elective, which should ease the transition from undergraduate to postgraduate training. In this transitional year, students should work in clinical settings, integrate and apply knowledge and skills from previous years, grow into bearing clinical responsibility, deepen their understanding within areas of interest, acquire early specialty-specific expertise, and explore career options [4-7].

Some students, who are determined about their choice of specialty focus in an undergraduate transitional year on preparation for residency in one single specialty. It allows them to acquire early expertise, which may optimize their chances of getting into the desired residency program. However, a transitional year aiming at one single discipline may not suit the numerous students who are undecided about their choice of specialty and wish to explore career options or want to work in more generalist fields. Moreover, during their final year, students initially convinced of their choice for a specialty may change their minds, or found to be ineligible or to lack aptitude. Additionally, a narrow, 'overly dedicated' transitional year may not be the broad capstone of medical school that integrates knowledge and skills acquired in preceding years [5].

Purpose of this article is to describe the design of a final year of medical school shaped as a multidisciplinary, yet dedicated transitional year that addresses the above issues. Its goals are the acquisition of competence in acute care at an introductory level and to offer preparation for the responsibilities of postgraduate training in a range of specialties. We chose these goals as recently graduated doctors are often called upon to provide care in emergency situations. 


\section{PROJECT DESCRIPTION}

\section{A multidisciplinary thematic dedicated transitional year}

The departments of anesthesiology, cardiology, emergency medicine, intensive care medicine and respiratory medicine at the UMC Utrecht, and St. Antonius Hospital, Nieuwegein, the Netherlands, have collaboratively developed a multidisciplinary thematic dedicated transitional year (DTY). The theme of our DTY is recognition and initial treatment of acutely compromised patients (therefore named Acute Care Transitional Year, ACTY). This is an important facet of all five participating disciplines, which combine an analytic approach with an interventional mind-set. At UMC Utrecht, students may elect to pursue our particular DTY. The twelve week research placement is chosen in one of the five involved specialties. The student chooses clinical rotations in three different specialties out of five partaking in the ACTY. One placement is twelve weeks and two placements are six weeks each. This composition allows the student to gain concentrated but balanced clinical experience in areas of their interest, without being overly specialty-focused [5]. During the clinical rotations the students work at near-intern level to get accustomed to the roles and responsibilities of a resident $[4,5$, 8]. This means that students get assigned identical tasks to those of junior residents, essential items are checked by supervisors, and prescriptions suggested by students need to be ratified by a physician.

Together with a six-week common introductory block, holidays and a six-week closing block, the transitional year completely covers the final year in medical school.

\section{Learning objectives: Entrustable Professional Activities}

Because the ACTY aims to facilitate the transition to residency, clinical tasks that starting residents must perform are suitable learning objectives $[1,9,10]$. Using tasks as learning objectives offers structure and clarity in the chaotic educational context of clinical practice [11]. It fosters learning by creating commitment and motivation [11]. Learning objectives, pertaining to clinical tasks, may be formulated as entrustable professional activities $[1,9,10]$. An entrustable professional activity (EPA) is a separately executable unit of clinical work, which can be performed with decreasing levels of supervision, and which may be entrusted to an individual that has been deliberately declared competent to execute that task without direct supervision [12]. The concept of EPAs fits well in the theoretical frameworks of Community of practice and Situated learning [13], which emphasize the importance of authentic tasks in (apprenticeship) learning. By being engaged in small but meaningful real world tasks, even novice learners may participate legitimately at the periphery of a community of practice and 
may progress towards the center with growing experience [13]. The main learning objectives of the ACTY are three EPAs that comprise relevant authentic tasks for starting residents covering 'common ground' of the five participating specialties: 'Recognition and initial treatment of patients with vital instability', 'Evaluation and initial treatment of patients with respiratory insufficiency', and 'Evaluation and initial treatment of patients with circulatory insufficiency' (Table 1-3). The three EPAs designate underpinning competencies, required knowledge, skills, and attitudes (c.f. [12]). The aim is to train students towards the level of performing these activities with indirect supervision (with post hoc review), which befits the level of responsibility that residents in their first year of training must take on $[4,10]$.

This set of three EPAs drives learning, teaching, and assessment in the entire ACTY. The ACTYEPAs were developed iteratively and collaboratively by experienced undergraduate and postgraduate faculty $(n=13)$ of the involved departments. The developmental process took place between September 2014 and June 2015 and consisted of several meetings, separated and followed by iterative rounds of developing concept EPAs by email. Consensus was reached on the final product by all involved faculty members. The ACTY EPAs are meant to align student training objectives with postgraduate expectations [10] and are special for not being confined to a single specialty, and thus transcend traditional barriers in being activities that are relevant for several specialties.

\section{Core EPAs versus ACTY EPAs}

During their rotations students are exposed to the breadth of the specialties they have chosen. In their work in emergency medicine, for example, they encounter patients with fractures, in anesthesiology they learn basics of providing anesthesia, in cardiology or pulmonary medicine they see patients with chronic disease. These aspects of their work are not part of the three ACTY EPAs per se. The EPAs deal with the shared interest of the participating specialties in recognition and initial treatment of acutely compromised patients. However, work that is not confined to the EPAs is valuable in containing parttasks that are useful experience for the EPAs (e.g. interpreting an ECG) and provides understanding of what the specialty encompasses.

The development of the ACTY EPAs preceded the development of core EPAs for medical school at UMC Utrecht, a process that is currently underway. Core EPAs will provide scaffolding for learning of all students during the clinical phase, with the ACTY EPAs providing advanced level objectives for the students choosing the ACTY. The ACTY EPAs intend to focus the attention of the student on these tasks during clinical placements that traditionally had no explicit learning objectives. 
TABLE 1: Elaborated entrustable professional activity on recognition and initial treatment of vitally threatened patients

\begin{tabular}{|c|c|}
\hline Title & Recognition and initial treatment of patients with vital instability \\
\hline Description & $\begin{array}{l}\text { Evaluate patient with the ABCD approach; } \\
\text { Measure and interpret vital signs; } \\
\text { Based on the above, come to a clinical evaluation; } \\
\text { In case of emergency: call directly for help/supervision; } \\
\text { Initiate Basic Life Support, perform bag-mask-ventilation and airway maneuvers and start } \\
\text { intravenous fluid therapy; } \\
\text { Be a member of the resuscitation team; } \\
\text { Discern limitations in capability. } \\
\text { This EPA does not comprise: } \\
\text { Provision of advanced cardiac/trauma life support, completely and/or indirectly supervised } \\
\text { Care for pediatric patients with vital instability ( }<16 \text { years) }\end{array}$ \\
\hline $\begin{array}{l}\text { Link to } \\
\text { competency } \\
\text { domains } \\
\text { CanMEDS (Dutch } \\
\text { KNMG version) }\end{array}$ & $\begin{array}{l}\text { Medical Expert: applies diagnostic, therapeutic, preventive repertoire (1.2) } \\
\text { Communicator: reports adequately on a case, orally and in writing (2.4) } \\
\text { Collaborator: consults others effectively (3.1), efficacious in interdisciplinary collaboration (3.4) } \\
\text { Manager: works effectively within a system (6.2) } \\
\text { Professional: discerns limits of competence (7.3) }\end{array}$ \\
\hline $\begin{array}{l}\text { Required } \\
\text { knowledge, skills, } \\
\text { and attitudes } \\
\text { (level of doctor } \\
\text { in postgraduate } \\
\text { year 1) }\end{array}$ & $\begin{array}{l}\text { Knowledge } \\
\text { Knowledge of normal ranges for blood pressure, heart rate, respiratory rate, saturation and } \\
\text { temperature; } \\
\text { Knowledge of symptoms of threatened vital parameters } \\
\text { Knowledge of Glasgow Coma Scale (GCS) and primary neurological survey; } \\
\text { Knowledge of causes of disturbances in consciousness; } \\
\text { Knowledge of Basic Life Support; } \\
\text { Knowledge of principles of advanced cardiac and trauma life support; } \\
\text { Knowledge of 4Hs, 4Ts, shock and no-shock algorithms; } \\
\text { Knowledge of indications for and application of (Automatic) External Defibrillators; } \\
\text { Knowledge of effective communication protocols to call for help (e.g. SBARR method); } \\
\text { Knowledge of local protocols regarding acute intervention teams, emergency telephone number, } \\
\text { resuscitation team etcetera; } \\
\text { Knowledge of equipment and materials for basic interventions in ABC (e.g. infusion materials, } \\
\text { AMBU-bag, non-rebreathing mask, Mayo tube) including (contra-) indications; } \\
\text { Knowledge of levels of care on different wards (normal ward to ICU); } \\
\text { Knowledge of indications to stop resuscitation efforts } \\
\text { Skills } \\
\text { Asks timely for help/supervision with an effective communication protocol (e.g. SBARR) and locally } \\
\text { applicable emergency procedure; } \\
\text { Performs and interprets a systematic physical exam according to ABCD and monitoring of vital } \\
\text { signs; } \\
\text { Clinical judgment based on ABCD and vital parameters; } \\
\text { Provides probable diagnosis regarding the cause of the vital instability; } \\
\text { Gives and receives orders/tasks and confirms the order/task and its execution; } \\
\text { Proposes a management plan; } \\
\text { Proposes orders regarding treatment; } \\
\text { Initiates Basic Life Support; } \\
\text { Performs Basic Life Support skills and part-tasks; } \\
\text { Performs bag-mask ventilation and airway maneuvers (head tilt/chin lift, jaw thrust); } \\
\text { Sites a peripheral intravenous catheter; }\end{array}$ \\
\hline
\end{tabular}


TABLE 1: Continued

\begin{tabular}{|c|c|}
\hline Title & Recognition and initial treatment of patients with vital instability \\
\hline & $\begin{array}{l}\text { Defibrillates a shockable rhythm with (automatic) external defibrillator; } \\
\text { Reports in medical record; } \\
\text { Provides a structured handover of a patient with vital instability to colleague/supervisor/ward. } \\
\text { Attitudes } \\
\text { Discerns and acknowledges personal limits of knowledge, skill and capability and can adequately } \\
\text { reflect on this; } \\
\text { Situational awareness; } \\
\text { Is set to short cycles of assessment, treatment, and re-assessment; } \\
\text { Collaborates in a team in an emergency setting; } \\
\text { Reveals professional role and level; } \\
\text { Professional conduct towards patient and/or relatives; } \\
\text { Uses Evidence Based Medicine. }\end{array}$ \\
\hline $\begin{array}{l}\text { Information to } \\
\text { assess progress }\end{array}$ & $\begin{array}{l}\text { Workplace assessment } \\
\text { Mini-CEXs with regard to the evaluation of patients with or without vital instability, including } \\
\text { indicating necessity for (acute) intervention and with regard to discernment of personal limits of } \\
\text { capability; } \\
\text { Multisource feedback: performance as a team member in urgent and non-urgent settings; } \\
\text { Assessment of knowledge, skills and attitudes } \\
\text { Knowledge examination (written, variety of formats); } \\
\text { Clinical reasoning and know-how (case-based discussions); } \\
\text { Demonstration of isolated skills in non-clinical setting (Objective Structured Examination of } \\
\text { Clinical Skills); } \\
\text { Reflection forms regarding performance, difficult moments, discernment of limitations. } \\
\text { Assessment of clinical performance } \\
\text { Simulation of acute care settings. }\end{array}$ \\
\hline $\begin{array}{l}\text { Target level of } \\
\text { supervision } \\
\text { (entrustment) }\end{array}$ & $\begin{array}{l}\text { Indirect supervision (immediately available): evaluation and initial management, awaiting arrival } \\
\text { of help/supervisor }\end{array}$ \\
\hline $\begin{array}{l}\text { When is } \\
\text { unsupervised } \\
\text { practice expected? }\end{array}$ & At completion of the ACTY \\
\hline
\end{tabular}


TABLE 2: Elaborated entrustable professional activity on evaluation of respiratory compromised patients

\begin{tabular}{|c|c|}
\hline Title & Evaluation and initial treatment of patients with respiratory insufficiency \\
\hline Description & $\begin{array}{l}\text { Rapid evaluation with the ABCD approach; } \\
\text { Take a focused history of a patient with respiratory insufficiency in an Emergency Room, Coronary Care } \\
\text { Unit, ward or urgent outpatient clinic (outside Operating Room and Intensive Care settings); } \\
\text { Perform a physical exam, including ABCD and vital signs; } \\
\text { Order and interpret basic diagnostic tests (blood, chest X-ray, ECG); } \\
\text { Draft and rank a differential diagnosis in a patient with respiratory insufficiency; } \\
\text { Start initial management and propose treatment plans. } \\
\text { This EPA does not comprise: } \\
\text { Care for the patient (nearly) in a cardiopulmonary resuscitation setting } \\
\text { Care for pediatric patients with respiratory instability (< } 16 \text { years) } \\
\text { Interpretation of advanced diagnostic tests (Ventilation-Perfusion scans, spirometry) }\end{array}$ \\
\hline $\begin{array}{l}\text { Link to } \\
\text { competency } \\
\text { domains } \\
\text { CanMEDS } \\
\text { (Dutch KNMG } \\
\text { version) }\end{array}$ & $\begin{array}{l}\text { Medical Expert: applies diagnostic, therapeutic, preventive repertoire (1.2) } \\
\text { Communicator: creates effective therapeutic relationships (2.1), reports adequately on a case, orally and } \\
\text { in writing (2.4) } \\
\text { Collaborator: consults others effectively (3.1) } \\
\text { Scholar: appraises medical information critically (4.1) } \\
\text { Health Advocate: recognizes determinants of disease (5.1) } \\
\text { Manager: works effectively within a system (6.2) } \\
\text { Professional: adequate (inter-)professional conduct (7.2), discerns limits of competence (7.3) }\end{array}$ \\
\hline $\begin{array}{l}\text { Required } \\
\text { knowledge, } \\
\text { skills, and } \\
\text { attitudes } \\
\text { (level of } \\
\text { doctor in } \\
\text { postgraduate } \\
\text { year 1) }\end{array}$ & $\begin{array}{l}\text { Knowledge } \\
\text { Knowledge of normal ranges for blood pressure, heart rate, respiratory rate, saturation and } \\
\text { temperature; } \\
\text { Knowledge of relevant criteria and scores (e.g. SIRS-criteria, Wells score; GOLD-criteria; Pneumonia } \\
\text { Severity Index; Pneumonia Likelihood Ratio; AMBU-65 and CURB-65; ALI/ARDS); } \\
\text { Knowledge of criteria for ventilation and admission to ward or ICU; } \\
\text { Knowledge of (results of) relevant diagnostic tests (i.e. laboratory blood tests, blood gas analysis, chest } \\
\text { X-ray and systematic interpretation, ECG); } \\
\text { Knowledge of results of pleural fluid investigations (chemistry, microbiology); } \\
\text { Knowledge of most important disorders leading to respiratory insufficiency; } \\
\text { Knowledge of options in additional diagnostic testing (e.g. rapid PCR tests, viral, bacterial and fungal } \\
\text { tests, CT scan, VP scan); } \\
\text { Knowledge of indications for ventilation; } \\
\text { Knowledge of indications and techniques of oxygen therapy (F }{ }_{2}{ }^{\prime} \text { nasal cannula, non-rebreathing } \\
\text { mask, CPAP, Venturi, Optiflow); } \\
\text { Knowledge of indications for chest drains; } \\
\text { Knowledge of indications for bronchoscopy; } \\
\text { Knowledge of initial pharmacological treatment of important disorders leading to respiratory } \\
\text { insufficiency. } \\
\text { Skills } \\
\text { Performs and interprets a systematic physical exam according to ABCD and monitoring of vital signs; } \\
\text { Asks timely for help/supervision; } \\
\text { Takes a focused history and performs a focused physical exam in patients with respiratory insufficiency; } \\
\text { Performs a blood gas analysis; } \\
\text { Interprets result of a blood gas analysis; } \\
\text { Connects patient to monitoring such as ECG/telemetry, non-invasive blood pressure, pulse oximetry, } \\
\text { and interprets findings; } \\
\text { Interprets } 12 \text {-lead ECG: myocardial ischemia, rhythm- and conduction disorders; }\end{array}$ \\
\hline
\end{tabular}


TABLE 2: Continued

\begin{tabular}{|c|c|}
\hline Title & Evaluation and initial treatment of patients with respiratory insufficiency \\
\hline & $\begin{array}{l}\text { Recognizes myocardial ischemia, rhythm- and conduction disorders on telemetry monitor; } \\
\text { Writes an order for chest X-ray; } \\
\text { Systematic interpretation of chest X-ray and recognition of relevant radiologic findings; } \\
\text { Interprets findings of pleural fluid tests; } \\
\text { Sites a peripheral intravenous catheter; } \\
\text { Drafts and ranks a differential diagnosis and provides a probable diagnosis in a patient with circulatory } \\
\text { insufficiency; } \\
\text { Proposes a management plan; } \\
\text { Proposes orders regarding treatment; } \\
\text { Reports in medical record and provides a structured handover. } \\
\text { Attitudes } \\
\text { Discerns and acknowledges personal limits of knowledge, skill and capability and can adequately } \\
\text { reflect on this; } \\
\text { Is set to short cycles of assessment, treatment, and re-assessment; } \\
\text { Reveals professional role and level; } \\
\text { Collaborates with ward staff; } \\
\text { Professional conduct towards patient and/or relatives; } \\
\text { Uses Evidence Based Medicine. }\end{array}$ \\
\hline $\begin{array}{l}\text { Information } \\
\text { to assess } \\
\text { progress }\end{array}$ & $\begin{array}{l}\text { Workplace assessment } \\
\text { Mini-CEXs with regard to the evaluation of patients with or without vital instability, including indicating } \\
\text { necessity for (acute) intervention and with regard to discernment of personal limits of capability; } \\
\text { Multisource feedback: performance as a team member in urgent and non-urgent settings; } \\
\text { Assessment of knowledge, skills and attitudes } \\
\text { Knowledge examination (written, variety of formats); } \\
\text { Clinical reasoning and know-how (case-based discussions); } \\
\text { Demonstration of isolated skills in non-clinical setting (Objective structured examination of skills); } \\
\text { Reflection forms regarding performance, difficult moments, discernment of limitations. } \\
\text { Assessment of clinical performance } \\
\text { Simulation of acute care settings. }\end{array}$ \\
\hline $\begin{array}{l}\text { Target level of } \\
\text { supervision } \\
\text { (entrustment) }\end{array}$ & $\begin{array}{l}\text { Indirect supervision (immediately available): evaluation and initial management, awaiting arrival of } \\
\text { help/supervisor }\end{array}$ \\
\hline $\begin{array}{l}\text { When is } \\
\text { unsupervised } \\
\text { practice } \\
\text { expected? }\end{array}$ & At completion of the ACTY \\
\hline
\end{tabular}


TABLE 3: Elaborated entrustable professional activity on evaluation of circulatory compromised patients

\begin{tabular}{|c|c|}
\hline Title & Evaluation and initial treatment of patients with circulatory insufficiency \\
\hline \multirow[t]{11}{*}{ Description } & Rapid evaluation with the $A B C D$ approach; \\
\hline & Take a focused history of a patient with circulatory insufficiency in an Emergency Room, Coronary Care \\
\hline & Unit, ward or urgent outpatient clinic (outside Operating Room and Intensive Care settings) ; \\
\hline & Perform a physical exam, including $A B C D$ and vital signs; \\
\hline & Order and interpret basic diagnostic tests (blood, chest X-ray, ECG); \\
\hline & Draft and rank a differential diagnosis in a patient with circulatory insufficiency; \\
\hline & Start initial management and propose treatment plans. \\
\hline & This EPA does not comprise: \\
\hline & Care for the patient (nearly) in a cardiopulmonary resuscitation setting \\
\hline & Care for pediatric patients with circulatory instability ( $<16$ years) \\
\hline & Interpretation of advanced diagnostic tests (cardiac catheterization, echocardiography) \\
\hline \multirow{7}{*}{$\begin{array}{l}\text { Link to } \\
\text { competency } \\
\text { domains } \\
\text { CanMEDS } \\
\text { (Dutch KNMG } \\
\text { version) }\end{array}$} & Medical Expert: applies diagnostic, therapeutic, preventive repertoire (1.2) \\
\hline & $\begin{array}{l}\text { Communicator: creates effective therapeutic relationships (2.1), reports adequately on a case, orally and } \\
\text { in writing (2.4) }\end{array}$ \\
\hline & Collaborator: consults others effectively (3.1) \\
\hline & Scholar: appraises medical information critically (4.1) \\
\hline & Health Advocate: recognizes determinants of disease (5.1) \\
\hline & Manager: works effectively within a system (6.2) \\
\hline & Professional: adequate (inter-)professional conduct (7.2), discerns limits of competence (7.3) \\
\hline \multirow{22}{*}{$\begin{array}{l}\text { Required } \\
\text { knowledge, } \\
\text { skills, and } \\
\text { attitudes } \\
\text { (level of } \\
\text { doctor in } \\
\text { postgraduate } \\
\text { year 1) }\end{array}$} & Knowledge \\
\hline & $\begin{array}{l}\text { Knowledge of normal ranges for blood pressure, heart rate, respiratory rate, saturation and } \\
\text { temperature; }\end{array}$ \\
\hline & Knowledge of relevant criteria and scores (e.g. Crusade, Heartscore, TIMI, CHADS2VASC, SIRS-criteria, \\
\hline & Knowledge of different types of shock and their treatments; \\
\hline & Knowledge of levels of care on different wards (normal ward to ICU); \\
\hline & Knowledge of (results of) relevant diagnostic tests (i.e. laboratory blood tests, blood gas analysis, chest \\
\hline & X-ray and systematic interpretation, ECG); \\
\hline & Knowledge of intravenous fluid therapy protocols; \\
\hline & $\begin{array}{l}\text { Knowledge of most important disorders leading to circulatory insufficiency (i.e. different types of } \\
\text { shock); }\end{array}$ \\
\hline & Knowledge of indications for echocardiography and of relevant reported findings; \\
\hline & $\begin{array}{l}\text { Knowledge of indications for cardiac catheterization (and percutaneous cardiac intervention) and of } \\
\text { relevant reported findings; }\end{array}$ \\
\hline & $\begin{array}{l}\text { Knowledge of initial (pharmacological) treatment of different types of shock. Inotropes and vasoactive } \\
\text { medications. }\end{array}$ \\
\hline & Skills \\
\hline & Performs and interprets a systematic physical exam according to $A B C D$ and monitoring of vital signs; \\
\hline & Asks timely for help/supervision; \\
\hline & Takes a focused history and performs a focused physical exam in patients with circulatory insufficiency; \\
\hline & Performs a blood gas analysis; \\
\hline & Interprets result of a blood gas analysis; \\
\hline & $\begin{array}{l}\text { Connects patient to monitoring such as ECG/telemetry, non-invasive blood pressure, pulse oximetry, } \\
\text { and interprets findings; }\end{array}$ \\
\hline & Evaluates heart rhythm on telemetry monitor; \\
\hline & Interprets 12-lead ECG : myocardial ischemia, rhythm- and conduction disorders; \\
\hline & Writes an order for chest X-ray; \\
\hline
\end{tabular}


TABLE 3: Continued

\begin{tabular}{|c|c|}
\hline Title & Evaluation and initial treatment of patients with circulatory insufficiency \\
\hline & $\begin{array}{l}\text { Systematic interpretation of chest X-ray and recognition of relevant radiologic findings; } \\
\text { Sites a peripheral intravenous catheter; } \\
\text { Drafts and ranks a differential diagnosis and provides a probable diagnosis in a patient with circulatory } \\
\text { insufficiency; } \\
\text { Proposes a management plan; } \\
\text { Proposes orders regarding treatment; } \\
\text { Reports in medical record and provides a structured handover. } \\
\text { Attitudes } \\
\text { Discerns and acknowledges personal limits of knowledge, skill and capability and can adequately } \\
\text { reflect on this; } \\
\text { Is set to short cycles of assessment, treatment, and re-assessment; } \\
\text { Reveals professional role and level; } \\
\text { Collaborates with ward staff; } \\
\text { Professional conduct towards patient and/or relatives; } \\
\text { Uses Evidence Based Medicine. }\end{array}$ \\
\hline $\begin{array}{l}\text { Information } \\
\text { to assess } \\
\text { progress }\end{array}$ & $\begin{array}{l}\text { Workplace assessment } \\
\text { Mini-CEXs with regard to the evaluation of patients with or without vital instability, including indicating } \\
\text { necessity for (acute) intervention and with regard to discernment of personal limits of capability; } \\
\text { Multisource feedback: performance as a team member in urgent and non-urgent settings; } \\
\text { Assessment of knowledge, skills and attitudes } \\
\text { Knowledge examination (written, variety of formats); } \\
\text { Clinical reasoning and know-how (case-based discussions); } \\
\text { Demonstration of isolated skills in non-clinical setting (Objective Structured Examination of Clinical } \\
\text { Skills); } \\
\text { Reflection forms regarding performance, difficult moments, discernment of limitations. } \\
\text { Assessment of clinical performance } \\
\text { Simulation of acute care settings. }\end{array}$ \\
\hline $\begin{array}{l}\text { Target level of } \\
\text { supervision } \\
\text { (entrustment) }\end{array}$ & $\begin{array}{l}\text { Indirect supervision (immediately available): evaluation and initial management, awaiting arrival of } \\
\text { help/supervisor }\end{array}$ \\
\hline $\begin{array}{l}\text { When is } \\
\text { unsupervised } \\
\text { practice } \\
\text { expected? }\end{array}$ & At completion of the ACTY \\
\hline
\end{tabular}

So, the ACTYEPAs can be seen as elective undergraduate EPAs [7], being more advanced than the core EPAs for entering residency that every medical graduate must master [10]. The EPAs can be linked to broader and more complex EPAs of postgraduate training in the participating specialties $[9,10]$, adding to the educational continuum in medical training. Currently, the EPA concept is being widely embraced in postgraduate medical training in the Netherlands [14]. 


\section{Assessment}

EPAs and their assessment are used to focus experiential learning during the clinical placements. Students take a multimodal exam, blueprinted to the three EPAs, at the start and at the end of the ACTY. This exam consists of several parts that test knowledge (written, closed and open format questioning), skills (several stations with Objective Structured Clinical Examinations), clinical reasoning (case-based discussions), and clinical performance in high-fidelity simulations of acute care settings. The pre-test focuses the students' minds on the learning objectives and the expected performance level. The post-test, being similar to the pre-test, assesses the students personal development in competence.

Workplace-based assessment in the ACTY is aligned with the EPAs. Short practice observations were developed collaboratively by the ACTY team to cover observable units that are part of the EPAs (e.g. 'Take a focused history of a dyspneic patient', Table 4). These specific short practice observations are additional to the existing general ones in use in the master phase of medical school at UMC Utrecht and draw the attention of student and supervisor to the learning objectives of the ACTY. Students document their practice observations in a paper-based portfolio, soon to be superseded by an electronic version.

Up until now, formal entrustment decisions on EPAs have not yet been part of summative evaluations of ACTY students.

\section{Longitudinal support}

The student is matched with one mentor for the entire year. The mentor is a senior resident in one of the participating specialties. This 'buddy' offers longitudinal developmental student support [15], serves as a role model, may assist in acculturation to the specialty, in career planning, in applying for residency, and in making most of the rotations $[5,6]$. Mentors do not have a role in formal assessments of the mentee. Anecdotally, this mentorship is appreciated highly by both mentees and mentors.

Another special feature of the ACTY is the monthly academic half-day. This is an interactive small group teaching session meant to exchange experiences of students and to discuss EPA-related topics from an integrative multidisciplinary viewpoint. In exit interviews, students report that it also fosters the motivating sense of belonging to a group, or class, whereas the usual transitional year in our medical school is purely individualistic. Our yearlong spaced-learning cycle of academic half-days covers the contents of intensive capstone bootcamp courses that are commonly employed in the transition to residency in the United States $[7,16]$. 


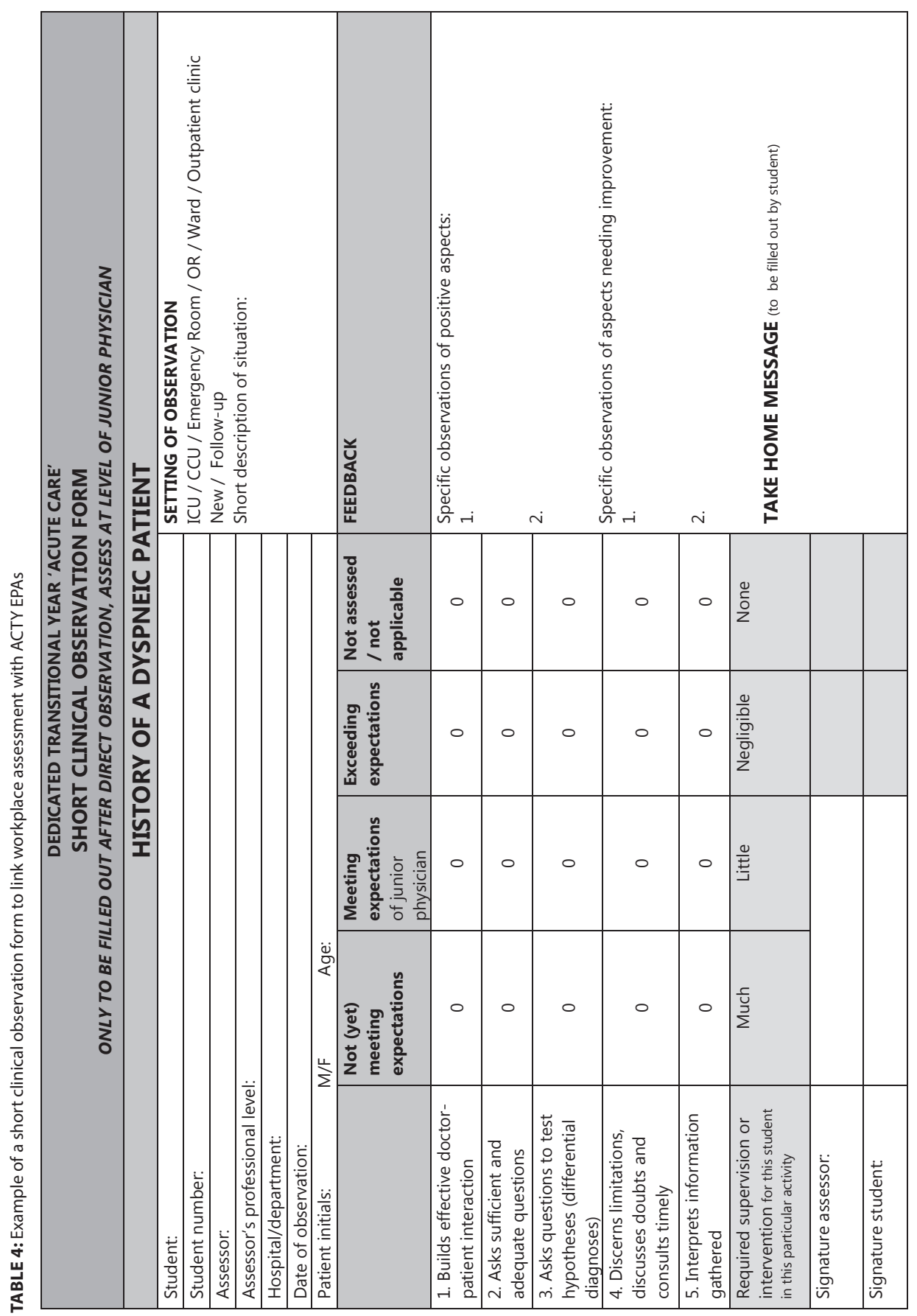




\section{RESULTS}

Since October 2014, we have enrolled 47 students in the ACTY (about 7\% of yearly cohorts). Until now, our multidisciplinary ACTY is unique in its sort. Other alliances of specialties at UMC Utrecht are currently teaming up to explore theme-oriented dedicated transitional years, following our example.

When entering the ACTY, many of the students envision a career in one of the participating specialties. Ninety-two percent of students enrolling in the ACTY primarily aim for a residency in one of the five specialties taking part in the DTY, with $16 \%$ of students being strongly determined of their choice. A minority wants to work in a discipline that does not participate in the ACTY (8\%). Of all students who are not fully decided in career choice at the start of their DTY, 68\% consider specialties which do not take part in the ACTY.

The ACTY is open to all final year medical students at UMC Utrecht. Admission to the ACTY is restricted by the limited availability of clinical placements. So far, we have been able to accommodate all interested students thanks to the flexibility in arranging the four placements and our regional collaborative partnership. There is no guarantee for a postgraduate residency placement or an accelerated residency program when taking part in the ACTY.

The ACTY is subject of three ongoing evaluative research studies. One study evaluates the efficacy of the ACTY to develop clinical competence in the three multidisciplinary EPAs. A second study explores the experience of students and staff with the ACTY. A third study is a follow-up of graduated students from the ACTY exploring their early careers.

\section{DISCUSSION}

We designed the ACTY around the theme of evaluation and initial management of vitally compromised patients. We have set clearly articulated multidisciplinary learning objectives that are authentic tasks of entering residents. This orientation on a theme, important for future doctors in many specialties, is one of its strengths. It assures enough breadth to graduate as a generalist, whilst offering enough depth to gain useful competence for postgraduate specialty training. Moreover, the theme-orientation and the learning objectives provide coherence in a year consisting of elective rotations. 
The design and implementation of the ACTTY has been a labor-intensive, albeit satisfying, process. It took considerable time and effort to collaboratively develop and describe the three EPAs, transcending traditional specialty boundaries, with faculty from five disciplines. We feel that it did reduce thinking in silos in the specialties.

The EPAs are the focus of assessment. The multimodal exam at the start and end of the ACTY may be an important way to demonstrate attained competence. However, it is labor-intensive as well and may not be a sustainable undertaking at larger scale. Workplace assessment has been linked to the EPAs by using the themed short clinical observation forms. In 2014, the ACTY adopted an EPA approach in a medical school curriculum that was not EPA-based at the time. Therefore, entrustment decisions have not yet been part of summative evaluations of ACTY students. An entrustment decision relies on multiple observations of clinical performance and takes test results of required knowledge and skills into account. After an entrustment decision the student is permitted to execute the activity with indirect supervision. With the advent of our new EPA-based medical school curriculum, entrustment decisions will inevitably become part of evaluating students in the clinical phase, including the ACTY. The attainment of EPAs, even at the undergraduate level of near-independence, may help to justify decisions to delegate tasks or to reconsider the appropriateness of delegation to entering residents in the light of patient safety $[10,17]$.

ACTY students do their rotations in the five specialties in several partnering regional teaching hospitals around the region. Uptake of the ACTY concept and principles will likely not be homogenous. In addition, several kinds of clinical students may do rotations in hospitals - even at the same time. It is therefore the principal responsibility of students themselves to continuously draw the attention of local supervisors to the DTY and its special objectives. At the same time, investments should be made to adequately prepare supervisors and mentors and inform them on a continuing basis.

\section{CONCLUSION}

In this article we describe the development and design of a multidisciplinary dedicated transitional year, around the theme of acute care, with entrustable professional activities as learning objectives. After the ACTY, students have learned to bear responsibility for patients, have refreshed, enhanced, and integrated knowledge and skills from previous years, and will have acquired a profile of competence in acute care at the level of nearindependent performance; this should be useful preparation for residency in the participating specialties. A similar set-up could be used to design other multidisciplinary 
dedicated transitional years either organized around related disciplines or around various themes (profiles) in medicine. This would enable more students to graduate with profile-specific competence, well-prepared to enter residency in a range of specialties. 


\section{REFERENCES}

1. Ten Cate O. What is a 21-st century doctor? Rethinking the significance of the medical degree. Acad Med 2014; 89:966-9.

2. Patricio M, de Burbure C, Costa MJ, Schirlo C, ten Cate O. Bologna in Medicine Anno 2012: experiences of European medical schools that implemented a Bologna two-cycle curriculum - an AMEE-MEDINE2 survey. Med Teach 2012; 34:821-32.

3. Ten Cate O. Medical education in the Netherlands. Med Teach 2007; 29:752-7.

4. Lyss-Lerman P, Teherani A, Aagaard E, et al. What training is needed in the fourth year of medical school? Views of residency program directors. Acad Med 2009; 84:823-9.

5. Walling A, Merando A. The fourth year of medical education: a literature review. Acad Med 2010; 85:1698-1704.

6. Wolf SJ, Lockspeiser TM, Gong J, Guiton G. Students' perspectives on the fourth year of medical school: a mixed-methods analysis. Acad Med 2014; 89:1-6.

7. Reddy ST, Chao J, Carter JL et al. Alliance for Clinical Education perspective paper: recommendations for redesigning the "final year" of medical school. Teach Learn Med 2014; 26:420-7.

8. Sen Gupta T, Hays R, Wolley T, Kelly G, Jacobs H. Workplace immersion in the final year of an undergraduate medicine course: the views of final year students and recent graduates. Med Teach 2014; 36:518-26.

9. Chen HC, van den Broek WES, ten Cate O. The case for use of entrustable professional activities in undergraduate medical education. Acad Med 2015; 90:431-6.

10. Englander R, Flynn T, Call $S$ et al. Toward defining the foundation of the MD degree: core entrustable professional activities for entering residency. Acad Med 2016; 91:1352-8.

11. Koens F, Mann KV, Custers EJ, ten Cate O. Analysing the concept of context in medical education. Med Educ 2005; 39:1243-9.

12. Ten Cate O. Nuts and bolts of Entrustable Professional Activities. J Grad Med Educ 2013; 5:1578.

13. Lave J, Wenger E. Situated Learning: Legitimate Peripheral Participation. 1991, Cambridge: Cambridge University Press.

14. Medischevervolgopleidingen.nl [homepage on the Internet]. Accessed July 7, 2017. Available from: https://www.medischevervolgopleidingen.nl/epas.

15. Sandars J, Patel R, Steele H, McAreavey M. Developmental student support in undergraduate medical education: AMEE Guide No. 92. Med Teach 2014; 36:1015-26.

16. Teo AR, Harleman E, O'Sullivan P, Maa J. The key role of a transition course in preparing medical students for internship. Acad Med 2011; 86:860-5.

15. Jonker G, Hoff RG, ten Cate O. A case for competency-based anaesthesiology training with entrustable professional activities. An agenda for development and research. Eur J Anaesthesiol 2015; 32:71-6. 


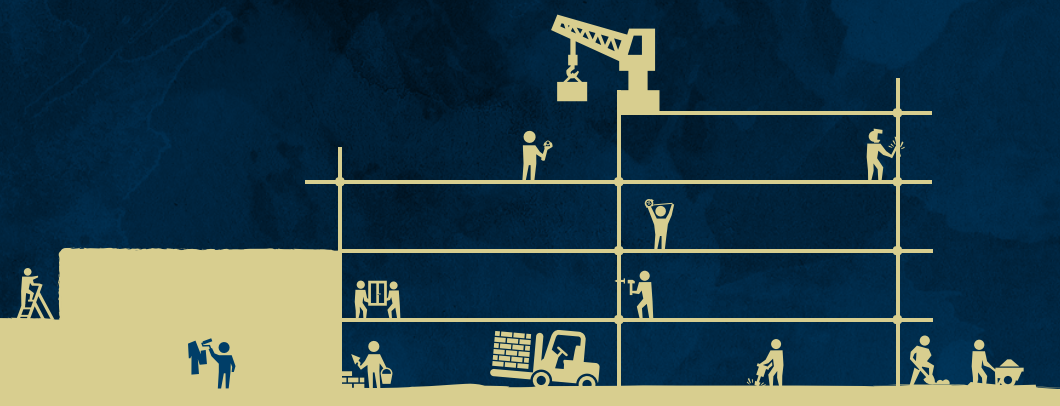




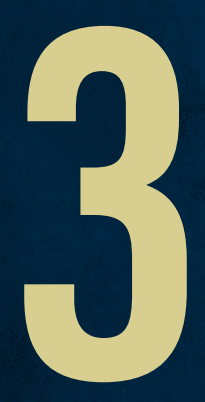

\section{AN ELECTIVE EPA-BASED THEMATIC FINAL MEDICAL SCHOOL YEAR}

\section{AN APPRECLATVE NQUURY STUDY AMONG STUDENTS, GRADUATES AND SUPERVISORS}

Published as:

Jonker G, Booij E, Otte WR, Vlijm CME, ten Cate O, Hoff RG.

An elective EPA-based thematic final medical school year. An appreciative inquiry study among students, graduates and supervisors.

Adv Med Educ Pract. 2018; 9:837-845. doi: 10.2147/AMEP.S176649. 


\section{ABSTRACT}

Purpose The transition from undergraduate to postgraduate training can be facilitated by offering electives that focus on increased patient care responsibilities. This transitional year model in the Netherlands has recently been expanded to offer packages of electives geared to specific residencies and was called "dedicated transitional year" (DTY). At University Medical Center Utrecht, an entrustable professional activity (EPA)based multidisciplinary DTY in acute care (ACTY), rooted in self-determination theory (SDT), has been implemented. The current study aimed to understand strengths and challenges regarding the implementation of this specific DTY.

Methods An explorative qualitative study among students, graduates, and faculty was conducted using an appreciative inquiry methodological approach. We gathered first-hand accounts of experiences with the ACTY in focus groups and interviews with students and interviews with graduates, supervisors, and mentors. Transcripts were analyzed with a directed content analysis approach.

Results Participants found the ACTY to focus learning, offering coherence by clear learning objectives, aligned assessment, and teaching sessions and offering a congenial learning community. However, EPAs were not the focal point of workplace assessment and evaluation. Providing sufficient hands-on student engagement in actual acute care situations was another challenge.

Conclusion The concept of the thematic DTY is embraced, and it seems to help in meeting the SDT needs. Enhancing delivery in the workplace by improving formal implementation with information and faculty development, expanding EPA-focused workplace assessment, and extending hands-on experience of students could further unlock the potential of this final medical school year design. Our lessons learned may help in the development and implementation of similar programs, other models of DTYs, and final-year redesigns. 


\section{INTRODUCTION}

Graduation from medical school is a significant step in the educational continuum from student to being a life-long learning professional [1, 2]. This transition is a well-known challenge. Students, graduates, and program directors have regularly identified gaps in medical graduates' readiness to assume clinical responsibility in postgraduate training [3-8] and educators have advocated to optimize this readiness in better designs of the final year of medical school [4, 9-11].

In the Netherlands, undergraduate medical education consists of a three-year mainly theoretical Bachelor phase, and a three-year Master phase, largely devoted to clinical rotations [12]. Usually, Master years 1 and 2 comprise compulsory rotations in several disciplines, whereas year 3 comprises elective rotations. To facilitate the transition to postgraduate training, schools have started to redesign the final year to create so called "dedicated transitional years" (DTY). The DTY is a final year elective track meant to enable development of early residency-level competence in order to give graduates a head start in postgraduate training [13]. In a DTY, students grow towards the responsibilities of a resident, acquire early specialty-specific expertise, explore career options, and try to improve their chances on the job market [14]. Dutch medical schools piloted and introduced local interpretations of this concept, but little is known about how and to what extent a DTY produces impact on learning.

In 2014, University Medical Center (UMC) Utrecht and the Antonius hospital introduced a multidisciplinary transitional year dedicated to acute care (Acute Care Transitional Year, ACTY) in a collaboration of five specialties: anesthesiology, cardiology, emergency medicine, intensive care medicine, and respiratory medicine. The ACTY distinguishes itself from the regular transitional year by being a coherent thematic year. Coherence is provided by the selection of disciplines, monthly teaching sessions, personal mentoring, learning objectives framed as entrustable professional activities (EPAs) which transcend disciplines, and multimodal assessments of course objectives prior, during and after the ACTY (Table 1) [15].

The ACTY has been running since September 2015 and has been offered as a pilot program within the elective constraints of the new Utrecht undergraduate curriculum $[16,17]$, preceding the full development and implementation of this curriculum reform.

This study aims to explore the experiences of students and faculty with this specific DTY. Understanding strengths of and challenges with the implementation of current design will help in the development and implementation of final year redesigns. 
TABLE 1: Key features of the Utrecht Acute Care Transitional Year (ACTY)

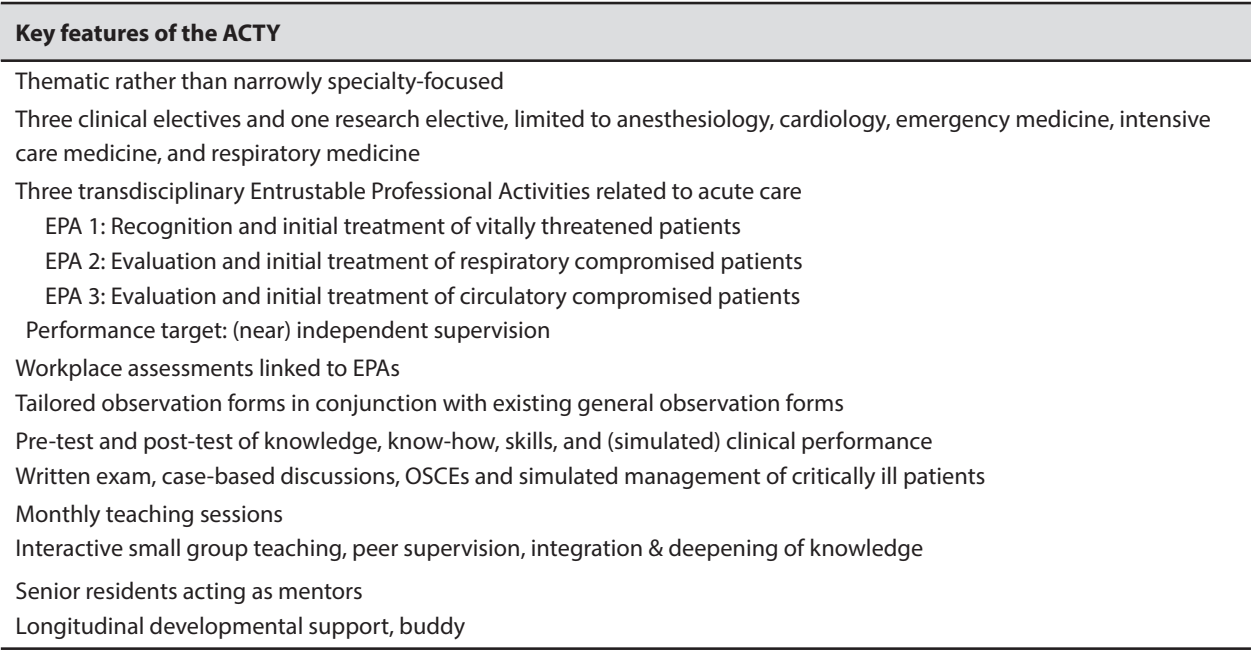

\section{METHODS}

\section{Study design}

To investigate the experiences with the ACTY an explorative qualitative study of perceptions from students, graduates and faculty was conducted. The study was conducted within the interpretivist research paradigm that considers social reality to be formed by subjective human experiences and social contexts [18, 19].

We took an appreciative inquiry (Al) methodological approach. Al identifies strengths and possibilities for change to unlock future potential, instead of diagnosing deficits in the process of interest [20].

The Ethical Review Board of the Dutch Association for Medical Education (NVMO) granted ethical approval for this study (NERB file 823).

\section{Setting}

Every six weeks, two to six students enroll in this year-long program on a rotational basis. Students take three clinical rotations and a research elective in UMC Utrecht and affiliated regional teaching hospitals. At any time, 15 to 25 students are taking part in the ACTY simultaneously. Departments also host other final year medical students not taking the ACTY. 


\section{Participants and sampling}

At the time of data collection 42 students were participating in or had graduated from the ACTY. We announced the study to students during a teaching session. Next, all students and graduates were approached individually by email providing information about the study. All graduates were asked permission to analyze their previously conducted and transcribed exit-interviews.

We aimed to study supervisors $(n=41)$ from all participating specialties and from UMC Utrecht and regional hospitals anticipating heterogeneity in knowledge and involvement. Initial purposeful sampling included supervisors responsible for student rotations and evaluations. Further snowball sampling was used to contact other supervisors. All 20 resident-mentors in our database were approached. All were approached individually by email providing information about the study.

\section{Data collection}

Data collection took place between February and April 2017. Two focus groups and individual interview sessions were organized to explore experiences from current ACTY students. Experiences of graduates were explored in individual face-to-face or telephone semi-structured interviews and by analysis of previously conducted exitinterviews. Supervisors and mentors were interviewed individually in a semi-structured face-to-face or telephone conversation.

Two researchers ( $\mathrm{RO}$ and $\mathrm{CV}$ ) developed and revised the initial interview guides based on ACTY documentation, conversations with the coordinators of ACTY, and discussion with the other authors. The interview guides were piloted for clarity and information yield and no subsequent changes were made. The interview guides were organized topically. Table 2 shows the topics and examples of questions. Interviews and focus groups were conducted in the UMC Utrecht by RO and CV, who both had prior experience in conducting interviews for research purposes.

\section{Data management and analysis}

Audio recordings, transcripts, and analyses were stored digitally password protected. Interviews were audiotaped and subsequently analyzed and summarized by two authors (RO and CV). The summary was sent to the participants for member checking. The focus group sessions were audiotaped and conjunctly analyzed by two authors (RO and (V). A directed content analysis approach [21] was applied, using pre-identified codes and codes that emerged during analysis. This approach was chosen as this study focused on perceived strengths and views of future potential in relation to the design 
of the ACTY and assuming contextual influences on these perceptions [20,22]. Content analysis was performed with the qualitative software package NVivo (QSR International, Daresbury, UK), using the topics of Table 2 as initial code tree.

TABLE 2: Interview topics with examples of questions for students (St) and supervisors (Su)

\begin{tabular}{|c|c|}
\hline Topic & Sampled question \\
\hline \multirow[t]{2}{*}{ Relatedness to the ACTY } & St: Do you identify yourself as an ACTY student? \\
\hline & Su: To what degree do you feel connected to ACTY? \\
\hline \multirow[t]{2}{*}{ Medical expertise } & $\begin{array}{l}\text { St: Are you able to build competence on junior doctor level in the domain of } \\
\text { acute care? }\end{array}$ \\
\hline & $\begin{array}{l}\text { Su: What would you say regarding ACTY students' knowledge, skills and attitudes } \\
\text { within the domain of acute care? }\end{array}$ \\
\hline \multirow[t]{2}{*}{ Curriculum } & St: What were your main reasons to choose ACTY? \\
\hline & Su: Can you elaborate on the ACTY philosophy? \\
\hline \multirow[t]{2}{*}{ Assessment } & St: How are you being evaluated in your rotations? \\
\hline & $\begin{array}{l}\text { Su: Which sources of information and tools do you use in evaluating your ACTY } \\
\text { students? }\end{array}$ \\
\hline \multirow[t]{2}{*}{ ACTY in the workplace } & St: Do you feel engaged with the department or department's work? \\
\hline & Su: How do you facilitate ACTY students in reaching their learning objectives? \\
\hline \multirow[t]{2}{*}{ EPAs } & St: Can you explain the role of the EPAs in your workplace learning? \\
\hline & $\begin{array}{l}\text { Su: What is your opinion on the ACTY EPAs? (prompt: regarding utility, feasibility, } \\
\text { clarity) }\end{array}$ \\
\hline \multirow[t]{2}{*}{ Organization and logistics } & St: What are the strengths of ACTY? \\
\hline & Su: What would you like to see improved in ACTY? \\
\hline \multirow[t]{2}{*}{ Professional identity and future } & $\begin{array}{l}\text { St: What is occurring with regard to your orientation on the job market and choice } \\
\text { for a specialty? }\end{array}$ \\
\hline & $\begin{array}{l}\text { Su: How do you view ACTY students, as compared to non-ACTY final year } \\
\text { students? }\end{array}$ \\
\hline
\end{tabular}

\section{RESULTS}

After written informed consent, first-hand accounts were gathered from 17 students, 17 graduates and 21 faculty (Figure 1). Findings are presented by the four broad themes found (involvement with the ACTY, medical expertise, curriculum, assessment).

\section{Involvement with the ACTY}

Most students knew about the ACTY from students enrolled in the ACTY, while some learned about the ACTY from formal information sources. Reasons to opt for the ACTY included a) the thematic focus on acute care, b) an opportunity to stand out among regular graduates and prepare for residency, and c) the exclusive monthly teaching sessions. 

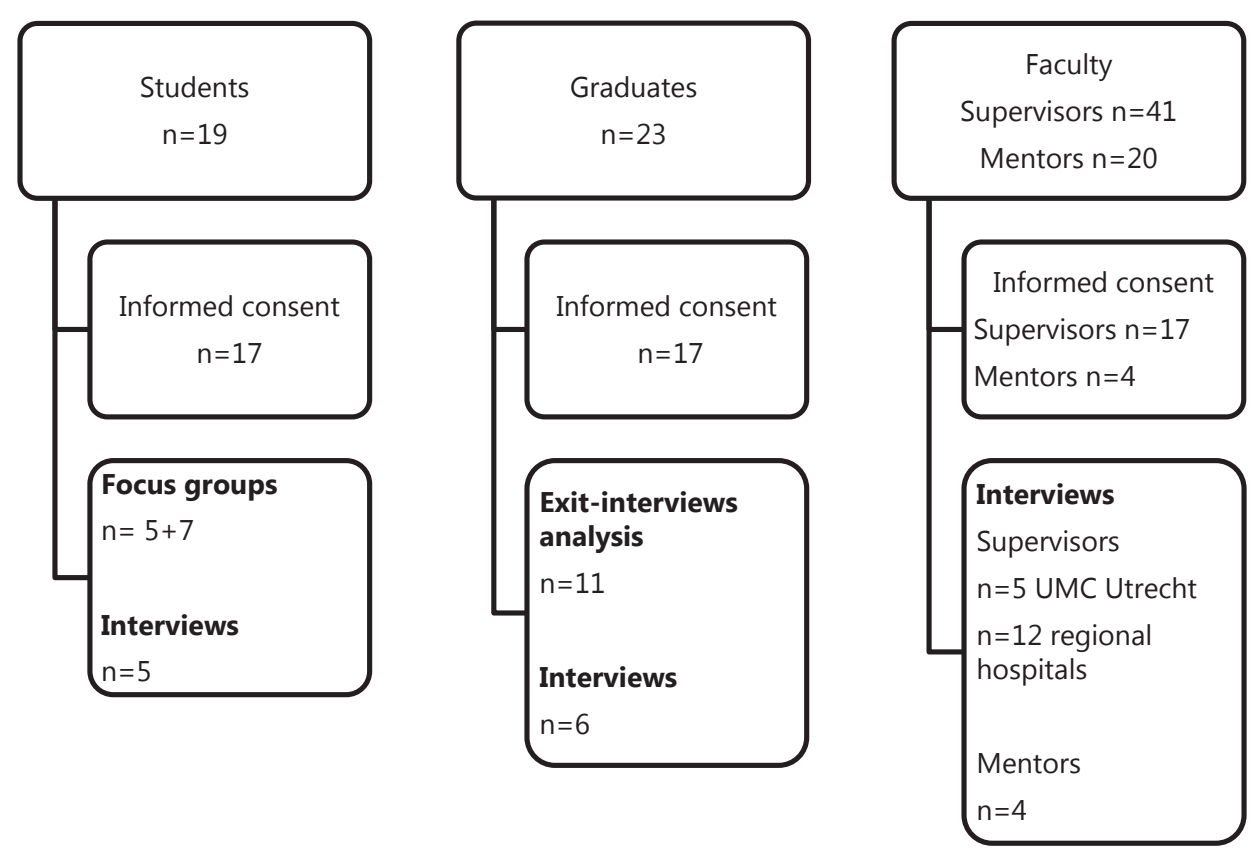

FIGURE 1: Overview of students, graduates and faculty participating in the study. Supervisors were from all five specialties.

Students highly appreciated the evolving sense of belonging to a peer-group of ACTY students. Virtually all felt connected to the ACTY and their peer-group. Students described their ACTY peers as motivated, ambitious, hardworking, like-minded students.

Specifically because we're all keenly interested we go that extra mile and delve that bit deeper. (St9)

In addition, thematic focus, mentors, and the pre- and post-tests reinforced cohesion. Above all the teaching half-days fostered the origin of a learning community:

It's especially the teaching half-days on which you reunite with your group, all focused on the same domain, and discuss things you've experienced; that's of surplus value as compared to the normal transitional year. (St15)

In contrast, virtually no supervisor felt to be part of a ACTY community as such, but did feel connected to individual ACTY students. Supervisors tutored three to twenty students, but for some it had not always been clear who was a ACTY student and who 
was not, given that other students could simultaneously do final year rotations in these disciplines. Often students had identified themselves as ACTY students, sometimes rotation planning had provided this information to supervisors.

A supervisor suggested that regional hospital faculty could get more involved by organizing ACTY network events, for example. Being kept up to date with developments was felt to be motivating:

I envision that if, for example, data on student outcomes were known, these would be shared among supervisors. This would make the ACTY come more alive. (Su21)

\section{Medical expertise}

Students felt that the ACTY contributed to their competence in delivering acute care and preparedness to work as a junior doctor. They stated to have obtained integrated and deepened knowledge in a medical domain they had only been minimally exposed to prior. The ACTY-specific pre- and post-tests provided insight in their knowledge, skill, and personal growth. ACTY students considered themselves, in comparison to peers, more interested as well as more knowledgeable in acute care.

Supervisors suggested that ACTY students are proactive and more motivated, more focused, ask more specific questions, and may have slightly more content knowledge than regular final year students in the same rotation.

Most students indicated that the ACTY confirmed their preference for a specialty. Half of the students appreciated the transdisciplinary set-up of the ACTY allowing for a shift in preference within the spectrum of acute care.

\section{Curriculum}

Familiarity of the training site with the curriculum of the ACTY varied per hospital and department, students said. Rotation supervisors tended to be well informed, but consultants and trainees less so. All supervisors knew which specialties participate in the ACTY and were aware of the ACTY principle that students differentiate within acute care to gear for a residency in this domain of medicine. Most supervisors lacked information on the background, objectives and curriculum of the ACTY. The timing of the information often did not match the need for information, long preceding the arrival of a first ACTY student. 
Many supervisors put effort in enabling students to reach ACTY learning objectives by advising which learning activities to pursue or altering their placement:

Basically, the rotation looks the same, but based on the goals of the student, I try to facilitate the student to reach those objectives; for example by placing them in the Emergency Room, or not. (Su30)

Most students used the three ACTY EPAs in clarifying the learning objectives for their rotations. Students usually made their learning objectives a topic in the conversation with their supervisor at the start of their rotations. Students said that the EPAs focused their learning process during the rotations.

By the end of the year, I want to master those EPAs, and that's what I'm working on. And, you know, without those objectives I would have just done the rotation and it would have been okay to semi-master them, but now I'm keen on fully mastering them. (St22)

Most supervisors were aware of the EPAs and many found the EPAs to provide a good overview of the expected level of competence at graduation and they appreciated the transdisciplinary nature of the EPAs:

Because of this specific setting of rotations that are connected and aligned within a theme, students are better prepared to work in all these specialties. (Su15)

Some supervisors viewed the EPAs as ambitious and perhaps unfeasible for students in practice. Although students deemed the expected performance level of the EPAs realistic and appropriate, they faced limited possibilities to get hands-on clinical experience in these acute care professional activities. Students advised making the EPAs better known to staff to improve supervision and involvement, which would extend possibilities to gain hands-on experience. Students felt that, instead of global rotation evaluations, explicitly making the entrustment decision the focus of assessment would reinforce the role of EPAs in the workplace.

I think you'd be more focused if you know that goal in advance. You have those EPAs and you want to get a pass mark on them, so you pay more attention to them. (St33)

Some students doubted whether entrustment decisions would lead to decrease of supervision, given that residents usually perform these acute care activities. 
Supervisors could imagine working with entrustment of the professional activity but most pointed out that they would like to personally observe the student or doctor before decreasing supervision:

With a new team member I think you'd want to double-check whether things are done well, as at the end of the day, you, as a supervisor, are responsible for your patients. But the entrustment process will be faster, you won't need a build-up anymore. (Su20)

The ACTY teaching sessions fostered learning especially by exchanging and discussing real-life experienced clinical cases. Students felt it broadened their view on acute care, enhanced retention of knowledge and promoted clinical reasoning. The exclusive, confidential setting of these sessions was deemed important for interactivity and safety to express oneself.

Specifically the small scale added value. We learn more in a small group and there's more opportunity to share experiences. In larger settings it's more like taking turns to contribute to the discussion. (St39)

Group size of around 12 students was believed to be optimal. Further value could be added by including simulation training, and input from a wider array of teachers from different backgrounds.

Students thought the mentor to be of added value. Students gave examples of mentors providing advice about rotation choices and helping with applications for training posts.

You have someone to direct questions to, discuss things, and obtain advice when you're in doubt; this is all very handy. (St4)

Mentor meetings left room for individual approaches, which students and mentors appreciated. Most mentors explained to have chosen a casual, companion approach. A few students stated that the purpose and role of mentoring was unclear and wished more clearly written guidance on mentoring. Mentors felt they did not need more instruction. Supervisors emphasized the merit of mentoring and mentors indicated that this varies per student:

I think it's very dependent on how things are going, which problems you encounter and how you're supported on the ward. If that goes arduous, it's great to have someone to unload with. I think one student has more needs there than another. (M4) 


\section{Assessment}

The ACTY-specific pre-assessment of knowledge, know-how, skills and performance in acute care was thought to be valuable as it provided insight in their current level and in areas for improvement.

The added value of the entry test is to get to see where the focus is put on and in which areas your level is reasonable and in which you need to improve. (St6)

The pre-test was a strong motivator to work on their acute care proficiency. Students would like to enhance opportunities to develop this ability, both in clinical and simulated settings.

Students and supervisors claimed workplace assessment and evaluation of rotations to be similar for all students. EPAs did not play a central role in these evaluations. Some students chose to use the ACTY-specific short observation forms which link to the EPAs, whereas most used the generic forms.

That's a good point, we don't use the ACTY-specific ones that much yet. Should we, are we obliged to? I would like some guidance on that. (Su10)

Supervisors deemed the ACTY-specific observation forms, when shown to them, to be clear and valuable and the generic ones too nonspecific.

We often complete such a standard form for a very specific encounter or aspect and most of the items are not applicable. (Su5)

Students suggested strengthening the role of EPAs in the workplace by requiring ACTYspecific observation forms. It would focus feedback on the performance regarding the learning objectives of the ACTY.

Supervisors evaluated students using the regular rating forms for elective clinical rotations. In addition to the observation forms, the global impressions supplied by colleagues were taken into account. Supervisors struggled to envision an improved workplace assessment practice within the ACTY. Many indicated the desire to incorporate more informal assessments into the big picture. Some supervisors suggested to use an e-portfolio containing objectives, formal feedback with strengths and points for improvement, as well as informal feedback. This would provide insight into the developmental trajectory of the student. 


\section{DISCUSSION}

This study investigated successes and challenges associated with the current design and delivery of a dedicated final year of medical school and aimed to formulate options to unlock further potential. The main findings (Table 3 ) and steps for improvement are discussed below.

TABLE 3: Successes and challenges with design and delivery of the ACTY

\begin{tabular}{ll}
\hline Strengths \\
\hline The ACTY focuses learning in a coherent program with clear learning objectives \\
Educational sessions contribute to coherence and focused learning and create a congenial learning community \\
The ACTY program attracts highly motivated and proactive students \\
\hline Possibilities for change and improvement \\
\hline Possibilities & Improvement strategies \\
Heterogeneity in involvement of supervisors & Just in time information \\
& Faculty development \\
Position of EPAs & Supervisor network events \\
& Expand workplace assessments \\
Hands-on experience in acute care & Entrustment decision \\
& Bed-side teaching \\
& Legitimate workplace roles \\
& Entrustment-based discussion \\
\hline
\end{tabular}

Foremost, the ACTY program focuses students'learning, as intended. It offers a coherent curriculum with learning objectives (EPAs) that transcend rotations and disciplines. Starting the year with a multimodal pre-test makes expectations explicit, and reinforces the focus of personal learning.

Second, the ACTY-exclusive teaching sessions contribute greatly to the impact of the program. They are perceived as a valuable and appealing asset of the ACTY. As intended, they provide coherence and focus for learning. Above all, students value to be part of a learning community. The ACTY class may be seen as a community of practice [23]: a group that shares common interests, tasks and activities in which participatory learning occurs. Students feel part of a distinct and exclusive group of peers who are on the same wavelength. From a social identity theory perspective, this "in-group" perception provides a highly accessible and fitting group identity [24]. The close class creates a congenial climate for peer supervision, i.e. learning from an exchange of experiences and reflections. 
A third ACTY strength is that it succeeds in attracting highly motivated pro-active final year students. We believe that the ACTY offers a motivating environment for student growth. Self-determination theory states that people's natural tendency to develop is stimulated when the need for confidence and effectance (competence), the need for volition, i.e. choosing what a person desires or finds useful (autonomy), and the need to belong to a group or community (relatedness) are satisfied [25]. This organismicdialectic framework of psychological needs [26] is mirrored in the findings of the study.

Despite the strengths of the ACTY, the quality of program delivery in the workplace could be improved. Supervisors appeared to feel only marginally involved with the program. The fact that ACTY students do rotations in parallel to non-ACTY students decreases the visibility of the ACTY. Provision of more and timely information could increase familiarity of supervisors and departments with the intentions of the ACTY and convey a clear message on what is expected from supervisors and mentors. Support should be offered to increase rotation sites' readiness to supervise ACTY students [27]. Faculty development sessions providing tailored training on how supervisors can contribute to the learning of students by exploiting learning opportunities potentially improves quality of delivery and may improve involvement of supervisors. Such sessions would provide networking opportunities as well.

Another avenue for unlocking potential regarding quality of delivery is reinforcing workplace assessment with ACTY-specific observation forms. Moreover, the EPAs could play a more central role in the evaluation of students. Mapping a developmental trajectory in an e-portfolio would raise the awareness of and growth towards the learning objectives and would be an essential condition for entrustment decisions. Also, the repertoire of workplace assessments could be expanded by adding multisource feedback [28] and entrustment-based discussions [29].

The theme of acute care with learning objectives described as professional activities for (junior) doctors in acute care settings is perceived as relevant. Students expressed the desire to have more hands-on experience in the ACTY EPAs. However, in practice, the care of instable or acutely deteriorating patients is in many settings a situation in which trainees or more experienced doctors are at the helm. Possibly, restricted workplace affordances, because of norms of practice, seniority, and unfamiliarity of team members with the learner [30], preclude students from engagement in acute care. This has impact on the feasibility of the program's goals and intentions. Supervisors could be encouraged to exploit acute care situations as learning opportunities. First of all, supervisors could debrief students observing the management of acute care [31], provide bedside teaching [32,33], and have case-based discussion to teach and evaluate 
clinical reasoning and management of unobserved situations [29]. Second, supervisors should provide legitimate workplace roles [34] by allowing students to perform observable and assessable acute care tasks (e.g. Take a focused history of a dyspneic patient). Furthermore, simulation training and assessment could be incorporated in the ACTY curriculum to guarantee a certain level of exposure to critically ill patients.

Implementation research studies how interventions produce impact within real world conditions, starting with the users of the intervention (here: students and faculty) and taking contextual factors into account [22]. Looking through an implementation research lens at the experiences with the ACTY, we can say that the delivery as intended has been well with regards to the aims of focusing learning and providing coherence. This may be explained by the acceptability, or relative advantage, of the thematic approach of the ACTY and the appropriateness, or perceived relevance, of the theme of acute care [22]. On the other hand, while adoption, i.e. the intention to try the intervention, is high in the workplace, delivery as intended has been hampered by lack of attention to feasibility and integration in the actual workplace settings [22]. We hypothesize that the hampering effect of limited implementation in the workplace may have been partly offset by the proactive role of the motivated students. Increasing penetration [22] of ACTY curricular ideas into daily clinical work of the students will be the focal point of improvement strategy. With the advent of the new EPA-based Utrecht undergraduate curriculum $[16,17]$ working with EPAs will be everyday practice in departments hosting clinical students and this will ease the full implementation of advanced EPAs in the ACTY.

This study on the delivery and adoption of a dedicated transitional year has strengths and limitations. A strength is that we took several measures to enhance dependability, credibility, and confirmability [35]. The data collection methods were developed by two authors in close collaboration with the other authors and were piloted. The two researchers collecting the data managed data confidentially, analyzed data separately, and checked extracts of the interviews with participants. A limitation of this study is that it was an appreciative inquiry into the implementation of this program, rather than a curriculum evaluation or a study on the efficacy of the program. As such, data only provide insight in the delivery of the program. Nevertheless, the identification of important factors associated with success and challenges of a design for the final year of medical school may well be transferable to other settings. 


\section{CONCLUSION}

In summary, we found the dedicated transitional year in acute care to provide a focus on an interdisciplinary domain of medicine, supported by learning objectives, aligned assessment and tailored teaching sessions, and by offering a solid learning community. Enhancing delivery of the program in the workplace by increasing visibility of the program, elaborating on workplace assessment and extending hands-on experience of students, can further unlock the potential of this final medical school year design. 


\section{REFERENCES}

1. Ten Cate O. Trusting graduates to enter residency: what does it take? J Grad Med Educ 2014; 6(1):7-10.

2. Ten Cate $\mathrm{O}$. What is a 21 st-century doctor? Rethinking the significance of the medical degree. Acad Med 2014; 89(7):966-9.

3. Lyss-Lerman P, Teherani A, Aagaard E, et al. What training is needed in the fourth year of medical school? Views of residency program directors. Acad Med 2009; 84(7):823-9.

4. Walling A, Merando A. The fourth year of medical education: a literature review. Acad Med 2010; 85(11):1698-1704.

5. Wolf SJ, Lockspeiser TM, Gong J, Guiton G. Students' perspectives on the fourth year of medical school: a mixed-methods analysis. Acad Med 2014; 89(4):602-7.

6. Wijnen-Meijer $M$, ten Cate $O$, van der Schaaf $M$, Borleffs JC. Vertical integration in medical school: effect on the transition to postgraduate training. Med Educ 2010; 44(3):272-9.

7. Wijnen-Meijer $M$, ten Cate $O$, van der Schaaf $M$, et al. Graduates from vertically integrated curricula. The Clin Teacher 2013; 10(3):155-9.

8. Lindeman BM, Sacks BC, Lipsett PA. Graduating students' and surgery program directors' views of the Association of American Medical Colleges core entrustable professional activities for entering residency: where are the gaps? J Surg Educ 2015; 72(6):e184-92.

9. Reddy ST, Chao J, Carter JL, et al. Alliance for clinical education perspective paper: recommendations for redesigning the "final year" of medical school. Teach Learn Med 2014; 26(4):420-7.

10. Aagaard EM, Abaza M. The residency application process - burden and consequences. NEng J Med 2016; 374(4):303-5.

11. Dewan M, Norcini J. A purpose-driven fourth year of medical school. Acad Med 2018; 93(4):581-5.

12. Ten Cate O. Medical education in The Netherlands. Med Teach 2007; 29(8):752-7.

13. Borleffs JC. Schakeljaar kent nu nog meerdere vormen [in Dutch]. Medisch Contact 2016; 71(11):18-21.

14. Van den Broek WES, Wijnen-Meijer M, ten Cate O, van Dijk M. Medical students' preparation for the transition to postgraduate training through final year elective rotations. GMS J Med Educ 2017; 34(5):Doc65.

15. Jonker G, Hoff RG, Max S, Kalkman CJ, ten Cate O. Connecting undergraduate and postgraduate medical education through an elective EPA-based transitional year in acute care: an early project report. GMS J Med Educ 2017; 34(5):Doc64.

16. Ten Cate O, Graafmans L, Posthumus I, Welink L, van Dijk M. The EPA-based Utrecht undergraduate clinical curriculum: development and implementation. Med Teach 2018; 40(5):506-13.

17. Ten Cate O, Borleffs J, van Dijk M, Westerveld T. Training medical students for the twentyfirst century: rationale and development of the Utrecht curriculum "CRU+". Med Teach 2018; 40(5):461-6. 
18. Bunniss S, Kelly DR. Research paradigms in medical education research. Med Educ 2010; 44(4):358-66.

19. Tavakol M, Sandars J. Quantitative and qualitative methods in medical education research: AMEE Guide No 90: Part I. Med Teach 2014; 36(9):746-56.

20. Sandars J, Murdoch-Eaton D. Appreciative inquiry in medical education. Med Teach 2017; 39(2):123-7.

21. Hsieh HF, Shannon SE. Three approaches to qualitative content analysis. Qual Health Res 2005; 15(9):1277-88.

22. Peters DH, Adam T, Alonge $\mathrm{O}$, Agyepong IA, Tran N. Implementation research: what it is and how to do it. BMJ 2013; 347:f6753.

23. Lave J, Wenger E. Situated Learning: Legitimate Peripheral Participation. 1991, Cambridge: Cambridge University Press.

24. Burford B. Group processes in medical education: learning from social identity theory. Med Educ 2012; 46(2):143-52.

25. Ten Cate O, Kusurkar RA, Williams GC. How self-determination theory can assist our understanding of the teaching and learning processes in medical education. AMEE guide No. 59. Med Teach 2011; 33(12):961-73.

26. Ryan RM, Deci EL. Self-determination theory and the facilitation of intrinsic motivation, social development, and well-being. Am Psychol 2000; 55(1):68-78.

27. Williams DV, Reid AM, Homer M. Boosting clinical performance: the impact of enhanced final year placements. Med Teach 2017; 39(4):383-8.

28. Lockyer JM, Violato C, Fidler H. A multisource feedback program for anesthesiologists. Can J Anesth 2006; 53(1):33-9.

29. Ten Cate O, Hoff RG. From case-based to entrustment-based discussions. The Clin Teacher 2017; 14(6):385-9.

30. Billett S. Workplace participatory practices. J Workplace Learn 2004; 16(6):312-24.

31. Ma M, O'Connor E. Learning with unwell patients in the intensive care unit. Med Teach 2018; 40(6):642-3 .

32. Jayakumar N. Bedside teaching with unwell patients: can it ever be appropriate? Med Teach 2017; 39(3):323-4.

33. Riyat $A$, Westall $H$. Bedside teaching with unwell patients: foundation of learning in anesthetics. Med Teach 2018; 40(9):972.

34. Chen HC, van den Broek WE, ten Cate O. The case for use of entrustable professional activities in undergraduate medical education. Acad Med 2015; 90(4):431-6.

35. Frambach JM, van der Vleuten CPM, Durning SJ. AM Last Page: Quality criteria in qualitative and quantitative research. Acad Med 2013; 88(4):552. 


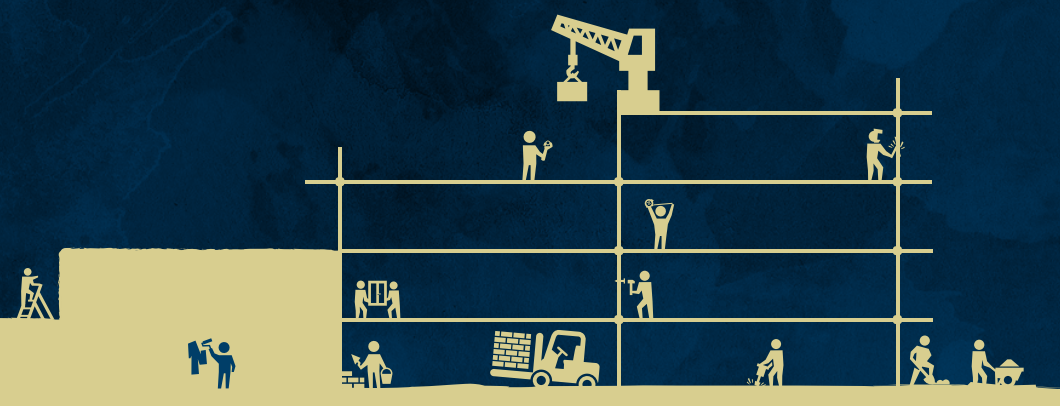




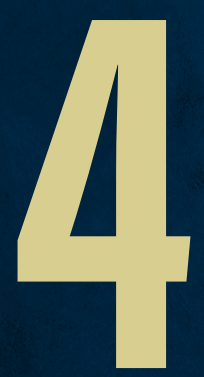

\section{SIMULATION AT THE FRONTIER OF THE ZONE OF PROXIMAL DEVELOPMENT}

\section{A TEST IN ACUTE CARE FOR INEXPERIENCED LEARNERS}

Published as:

Groot F \& Jonker G, Rinia M, ten Cate O, Hoff RG.

Simulation at the frontier of the Zone of proximal development: a test in acute care for inexperienced learners.

Acad Med. 2020; 95(7):1098-1105. doi: 10.1097/ACM.0000000000003265. 


\section{ABSTRACT}

Purpose Vygotsky's Zone of proximal development (ZPD) refers to the space between what learners have mastered and what they should master in the next developmental stage. Physicians' tasks are ZPD activities for medical students, with high-acuity tasks such as resuscitation representing activities at the ZPD's frontier. This type of task can be taught and assessed with simulation but may be demanding and stressful for students. Highly challenging simulation may lead to negative simulated patient outcome and can affect the participant's emotional state, learning, and motivation. This study aimed to increase understanding of the psychosocial and educational impact of simulation at the frontier of the ZPD.

Method The authors conducted 11 phenomenological interviews between September 2016 and May 2017, to describe medical students' experiences with a challenging residency-level simulation test of acute care competence at the start of the final undergraduate year at University Medical Center Utrecht. Interviews took place within 2 weeks after the participants' simulation experience. The authors analyzed transcripts using a modified Van Kaam method.

Results Students experienced a significant amount of stress fueled by uncertainty about medical management, deterioration of critically ill simulated patients, and disappointment about their performance. Stress manifested mainly mentally, impeding cognitive function. Students reported that awareness of the practice setting, anticipation of poor performance, the debriefing, a safe environment, and the prospect of training opportunities regulated their emotional responses to stress. These stress-regulating factors turned stressful simulation into a motivating educational experience.

Conclusions Simulation at the ZPD's frontier evoked stress and generated negative emotions. However, stress-regulating factors transformed this activity into a positive and motivating experience. 


\section{INTRODUCTION}

Vygotsky's Zone of proximal development (ZPD) [1] is a widely cited concept in education. It refers to "the distance between the actual developmental level as determined by independent problem solving and the level of potential development under adequate guidance" [1]. The ZPD is the variable space between what a learner has mastered and what they are not yet able to do and is determined by what an individual can sufficiently perceive as doable when assisted [2]. The ZPD does not simply refer to the amount of support a learner needs when acquiring a new skill but also to the steps needed to transition to the next developmental stage of capability.

While Vygotsky related the ZPD specifically to the age-related cognitive child development stages, the concept has been applied widely in all educational settings. In higher education the ZPD has been linked to the concepts of constructive and destructive friction between teaching and learning [3]. A student's comfort zone is where he or she can perform tasks independently. When students are presented with teaching activities that invite them to leave this comfort zone - that is, when they can only complete an activity when they receive expert guidance - constructive friction is generated $[4,5]$. Destructive friction occurs when the gap between the comfort zone and the task is so large that the student cannot complete the activity (even with support) or when the gap is too small (instruction is redundant and might even hamper completion of the activity) $[3,4]$.

Medical students who perform physicians' tasks are completing activities in their ZPD if guidance is provided. Complex medical responsibilities may be too difficult for the student to take on, leading to destructive friction, and can be viewed as activities at the far edge, or frontier, of the ZPD.

Acute care activities, e.g. resuscitation of critically ill patients, exemplify how inexperienced learners may have to confront the ZPD frontier in a very visible fashion in medical education. Medical students can be trained for such high-acuity events and assessed with simulated clinical immersion [6, 7]. Simulation training and assessment can be used at different stages of the medical educational continuum [7-9], but to be educationally effective, the difficulty of the simulation task should be tailored to the developmental level of the participants [10], pushing them beyond their current level of mastery, into the ZPD, to guide development in constructive friction. Simulation scenarios that are too demanding, i.e. at the far edge of the ZPD, cause destructive friction, and may be a waste of learning opportunities and resources. Moreover, at 
the frontier of the ZPD, poor participant performance is likely, leading to a negative simulated patient outcome. How such a negative outcome affects the participant's emotional state, learning, and motivation is not completely understood.

Simulation can induce physiologically measurable levels of stress [11, 12]. Stress can also manifest at a mental level, imposing cognitive load and reducing a student's mental resources for learning [13]. The distress that arises from failing to manage a deteriorating patient likely adds to a student's cognitive load [13]. It is safe to state that working with simulated critically ill patients is stressful [12, 14-16].

Management of critically ill simulated patients occurs at the ZPD's frontier for most medical students and, to the greatest extent, for untrained students, such as those participating in a pretest.

A pretest is an assessment of a student's level of knowledge, skill, or competence before instruction and learning. Simulation pretesting can be a powerful tool to clarify the learning objectives of a course. A student can experience such a formative assessment as valuable and motivating [17-19]. However, pretesting that is too challenging and stressful and that results in poor performance could cause destructive friction and may demoralize the student. How to strike the right balance in simulation pretesting at the ZPD's frontier is unknown.

We undertook a study to answer the following question: How do untrained medical students experience the simulation of overly challenging cases? The aim of the study was to increase understanding of the psychosocial and educational impact of simulation at the edge of the ZPD. The goal was not only to gain knowledge about Vygotsky's ZPD in the context of simulation but also to provide insight in the use and effect of highly challenging pretests.

\section{METHOD}

We designed a qualitative phenomenological study to explore students'lived experience of simulations at the ZPD's edge. Phenomenology is a methodological approach within the interpretivist research paradigm that considers social reality to be formed by subjective human experiences and social contexts [20,21]. It aims to understand the social reality of a phenomenon by collecting firsthand accounts of the phenomenon and describing the common meaning of those experiences [21-23]. Phenomenology holds that the presented reality of a phenomenon is constructed from the subjects' conscious thoughts, feelings, and ideas about their experiences [22]. 


\section{Context}

In an effort to ease the transition to postgraduate training, medical schools in the Netherlands have redesigned the sixth (the final year) into a "transitional year" [24]. The transitional year includes dedicated elective tracks to enable students to develop early residency-level competence and a specialty preference [24,25]. The University Medical Center Utrecht introduced a multidisciplinary elective track in the transitional year aimed at providing students the opportunity to acquire acute care competence, preparing them for postgraduate training in anesthesiology, cardiology, emergency medicine, intensive care, or pulmonary medicine $[26,27]$. Students in this themed final year program take multiple electives from these specialties. Another specific feature is a formative pretest of acute care competence. This junior residency-level test is meant to focus students on acute care elective entrustable professional activities (EPAs) that are objectives of the year ahead and to provide insight into the students' strengths and weaknesses at the outset of the track. The multimodal assessment measures knowledge, skills, clinical reasoning, and clinical performance in high-fidelity simulations of acute care settings. Students take a similar posttest at the end of the year to measure their individual development. All data are used both to provide feedback to students and for research purposes. The introduction of the pretest gave rise to the research question of this study.

\section{The simulation pretest}

The Simulation Center of Rijnstate Hospital, Velp, the Netherlands, hosted the simulation pretest, which took $3 \frac{1}{2}$ hours for groups of 4 students concurrently. Anesthesiologists, anesthetic nurses, and an anesthesiology resident, who were all EUSim-certified simulation facilitators [28] ran the test. Every student took part in 3 simulations, each lasting approximately 12 minutes. Scenarios required acute care in emergency room and ward settings (e.g. anaphylaxis, postoperative hemorrhage, acute myocardial infarction). A nurse was present and acted on instruction of the student only. Using a scenario-specific checklist, an anesthesiologist assessed students from behind a oneway screen. The resident debriefed each student after the scenario in private, allowing the student to vent emotions and to ask questions about medical or technical aspects. Debriefing was nonevaluative, pinpointing positive performance and highlighting poor performance as learning opportunities. To adhere to simulation research reporting guidelines [29] we have provided a detailed description of the simulation context, a typical scenario, and the assessor's checklist (Appendix 1). 


\section{Participants}

Every 6 weeks, 2 to 6 final-year medical students enroll in the acute care themed finalyear program on a rotational basis and start with the simulation pretest of acute care competence. During the study period, we approached all students who had taken the simulation pretest to participate in the interview study. Immediately after students had completed the simulations and were leaving the simulation center, a member of our team asked each of them to participate in our study. We invited the students after the simulation to avoid potential influence of study goal awareness on their lived experiences. Students received oral and written information and gave written informed consent. The Ethical Review Board of the Netherlands Association for Medical Education approved the study in May 2016 (NERB file 712).

\section{Data collection}

We gathered first person accounts of lived experiences with the simulation pretest by single in-depth, face-to-face private interviews. Interviews were conducted in Dutch, and members of the research team translated into English the representative quotations from those interviews that appear in this research report.

We devised an interview guide with open-ended questions, following guidelines by Moustakas [22]. The interviewer asked the participant, after a prompt, to focus attention on the experience and to become aware of feelings and thoughts, to describe his or her lived experience thoroughly. The interviewer asked clarifying, probing questions to obtain thick descriptions. Next, the interviewer asked open-ended questions that followed the chronology of the simulation pretest experience. The interviewer evoked reflections on felt space and time, bodily sensations, and the relation to others and self to gain thick descriptions [22]. Next, the interviewer elicited factors that the participant perceived to affect the experience. All authors approved the interview guide (Appendix 2) before we piloted it on one student. Interviewing took place between September 2016 and May 2017, within 2 weeks after the participants' simulation experience. Concurrent analysis of interviews enriched questioning in subsequent iterations of data collection, and this process continued until we achieved theoretical sufficiency, i.e. until we could categorize new data without the need for additional themes.

Our participation rate was 100\%: The first 11 students we invited to participate all accepted. There were 4 male and 7 female participants with an interview duration of approximately 30 minutes. 


\section{Data analysis}

A commercial agency transcribed the audiorecorded interviews verbatim.

Two authors (FG, GJ) analyzed the transcripts using a 9-step modified Van Kaam method [22]. After immersing themselves in the data by listening and reading, F.G. and G.J. carried out step 1, "horizonalization," individually by identifying each statement referring to the experience in each transcript. In step 2, reduction and elimination, the 2 researchers organized the horizons identified in step 1 into units of meaning, called constituent themes, and clustered these in steps 3 and 4 into invariant core themes of the experience, leading to individual textural descriptions (step 5). Participants checked these descriptions to verify that they portrayed their lived experience. In step 6, the 2 researchers sought the essence of the experience by recurrently engaging in critical dialogue and applying imaginative variation, looking at the transcripts and individual textural descriptions from various vantage points. Through reflection and discussion, the researchers interpreted accounts on a more abstract level, looking at implicit meanings, leading to an individual structural description of how the phenomenon was experienced (step 7). Finally, the researchers integrated individual descriptions into a collective one, called a composite textural description (step 8, Appendix 3). From that description, they synthesized a composite structural description that describes the universal essence of experiencing the phenomenon for the group of participants (step 9). Up to this point, the other authors were not involved in the data analysis.

We used the Journal Article Reporting Standards for Qualitative Research checklist to guide reporting of our research [30].

\section{Reflexivity}

Adopting a phenomenological attitude, weaimed to better understand the phenomenon by exploring subjects' lived experiences open-mindedly, suspending all judgments about what was significant until we had grounded the significance in the data [22, 31]. To do this, we reflexively explicated our own experience with the phenomenon and our preexisting opinions about the phenomenon. Throughout the research process, we balanced awareness of these so-called pre-understandings with setting them aside [31]. The primary interviewer ( $\mathrm{FG}$ ) had observed the students during the simulations and led the informal debriefings after each simulation scenario. When FG was unavailable, another investigator (GJ) acted as an observer during the simulation and conducted the interviews. Presence of the interviewer at the simulation served to establish rapport and allowed the interviewer to relate to the events. 
FG was an anesthesiology resident at the time of this study and was unknown to the participants. As a certified simulation facilitator, FG was concerned that the simulation pretest would be too difficult. At the time of the study, GJ was an anesthesiologist and coordinator of the acute care track in the transitional year that participants enrolled in. As such he had met with the students before this study began to explain the structure of the track and the pre- and posttests as a part of the track. GJ had no role in the evaluation of students in the tests or during the year. GJ's acquaintance with the students seemed beneficial, and his role as coordinator did not negatively affect participants' willingness to express themselves. GJ had limited personal experience as a simulation participant.

In the initial stage of analysis, participants established proximity of the individual textural description to their lived experience. In addition to describing the essence of experiencing the phenomenon, by staying close to individual stories, we interpreted the experiences to gain transferable understanding of the phenomenon, "dancing between positions" [31] of pure descriptive and interpretative hermeneutic phenomenology. Interpretation took place in intensive dialogues between FG and GJ, during which they assumed various roles such as educator, caregiver, simulation trainer, and exam candidate to understand meanings from different vantage points. The two researchers used these roles to address pre-understandings and reflect on what the data evoked in them.

\section{RESULTS}

All participants agreed with the individual textural descriptions of their experience. We amalgamated the students' lived experiences of simulating at the frontier of the ZPD into a quotation-rich composite textural description (Appendix 3). In this section we have provided a composite structural description, which is our interpreted synthesis of the meanings of the students' experiences of the phenomenon.

We have also distilled these experiences into their essence, also included in this section. We found three distinct core themes to be relevant to the research question: realism, emotional response, and motivation to learn.

\section{Realism}

Students generally experienced the simulation area, manikin, and scenarios as realistic. Participants were highly appreciative of the authenticity of the simulation, and some were impressed by it: 
I was astounded, finding myself giving orders or instructions to a nurse and pressing the defibrillator button. I couldn't stop thinking about this experience the rest of the day. (Participant $[P] 2)$

All students believed they could encounter similar situations as newly qualified doctors. They perceived the manikin almost as a person, eliciting in some a desire to "rescue the patient" and "comfort him." Despite the high level of realism, all students were continuously aware of being in a simulation:

I was kind of assuming the manikin was going to crash. So I was thinking about the diagnosis: What could it be? And what could then go wrong? (P11)

\section{Emotional response}

The main emotion students experienced during the simulation was universally described as stress. Many students also experienced a sense of responsibility and a feeling of failure.

\section{Stress}

The amount of stress varied from person to person. In most cases, feelings of stress were related to the uncertainty about diagnosis or treatment options. Although some noticed palpitations and sweating, most students were not aware of a physical stress response but did experience stress mentally. Students described feelings of being frozen in place or time:

The pulse oximeter made a penetrating, beeping sound. It felt like time stood still. ... If you don't know what to do, then every second is painful and feels like a minute. (P3)

Many felt overwhelmed, had difficulty structuring their thoughts, struggled to prioritize or forgot what they intended to do:

When I saw on the monitor that it wasn't going well, thoughts were racing through my mind. "It could be this, or this, or this." (P6)

But then I realized I'm reading the sheet with CPR instructions, but I'm not processing them. (P8)

A significant contributor to stress was students' perception of their performance: 
I don't stress out easily, but on the other hand I do have certain expectations of myself. So it is stressful in a sense of not being able to live up to those expectations. (P7)

The level of stress increased when the patient deteriorated:

I was sweating more, had a real adrenaline rush. It made me double my efforts, but once the patient deteriorated, I started to feel a little claustrophobic in that room. (P2)

The constant awareness of being in a simulated environment eased feelings of stress. The atmosphere at the simulation center helped to reduce tension:

I was pleasantly surprised to find out that I stayed calm and was still able to think. ... I knew it was a manikin, and a disastrous situation was going to be created. I did realize something is going to happen that won't necessarily be my fault; I just need to solve it to my best ability. (P10)

Students emphasized that although the experience was stressful, they still enjoyed the simulation. It felt gratifying to solve a puzzle, experience a unique learning opportunity, and realize they were able to handle complex medical situations to a certain degree:

Besides knowing where I should be at the end of medical school, it gives me a sort of confidence, knowing I am capable of helping out in an emergency situation until the real team arrives. (P9)

\section{Sense of responsibility and failure}

The students' perception of role was fluid during the scenarios. Most students initially felt like junior doctors, finding it exciting and novel to give directions to the nurse:

I felt like a real doctor in the simulation. This was one of the few times I felt completely responsible for a patient. I realized this immediately. And it felt quite good. (P2)

Often, this initial feeling of confidence faded upon encountering urgent situations in which the course of action was not evident. Students experienced a significant degree of incompetence, and their self-image changed from junior doctor to medical student. Also, they felt they were being unprofessional when giving unclear instructions or retracting orders: 
I felt like crawling into a corner. . . . I was like, "Oh dear, I am sending her all over the shop!" (P6)

There were brief moments when I knew what to do. Those felt like being a resident doctor. But as soon as I thought "help!" I was more like, "I'm a medical student. I don't know!" (P8)

Often, the student's uncertainty reverted to confidence when the patient had a cardiac arrest. Having a protocolled basic life support algorithm to execute provided the students a paradoxical sense of relief during this specific clinical deterioration. (However, none of the students mastered the advanced life support algorithm satisfactorily.)

If the patient arrests, it places you on firm ground. At least you can do something. (P3)

Self-assessment of performance varied from "outright failure" to a "bare pass." Most students expected not to perform well and did not mind because the pretest was formative. The students' perceptions were in accordance with the test results: Most students scored low on all 3 scenarios.

I can't really say I felt angry or like a very big failure because I didn't expect to perform much better than I did. (P6)

Despite the expectation of failure and the formative nature of the pretest, all students regarded their performance level as "a shocking revelation" and "disappointing".

It was so bizarre that I didn't notice the patient was basically bleeding out. It was so obvious! ... It's just a shocking revelation. Because at that moment, I realized I am far from knowing enough [to manage] such a situation. (P6)

It was very intense. I was confronted with my incompetence, and the realness of the simulation, and the demanding nature of emergency situations. It truly was a mirror. (P3)

Students were aware of faculty witnessing their performance through the one-way mirror but generally did not mind that staff were assessing their performance. During moments of uncertainty, students became slightly more aware of the one-way mirror:

I am being watched. I must do something! (P3) 
In addition, most students felt relieved at the end of the scenario, especially if they were uncertain about the management of the case:

If it went that badly, then [the end of the scenario] felt like a kind of relief. Like being put out of my misery. (P4)

The informal and nonjudgmental atmosphere in the simulation center contributed significantly to the students' not minding being watched and scored. All students appreciated that staff introduced themselves at the start of the day, so they knew who was observing them:

It was really helpful that the staff acted very casual at the start of each simulation and often made a joke. For me that reduced the tension. (P2)

\section{Motivation to learn}

All students found the short personal debriefing sessions after each scenario crucial to their learning. They appreciated the immediate and to-the-point nature of these sessions and that staff highlighted not only mistakes but also correct actions. In addition, students found that being able to vent emotions in a safe and nonjudgmental environment was a valuable experience:

You only learn from mistakes if you get the correct answer later or if you can discuss it. Without that debriefing, the simulation would be far less useful. (P4)

In most cases, the simulations reinforced the students' orientation toward acute medicine. None felt that the simulation had demonstrated they were unsuitable to work in acute medical specialties. But their experiences in the simulation did make them more aware of the challenges ahead and motivated them to improve themselves.

Without the simulations, I also would have started my final year clerkships. But perhaps I would have been more passive. Now I really want to get the most out of this year. (P2)

It [the simulation] reinforced my aspirations. This is what I want to excel in so I'd better put in some effort now because I want to do better than I did today. (P3)

In the days following the simulation, all students reflected on their experiences positively. The simulation pretest made the students more aware of the goals and requirements of the program, and the students expected that their experience with the simulation would direct their learning in the year ahead. 
From now on, when situations like these occur, I'll perceive them differently. I'll try to engage more with what's happening at the time. (P11)

It is very informative to know what's expected of me once I qualify.... It [the level expected of a qualified junior doctor] is a sort of guideline, outlining the gaps in my knowledge. It demonstrates what I should study in greater depth or what I should pay attention to during my clerkships. (P9)

\section{Essence}

Students experienced difficulties in managing simulated acute care situations, leading to a significant amount of stress fueled by uncertainty about medical management, deterioration of critically ill simulated patients, and disappointment about their performance. Their stress manifested itself mainly mentally, impeding cognitive function. Students reported that awareness of the practice setting, anticipation of poor performance, debriefing, a safe learning environment, and the prospect of training opportunities regulated their emotional responses to stress. These stress-regulating factors turned stressful simulation into a motivating educational experience.

\section{DISCUSSION}

Our study explored the psychosocial and educational impact of simulation at the frontier of the ZPD in medical students after a residency-level pretest of acute care competence at the start of the students' final year.

Our main finding is that, in a formative pre-assessment setting, simulation at the far edge of the ZPD causes constructive friction leading to an experience that generates a motivation to learn. This finding contrasts with the current opinion that the difficulty of the simulation task should be tailored closely to the developmental level of the participant [10] to avoid destructive friction and demoralization.

The ZPD spans the difference between an individual's current level of capabilities and the level of functioning needed in the next stage of development [2]. The ZPD comprises maturing functions relevant for the next level of capability, activities that cannot be carried out independently but that can be taught or carried out with direction, generally from a teacher [2]. We exposed students to activities from their next stage of development, that of a junior physician, without providing teacher support or direction. The students' inability to sufficiently manage the activities indicates that these activities were at the far edge of their ZPD. In addition, students perceived shifts between doctor 
and student identities; this shift can be seen as an indication that the simulations were at the ZPD's frontier, with participants moving back and forth over the border between their current level and the next developmental level.

Study participants indicated that their stress was caused by their uncertainty about medical management, the deterioration of the simulation patient, and disappointment about their performance. The discomfort of an undesirable outcome in dramatic cases in which "things go wrong" has recently been identified as a key feature of powerful simulation experiences [19]. Without appropriate facilitation, this disruption could be damaging, but debriefing and feedback may turn the simulation into a powerful learning experience [19]. In other words, a challenging task can induce the development of new skills if the teacher provides tailored direction, creating constructive friction. Without direction, destructive friction may occur, decreasing learning [3].

The students'stress manifested in feelings of bewilderment and disturbance of cognitive processes. The detrimental effect of stress on cognitive function during simulation is due to a reduction in "tranquility," leading to agitation, combined with positive feelings of "invigoration" [13]. These reactions are associated with an increase in task-irrelevant, extraneous cognitive load and thus reduce working memory space for learning [13, 32]. Extraneous load caused by invigoration may include self-evaluating thoughts on performance [13] and indeed some participants feel exposed during simulation [33]. Students in our study worried about their performance and the impression they made on faculty, especially when they felt they were performing poorly. Disappointment made them aware of being observed and assessed.

In our study, students engaged in the management of critically ill simulation patients who deteriorated despite the students' best efforts, with some cases ending during cardiac arrest, as case duration was limited due to time constraints. Whether patient death in a simulation affects cognitive load, stress, or learning outcomes remains controversial [11, 14, 34-36].

Cases that are beyond the learner's control may lead to the learner's disengagement and impair his or her ability to handle the situation [37]. Of interest, participants in our study experienced a sense of control that brought them relief in the case of cardiac arrest. So, although the patient was moribund, the situation provided solid ground for protocolled action (i.e. students suddenly knew what to do); we suggest calling such a situation "the paradox of cardiac arrest" in simulation. This finding also indicates the 
importance of teaching students how to prevent cardiac arrest by recognizing and treating deteriorating patients, which we chose as an objective of our transitional year [26].

The students' emotional response to the stressful simulation was regulated by awareness of the practice setting. Previous research has suggested that when participants expect a life-threatening event or negative outcome to occur, their level of stress is reduced during a simulation [38].

Students' anticipation of poor performance was another stress modifier. The pretest worked as an eye-opener that explicated the level of performance that would be required for graduation. It motivated the students to exploit learning opportunities during the year: Pre-assessment can drive learning. The beneficial effect of a pretest on subsequent learning has recently been demonstrated in surgical skill acquisition [39]. The educational effect of the pretest is rooted in the close alignment between simulated cases and the learning objectives tested [10, 40-42], in this case the entrustable professional activities of a final year focused on acute care [26]. Because of the pretest, students started their final year with a clear view of the learning objectives [27]. Their choice for this specific final year elective program and their interest in acute care moderated their response to the pretest.

Finally, the developmental atmosphere in the simulation center created a safe learning environment and helped make the test a motivating experience. In general, positive emotions can improve cognitive processing and increase motivation [43]. Previous research highlighted that learning and using stress-coping strategies in simulation training and assessment helped students turn negative emotions into positive ones [14-16]. In addition, feedback in the form of debriefing is crucial for the educational effectiveness of simulation [10,40,42] because it improves the transfer of learning after simulation [44]. Debriefing helps to restore tranquility, thereby reducing extraneous cognitive load and providing space for learning [43]. Venting emotions is a good starting point for a debriefing session to increase the students' tranquility before they focus on medical and crew resource management aspects of their performance.

In the simulations, students took on the role of doctor, but this self-image crumbled when they experienced feelings of incompetence. The resultant disappointment subverts students' common belief that doctors should be in control even in complex situations, which influences emotional and behavioral responses to challenging clinical situations [37]. The response to complex situations could be a topic for the debriefing to help students be reflective about their expectations of being in control. 


\section{Implications}

We found that simulations of challenging stressful acute care situations, without guidance during scenarios and despite poor participant performance and simulation patient outcome, do not demoralize participants but rather lead to positive, instructive, and motivating experiences, when conducted in safe, formative, developmental circumstances.

Our findings imply that simulations at the far edge of the ZPD may be used safely to motivate learners. This finding contrasts with current opinion on simulation learning [10] and has practical significance by providing preliminary data on simulating beyond traditional borders.

\section{Limitations}

Our study had several limitations. We conducted an explorative study in the specific context of pretested students at the start of a final year focused on acute care. The study did not control for the extent to which the far edge of the students' ZPD was reached, nor did it include control groups of participants with variable levels of competence or intrinsic motivation. Also, the study reached theoretical sufficiency, i.e. there was no need for additional constituent or core themes to categorize new data, with a relatively small number of interviews, which could be attributable to participants all being part of the same elective track. Lived experiences could have been more divergent in a random sample of students. Future studies could investigate the phenomenon in other groups, including students with less focus on acute care and graduating students. Another limitation is that we did not measure a longer-term learning effect. Participants stated that the simulation was a valuable learning experience, but we did not test for educational effectiveness. By providing a precise description of the context, we aimed to improve the transferability of our data and provide generalizable insights regarding the ZPD in the context of simulation. Better comprehension of the psychosocial and educational impact of exposing inexperienced learners to activities far outside of their comfort zones may support the responsible and effective use of simulation at the ZPD's frontier, such as in pre-assessment. Further research could investigate the effects of teacher support and instructional design on students' experiences of crossing the ZPD border in simulation $[2,6]$. 


\section{CONCLUSION}

This study demonstrated that simulation at the frontier of the ZPD evokes a significant amount of stress, impeding cognitive functioning, but also causing constructive friction that leads to a motivating experience in untrained learners. Our premises for this type of simulation are that a safe and formative learning environment is offered, the practice setting is emphasized, feedback and debriefing are provided, and the prospect of further training is present. In this way, experiencing failure turns into a successful learning experience. 


\section{REFERENCES}

1. Vygotsky L. Mind in society. The development of higher psychological processes. 1978, Cambridge, MA: Harvard University Press.

2. Chaiklin S. The Zone of proximal development in Vygotsky's analysis of learning and instruction, in Vygotsky's educational theory in cultural context, A. Kozulin, et al., Editors. 2003, Cambridge University Press: Cambridge UK. 39-64.

3. Vermunt J, Verloop N. Congruence and friction between learning and teaching. Learning \& Instruction 1999; 9:257-80.

4. Ten Cate O, Snell L, Mann K, Vermunt J. Orienting teaching toward the learning process. Acad Med 2004; 79(3):219-28.

5. Sandhu G, Thompson-Burdine J, Nikolian VC, et al. Association of faculty entrustment with resident autonomy in the operating room. JAMA Surg 2018; 153(6):518-24.

6. Chiniara G, Cole G, Brisbin K, et al. Simulation in healthcare: a taxonomy and a conceptual framework for instructional design and media selection. Med Teach 2013; 35(8):e1380-95.

7. Lim G, Mclvor WR. Simulation-based anesthesiology education for medical students. Int Anesthesiol Clin 2015; 53(4):1-22.

8. Brydges R, Hatala R, Zendejas B, Erwin PJ, Cook DA. Linking simulation-based educational assessments and patient-related outcomes: A systematic review and meta-analysis. Acad Med 2015; 90(2):246-56.

9. Ryall T, Judd BK, Gordon CJ. Simulation-based assessments in health professional education: a systematic review. J Multidiscip Healthc 2016; 9:69-82.

10. Issenberg SB, McGaghie WC, Petrusa ER, Lee Gordon D, Scalese RJ. Features and uses of highfidelity medical simulations that lead to effective learning: a BEME systematic review. Med Teach 2005; 27(1):10-28.

11. DeMaria S, Silverman ER, Lapidus KA, et al. The impact of simulated patient death on medical students' stress response and learning of ACLS. Med Teach 2016; 38(7):730-7.

12. Clarke S, Horeczko T, Cotton D, Bair A. Heart rate, anxiety and performance of residents during a simulated critical clinical encounter: a pilot study. BMC Med Educ 2014; 14:153.

13. Fraser $\mathrm{K}, \mathrm{Ma} \mathrm{I}$, Teteris $\mathrm{E}$, et al. Emotion, cognitive load and learning outcomes during simulation training. Med Educ 2012; 46(11):1055-62.

14. Hunziker $S$, Laschinger $L$, Portmann-Schwarz $S$, et al. Perceived stress and team performance during a simulated resuscitation. Intensive Care Med 2011; 37(9):1473-9.

15. Harvey A, Nathens AB, Bandiera G, Leblanc VR. Threat and challenge: cognitive appraisal and stress responses in simulated trauma resuscitations. Med Educ 2010; 44(6):587-94.

16. Breuer G, Schweizer K, Schuttler J, Weiss M, Vladut A. "Jump in at the deep end": simulatorbased learning in acute care [in German]. Anaesthesist 2014; 63(1):16-22.

17. Bearman M. Is virtual the same as real? Medical students' experiences of a virtual patient. Acad Med 2003; 78(5):538-45.

18. Takayesu J, Evans A, Sullivan J, Pawlowski J, Gordon J. How do clinical clerkship students experience simulator-based teaching? A qualitative analysis. Simul Healthc 2006; 1(4):215-9. 
19. Bearman M, Greenhill J, Nestel D. The power of simulation: a large-scale narrative analysis of learners' experiences. Med Educ 2019; 53(4):369-79.

20. Bunniss S, Kelly DR. Research paradigms in medical education research. Med Educ 2010; 44(4):358-6.

21. Tavakol M, Sandars J. Quantitative and qualitative methods in medical education research. AMEE medical education guide no. 90 part I. Med Teach 2014; 36(9):746-56.

22. Moustakas C. Phenomenological Research Methods. 1994, Thousand Oaks, CA: Sage Publications.

23. Tavakol M, Sandars J. Quantitative and qualitative methods in medical education research. AMEE medical education guide no. 90 part II. Med Teach 2014; 36(10):838-48.

24. Borleffs J. Schakeljaar kent nu nog meerdere vormen [Transitional year now has several forms, in Dutch]. Medisch Contact 2016; 71(11):18-21.

25. Van den Broek WES, Wijnen-Meijer M, ten Cate O, van Dijk M. Medical students' preparation for the transition to postgraduate training through final year elective rotations. GMS J Med Educ 2017; 34(5):Doc65.

26. Jonker G, Hoff RG, Max S, Kalkman CJ, ten Cate O. Connecting undergraduate and postgraduate medical education through an elective EPA-based transitional year in acute care: an early project report. GMS J Med Educ 2017; 34(5):Doc64.

27. Jonker G, Booij E, Otte WR, et al. An elective entrustable professional activity-based thematic final medical school year: an appreciative inquiry study among students, graduates, and supervisors. Adv Med Educ Pract 2018; 9:837-45.

28. EuSim. Simulation based education. https://eusim.org/ [homepage on the internet]. Accessed February 14, 2020.

29. Cheng A, Kessler D, Mackinnon R, et al. Reporting guidelines for health care simulation research: extensions to the CONSORT and STROBE statements. Adv Simul (Lond) 2016; 1:25.

30. Levitt HM, Bamberg M, Creswell JW, et al. Journal article reporting standards for qualitative primary, qualitative meta-analytic, and mixed methods research in psychology: the APA Publications and Communications Board task force report. Am Psychol 2018; 73(1):26-46.

31. Hopkins RM, Regehr G, Pratt DD. A framework for negotiating positionality in phenomenological research. Med Teach 2017; 39(1):20-5.

32. Young JQ, van Merrienboer J, Durning S, ten Cate O. Cognitive load theory: implications for medical education. AMEE medical education guide no. 86. Med Teach 2014; 36(5):371-84.

33. Brandao C, Collares C, Marin H. Student perception on high-fidelity simulation during the medical clerkship. Stud Health Technol Inform 2013; 192:960.

34. Corvetto MA, Taekman JM. To die or not to die? A review of simulated death. Simul Healthc 2013; 8(1):8-12.

35. Pai D, Ram S, Madan S, Soe H, Barua A. Causes of stress and their change with repeated sessions as perceived by undergraduate medical students during high-fidelity trauma simulation. Nat I Med J India 2014; 27(4):192-7.

36. Fraser K, Huffman J, Ma I, et al. The emotional and cognitive impact of unexpected simulated patient death: a randomized controlled trial. Chest 2014; 145(5):958-63. 
37. Helmich E, Diachun L, Joseph R, et al. "Oh my God, I can't handle this!": trainee's emotional responses to complex situations. Med Educ 2018; 52(2):206-15.

38. Baker BG, Bhalla A, Doleman B, et al. Simulation fails to replicate stress in trainees performing a technical procedure in the clinical environment. Med Teach 2017; 39(1):53-7.

39. Willis R, Erwin D, Adelaja F. Struggling prior to a teaching event results in superior short-term skills acquisition in novice learners. J Surg Educ 2020; 77(1):34-39.

40. Motola I, Devine LA, Chung HS, Sullivan JE, Issenberg SB. Simulation in healthcare education: A best evidence practical guide. AMEE medical education guide no. 82. Med Teach 2013; 35(10):e1511-30.

41. Hamstra SJ, Brydges R, Hatala R, Zendejas B, Cook DA. Reconsidering fidelity in simulationbased training. Acad Med 2014; 89(3):387-92.

42. Garden A, Le Fevre D, Waddington H, Weller J. Debriefing after simulation-based nontechnical skill training in healthcare: A systematic review of effective practice. Anaesth Intens Care 2015; 43(3):300-8.

43. Fraser $\mathrm{K}, \mathrm{McLaughlin} \mathrm{K}$. Temporal pattern of emotions and cognitive load during simulation training and debriefing. Med Teach 2019; 41(2):184-9.

44. Zendejas B, Cook DA, Farley DR. Teaching first or teaching last: does the timing matter in simulation-based surgical scenarios? J Surg Educ 2010; 67(6):432-8. 


\section{APPENDIX 1. DESCRIPTION OF SIMULATION CONTEXT AND SCENARIOS}

\section{Simulation overview}

Before enrolling in the multidisciplinary dedicated transitional year on acute care at the University Medical Center Utrecht, students take a formative multimodal pretest to focus on the elective entrustable professional activities that are the objectives of the year ahead. The junior residency-level test consists of 2 parts. The first part assesses knowledge with a written test, know-how with case-based discussions, and skills, with objective structured clinical examinations. The second part is an assessment of clinical performance in acute care that takes place in a simulated environment. Students take a similar posttest at the end of the year.

This study focused on the second part of the pretest, i.e. the simulations. The simulation test has a total duration of $31 / 2$ hours for groups of 4 students, including introduction, familiarization, 12 individual tests (4 students in 3 scenarios), individual debriefing, waiting, breaks, and a group debrief and closure.

With the description below we adhere to the guidelines for reporting simulation research by Cheng et al. [29].

\section{Simulation environment}

The simulation pretest took place in the Simulation Center of Rijnstate Hospital, Velp, the Netherlands. The Center offers a secluded and quiet area for simulation consisting of a briefing room, a $54 \mathrm{~m}^{2}\left(581 \mathrm{ft}^{2}\right)$ simulator room, a control room behind a one-way screen, a debriefing room, and a waiting area. The simulator room mimics a room in a clinical environment and deploys a 2010 Laerdal Sim Man (Laerdal Benelux B.V., Amersfoort, the Netherlands). This high-fidelity manikin features a wide range of pulsations, heart sounds, and breath sounds and allows surgical interventions such as chest drains and a full range of airway management from bag-mask ventilation to cricothyroidotomy. The manikin is positioned in a hospital bed. No moulage is used on the manikin. Props are occasionally used, e.g. a bladder-flushing system in a post-TURP (trans-urethral resection of the prostate) hemorrhage scenario. A working 18G IV cannula is in situ in an antecubital vein.

The manikin can be connected to a monitor that can display pulse oximetry, noninvasive blood pressure, 3-lead electrocardiogram, capnography, and temperature. Further 
options, such as invasive blood pressure, are theoretically available but are not used in the scenarios. The interval between successive blood pressure measurements can be adjusted, alarms can be muted or switched off, and alarm limits changed.

Three trolleys are present in the room, containing all the medication commonly used during resuscitation and emergency care, standard airway equipment, and disposables (crystalloid solutions, oxygen face masks, nebulizers, oropharyngeal airways, endotracheal tubes, etc.). A CPR cart is available with a biphasic defibrillator and medication commonly used during CPR (adrenaline, amiodarone). The shockable and non-shockable cardiac arrest algorithms are attached to the CPR cart. An IV pole is present and includes syringe pumps. Oxygen is supplied from the hospital medical gases pipeline system. A working suction system is present. A working telephone is mounted on the wall. A desktop computer is available with a working internet connection to facilitate online information searches.

Simulation sessions are run by anesthesiologists and anesthetic nurses who are all level 1 EuSim certified simulation facilitators [28].

\section{Participant orientation}

The simulation session starts with an induction talk describing the program of the day and introduction of all facilitators. Next, participants are offered a tour so they can familiarize themselves with the simulation environment. The tour includes looking at the content of the carts and trolleys and getting acquainted with the look and feel of the manikin and operation of the monitor, piped oxygen and suction system, telephone, and defibrillator.

\section{Simulation exposure and scenarios}

The participant acts individually as the doctor attending to emergency calls to the emergency room or ward. Participants collaborate with a single "nonobstructive" nurse colleague. The nurse is able to provide whatever the student requests (within reason) but does not make any suggestions regarding therapy and drug doses. The nurse can gently prompt the student by asking what the next step or priority will be. The nurse does not correct inappropriate therapy suggestions and will not take the initiative to commence life-saving interventions (e.g. chest compressions).

Scenarios have been developed collaboratively by simulation center physicians and physicians involved in student and resident training in anesthesiology, cardiology, emergency medicine, intensive care medicine, or respiratory medicine. Scenarios require acute care for cases of anaphylaxis, postoperative hemorrhage, or acute myocardial 
infarction. Scenarios are tasks that a first-year postgraduate could encounter. The scenarios reflect the entrustable professional activities that have been defined for the Utrecht dedicated transitional year on acute care. Participants are requested to provide the best care possible within their abilities. They are allowed to use personal aids such as handbooks, written notes, and smartphones.

Three scenarios are run consecutively. After all students in a group have completed a scenario in turn, the simulator is set up for the next scenario. Each scenario lasts approximately 8 to twelve 12 , and participants are allowed one attempt per scenario.

Right before the simulation, the participant is briefed on the emergency call by one of the facilitators. The participant is allowed to make additional enquiries (examples below) or ask for clarifications.

An example of a scenario is provided below:

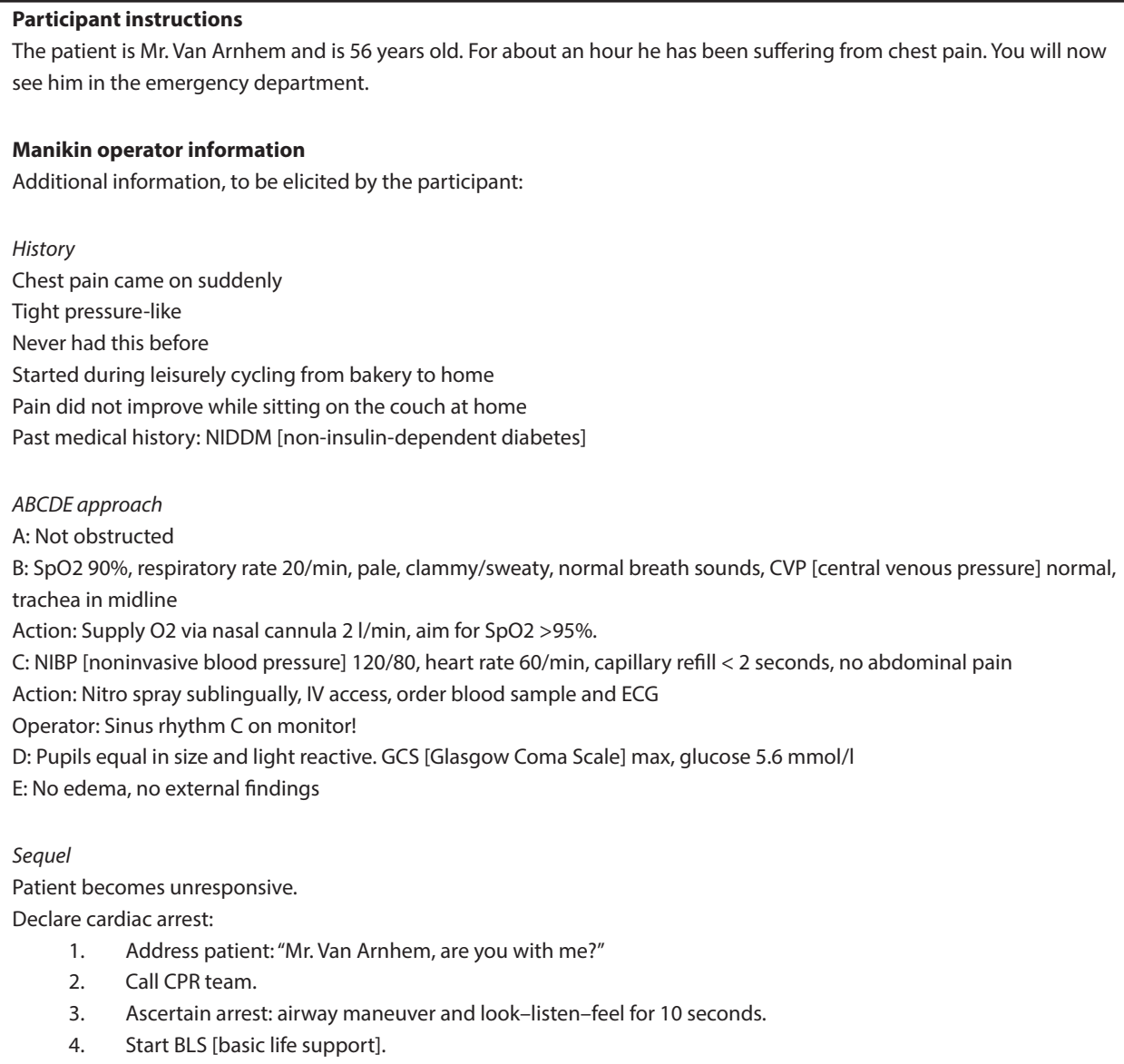




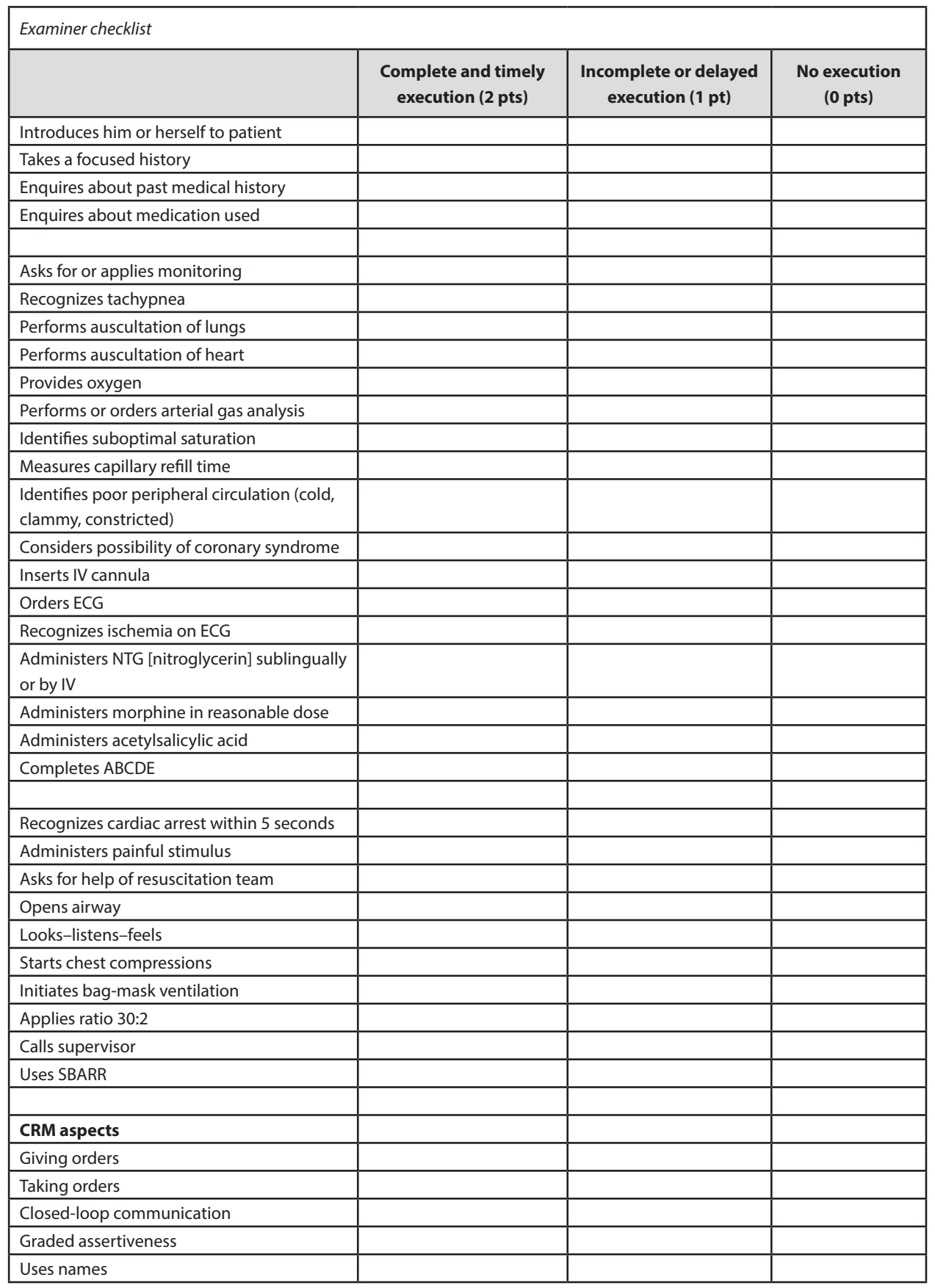


Impression of overall clinical performance (technical and nontechnical) during this case

\begin{tabular}{|l|l|l|}
\hline Fail & Borderline & \multicolumn{1}{|c|}{ Pass } \\
\hline How can the participant improve their performance? \\
\hline \\
\hline
\end{tabular}

Abbreviations: NTG indicates nitroglycerin; SBARR, situation, background, assessment, recommendation, response; CRM, crisis resource management.

A facilitator (anesthesiologist) assesses students from behind a one-way screen with a scenario-specific checklist, with consultation with the other facilitators. Given the assessment setting, scenarios are not adapted to the actual experience level of the participants. Scenarios have the same difficulty level for all participants.

\section{Feedback and debriefing}

Each participant is debriefed in private immediately after the scenario by the EuSimcertified anesthesiology resident who observed the participant during the scenario. First of all, attention is given to the emotions of the participant. Then feedback is provided according to Pendleton's rules (what went well, what were areas for improvement). Diagnosis and medical management are discussed succinctly with possible suggestions for further study. The debriefing lasts approximately 5 minutes. Video reflection is not used.

After all participants have completed the 3 rounds of scenarios, the facilitator that acted as session lead gives a group debrief. The group debrief lasts approximately 20 minutes and includes discussion of CRM principles. 


\section{APPENDIX 2. INTERVIEW GUIDE}

\section{Opening}

Discuss: Introduction of interviewer and participant, objective of the interview, analysis of data, anonymity, audiorecording (deleted after analysis), right to end study participation (during or after interview)

[Start recording.]

\section{Focus on experience}

Please take a moment to think back about the simulation test. Try to remember how you felt, what aspects made an impression... . Take all the time you need.

[Pause.]

\section{Opening question}

Could you please describe your experience, your thoughts and feelings at the time, to the best of your ability?

\section{Explicating and explorative questions about the simulation experience}

- Which aspects and/or moments were most prominent and significant?

- What feelings were elicited?

- What thoughts were you having?

- How did you feel physically?

- How did you feel psychologically?

\section{Clarifying questions (applicable to all stages of interview)}

- Can you explain that further? What do you mean exactly?

- Can you give me an example?

\section{Questions regarding time prior to the simulation test}

- What were your thoughts and feelings regarding the simulation pretest in the preceding days?

- What were your thoughts and feelings regarding the simulation pretest the day before?

- What contributed most to those thoughts and feelings? 


\section{Further questions regarding the simulation pretest itself}

- How did you feel in the simulation room?

- What did you feel physically during the simulation?

- Did you experience stress? In what way did this manifest itself?

- Were you in a hospital environment?

- How did you experience time during the simulation?

- Which medical role(s) did you assume? (e.g., student, junior doctor)

- Were you dealing with a patient (rather than a manikin)?

- Did the manikin elicit emotions? If so, which ones?

- If the "patient" deteriorated, were you affected? And if so, how?

- Which aspects of the simulation contributed most to your experience?

- After the simulation pretest

- How did you feel immediately afterwards?

- What did you think of the short debriefings?

- How did you feel the first couple of days following the simulation pretest?

- Did the simulation pretest influence your feelings regarding the dedicated transitional year? If so, in what way?

- Did the simulation pretest influence your motivation regarding the dedicated transitional year or regarding your future as a doctor? If so, in what way?

- How did it feel to be tested on a level you haven't reached yet?

- Do you think you could encounter similar situations as a junior doctor?

\section{Conclusion}

- Can you think of anything relevant to your experience that hasn't been discussed?

- Is there anything you would like to add, change, or clarify?

\section{Thank the participant.}

[Stop recording.] 


\section{APPENDIX 3. COMPOSITE TEXTURAL DESCRIPTION}

\section{Coming to the simulation center}

Before the simulation pretest, students felt low-level tension, as for any assessment, but all students slept well. Many students felt a bit apprehensive because they did not know exactly what to expect or how they would react to the unfamiliar circumstances. Whereas a single student dreaded the test, anticipating failure, most travelled to the simulation center in good spirits. Students did not prepare extensively for the test, but some students discussed possible scenarios or the ABCDE (airway, breathing, circulation, disability, exposure) approach with peers.

Students universally appreciated the cordial welcome to the center. The friendly, relaxed atmosphere was comforting and students emphasized the professional nonjudgmental first impression staff made:

It was really helpful that the staff acted very casual ... and often made a joke. For me that reduced the tension. (Participant [P] 2)

The simulator facility tour relieved tension further, although some students found too much detailed information was given.

\section{Authenticity}

The simulation room was collectively perceived as an authentic hospital facility, for example, an emergency care room. Students experienced it as a "pleasant" and "spacious" room. The presence of relevant working equipment was particularly perceived as real. Items consistently mentioned were the vital signs on the monitor changing in accordance with the clinical situation, the defibrillator, piped oxygen system, drug vials, and a telephone with access to the simulated hospital switchboard. Participants noted that wearing a doctor's coat and the presence of a nurse added to the sense of realness. According to a few participants, the direct availability of equipment trolleys and a crash cart did not correspond to a realistic ward setting.

All students mentioned the manikin in relation to the authenticity of the simulation. The manikin was perceived as almost a real person. The manikin's ability to speak, its palpable pulsations and breath sounds, and the ability to monitor its vital sounds made it almost seem "alive." 
I kind of believed that the sounds were coming from the manikin and not from a person speaking someplace else. Especially at moments of high stimulus density, one isn't able to mark it [the manikin] as unrealistic. (P4)

Initially, it's strange to talk to a manikin, but once you get an answer back, you are completely drawn in. (P1)

I was talking to a manikin, but I did approach him as I would approach a patient. (P10)

The lack of facial expression and temperature and the unchanging skin color were perceived as unreal. Several students thought a changing skin color was the crucial missing element for making a diagnosis of anaphylaxis.

I do think [skin color] is very important. After I had missed [the anaphylaxis], you do realize you have to explicitly ask, "What can you tell me about the appearance of the patient? What is this person's color?" With normal patients, obviously, you can immediately tell something's wrong. (P11)

The manikin elicited empathy in quite a few students who wanted to "comfort him" and "rescue the patient," especially when the manikin was expressing his fear or begged for help:

When the situation deteriorated, it felt like losing a patient for real. (P2)

Students largely remained aware of being in a simulated environment, and some students saw the manikin mostly as an educational tool.

If the patient deteriorated, I saw this as a prompt that something had to be done. (P3)

I wasn't very stressed about doing something wrong, like giving the wrong medication. . If it had been a real person, I would have been much more stressed out.... It was more like, “Let's see what goes wrong and learn from that.... This is practice, and this is a manikin." (P10)

Being able to speak with the manikin, do a physical exam, and provide treatment made it almost like a patient encounter. A few students were concerned about damaging the manikin with invasive procedures: 
I didn't dare to do everything, like stabbing the manikin with a needle in case of a pneumothorax. (P3)

The scenarios were considered very compelling, and all students believed they could end up in similar situations as newly qualified doctors. The only unrealistic aspect of the scenarios was the fact that no one appeared after the student called for help. Most students accepted this as part of the simulation, assuming "nobody would arrive anyway."

\section{During the scenario}

Scenarios started gently, but the manikin soon started to deteriorate, rapidly increasing pressure on the participants, oftentimes overwhelming them.

The simulation started gradually and then stimulus 1, and stimulus 2, and stimulus 3 hit me, and I had to filter.... There are so many possibilities. And where is everything stocked? So many things to be sought, so many things not to be found, all those options. Leave them be; let's focus on the patient. (P4)

Sometimes I felt like a deer caught in the headlights. That unease, that is what I call stress. (P3)

Virtually all participants experienced the deterioration as stressful. Some students noticed sweaty palms or an increase in heart rate, whereas others were unaware of any bodily sensations. A few students described the room as "intimidating," experienced the "walls closing in" in relation to stress about the deteriorating manikin:

You are sweating more, are getting a real adrenaline rush. It made me double my efforts, but once the patient deteriorates, you start to feel a little claustrophobic in that room. (P2)

Primarily, stress manifested mentally. Students felt pressed to take decisions and do things but struggled to think clearly. Students indicated having difficulty accessing their knowledge or prioritizing and sometimes forgetting what they intended to do.

When I saw on the monitor that it wasn't going well, thoughts were racing through my mind. "It could be this, or this, or this. I could do several things, but which one? And when? (P6) 
I tried to read the sheet with CPR instructions, to understand them, and then execute them. But then I realized: I'm reading them, but I'm not processing them. I'm not my usual calm self. (P8)

Outside the room, before and after the simulation, I had a clear picture of the situation and what course of action to take. As soon as I went inside, I had a blackout. (P8)

Students also described feelings related to being frozen in place or in time. Generally, time passed slowly when students felt stuck, and time went faster during periods of activity.

I think initially I didn't move at all. I walked up to the patient, and then I stood there, being stuck and extremely nervous. (P3)

The pulse oximeter made a penetrating, beeping sound. It felt like time had frozen. ... If you don't know what to do, then every second is painful and feels like a minute. (P3)

I thought, "I don't know what to do". . . and then time is going so slowly. At those moments, I thought, "Ooh, they might as well come in because there's no point to it anymore!" (P5)

\section{"Not just a game, but still simulation"}

Every student remained more or less aware of being in a simulation. Some in particular saw almost everything in light of the simulation exercise. The continuous awareness of being in a simulated environment mitigated the effects of stress and helped these students stay composed.

I see those ST elevations [elevation of the ST segment on the ECG]. That's probably just a myocardial infarction. Then I thought, "This is a simulation, what will probably go wrong?"I thought, "He will probably get VF [ventricular fibrillation]." (P9)

I was kind of assuming the manikin was going to crash. So I was thinking about the diagnosis: "What could it be? And what could then go wrong?" (P11)

It is in my nature to perform best in a demanding and stressful situation. I never experience this as such; rather, I act hyperalert and feel very much at ease. . . . Primarily, it made me happy and euphoric. (P9) 
Most of the time I felt quite calm. Except for that tunnel vision [I had]. But I certainly didn't experience a panic attack. (P11)

I was pleasantly surprised to find I stayed calm and was still able to think, especially as I want to specialize in anesthesiology. But, of course, the real world is different. I knew it was a manikin, and a disastrous situation was going to be created. You do realize something is going to happen that won't necessarily be my fault; I just need to solve it to my best ability. (P10)

\section{Role and performance}

The setup with a "non-obstructive" nurse requiring instructions forced the students into the role of doctor, and this situation was novel, exciting, and impressive for the participants.

I felt like a real doctor in the simulation. This was one of the few times I felt completely responsible for a patient. I realized this immediately. And it felt quite good. (P2)

I particularly enjoyed the independence one had to demonstrate. It makes me thrive. I find it amazing. . . . Having to give very precise orders to make sure something gets done is something I really enjoyed. (P9)

A majority of the participants indicated that they focused on medical management, and this focus kept feelings about the patient at bay. However, many mentioned feelings of doubt and worry about their performance, and these feelings were "unpleasant" and "a shocking revelation".

I was primarily occupied by my own medical competence and incompetence, so I wasn't thinking, “Darn, I am losing that patient." (P2)

A junior doctor on his first evening shift, with realistically too little ability. That's what I felt like. (P4)

It also made students feel "unprofessional" when not giving clear instructions to the nurse or retracting them:

I felt like crawling into a corner. . . . It was like, "Oh dear, I am sending her [the nurse] all over the shop!" (P6)

Perceptions of poor performance significantly contributed to stress. 
I don't stress out easily, but on the other hand I have certain expectations of myself. So it is stressful in some way if you cannot live up to those. (P7)

I wouldn't call it fear, but perhaps that's the best way to describe it.... Somebody could die just because I intervene in the wrong way. (P6)

Urgent situations in which the course of action was not evident triggered feelings in the students of incompetence and "lack of control" in which their initial confidence faded, the self-image of a doctor crumbled, and the limits of their competence were exposed.

When I knew more, or felt in control, I felt a little bit ahead in my medical training. When not [feeling in control], I went back to being a medical student. (P11)

There were short moments when I knew what to do. Those felt like being a resident doctor. But as soon as I thought "help!" it was more like, "I'm a medical student. I don't know!" (P8)

Often, this feeling of uncertainty reverted to one of certainty if the manikin had a cardiac arrest. Students explained that the protocolled approach of basic life support provided "firm ground"; the students often experienced a paradoxical sense of relief or even of being in their "comfort zone" executing "standard procedures."

If the patient is deteriorating, it places you on firm ground. At least you can do something. (P3)

When the patient had to be resuscitated, I thought: "Shit! . . but let's do it!" You kind of know how to make a start, which is comforting. ... Comforting, because you know where you stand. (P11)

Students' perceptions of their own performance varied from "outright failure" to a "bare pass." Most students had expected to perform poorly in this pretest and did not really mind as there were no consequences to "failing" the formative test.

I'm just not ready [for such clinical situations]. I can't really say I felt angry or like a very big failure. Because I didn't expect to perform much better than I did. (P6)

I'm rather perfectionist by nature, so it is annoying to fail. Regardless of what you do. On the other hand, it's a relief, knowing you're not expected to be perfect. (P11) 
Despite this expectation not to do well and the absence of formal consequences, all students regarded their performance and knowledge level as "a shocking revelation" and "disappointing" to varying degrees.

Basically, I think it's a matter of not wanting to fail. And you know you will fail. (P4)

It was very intense. I was confronted with my incompetence, the realness of the simulation, and the demanding nature of emergency situations. It truly was a mirror. (P3)

It was so bizarre that I didn't notice the patient was basically bleeding out. It was so obvious! . . . It's just a shocking revelation. Because at these moments, you realize you are far from knowing enough [to manage] such a situation. (P6)

That evening, I thought:"Hopefully I won't experience these feelings as a qualified doctor." Being at such a loss. (P2)

Of course it is frustrating to still feel, after 5 years of studying, like [you are] failing. (P4)

\section{Being observed and assessed}

Generally, students did not mind, hardly noticed, or tended to forget the observation. Several students mentioned the one-way screen helped them to ignore the fact that they were being watched. Also, the staff's attitude was helpful. Students appreciated the nonjudgmental and informal atmosphere and that they knew who was observing.

I knew [the staff] weren't eager to let us fail. Rather to make sure we learn something. (P9)

During moments of uncertainty, students became slightly more aware of the one-way mirror, and a few were preoccupied by the ongoing assessment of their performance.

I am being watched. I must do something! (P3)

When the scenario ended, I walked out, and then I realized they have seen me blow it. That voice saying, "Let's stop" felt a bit like a condemnation. Especially if the scenario went badly. Then it [leaving the room] kind of felt like a walk of shame. (P2)

[Note: The facilitator's actual words were "End of scenario."] 


\section{After the scenario}

Most students felt a sense of relief at the end of the scenario, especially if they felt uncertain or stuck.

If it went that badly, then [the end of the scenario] felt like a kind of relief. Like being put out of my misery. (P4)

I felt relieved. I was thinking, "Alright, I can't think of anything else to do!" (P11)

All students found the short personal debriefing sessions after each scenario crucial to their learning, especially the "immediate" and "to-the-point" nature. They appreciated the constructive feedback in that not just the mistakes but also the correct actions were highlighted. This was helpful in regaining self-confidence. In addition, participants regarded being able to vent emotions, "to let off steam," in a safe and nonjudgmental environment as valuable.

You only learn from mistakes if you get the correct answer later, or if you can discuss it. Without that debriefing, the simulation would be much less useful. (P4)

I am very good at recalling what went wrong, even though there were also things that did go well. It is nice that that is being pointed out. (P6)

\section{Motivation to Learn}

The simulation pretest reinforced students' orientation toward acute medicine, and students did not experience being unfit for this domain. Students felt more aware of the short-term and long-term challenges ahead and were motivated to improve upon themselves.

It reinforced my aspirations. This is what I want to excel in, so l'd better put in some effort now, because I want to do better than I did today. (P3)

As a resident in - say - cardiology, being called for a resuscitation, you could easily make the same mistakes. ... Only with more responsibility. . . . I want to have the skills to do it well. It is such a weird idea that it actually happens: People with my current competence level ending up in real situations like these. (P7)

I was a little frustrated, because you know you will fail. But it was also rather nice, as it provided me with another goal to work toward. (P1) 
I feel I have a long way to go, before I'm ready to be a resident. . . I now know where my gaps are and which areas to improve upon. (P8)

The simulation pretest made the students more aware of the goals and expectations of the dedicated transitional year, and the students expected it to direct their learning in their final year. They were keen to exploit the learning opportunities in the year ahead.

Without the simulations, I also would have started my final year clerkships. But perhaps I would have been more passive. Now I really want to get the most out of this year. (P2)

I assume I will experience this [similar situations] multiple times in the year ahead, and that I will progress. So, it'll probably be all fine in the end. (P8)

From now on, when situations like these occur, I may perceive them differently. Meaning, I'll try to engage more with what's happening at the time. Also, as a means to prepare me for the posttest. (P11)

It is very informative to know what's expected from you once you qualify.... It's a sort of guideline, outlining the gaps in my knowledge. It demonstrates what I should study in greater depth or what I should pay attention to during my clerkships. (P9)

I didn't mind being tested on a more advanced level. [It is] just something to work toward. I now know where I stand today and where I'll hopefully be at the end of the year. (P5)

\section{Aftermath}

Many students felt "exhausted" and "mentally tired" on the day of the simulation, but some felt "euphoric" or "energetic." Some students realized they had gone through something special:

I realized this is a unique experience nobody or hardly anybody from my medical school will have. (P2)

Everybody enjoyed the simulation, describing it as "fun." Students emphasized this, stating that although the simulation was intense and stressful, they still had a great time and enjoyed it. The enjoyable aspect of the simulation for the students was solving a puzzle and realizing they could handle complex medical situations to a certain degree. 
I was impressed that I myself had to give orders or directions to a nurse and had to press the "defibrillate button" myself. I couldn't stop thinking about it the rest of the day. (P2)

Besides knowing where I should be at the end of medical school, it [the experience of the simulation] might also give me a sort of confidence, knowing I am capable to helping out in an emergency situation until the real team arrives. (P9) 


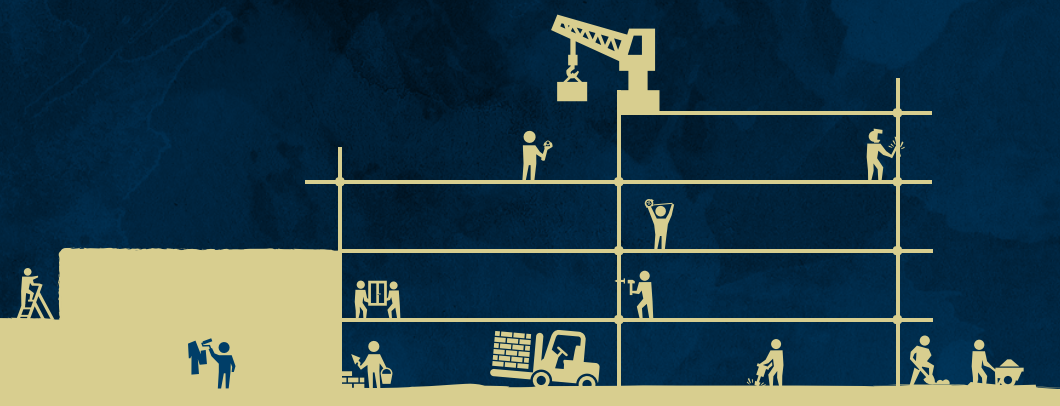




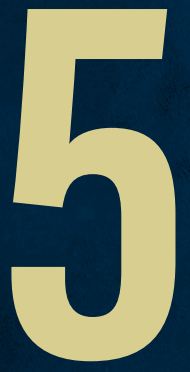

\section{IN PURSUIT OF A BETTER TRANSITION TO SELECTED RESIDENCIES}

\section{A FINAL YEAR OF MEDICAL SCHOOL DEDICATED TOTHEACUTECARE DOMAN}

Jonker G, Booij E, Vernooij JEM, Kalkman CJ, ten Cate O, Hoff RG.

In pursuit of a better transition to selected residencies: a final year of medical school dedicated to the acute care domain.

Submitted 


\section{ABSTRACT}

Introduction Medical schools seek the best curricular designs for the transition to postgraduate education, such as the Dutch elective-based final, 'transitional' year. Most Dutch graduates work a mean of three years as a physician-not-in-training (PNIT) before entering residency training. To ease the transition to selected specialties and to decrease the duration of the PNIT period, UMC Utrecht introduced an optional, thematic variant of the usual transitional year, that enables the development of theme-specific competencies, in addition to physicians' general competencies.

Methods We introduced an optional transitional year for interested students around the theme of acute care, called the Acute Care Transitional Year (ACTY). This study aimed to evaluate the ACTY by judging whether graduates meet postgraduate acute care expectations, indicating enhanced learning and preparation for practice.

In a comprehensive assessment of acute care knowledge, clinical reasoning, skills, and performance in simulations, we collected data from ACTY students, non-ACTY students interested in acute care, and PNITs with approximately six months of acute care experience.

Results ACTY graduates outperformed non-ACTY graduates on skills and simulations, and had higher odds of coming up to the expectations faculty have of a PNIT, as determined by global ratings. PNITs did better on simulations than ACTY graduates.

Discussion ACTY graduates show better resemblance to PNITs than non-ACTY graduates, suggesting better preparation for postgraduate acute care challenges.

Transitional years, offering multidisciplinary perspectives on a certain theme, can enhance learning and preparedness for entering residency. 


\section{INTRODUCTION}

Transitions within the medical education continuum have enjoyed the attention of medical educators for a long time [1, 2]. Learners experience difficulties in adapting to the expectations of the new phase when moving from classroom education to clinical clerkships [3], from medical school to residency [4, 5], and from postgraduate training to fellowship or practice [6-8]. Overall, as learners advance to the next phase, they frequently experience an incomplete set of competencies for that phase. In particular, the undergraduate to postgraduate transition has received attention and schools and countries have dealt with this transition in different ways $[9,10]$. The UK has introduced a two-year Foundation period, whereas the USA and Canada do not apply any transitional phase but require all graduates to start residency with an internship year, and many other countries require one or more years of clinical service experience [11]. Medical schools struggle to seek the best curricular structures to ease the transition to residency. Introducing longitudinal, integrated clinical experiences [12] and creation of an education continuum within a single specialty [13] are examples.

In the Netherlands, most graduates start their careers working as a physician-not-intraining (PNIT), assuming clinical responsibilities and expanding clinical experience as a licensed doctor, before entering residency [14-16]. This voluntary phase of practice without formal education [14], is of variable duration - from less than one to over three years - and originated from a surplus of graduates for residency positions. On average, graduates work 34 months as a PNIT before starting postgraduate training [17]. Residency selection procedures happen in an open market model, and committees have become accustomed to experienced candidates. This competitive process has urged applicants to expand their clinical experiences, and even adding doctoral research degrees, to maximize their chances to be selected for highly sought residencies. Dutch medical schools, as well as the government, have become aware of the need to better align medical school and residency, to decrease the total length of preparatory training and clinical practice before residency, and thus shorten the whole trajectory of specialization. Dutch medical school reforms in the 2000 decade have led to an elective-based final, 'transitional' year model [14, 18, 19]. The primary goal of the transitional year is to improve graduates' readiness for work, and in addition it potentially reduces the duration of the PNIT period by decreasing the need to learn carrying clinical responsibilities. This final, transitional year contains substantial elective opportunities to help students grow toward the responsibilities of a doctor under appropriate supervision, obtain clinical experience and expertise, explore career options, and improve chances on the job market $[19,20]$. At University Medical Center (UMC) Utrecht, final year students assemble an individual program [14, 19]. Students 
spend a 12 weeks sub-internship in a broad clinical specialty of their choice in which they take responsibility for a limited number of "own" patients. They expend another 6 to 12 weeks to one or two clinical electives at a sub-internship level. In addition, students do 12 to 18 weeks research in a domain of choice. They use another six weeks for mandatory training courses in research, teaching and professionalism.

Instead of composing a fully individual package of rotations, students may opt for a thematic track during their transitional year that enables the development of specific competencies within a medical domain (the theme), in addition to the general competencies that graduates need. A thematic track offers focused preparation and professional orientation within the domain of medicine.

\section{Aim of the study}

In pursuit of a better transition to work in selected residencies and specialties, the current study aimed to evaluate to which degree a thematic final year track, geared to specialties in a limited domain, could prepare students better for clinical practice. We combined a scholarly approach to curriculum design and assessment with the collection of research data, and chose the domain of acute care.

\section{METHODS}

\section{Context}

In 2015, we introduced an optional Acute Care Transitional Year (ACTY) at the UMC Utrecht to ease the transition to not just any postgraduate training or non-training post, but to a selected set of residencies or specialties. Per year, on average 18 students interested in acute care (about 7\% of an annual cohort) enroll in the ACTY [21].

Anesthesia, cardiology, emergency medicine, intensive care medicine, and pulmonary medicine have a shared interest in acute care and faculty members of these five specialties designed and implemented the ACTY collaboratively. The three goals of the ACTY are: a) to enhance acute care learning by boosting motivation, b) to prepare graduates for clinical acute care practice, and c) to offer a focused specialty orientation.

The ACTY strives to enhance learning through a coherent final year program that brings together a group of students who share a profound interest in acute care. ACTY's learning objectives are the acute care challenges recently graduated doctors in several specialties may face. The tasks, formulated as entrustable professional activities (EPAs), link the learning objectives directly to postgraduate expectations [22, 23]. The educational 
team created three ACTY EPAs: 'Recognition and initial treatment of patients with vital instability', 'Evaluation and initial treatment of patients with respiratory insufficiency', and 'Evaluation and initial treatment of patients with circulatory insufficiency' (See Chapter 2 for full descriptions).

In monthly three-hour teaching sessions, all ACTY students and teachers discuss acute care content related to the EPAs. We designed these sessions to foster a learning community of highly motivated, congenial peers [24]. The sessions present a forum for teacher-guided peer reflections on clinical situations students experienced.

Students commencing the ACTY take an extensive multimodal formative pre-test blueprinted to the ACTY EPAs, to assess knowledge, clinical reasoning, skills, and performance in high-fidelity simulations. The test is designed as a motivating and eyeopening starter to set the stage for the final year, to identify both existing strengths and areas for improvement, and to guide personal learning during the subsequent clinical rotations $[24,25]$.

ACTY students choose three out of five participating specialties for one sub-internship of twelve weeks and two of six weeks. Additionally, students take a twelve-week research elective in one of the five ACTY specialties.

At completion of the ACTY, students take a formative post-test, similar to the pre-test, to identify the degree of personal growth, provide insight in acute care competence, and detect areas for further learning. The test is mandatory, but not created to serve as a pass/fail assessment.

The ACTY provides orientation on a career within the acute care domain. The ACTY targets the sweet spot between breadth and depth in a final year. Breadth is essential to deliver broadly trained physicians; depth is vital for individualization and prespecialization. The track offers concentrated but balanced clinical experience, without being overly focused or narrowed down to a single specialty [26]. The ACTY aims to equip graduates with acute care competence, useful for doctors aspiring a career in the ACTY specialties and in other fields. Simultaneously, the year allows students to discover which specialty within the acute care domain best matches their interests, while educators can gauge the fit of a student within the specialty. Specialty orientation is a worthwhile goal. One third of students make their choice in the final year and the majority indicate that final year experiences have a strong influence on their ultimate choice of specialty [27]. All ACTY students are assigned to a senior postgraduate trainee 
in one of the five acute care specialties. This trainee acts as a buddy, provides 'mentoring on demand', supports the acculturation to the specialty, gives career advice, and helps to validate the student's choice for this direction.

We have reported before on early experiences with the program [24] and on experiences with the simulations [25]. The current study aims to evaluate to which degree ACTY's graduates meet postgraduate expectations of junior doctors to provide acute care, as an indication of enhanced learning and preparation for clinical practice.

\section{Design}

We collected pre-test and post-test data from ACTY students and participants in two comparison groups in a quasi-experimental design.

\section{Recruitment}

All students who commenced the ACTY from September 2015 onwards (small cohorts could start every six weeks) were eligible to participate in the study. We aimed to obtain post-test results from 25 ACTY participants.

To value ACTY test results we included two comparison groups. The first group consisted of UMC Utrecht students who did not take part in the ACTY track and composed an individual transitional year program. To match these participants for motivation and affinity with acute care, we invited students who had chosen at least one sub-internship in anesthesia, cardiology, emergency medicine, intensive care medicine, or pulmonology for participation in the pre-test and post-test by email. Despite sending reminders, we experienced difficulty in recruiting student controls at the start of the transitional year. We figured that graduating students might be interested to obtain insight in their level of acute care competence and late 2017 we decided to recruit similarly matched nonACTY medical students around graduation for a single post-test comparison.

A second comparison group contained recently graduated, junior doctors currently employed as physicians, not yet in a residency (PNITs). We recruited PNITs with three to nine months of clinical experience in ACTY specialties, by asking regional hospital departments and educationalists to distribute recruitment emails and reminders. Participating PNITs had not graduated from the ACTY.

\section{Procedure}

Participants took part in the comprehensive multimodal assessment of acute care knowledge, clinical reasoning, clinical skills, and performance in high-fidelity simulated situations. Table 1 provides an overview of the assessment modalities (further details 
are provided in Appendix 1). The ACTY EPAs served as an assessment blueprint, i.e. as assessment elements we included the knowledge, skills, attitudes, and competencies listed in the EPA descriptions (Chapter 2).

\section{Assessors}

Clinicians with appropriate expertise for the stations volunteered to assess when available. Assessors evaluated all participants as if they were a PNIT with six months of clinical experience. Assessors were not made aware whether participants were from intervention or comparison groups, nor whether they did a pre-test or a post-test.

The investigators briefed all assessors individually on the use of the scoring rubric, expected performance level and station duration. Assessors scored participants' performance live on a paper checklist.

TABLE 1: multimodal acute care assessment

\begin{tabular}{|c|c|c|}
\hline Assessment modality & Test description & Examples of stations \\
\hline $\begin{array}{l}\text { Written knowledge exam } \\
\text { - } 40 \text { minutes } \\
\text { - around } 40 \text { closed and } 6 \text { open format } \\
\text { questions }\end{array}$ & $\begin{array}{l}\text { - } \text { paper-based } \\
\text { - to assess factual and applied } \\
\text { knowledge and higher order thinking }\end{array}$ & \\
\hline $\begin{array}{l}\text { Case-based discussions (CBDs) } \\
\text { - } 2 \times 10 \text { minutes } \\
\text { - patients requiring urgent attendance } \\
\text { at the ED }\end{array}$ & $\begin{array}{l}\text { one-on-one structured questioning } \\
\text { to assess information gathering, clinical } \\
\text { reasoning, and know-how of case } \\
\text { management }\end{array}$ & $\begin{array}{l}\text { A } 65 \text {-year old male presenting } \\
\text { with chest pain at the ED } \\
\text { A 38-year old female presenting } \\
\text { with dyspnea and sharp pain } \\
\text { on breathing at the ED }\end{array}$ \\
\hline $\begin{array}{l}\text { Skills stations } \\
\text { - } 5-7 \times 5 \text { minutes }\end{array}$ & $\begin{array}{l}\text { - OSCE format } \\
\text { - to assess skill performance }\end{array}$ & $\begin{array}{l}\text { Bag-mask ventilation } \\
\text { Defibrillation } \\
\text { ECG interpretation }\end{array}$ \\
\hline $\begin{array}{l}\text { High-fidelity simulations } \\
\text { - } 3 \text { x approximately } 12 \text { minutes } \\
\text { - challenges a PNIT could encounter at } \\
\text { the ED or on the ward } \\
\text { - participant enacted the role of } \\
\text { first responding doctor. A non- } \\
\text { obstructive nurse was present, who } \\
\text { only acted on instruction. }\end{array}$ & $\begin{array}{l}\text { real-time scenarios with standardized } \\
\text { scripts } \\
\text { to assess clinical reasoning, } \\
\text { clinical judgment, technical skills, } \\
\text { and behavioral skills, including } \\
\text { communication and crisis resource } \\
\text { management } \\
\text { - certified simulation facilitators } \\
\text { - debriefing after each scenario to foster } \\
\text { learning and well-being }\end{array}$ & $\begin{array}{l}\text { A } 60 \text {-year old male is reported } \\
\text { to be "just not right" in the } \\
\text { urology ward } \\
\text { A } 21 \text {-year old comatose male is } \\
\text { brought in from a party to the } \\
\text { ED by paramedics }\end{array}$ \\
\hline
\end{tabular}

OSCE= Objective Structured Clinical Examination,$E D=$ Emergency Department, ECG= electrocardiogram 


\section{Assessment scores}

Each station had a specific checklist following the chronology of the consultation, steps in skill execution, or expected actions and important steps in case management. Assessors scored each item on a three-point scale (done adequately - done incompletely or not timed well - done insufficiently or omitted).

Every assessment element (e.g. station) yielded a summary score, calculated as the awarded points as percentage of the maximum points. From the element summary scores a mean modality score could be calculated for CBDs, for OSCEs, and for simulations.

On CBDs, assessor-observed OSCEs, and simulations, assessors evaluated participant performance with a global rating score (GRS), in addition to checklist scores. This score was a holistic, gestalt, expert evaluation of overall performance on a three-point scale (does not meet expectations - borderline - meets expectations) in answer to the question "How did the participant's performance compare to the expected level of a PNIT with six months of clinical experience?". We chose the arbitrary level of six months to have assessors think of a graduate with substantial but delineated experience and to make a match with the actual experience of the PNIT comparison group.

We ran 25 highly similar test sessions, consisting of two separate half-days. In one test session, all participants would take the same test, either as pre-test or as post-test. Participants' pre-test and post-test content was never identical. Students attended the pre-test in the first month of their final year and the post-test near the end of the year. Recruited as recent graduates, PNITs could not take a pre-test at the start of their final year. Thus, PNITs attended the test once and, in the comparison, this is regarded as a post-test. All participants received feedback on their performance in the tests.

\section{Ethical approval}

The ethical review board of the Netherlands Association for Medical Education approved the study (NERB file 369, November 2014). All participants gave written informed consent.

\section{Analysis}

Modality scores (i.e. knowledge score, mean CBD score, mean OSCE score, and mean simulation score) are expressed in percent points and are compared as group means with SD and differences with $95 \% \mathrm{Cl}$ in rounded percent points. 
We explored differences between groups in mean modality scores, in the pre-test, the post-test, and in gain between pre- and post-test, for statistical significance with oneway ANOVA. We used post hoc independent samples t-tests to evaluate differences between two groups. Statistical significance was assumed at $p<.05$.

We used cumulative odds ordinal logistic regression with proportional odds to determine the effect of group type on domain GRS. We report differences between groups as odds ratios.

\section{RESULTS}

All 33 ACTY students during the inclusion period participated in the study (group ACTY). They spent 24 weeks in three different sub-internships in anesthesia (24.2\%), cardiology (25.3\%), emergency medicine (18.2\%), intensive care medicine $(27.3 \%)$ and pulmonology (5.1\%).

The 21 participants in the student comparison group (group C), 10 for the pre-test and post-test, and 11 for the post-test only, had chosen a median of 2 acute care related subinternships (range 1 - 3), spending a median of 12 weeks (range 6 - 24) in anesthesia (15\%), cardiology (25\%), emergency medicine (20\%), intensive care medicine (20\%) and pulmonology (15\%).

The 17 PNITs (group P) had a mean clinical experience of 5.5 months (range 3.5 - 8.0) in anesthesia (6\%), cardiology (12\%), emergency medicine $(24 \%)$, or intensive care medicine (59\%).

Figure 1 displays participant flow. No participants withdrew from the study. Some participants in group ACTY and group $C$ were unable to attend the post-test. In all groups, a few participants could only partly attend the post-test. 


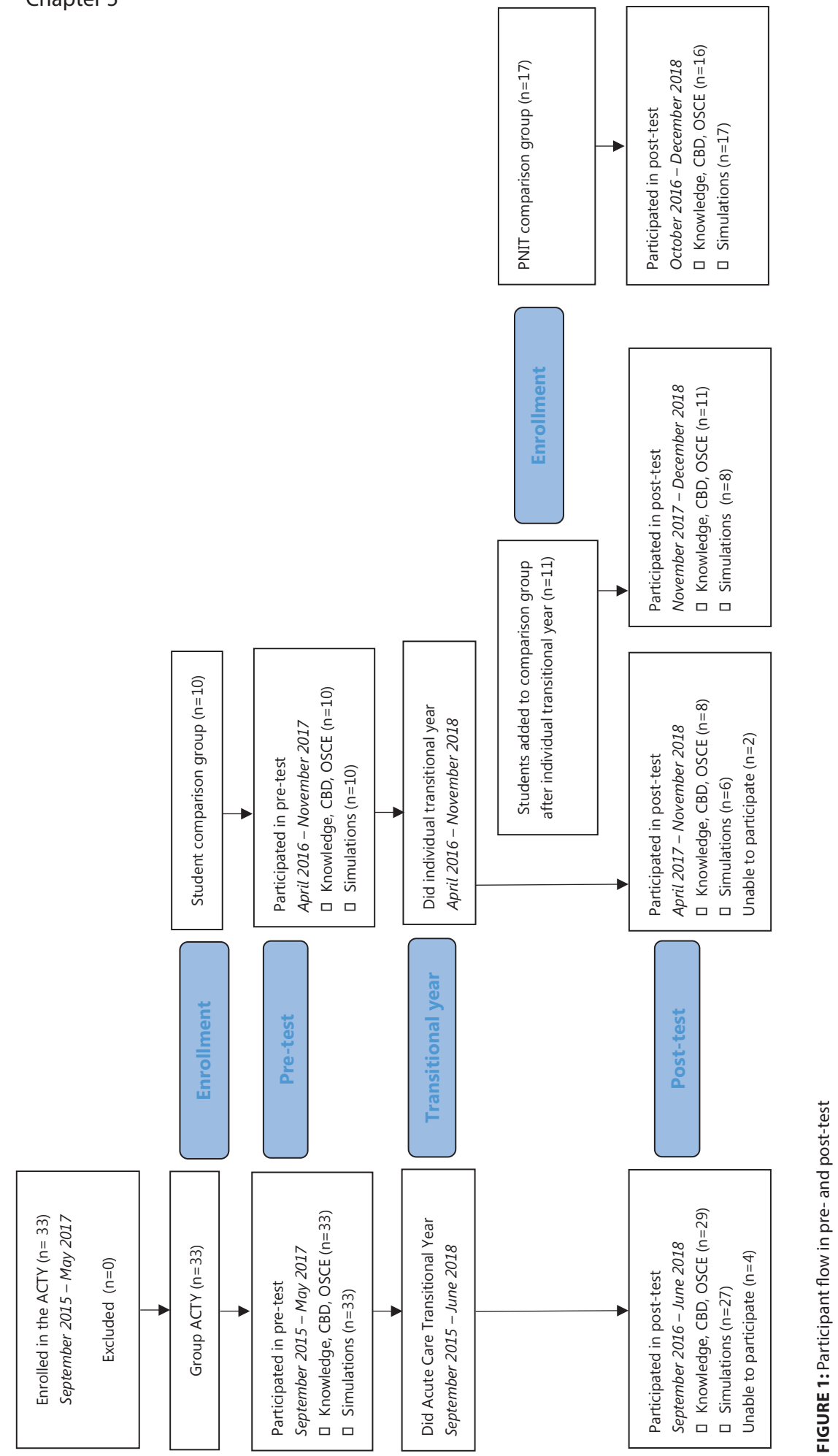




\section{Test modality scores}

At baseline, there were no statistically significant differences between group ACTY and group $C$ in mean scores on the knowledge test, CBDs, and OSCEs (for statistical details, see Appendix 2). On simulations, there was a statistically significant difference in means, with students in group ACTY having significantly higher scores than students in group $C$ $(p=.026$, mean difference $6(2), 95 \% \mathrm{Cl} 1-11)$.

In the post-test (Table 2), there were no statistically significant differences in group means on the knowledge exam and CBDs (Appendix 2). There were statistically significant differences in group means for OSCEs $(p=.01)$ and simulations $(p=.001)$. Group ACTY $(p=.004$, mean difference $8(3), 95 \% \mathrm{Cl} 3-13)$ and group $P(p=.026$, mean difference 5 (2), $95 \% \mathrm{Cl} 1-10$ ) had significant higher mean scores on OSCEs than group $\mathrm{C}$.

Group ACTY ( $p=.036$, mean difference 7 (3), 95\% Cl 1 - 13) and group $P(p<.001$, mean difference 12 (3), 95\% Cl 6 - 18) had significantly higher mean scores on simulations than group $C$. Group P had a significantly higher mean score on simulations than group ACTY ( $p=.019$, mean difference $6(2), 95 \% \mathrm{Cl} 1-10)$.

There were no statistically significant differences between means in gain between pre-test and post-test scores of group ACTY and group C for all assessment modalities (Appendix 2).

TABLE 2: Post-test mean scores (in percentage of maximum score) on four assessment modalities

\begin{tabular}{llllllllll}
\hline & \multicolumn{4}{c}{ Group ACTY } & \multicolumn{2}{c}{ Group C } & \multicolumn{2}{c}{ Group P } \\
\cline { 2 - 9 } Assessment modality & $\mathbf{n}$ & Mean (SD) & $\mathbf{9 5 \%} \mathbf{C l}$ & $\mathbf{n}$ & Mean (SD) & $\mathbf{9 5 \% ~ C l}$ & $\mathbf{n}$ & Mean (SD) & $\mathbf{9 5 \% ~ C l}$ \\
\hline Knowledge & 29 & $67(11)$ & $63-71$ & 19 & $63(13)$ & $56-69$ & 16 & $67(7)$ & $63-70$ \\
CBDs & 29 & $79(11)$ & $75-84$ & 19 & $72(10)$ & $67-77$ & 16 & $79(9)$ & $74-84$ \\
OSCEs & 29 & $74(9) *$ & $71-78$ & 19 & $67(8) * \dagger$ & $63-70$ & 16 & $72(5) \dagger$ & $69-75$ \\
Simulations & 27 & $65(8) \neq * *$ & $62-69$ & 14 & $59(11) \neq \S$ & $52-65$ & 17 & $71(6) \S * *$ & $68-74$ \\
\hline
\end{tabular}

$A C T Y=$ Acute Transitional Year group, $C=$ student comparison group, $P=P N I T$ comparison group. $C B D=$ case-based discussion, OSCE = objective structured clinical examination. Assessment modality scores expressed as \% of maximum obtainable score, as group mean ( $S D=$ standard deviation) and $95 \%$ confidence interval $(C l) .{ }^{*} p=.004 ;+p=.026 ; \neq p=.036 ; \S p<.001 ; * * p=.019$

\section{Global rating scores}

In all groups in the post-test, on global ratings of overall station performance, assessors most often scored "meets expectations" on CBDs and least often on simulations (Table 3). 
ACTY students more frequently scored "meets expectations" than group C students. Ordinal logistic regression showed that group type had a statistically significant effect on the prediction of getting a high GRS on CBDs, OSCEs, and simulations (see Appendix 3 for a comprehensive report of the model). This finding can be rephrased with odds ratios of getting a high GRS, using group $C$ as a reference (or: standard). The odds of participants in group ACTY getting a high GRS were 2.06 - 2.49 that in group C, statistically significant for OSCEs and simulations. Participants in group P had statistically significant higher odds (OR 2.45 - 6.69) of receiving a high GRS than those in group C. Also, the odds of obtaining a high GRS in group P was 2.70 for CBDs, 0.99 for OSCEs, and 3.23 for simulations compared to group ACTY; a statistically significant difference on simulations (Appendix 2).

TABLE 3: Global rating scores (GRS) in post-test per assessment modality. Frequency of scores, per group type. Pie charts showing relative occurrence of global rating scores on CBDs, OSCEs, simulations.

\begin{tabular}{|c|c|c|c|}
\hline & $\begin{array}{c}\text { Group ACTY } \\
\text { n (\%) }\end{array}$ & $\begin{array}{c}\text { Group C } \\
n(\%)\end{array}$ & $\begin{array}{c}\text { Group P } \\
\mathbf{n}(\%)\end{array}$ \\
\hline \multicolumn{4}{|l|}{ GRS on CBDs } \\
\hline Does not meet expectations & $2(3.4)$ & $4(11.1)$ & $0(0)$ \\
\hline Borderline & $7(12.1)$ & $7(19.4)$ & $2(6.5)$ \\
\hline Meets expectations & $49(84.5)$ & $25(69.4)$ & $29(93.5)$ \\
\hline \multicolumn{4}{|l|}{ Pie chart (\%) } \\
\hline \multicolumn{4}{|l|}{ GRS on OSCES } \\
\hline Does not meet expectations & $12(7.4)$ & $12(13.2)$ & $4(4.9)$ \\
\hline Borderline & $25(15.3)$ & $27(29.7)$ & $15(18.5)$ \\
\hline Meets expectations & $126(77.3)$ & $52(57.1)$ & $62(76.5)$ \\
\hline \multicolumn{4}{|l|}{ Pie chart (\%) } \\
\hline \multicolumn{4}{|l|}{ GRS on Simulations } \\
\hline Does not meet expectations & $18(22.5)$ & $14(33.3)$ & $4(7.8)$ \\
\hline Borderline & $25(31.3)$ & $17(40.5)$ & $10(19.6)$ \\
\hline Meets expectations & $37(46.3)$ & $11(26.2)$ & $37(72.5)$ \\
\hline Pie chart (\%) & & & \\
\hline
\end{tabular}

does not meet expectations borderline

$\square$ meets expectations
$A C T Y=$ Acute Care Transitional Year, $C=$ student comparison group, $P=$ PNIT comparison group. $C B D=$ case-based discussion, OSCE = objective structured clinical examination. Because each participant did more than one station per modality, $n$ refers to the times that, on a modality, the respective score was awarded. 


\section{DISCUSSION}

We implemented a thematic transitional year focused on acute care (ACTY) and collected data in a multimodal assessment to evaluate whether ACTY graduates meet postgraduate expectations of junior doctors to provide acute care.

Students graduating from ACTY performed better in the assessment than non-ACTY students with an interest in acute care, especially on performance test modalities (i.e. skills and simulations). Moreover, ACTY students had higher odds than non-ACTY students of meeting the expectations of a PNIT, as determined by GRS. Thus, ACTY graduates show better resemblance to PNITs than non-ACTY graduates, suggesting they are better prepared for junior doctor acute care challenges.

However, PNITs with a mean of 5.5 months of clinical experience did better than students graduating from ACTY on simulations, both in scores and GRS. This suggests that PNITs have a steep learning curve in the first six months of 'real' clinical work following graduation. Their clinical experience helped in showing an "organized, orderly approach" [28]. Furthermore, PNITs starting in a first acute care job often take additional acute care training. Certification as an advanced life support provider has a medium-size effect on performance in a simulation test of acute care competence [28]. Of interest, a few GRS awarded to PNITs were below assessor expectations of PNITs with six months of experience. This may indicate the recent graduates' incomplete preparedness for acute care and imperfect or inhomogeneous competence development. However, also failure of an occasional test station in a standardized test may explain this finding.

In times of great need for labor force, such as currently (2020 - 2021) with the Covid-19 pandemic [29,30], demonstrable competence, obtained as a student in the transitional year, is a way to select the right graduates for critical junior doctor positions. We postulate that ACTY graduates, performing approximately on a midpoint between nonACTY graduates and acute care PNITs, have a head start for deployment in such jobs.

The ACTY is an example of a thematic transitional year. Many other elective transitional years, offering multidisciplinary perspectives on a certain theme, are conceivable. Similar to the ACTY, these could attract students motivated to develop a specific profile of competence while exploring career options within an area of medicine.

Elective thematic final years present a promising way to design the transition phase from student to doctor. This phase has the potential for professional transformation if learning opportunities are fully exploited [5,31]. To seize opportunities, this phase 
requires a comprehensive curriculum of experiential learning and articulated goals [31-33]. Students will get opportunities to pursue personal interests, explore specialty preferences, and gain confidence in graduated responsibilities in patient care [31]. And, this final phase will offer opportunities to promote optimal preparation for clinical practice $[5,26,31-33]$.

The ACTY meets many of the requirements of a transformative final phase. Still, awarding graduated responsibilities in acute care tasks is limited by legal and practical restrictions. Student training must not endanger the critically ill patient or delay needed treatment.

Growing into bearing acute care responsibility starts with experiential learning in a supervised setting. However, hands-on learning opportunities in time-pressured and infrequent clinical situations are scarce. Lack of opportunities poses a pivotal problem in undergraduate acute care training, with final year medical students reporting one to two hands-on experiences in providing acute care [34, 35]. Even in ACTY, we found that students have limited opportunities for frontline acute care experiences [24]. Affording acute care experiential learning, with progressive responsibilities in a supervised setting, may improve ACTY's preparatory efficacy. The ACTY EPAs would have been suitable tools to apply progressive responsibilities in workplace learning.

However, the introduction of the ACTY and ACTY EPAs in 2015 preceded the adoption of the core undergraduate EPAs by UMC Utrecht medical school. The unfamiliarity of clinical supervisors with EPAs at the time may have impeded the exploitation of ACTY EPAs [24].

EPAs are a way to make accumulating clinical experience and competence visible from medical school to postgraduate training, including the 'intercurricular' period of working as a PNIT. Demonstrable competence could be taken into account in the individualization of PGT learning plans and could result in shortening of PGT time [15].

Since the implementation, the ACTY curriculum has been essentially unchanged. The ACTY design inspired the development of more thematic final years locally. This study and related research [24] call for a prominent role of the EPAs in ACTY workplace learning.

\section{Limitations}

As part of a program evaluation, the quasi-experimental assessment data provide insight in graduates' acute care performance. The study was not a controlled trial to prove the superiority of the intervention over the traditional curriculum. We did not control for 
confounding variables. For example, a study showed that students and interns who had taken an intensive care clinical elective performed better in a simulated test of acute care competence [28]. However, we applied strict inclusion criteria for all groups and measured pre-intervention performance, to constitute relevant comparisons.

Group sizes were relatively small. We had particular difficulty in recruiting comparison group students in the pre- and post-test set-up and reverted to including students for just the post-test, creating a larger but mixed control group. Student controls who did both pre- and post-tests did not score differently in the post-test compared to group $A C T Y$, but this subgroup analysis lacks the power to conclude the absence of differences.

Depending on clinicians volunteering as assessors, we were unable to deploy multiple raters per station. Multiple raters might have reduced any bias and improved reliability. However, different raters evaluated participants at different stations, so we assume the influence of rater bias on overall test results to be small. Although we extensively briefed each examiner prior to the assessment, we did not use an examiner team calibration training to prepare assessors.

The three-point global rating scale had the levels "does not meet expectations borderline acceptable - meets expectations" (that faculty have of a PNIT with six months of clinical experience). An extra level for performance that "exceeded expectations" could have provided more discrimination between participants.

Lastly, the assessment was labor-intensive and costly, limiting sustainability and transferability.

This assessment study provides data on graduates' acute care performance. In an ongoing study, we are surveying graduates' perceptions of preparedness, on specialty orientation, and on the potential of the ACTY to shift career trajectories (i.e. shorter periods of working as a PNIT, shortening of residency training).

\section{CONCLUSION}

In pursuit of a better transition to postgraduate expectations, we reported on a final year of medical school dedicated to acute care and found that graduates from this program show better resemblance to junior doctors with clinical experience than other graduates.

This final year dedicated to acute care enhances learning and preparedness for challenges that junior doctors in this area will face. 


\section{REFERENCES}

1. Aschenbrener CA, Ast C, Kirch DG. Graduate medical education: its role in achieving a true medical education continuum. Acad Med 2015; 90(9):1203-9.

2. Custers $\mathrm{E}$, ten Cate O. The history of medical education in Europe and the United States, With respect to time and proficiency. Acad Med 2018; 93(3S Competency-Based, Time-Variable Education in the Health Professions):S49-54.

3. O'Brien BC, Poncelet AN. Transition to clerkship courses: preparing students to enter the workplace. Acad Med 2010; 85(12):1862-9.

4. Cohen ER, Barsuk JH, Moazed F, et al. Making July safer: simulation-based mastery learning during intern boot camp. Acad Med 2013; 88(2):233-9.

5. O'Brien BC. What to do about the transition to residency? Exploring problems and solutions from three perspectives. Acad Med 2018; 93(5):681-4.

6. Teunissen PW, Westerman M. Junior doctors caught in the clash: the transition from learning to working explored. Med Educ 2011; 45(10):968-70.

7. Westerman M, Teunissen PW, Fokkema JP, et al. The transition to hospital consultant and the influence of preparedness, social support, and perception: a structural equation modelling approach. Med Teach 2013; 35(4):320-7.

8. Mattar SG, Alseidi AA, Jones DB, et al. General surgery residency inadequately prepares trainees for fellowship: results of a survey of fellowship program directors. Ann Surg 2013; 258(3):440-9.

9. Wijnen-Meijer M, Burdick W, Alofs L, Burgers C, ten Cate O. Stages and transitions in medical education around the world: clarifying structures and terminology. Med Teach 2013; 35(4):301-7.

10. Weggemans MM, van Dijk B, van Dooijeweert B, Veenendaal AG, ten Cate O. The postgraduate medical education pathway: an international comparison. GMS JMed Educ 2017; 34(5):Doc63.

11. O'Brien BC, Forrest $\mathrm{K}$, Wijnen-Meijer $\mathrm{M}$, ten Cate $\mathrm{O}$. A global view of structures and trends in medical education, in Understanding Medical Education, Swanwick T, Forrest K, O'Brien BC, Editors. 2019, 3 ed, Hoboken, NJ, USA: Wiley-Blackwell.

12. Hirsh D, Walters $L$, Poncelet AN. Better learning, better doctors, better delivery system: possibilities from a case study of longitudinal integrated clerkships. Med Teach 2012; 34(7):548-54.

13. Andrews JS, Bale JF, Soep JB, et al. Education in pediatrics across the continuum (EPAC): first steps toward realizing the dream of competency-based education. Acad Med 2018; 93(3):414-20.

14. Ten Cate O. Medical education in the Netherlands. Med Teach 2007; 29(8):752-7.

15. Hoff RG, Frenkel J, Imhof SM, ten Cate O. Flexibility in postgraduate medical training in the Netherlands. Acad Med 2018; 93(3S Competency-Based, Time-Variable Education in the Health Professions):S32-S6. 
16. Querido S, de Rond M, Wigersma L, van den Broek S, ten Cate O. The significance of experiencing clinical responsibilities for specialty career choice. Med Sci Educ 2020; 30:16371.

17. Van der Velde F, van de Leemkolk B, Lodder A. Careers and career-preferences of medical graduates. Measurement 2019. [Loopbanen en loopbaanwensen van basisartsen. Meting 2019.] [In Dutch].2019, Utrecht: Prismant.

18. Wijnen-Meijer M, ten Cate O, Rademakers JJ, van der Schaaf M, Borleffs JC. The influence of a vertically integrated curriculum on the transition to postgraduate training. Med Teach 2009; 31(11):e528-32.

19. Van den Broek WES, Wijnen-Meijer M, ten Cate O, van Dijk M. Medical students' preparation for the transition to postgraduate training through final year elective rotations. GMS J Med Educ 2017; 34(5):Doc65.

20. Wijnen-Meijer M, ten Cate O, van der Schaaf M, Burgers C, Borleffs J, Harendza S. Vertically integrated medical education and the readiness for practice of graduates. BMC Med EduC 2015; 15:229.

21. Jonker G, Hoff RG, Max S, Kalkman CJ, ten Cate O. Connecting undergraduate and postgraduate medical education through an elective EPA-based transitional year in acute care: an early project report. GMS J Med Educ 2017; 34(5):Doc64.

22. Chen $\mathrm{HC}$, van den Broek WE, ten Cate $\mathrm{O}$. The case for use of entrustable professional activities in undergraduate medical education. Acad Med 2015; 90(4):431-6.

23. Murray KE, Lane JL, Carraccio C, et al. Crossing the gap: using competency-based assessment to determine whether learners are ready for the undergraduate-to-graduate transition. Acad Med 2019; 94(3):338-45.

24. Jonker G, Booij E, Otte WR, et al. An elective entrustable professional activity-based thematic final medical school year: an appreciative inquiry study among students, graduates, and supervisors. Adv Med Educ Pract 2018; 9:837-45.

25. Groot F \& Jonker G, Rinia M, ten Cate O, Hoff RG. Simulation at the frontier of the Zone of proximal development: a test in acute care for inexperienced learners. Acad Med 2020; 95(7):1098-1105.

26. Reddy ST, Chao J, Carter JL, et al. Alliance for clinical education perspective paper: recommendations for redesigning the "final year" of medical school. Teach Learn Med 2014; 26(4):420-7.

27. Wijnen-Meijer $M$, ten Cate $O$, van der Schaaf $M$, Borleffs JC. Vertical integration in medical school: effect on the transition to postgraduate training. Med Educ 2010; 44(3):272-9.

28. Boulet JR, Murray D, Kras J, et al. Reliability and validity of a simulation-based acute care skills assessment for medical students and residents. Anesthesiology 2003; 99(6):1270-80.

29. Flotte TR, Larkin AC, Fischer MA, et al. Accelerated graduation and the deployment of new physicians during the COVID-19 pandemic. Acad Med 2020; 95(10):1492-4.

30. Lapolla P, Mingoli A. COVID-19 changes medical education in Italy: will other countries follow? Postgrad Med J 2020; 96(1137):375-6. 
31. Keeley MG, Gusic ME, Morgan HK, Aagaard EM, Santen SA. Moving toward summative competency assessment to individualize the postclerkship phase. Acad Med 2019; 94(12):1858-64.

32. Dewan M, Norcini J. A purpose-driven fourth year of medical school. Acad Med 2018; 93(4):581-5.

33. Lumb A, Murdoch-Eaton D. Electives in undergraduate medical education. AMEE Guide No. 88. Med Teach 2014; 36(7):557-72.

34. Lempp $H$, Seabrook $M$, Cochrane $M$, Rees J. The transition from medical student to doctor: perceptions of final year students and preregistration house officers related to expected learning outcomes. J Clin Pract 2005; 59(3):324-9.

35. Burford B, Ellis E, Williamson A, Forest I, Vance G. Learning opportunities in student assistantships. The Clin Teacher 2015; 12(2):121-7. 


\section{APPENDIX 1. DETAILED DESCRIPTION OF THE MULTIMODAL ACUTE CARE ASSESSMENT}

Participants took part in a multimodal acute care assessment in which they were evaluated at junior doctor-level, i.e. the expected level of a recent graduate with 6 months clinical experience.

Specifically for ACTY and this study, expert clinicians of the five specialties participating in ACTY collaboratively designed a multimodal assessment inspired by the levels of Miller's pyramid: Knows, Knows how, Shows how, and Does [1]. We chose to assess these components of competence as a proxy for assessing competence. Because we required highly comparable assessments of all participants under controlled circumstances, we were not able to use clinical workplace assessments to evaluate participants at the Does level. Instead, we used high fidelity simulations in contextually rich scenarios of acutely compromised patients to mimic clinical practice. Simulations can be considered to evaluate performance high in the Shows how level, approaching the Does level [2].

The clinical learning objectives of the Acute Care program, formulated as Entrustable Professional Activities (EPAs) and describing authentic acute care tasks that junior doctors face, served as assessment blueprint. The EPAs listed the knowledge, skills, attitudes and competencies required for execution of the task [3]. Each listed aspect formed a row in the blueprint matrix and linked to one or more assessment elements, forming the columns of the matrix.

We assessed Knows level with a knowledge test, Knows how level with case-base discussions (CBDs), Shows how with skills stations in Objective Structured Clinical Examination format, and Higher shows how level with high-fidelity simulations.

\section{Assessment modes}

\section{Knowledge test}

This was a 40 minute paper-based written test, containing around 40 closed and six open format questions, targeting factual or applied knowledge or higher order thinking. Items requiring application or higher order thinking yielded more points than factual items. We created new questions or drew upon ACTY faculty databases, and one of the authors (GJ) and an assessment expert evaluated and amended items as needed. Three versions of parallel content existed. 


\section{CBDs}

Through one-on-one structured questioning and discussion, assessors evaluated the process of information gathering, clinical reasoning and know-how of case management. ACTY faculty devised four cases describing patients requiring urgent attendance at the Emergency Department. Faculty and GJ fine-tuned cases iteratively. Each case had a specific detailed checklist following the chronology of the consultation, with anchors describing essential steps or expected actions. Examiners scored the performance on a three-point scale (done adequately - done incompletely or not timed well - done insufficiently or omitted). Specific aspects, such as appropriate prioritization, completeness, or clinical overview, could be awarded with extra points, where indicated on the checklist. Assessors completed the paper-based scoring checklist during and directly after the discussion.

Participants did two CBDs of 10 minutes duration, with two different assessors, on patients requiring urgent attendance at the Emergency Department. We used two sets of two cases.

\section{OSCEs}

This part of the assessment consisted of 5 to 7 skills stations of 5 minutes duration. ACTY faculty devised several stations in OSCE format for skills mentioned in the learning objectives. Each station had a specific detailed checklist made up of the consecutive steps in the execution of the skill. Assessors rated performance on a three-point scale (done adequately - done incompletely or not timed well - done insufficiently or omitted. Assessors completed the paper-based scoring checklist during and directly after skill performance.

\section{Simulations}

The part, resembling clinical work most, consisted of three real-time simulation scenarios, each lasting approximately 12 minutes, run by anesthesiologists and anesthetic nurses who were all EUSim or CMS certified simulation facilitators (https:// eusim.org and harvardmedsim.org). Anesthesiologists from the simulation center developed scenarios in collaboration with ACTY faculty and one of the authors (GJ). Scenarios used a standardized script and were enacted to occur in the emergency room or ward and were tasks that a physician-not-in-training could encounter. The participant enacted the role of the first responding doctor and a nurse was present who acted only on instruction.

The simulator room mimicked a room in a clinical environment and deployed a 2010 Laerdal Sim Man (Laerdal Benelux B.V., Amersfoort, the Netherlands). The high-fidelity 
manikin featured a wide range of sounds and pulsations and could be connected to a monitor. Props such as white coats, drug carts, telephone system, disposables and relevant working equipment resulted in an authentic hospital-like environment [4].

We devised detailed scenario-specific checklists of expected actions and important steps in the management of the case. Assessment, by the simulation center faculty, entailed clinical reasoning, clinical judgment and technical and behavioral skills including communication and crisis resource management. We did not use video recordings. Assessors rated checklist items on a three-point scale (done adequately - done incompletely or not timed well - done insufficiently or omitted. Assessors completed the paper-based scoring checklist during and directly after skill performance.

Facilitators debriefed participants after each scenario to foster learning and well-being.

\section{Pre- and post-test}

Every six weeks, students could commence in their transitional year and, normally, would graduate a year later. Therefore, we organized a test instance every six weeks. At one instance, all participants took the same test, either as pre-test or post-test. Participants in the intervention group and student control group attended the pre-test before starting in their final year rotations and the post-test in about the last month of their final year. We informed all participants about the aim of the study and assessment procedures. Participants agreed not to disclose exam content to their peers.

To complete the assessment participants attended two separate half-days within a timeframe of one week. On the first half-day, he knowledge test, CBDs and OSCEs took place at University Medical Center Utrecht, the Netherlands. With preparation and rest stations, this part had a duration of three hours. On the second half-day, simulations took place at the simulation center of Rijnstate Hospital, Velp, the Netherlands. With induction, briefing, rest and waiting time and debriefing, this part took about three hours.

One of the authors (GJ) supervised all assessment instances, assuring that the assessment elements together were a representative coverage of the domain. We ran 25 test instances, which were highly similar. Participants' pre-test content was different from their post-test. Marshalls coordinated the assessment, managed time protocols, to create equal opportunities for participants between instances and reduce random and systematic error. 
Within the ACTY, the pre- and post-test were formative and results had no formal consequences for students. Purpose of the pre-test, from a curricular point of view, was to identify personal performance gaps, force focus on the learning objectives, and confront students with the expected performance level of junior doctors. Therefore, all participants received feedback on their performance in the tests.

\section{Examiners}

Assessors at CBDs and OSCEs were all clinicians with appropriate expertise and experience for the stations at which they examined. They volunteered when available. The investigators briefed all examiners individually on the use of the scoring rubric, expected performance level and station duration. Examiners were not made aware whether participants were from intervention or control groups, nor whether participants did a pre- or post-test. Examiners scored participants' performance live on a paper checklist.

\section{REFERENCES}

1. Miller GE. The assessment of clinical skills/competence/performance. Acad Med 1990; 65(9):S63-7.

2. Ten Cate O, Carraccio C, Damodaran A, Gofton W, Hamstra SJ, Hart D, et al. Entrustment decision making: extending Miller's pyramid. Acad Med 2021; 96(2):199-204.

3. Ten Cate O. Nuts and bolts of entrustable professional activities. J Grad Med Educ 2013; 5(1):157-8.

4. Groot F \& Jonker G, Rinia M, Ten Cate O, Hoff RG. Simulation at the frontier of the Zone of proximal development: a test in acute care for inexperienced learners. Acad Med 2020; 95(7):1098-1105. 


\section{APPENDIX 2. DETAILED REPORT OF STATISTICAL ANALYSES}

TABLE 1: Pre-test, post-test and gain in mean scores on knowledge, CBDs, OSCEs, and simulations

\begin{tabular}{|c|c|c|c|c|c|c|c|c|c|c|c|c|c|c|}
\hline \multirow[b]{3}{*}{$\begin{array}{l}\text { Assessment } \\
\text { modality }\end{array}$} & \multicolumn{6}{|c|}{ Group ACTY } & \multicolumn{6}{|c|}{ Group C } & \multirow{2}{*}{\multicolumn{2}{|c|}{$\begin{array}{c}\text { Group P } \\
\text { Post }\end{array}$}} \\
\hline & \multicolumn{2}{|c|}{ Pre } & \multicolumn{2}{|c|}{ Post } & \multicolumn{2}{|c|}{ Gain } & \multicolumn{2}{|r|}{ Pre } & \multicolumn{2}{|c|}{ Post } & \multicolumn{2}{|c|}{ Gain } & & \\
\hline & $\mathbf{n}$ & $\begin{array}{c}\text { Mean } \\
\text { (SD) } \\
95 \% \\
\mathrm{Cl}\end{array}$ & $\mathbf{n}$ & $\begin{array}{c}\text { Mean } \\
\text { (SD) } \\
95 \% \\
\mathrm{Cl}\end{array}$ & $\mathbf{n}$ & $\begin{array}{c}\text { Mean } \\
\text { (SD) } \\
95 \% \\
\mathrm{Cl}\end{array}$ & $\mathbf{n}$ & $\begin{array}{c}\text { Mean } \\
\text { (SD) } \\
95 \% \\
\mathrm{Cl}\end{array}$ & $\mathbf{n}$ & $\begin{array}{c}\text { Mean } \\
\text { (SD) } \\
95 \% \\
\mathrm{Cl}\end{array}$ & $\mathbf{n}$ & $\begin{array}{c}\text { Mean } \\
(\mathrm{SD}) \\
95 \% \\
\mathrm{Cl}\end{array}$ & $\mathbf{n}$ & $\begin{array}{c}\text { Mean } \\
\text { (SD) } \\
95 \% \\
\mathrm{Cl}\end{array}$ \\
\hline \multirow[t]{5}{*}{ Knowledge } & 33 & 59 & 29 & 67 & 29 & 8 & 10 & 53 & 19 & 63 & 8 & 11 & 16 & 67 \\
\hline & & (8) & & (11) & & (14) & & (8) & & (13) & & (14) & & (7) \\
\hline & & 56 & & 63 & & 3 & & 47 & & 56 & & -1 & & 63 \\
\hline & & - & & - & & - & & - & & - & & - & & - \\
\hline & & 62 & & 71 & & 14 & & 59 & & 69 & & 23 & & 70 \\
\hline \multirow[t]{5}{*}{ CBDs } & 33 & 64 & 29 & 79 & 29 & 16 & 10 & 62 & 19 & 72 & 8 & 13 & 16 & 79 \\
\hline & & (12) & & (11) & & (11) & & (12) & & (10) & & (14) & & (9) \\
\hline & & 60 & & 75 & & 12 & & 53 & & 67 & & 1 & & 74 \\
\hline & & - & & - & & - & & - & & - & & - & & - \\
\hline & & 68 & & 84 & & 20 & & 71 & & 77 & & 24 & & 84 \\
\hline \multirow[t]{6}{*}{ OSCES } & 33 & 64 & 29 & 74 & 29 & 10 & 10 & 62 & 19 & 67 & 8 & 10 & 16 & 72 \\
\hline & & (7) & & $*$ & & (9) & & (6) & & $*+$ & & (5) & & $t$ \\
\hline & & 61 & & (9) & & 6 & & 57 & & (8) & & 6 & & (5) \\
\hline & & - & & 71 & & - & & - & & 63 & & - & & 69 \\
\hline & & 67 & & - & & 14 & & 66 & & - & & 14 & & - \\
\hline & & & & 78 & & & & & & 70 & & & & 75 \\
\hline \multirow[t]{6}{*}{ Simulations } & 33 & 51 & 27 & 65 & 27 & 14 & 10 & 46 & 14 & 59 & 6 & 13 & 17 & 71 \\
\hline & & $t+$ & & $\neq^{* *}$ & & (11) & & $t+$ & & $\neq \S$ & & (17) & & $\S * *$ \\
\hline & & (6) & & (8) & & 9 & & (8) & & (11) & & -6 & & (6) \\
\hline & & 49 & & 62 & & - & & 40 & & 52 & & - & & 68 \\
\hline & & - & & - & & 18 & & - & & - & & 31 & & - \\
\hline & & 53 & & 69 & & & & 51 & & 65 & & & & 74 \\
\hline
\end{tabular}

$A C T Y=$ Acute Transitional Year group, $C=$ student comparison group, $P=P N I T$ comparison group. Pre $=$ pre-test, Post $=$ post-test . Gain= difference between post-test and pre-test. Assessment modality scores expressed as \% of maximum obtainable score, as group mean ( $S D=$ standard deviation) and 95\% confidence interval (CI). PNITs did not participate in the pre-test, for comparison with groups $A C T Y$ and $C$ we label their participation as post-test. The focus in the paper is on post-test comparison. ${ }^{*} p=.004 ;+$ $p=.026 ; \neq p=.036 ; \S p<.001 ; * * 0=.019 ;+t p=.026$

\section{Pre-test}

Only group ACTY and (part of) group C took part in the pre-test.

There were no statistically significant differences in group means on knowledge, CBDs, and OSCEs, as determined by one-way ANOVA (Table 2). There was a statistically significant difference between groups on simulations, as determined by one-way ANOVA. 
TABLE 2: Pre-test ANOVA

\begin{tabular}{lcc}
\hline Assessment modality & ANOVA F(1,41) & p \\
\hline Knowledge & 3.822 & .057 \\
CBDs & .221 & .641 \\
OSCES & .957 & .334 \\
Simulations & 5.355 & .026 \\
\hline
\end{tabular}

Group ACTY had statistically significant higher group mean on simulations than group $C$, as determined by independent samples t-test: $t(41)=2.314, p=.026$, mean difference $6(2), 95 \% \mathrm{Cl} 1-11$.

\section{Post-test}

On knowledge and CBDs, there were no statistically significant differences between groups, as determined by one-way ANOVA (Table 3). However, on OSCEs and simulations, there were statistically significant differences between groups, as determined by oneway ANOVA.

TABLE 3: Post-test ANOVA

\begin{tabular}{lcc}
\hline Assessment modality & ANOVA & p \\
\hline Knowledge & $\mathrm{F}(2,61)=0.941$ & .396 \\
CBDs & $\mathrm{F}(2,61)=3.272$ & .05 \\
OSCEs & $\mathrm{F}(2,61)=5.587$ & .01 \\
Simulations & $\mathrm{F}(2,55)=8.239$ & .001 \\
\hline
\end{tabular}

On OSCEs, group ACTY had statistically significant higher group mean than group $C$, as determined by independent samples t-test: $\mathrm{t}(46)=3.068, \mathrm{p}=.004$, mean difference $8(3)$, $95 \% \mathrm{Cl} 3-13$.

Group P had statistically significant higher group mean on OSCEs than group $C$, as determined by independent samples t-test: $t(33)=2.325, p=.026$, mean difference 5 (2), 95\% Cl 1 - 10.

On simulations, group ACTY had statistically significant higher group mean than group $\mathrm{C}$, as determined by independent samples t-test: $\mathrm{t}(39)=2.172, \mathrm{p}=.036$, mean difference 7 (3), 95\% Cl $1-13$. 
Group P had statistically significant higher group mean than group $C$, as determined by independent samples t-test: $\mathrm{t}(29)=4.089, \mathrm{p}<.001$, mean difference 12 (3), 95\% Cl 6 - 18 .

Group $\mathrm{P}$ also had statistically significant higher group mean than group ACTY, as determined by independent samples t-test: $\mathrm{t}(42)=2.430, \mathrm{p}=.019$, mean difference $6(2)$, $95 \% \mathrm{Cl} 1-10$.

\section{Gain}

In gain between pre-test and post-test scores, there was no statistically significant difference between means of group ACTY and group C on all assessment modalities, as determined by one-way ANOVA (Table 4).

TABLE 4: Gain ANOVA

\begin{tabular}{lcc}
\hline Assessment modality & ANOVA & p \\
\hline Knowledge & $\mathrm{F}(1,35)=0.287$ & .596 \\
CBDs & $\mathrm{F}(1,35)=0.514$ & .478 \\
OSCEs & $\mathrm{F}(1,35)=0.002$ & .964 \\
Simulations & $\mathrm{F}(1,31)=0.035$ & .853 \\
\hline
\end{tabular}

\section{Post-test GRS}

In addition to checklist scores, on CBDs, OSCEs and simulations, assessors evaluated participant performance on a three-point global rating score (does not meet expectations - borderline - meets expectations), in answer to the question "How did the participant's performance compare to the expected level of a PNIT with six months of clinical experience?".

We used a cumulative odds ordinal logistic regression with proportional odds to determine the effect of group type on receiving a high GRS.

The deviance goodness-of-fit test indicated that the model was a good fit to the observed data of CBDs, $X^{2}(2)=1.37, p=.504$, OSCEs, $X^{2}(2)=1.01, p=.603$, and simulations, $X^{2}(2)=.621, p=.733$. The final model statistically significant predicted the dependent variable over and above the intercept-only model for CBDs $X^{2} 7.37, p=.023$, OSCEs $X^{2}$ $12.24, p=.002$, and simulations $x^{2} 21.62, p<.001$. 
Group type had a statistically significant effect on the prediction of getting a high GRS on CBDs, Wald $x^{2}(2)=6.69, p=.035$, on OSCEs, Wald $x^{2}(2)=12.44, p=.002$, and on simulations, Wald $X^{2}(2)=19.43, p<.001$.

Compared to group C, the OR of participants in group ACTY getting a high GRS was 2.49 for CBDs, 2.47 for OSCEs, and 2.06 for simulations; statistically significant for OSCEs and simulations (Table 5). The OR of PNITs to get a high GRS, compared to group C, was 6.69 for CBDs, 2.45 for OSCEs, and 6.57 for simulations; all statistically significant.

The odds of PNITs getting a high GRS on simulations was 3.22 times that of DTY students, a statistically significant effect (Table 6). For CBDs and skills, the odds did not differ significantly from DTY students (OR 0.37 and OR 1.01, respectively).

In summary, both ACTY graduates and PNITs had statistically significant higher odds to get a high GRS than graduates form group C on skills and simulations. PNITs had statistically significant higher odds to get a higher GRS on CBDs, as well. PNITs also had statistically significant higher odds to get a high GRS on simulations than ACTY graduates. 

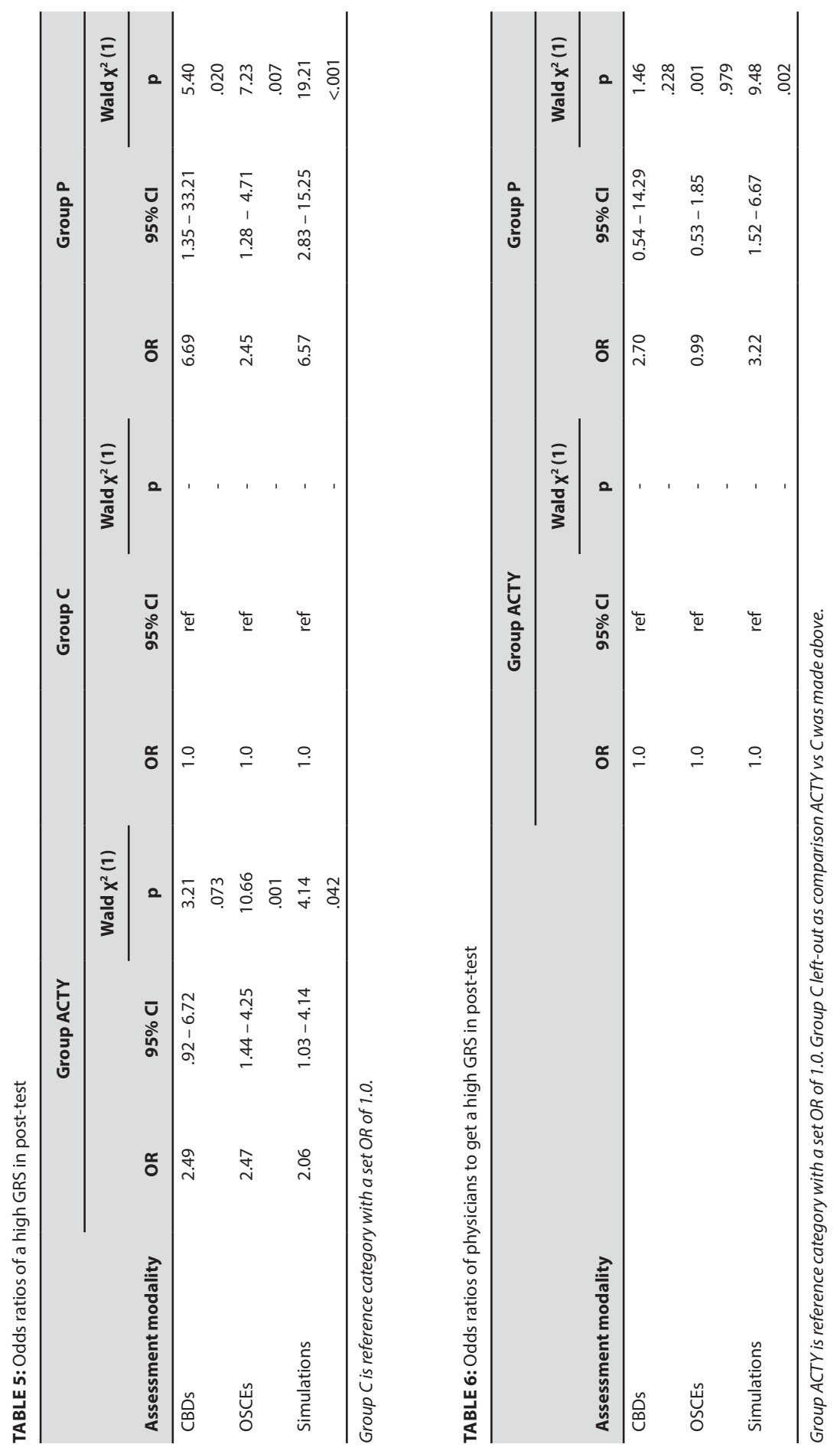


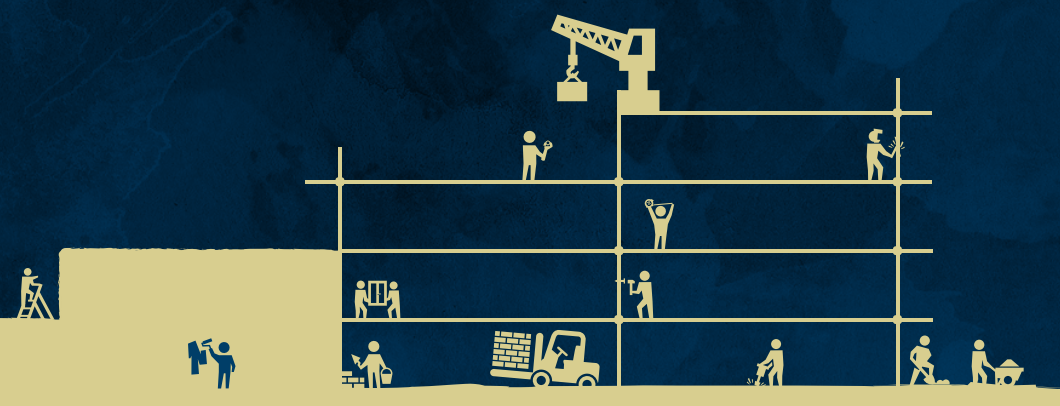




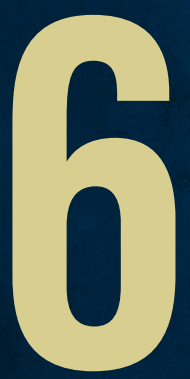

\section{VARIATIONS IN ASSESSMENT AND CERTIFICATION IN POSTGRADUATE ANESTHESIOLOGY TRAINING}

\section{A EUROPEAN SURVEY}

\section{Published as:}

Jonker G, Manders LA, Marty AP, Kalkman CJ, ten Cate O, van Gessel EF, Hoff RG.

Variations in assessment and certification in postgraduate anaesthesiology training: a European survey.

Br J Anaesth. 2017; 119(5):1009-14. doi: 10.1093/bja/aex196. 


\section{ABSTRACT}

Background Postgraduate specialty training has traditionally been based on a timeand rotation-based model, but competency-based models are emerging. Because anesthesiology training evolves differently across Europe, variations in assessment and certification processes are expected, but the extent of similarities and differences is unknown. Aim of this study was to compare anesthesiology training programs in Europe, focusing on assessment and certification processes.

Methods We performed an online survey among national representatives to Union of European Medical Specialists/European Board of Anaesthesiology (UEMS/EBA).

Results All 36 countries participated. Duration of training had a median of 5 years (range 2.75 - 7). Mean number of different assessment tools was 7.45 (range $4-13$ ), with more tools being used in competency-based programs (mean 9.1 (SD 2.97) vs. 7.0 (SD 1.97; $p=0.03$ ). Most countries had a nationally uniform certification process. Based on a qualitative analysis of the survey findings a categorization of countries emerged, reflecting the approach to assessment and certification. We observed two main streams of countries with an underlying knowledge or procedural focus within a time- and rotation-based apprenticeship model. These main streams are evolving, to different extents, towards a third orientation, competency-based training.

Conclusion Assessment and certification processes in European anesthesiology training are diverse. In many countries, a time-based apprenticeship model is evolving towards a competency-based certification process. This diversity precludes comparison of competence of graduating anesthesiologists across Europe. 
Postgraduate medical training leads to certification as a medical specialist. Certification is a self-regulatory process under the jurisdiction of medical specialties and includes credentialing of training experience with some form of assessment [1]. Certification is meant to provide assurance that professionals are qualified to safely practice the specialty.

In 2012, UEMS European Board of Anaesthesiology (UEMS/EBA) issued the latest revision of their guidelines on Training Requirements for the Specialty of Anaesthesiology, Pain and Intensive Care Medicine [2-4]. These guidelines advocate comparability and harmonization of postgraduate training programs to facilitate transfer of anesthesiologists across Europe safeguarding a minimum training level. They also intend to stimulate training and assessment using modern educational principles [4, 5]. Proper assessment based on clearly defined educational objectives is a prerequisite to mutual recognition of certification of non-domestic anesthesiologists [3].

Postgraduate specialty training has long been based on a classic apprenticeship model. In this model a trainee spends a fixed time in the specialty during which she learns from experienced practitioners in different clinical settings. Often training ends after the prescribed duration and passing of an exam. From this initial model, training has evolved in numerous ways, influenced by national or international regulations and guidelines and local job requirements. Therefore, considerable differences in criteria and processes for certification in anesthesiology in Europe are expected, but the extent to which these differences exist is unknown.

The aim of this study was to investigate and compare postgraduate anesthesiology training programs across Europe, focusing on assessment and certification processes.

\section{METHODS}

\section{Design}

An online survey was performed among national representatives to UEMS/EBA, which includes thirty-six European and affiliated countries. As a representative body, UEMS/ EBA is devoted to fostering high standards in quality of anesthesiology care and training in Europe.

We assumed that each national representative had insight in the current status and developments in postgraduate training in their countries. With the survey, we requested for supporting documentation. 


\section{Ethical considerations}

Our study adhered to the World Medical Association Declaration of Helsinki - Ethical Principles for Medical Research Involving Human Subjects [6].

The study was announced and discussed at a UEMS/EBA national representatives' meeting of November 2015, which generated support for the project. Detailed information on the study was provided in a letter sent by email explaining the goals and design of the study, specifying confidentiality and the handling of data. Participation was voluntary. Participants' informed consent was obtained by e-mail.

Formal ethical review was not sought, as only publicly available information was collected from individuals, who, in their capacity as national delegates, were known to be knowledgeable insiders and to have easy access to this information.

\section{Procedure}

For the purpose of this study 'certification process' was defined as: the process of all steps in meeting requirements and in decision-making, that eventually leads to the completion of training and access to registration as medical specialist in anesthesiology.

Each participant was asked to describe the certification process, or processes, in their country in a survey consisting of five questions with a constructed response format (three open questions and two short-answer questions), and four questions with a selected response format (one yes/no question and three questions with a list of options) (Table 1).

Authors GJ and LM designed the survey questions after orientation on the topic by initial review of online available training documents, followed by discussion with and input from the other authors. No formal piloting of the survey was performed, although all authors approved the survey for clarity and feasibility.

Participants could either answer the survey questions in a text file attached to the invitation e-mail or follow a link to an identical online survey (SurveyMonkey ${ }^{\oplus}$ ). In addition, participants were asked to provide relevant supporting documents on postgraduate anesthesiology training such as training frameworks, national syllabi, policies and legislation. Email reminders and personal contact by telephone were used to increase the response rate. 
TABLE 1: Survey questions on assessment and certification process

\begin{tabular}{|c|c|}
\hline Question & Response format \\
\hline Please select your country & Choose from list \\
\hline Year of publication of the provided documents & Short answer textboxes \\
\hline What is the (minimal) duration of training? & Short answer textbox \\
\hline $\begin{array}{l}\text { What are the prerequisites/requirements to initiate the } \\
\text { certification process? }\end{array}$ & Open answer textbox \\
\hline $\begin{array}{l}\text { Is there a uniform certification process in your country, or } \\
\text { do differences in local/regional processes exist? }\end{array}$ & Open answer textbox \\
\hline Please describe the certification process. & Open answer textbox \\
\hline $\begin{array}{l}\text { Is there a national registration of medical specialists in } \\
\text { anesthesiology? }\end{array}$ & Yes/no \\
\hline $\begin{array}{l}\text { Which assessment tools are used during postgraduate } \\
\text { training in anesthesiology? } \\
\text { Nationally and locally. }\end{array}$ & Choice from list of tools \\
\hline $\begin{array}{l}\text { Please indicate which of the following competencies are } \\
\text { assessed? }\end{array}$ & Choice from: Medical Expert, Leader, Scholar, Professional \\
\hline
\end{tabular}

\section{Analysis}

Numerical data underwent descriptive statistics where appropriate. Difference of mean scores between groups was tested with independent samples t-tests with statistical significance assumed at $p<.05$.

Narrative data from all countries were qualitatively analyzed independently by three researchers (GJ, LM, AM). Differences in qualitative analysis by the researchers were discussed to reach consensus. Clarification from respondents of the survey was sought for any uncertainty in interpretation of the answers. Supporting documents were used to substantiate or supplement findings from the survey responses.

The report of this study adheres, wherever applicable, to the Survey Reporting List [7].

\section{RESULTS}

\section{Response}

Survey responses were collected from November 2015 until March 2016, with clarification and completion of responses during the analysis phase, which took place until August 2016. Informed consent, completed surveys and documents were obtained from all respondents of the 36 countries represented at UEMS/EBA in 2015 (response rate $100 \%$ ). One country did not have a postgraduate training program in anesthesiology; the remaining 35 countries were included in the analysis. 


\section{Classification of training programs}

From preliminary qualitative analysis of the data from nine countries by one of the authors (GJ), a proposed classification in four categories (groups A - D) emerged that subsequently allowed grouping of countries with similar certification processes. From the assessment and certification perspective, countries in Group A typically focus on securing the level of acquired knowledge of trainees by having a final exam (usually oral or written). Often few other assessment methods are used. Characteristically, curricula in Group A elaborate on the knowledge to be attained (cognitive domain) and competencies are not mentioned. In Group B, assessment focuses on the completion of specified numbers of procedures (e.g. xx general anesthetics, $x x$ upper extremity regional blocks, etcetera), as evidenced by a logbook. This is typically the main type of evaluation and there is not much emphasis on other techniques to assess trainees. Curriculum descriptions and expectations are largely knowledge and skill based and not competency oriented. In Group C certification is granted on the basis of gathered evidence of competence at the end of training. Typically, multimodal assessment, with an emphasis on workplace assessment, is in place. Often there is a blueprint and/or a competency-based curriculum on which assessment is based. A fourth category that emerged from the preliminary analysis of the first survey results was Group $D$, a hybrid group harboring countries with training programs that have features from Group A or $\mathrm{B}$, but also resemble programs from group $\mathrm{C}$ to a certain extent. This preliminary classification is summarized in Table 2.

TABLE 2: Preliminary categories of training programs

\begin{tabular}{|c|c|}
\hline Group & Description \\
\hline \multirow[t]{2}{*}{ A } & Curriculum: knowledge-based \\
\hline & Assessment: focus on knowledge, final exam is main method \\
\hline \multirow[t]{2}{*}{ B } & Curriculum: knowledge and skills-based \\
\hline & Assessment: completion of number of procedures (e.g. general anaesthetics) \\
\hline \multirow[t]{2}{*}{$\mathrm{C}$} & Curriculum: competency-based \\
\hline & Assessment: often multiple methods, focus on workplace assessment \\
\hline $\mathrm{D}$ & Curriculum and assessment share features from at least two categories (A-C) \\
\hline
\end{tabular}

The subsequent step of qualitative analysis of survey data consisted of categorization of the 35 European training programs according to this classification (Table 2) by three researchers independently. 
Seventeen countries were categorized identically by all three researchers. On four further countries immediate consensus was reached after discussion. Three countries were in group $A$, five in group $B$, six in group $C$, and seven in group D. For thirteen countries the $\mathrm{D}$ category was considered, but there was no direct consensus on classification.

Thus, in total, 20 countries could be classified as D, meaning they have features of two or three categories. This led to an extensive discussion on the appropriateness of the D category, being a hybrid category and containing the majority of countries. All countries categorized as group D were therefore reconsidered. For these countries further information was gathered from the representatives. On one country there was insufficient information to allow for classification. When reviewed more closely, many countries appeared to have evolved, or be evolving, from categories A or B towards C, albeit in different ways and to different extents. It was decided that a rigid four-category classification did not do justice to the diversity in evolution of training programs in Europe. We agreed to use a more fluid classification instead, which could depict this diversity and evolution graphically. This led to a triangular spectrum in which most countries could be positioned along the $A-C$ or $B-C$ axes (Figure 1). A few countries are positioned in the middle of the triangle, essentially representing remains of the former group D.

\section{Assessment}

The median duration of training programs was 5 years (range 2.75 - 7). In six countries duration of training was less than the minimum of five years recommended by UEMS/ EBA [2].

All countries but three had national uniform certification processes.

The mean number of different assessment tools mentioned per country was 7.45 (range 4 - 13). The mean number of tools used nationally as prescribed by the national training program was 6.2 (range 1 - 12) per country. The application of various assessment tools is shown in Table 3.

The most frequently mentioned assessment tools were direct clinical observation and feedback, oral and MCQ examinations, logbook, and portfolio. The European Diploma in Anaesthesiology and Intensive Care examination (EDAIC), that is a multilingual, end-oftraining, two-part examination covering the relevant basic sciences and clinical subjects appropriate for a specialist anesthesiologist, was used in a minority of countries: six 
countries have part I as a mandatory exam, in six countries part I and II are mandatory, and regulations in three countries stipulate that EDAIC may serve as a substitute for a national knowledge exam.

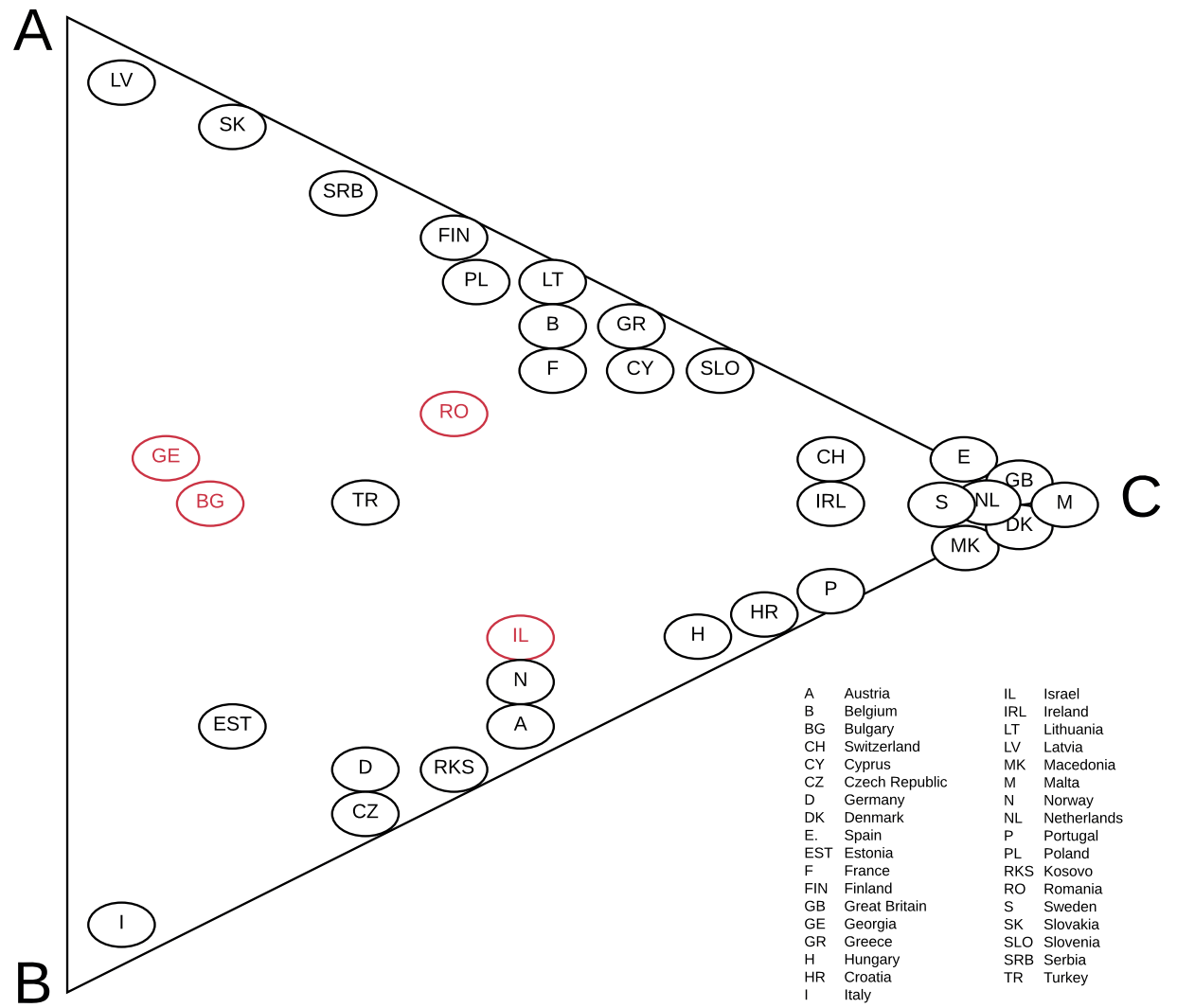

Figure 1: Classification of countries by orientation of training programs.

A: Curriculum: knowledge-based. Assessment: focus on knowledge, final exam is main method.

B: Curriculum: knowledge and skills-based. Assessment: completion of number of procedures (e.g. general anesthetics).

C: Curriculum: competency-based. Assessment: often multiple methods, focus on workplace assessment.

Countries on the A-C axis share an A-type origin with varying degrees of orientation towards $C$. Countries on the $B-C$ axis share $a$ $B$-type origin with varying degrees of orientation towards $C$. Countries in the middle of the triangle (seem to) have a hybrid orientation.

Classification of the countries in red are with higher degree of uncertainty because of lack of information despite multiple efforts to obtain this. 
TABLE 3: Application of different assessment tools

\begin{tabular}{lc}
\hline Assessment tool & $\begin{array}{c}\text { Results } \\
\text { Number of countries (\%) }\end{array}$ \\
\hline Direct clinical observation and feedback & $33(94)$ \\
Oral examinations & $31(88)$ \\
Logbook & $29(82)$ \\
Multiple choice questions / exams & $26(74)$ \\
Portfolio & $26(74)$ \\
Objective structured clinical examination & $20(57)$ \\
Essays / Paper / Assignment & $18(51)$ \\
Multi source feedback & $15(42)$ \\
Simulation examination & $14(40)$ \\
EDAIC Part 1 examination & $14(40)$ \\
Mini clinical evaluation exercise (Mini-CEX) & $13(37)$ \\
Standardized patient exams & $12(34)$ \\
EDAIC Part 2 examination & $8(23)$ \\
Video assessment & $4(11)$ \\
\hline
\end{tabular}

The number of assessment tools in group $C$ was higher than in countries not in group $C$, with a mean of 9.1 (SD 2.97) tools, compared to a mean of 7.0 (SD 1.97) tools per country in other groups $(p=.03)$.

\section{Certification processes}

In the majority of countries certification is ultimately granted by a governmental organization. In a few countries a university issues the certificate. The issuing bodies are advised to do so by the training institution. In some countries heads of department or program directors give this advice. Some countries have certifying committees that advise the issuing body, whereas a few other countries work with a national training body that oversees the process and advises the issuing body on granting certification. Aspects considered when advising the issuing body are: credentialing of training experience (completion of required time in training, required rotations and/or required procedures), often passing a final exam and/or approval of a piece of scholarly work, and in some cases an attestation of competence.

\section{DISCUSSION}

This study shows a great diversity in current assessment and certification practices in specialty training in anesthesiology in Europe. We also found that countries can be categorized according to their approach to assessment and certification (Figure 1). 
All countries report to have time-based programs composed of rotations, sometimes referred to as the apprenticeship model $[8,9]$. This is in accordance with earlier reports describing anesthesiology training $[3,10]$.

Postgraduate training in anesthesiology in Europe has evolved in many different ways. There appear to be two main streams of orientation towards training underlying the diversity. The first one is an apprenticeship model with a knowledge orientation. Assessment focuses on securing a certain level of knowledge in the trainee, often evaluated with a final exam. During curricular reforms, many countries have added other assessment modalities, including the exam for EDAIC and workplace based assessment. This evolution is exemplified by countries along the $\mathrm{A}-\mathrm{C}$ axis of the triangle in Figure 1 .

The second main stream is the procedural orientation within an apprenticeship model. Here, expertise of the trainee is evidenced by completing a logbook with required numbers of procedures. Just as in the first main stream, in more recent times, other assessment modalities have been adopted for use in conjunction with the achievement of specified numbers of anesthetics. Countries on the $B-C$ axis are examples of this approach. In the 2001 and 2008 UEMS/EBA Guidelines on training such a procedural orientation was advocated [3]. The 2008 Guidelines indicate a reorientation towards competencies, with the 2012 Guidelines promoting competency-based training in anesthesiology. In the past 15 years, competency-based medical education has been a major force influencing thinking on medical training and giving direction to curricular change $[9,11]$. Competency-based medical education intends a shift from the timebased apprenticeship model, with variable learning outcomes, to an outcome-based model that deemphasizes fixed durations of training but focuses on outcomes, i.e. learning objectives, to be met $[9,11]$. Interestingly, competency-based training programs in anesthesiology have fixed durations of training. Allowing variable time spent in rotations is an organizational challenge that has not been settled [12]. An outcomebased model offers transparency of what meaningful capabilities, competencies or roles are expected from graduates. These transparent outcomes may facilitate comparison of programs and harmonization of curricula $[3,9,11,13]$. Competency- and outcomebased training set in motion a concurrent shift of assessment methods from mainly knowledge focused to an additional orientation on skills, competencies and clinical performance. Assessing competence implies using a variety of tools such as workplace assessments (clinical evaluation exercise (mini-CEX), direct observation of procedural skills), case-based discussions, simulation etcetera [14, 15]. In our study, countries closer to the C-end of the triangle (Figure 1), with an adoption of or orientation towards 
competency-based training, tend to use a larger number of assessment tools. However, the survey only provides information on which tools are used, and not on how often they are used.

Certification is the "ultimate hurdle after many years of training" [3] to qualify for working unsupervised as a medical specialist. This study confirmed previous statements that no uniform certification process exists in Europe for anesthesiology training $[3,10]$. Although similar studies in other medical specialties are unknown to the authors, the literature indicates that other disciplines face comparable issues. Assessment is often mainly focused on knowledge and know-how and less on skills, competencies or roles [16-18]. In those specialties, uniform European certification processes do not exist and harmonization of assessment (e.g. a European exam) and training appears to be a difficult goal to achieve because of differences in practices and cultures [16-19]. Differences in health care systems, anesthetic team compositions and roles (such as the inclusion of intensive care or chronic pain therapy) call for diversity in learning objectives and their assessment. These factors may preclude full harmonization of requirements [1]. Nevertheless, the globalization of healthcare and free movement of EU doctors require agreement on minimal standards of competence [1,3]. Also, these standards could stimulate sharing best practices in assessment and certification processes [1].

All countries represented at UEMS/EBA participated, offering a complete overview of the current situation regarding assessment and certification. Information provided by the national representatives to UEMS/EBA is assumed to be accurate, as they are knowledgeable in current status and developments in postgraduate training in their countries. Further clarifying information was found in official documents provided by the participants or retrieved from national societies' websites, where available. No discordance between survey results and document information was encountered. Triangulation by comparing to another source supports the assumption of reliability of the data and credibility of the results [20]. Investigator triangulation, comparing the independent analyses of more than one investigator, enhances quality in qualitative research by improving credibility [20]. The diagrammatic representation process has inherent limitations, as there are no numerical data available to calculate a position in the diagram. We consider the positioning of a country primarily to be relative to other countries.

Although our study gives an overview of the design of assessment and certification practices it does not provide insight into its quality. Future research could zoom in on the certification decision, defining crucial elements in and robustness of the certification process. 


\section{CONCLUSION}

Assessment and certification practices in European postgraduate anesthesiology training are diverse. Most countries have an underlying tradition of knowledge focus or procedural focus within a time-based apprenticeship model of training. However, many countries are evolving, or have evolved, towards a competency-based approach to training. The move to competency-based training is accompanied by the use of a larger number of assessment tools to support an ultimate summative decision on trainees' competence. Establishing learning outcomes that can be assessed to guarantee a required level of competence of all European anesthesiologists demands ongoing effort. 


\section{REFERENCES}

1. Boulet J, van Zanten M. Ensuring high-quality patient care: the role of accreditation, licensure, specialty certification and revalidation in medicine. Med Educ 2014; 48:75-86.

2. Training Requirements for the Specialty of Anaesthesiology, Pain and Intensive Care Medicine. http://www.eba-uems.eu/resources/PDFS/Training/Anaesthesiology-TrainingRequirements-March-2013.pdf. [Accessed January 2017].

3. Van Gessel EF, Østergard HT, Niemi-Murola L. Harmonisation of anaesthesiology training in Europe. Best Pract Res Clin Anaesthesiol 2012; 26:55-67.

4. Van Gessel EF, Mellin-Olsen J, Østergard HT, Niemi-Murola, L. Postgraduate training in anaesthesiology, pain and intensive care: the new European competence-based guidelines. Eur J Anaesthesiol 2012; 29:165-8.

5. Van Gessel EF, Goldik Z, Mellin-Olsen J. Postgraduate training in anaesthesiology, resuscitation and intensive care: state-of-the-art for trainee evaluation and assessment in Europe. Eur J Anasethesiol 2010; 27:673-5.

6. World Medical Association Declaration of Helsinki - Ethical Principles for Medical Research Involving Human Subjects. http://www.wma.net/en/30publications/10policies/b3/. [Accessed January 2017].

7. Story DA, Gin V, na Ranong V, et al. Inconsistent survey reporting in anesthesia journals. Anesth Analg 2011; 113:591-5.

8. Hodges BD. A tea-steeping or i-Doc model for medical education? Acad Med 2010; 85:S3444.

9. lobst WF, Sherbino J, ten Cate O, et al. Competency-based medical education in postgraduate medical education. Med Teach 2010; 32:651-6.

10. Egger-Halbeis CB, Schubert A. Staffing the operating room suite: perspectives from Europe and North America on the role of different anesthesia personnel. Anesthesiol Clin 2008; 26:637-63.

11. Frank JR, Snell LS, ten Cate O, et al. Competency-based medical education: theory to practice. Med Teach 2010; 32:638-45.

12. Ebert TJ, Fox CA. Competency-based education in anesthesiology. Anesthesiology 2014; 120:24-31.

13. Harden RM. Outcome-based education - the ostrich, the peacock and the beaver. Med Teach 2007; 29:666-71.

14. Bould MD, Crabtree NA, Naik VN. Assessment of procedural skills in anaesthesia. Br J Anaesth 2009; 103:472-83.

15. Norcini JJ, Lipner RS, Grosso LJ. Assessment in the context of licensure and certification. Teach Learn Med 2013; 25:S62-7.

16. Gasco J, Barber SM, McCutcheon IE, Black PM. Neurosurgery certification in member societies of the WFNS: Europe. World Neurosurg 2010; 74:375-86.

17. Semple CG, Lindgren S. European examinations in internal medicine. Eur J Int Med 2010; 21:1. 
18. Struhal W, Sellner J, Lisnic V, et al. Neurology residency training in Europe - the current situation. Eur J Neurol 2011; 18:e35-e40.

19. Brittlebank $A$, Hermans $M$, Bhugra $D$, et al. Training in psychiatry throughout Europe. Eur Arch Psychiatry Clin Neurosci 2016; 266:155-64.

20. Miles M, Huberman A, Saldana J. Qualitative Data Analysis. 2014, Los Angeles, CA: Sage Publications. 



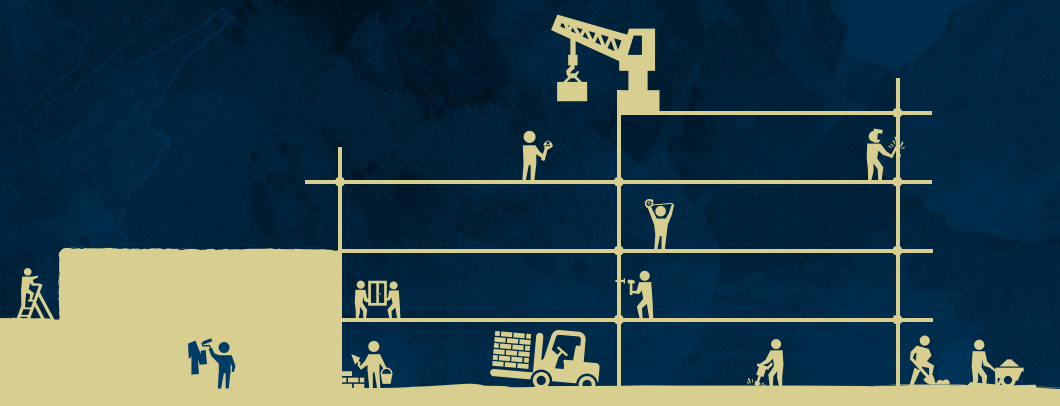




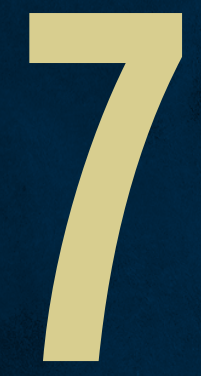

\section{WOULD YOU TRUST YOUR LOVED ONES TO THIS TRAINEE?}

\section{CERTIFCATION DECIIIONS IN POSTGRADUATE ANESTHESIA TRANNNG}

Published as:

Jonker G, Ochtman A, Marty AP, Kalkman CJ, ten Cate O, Hoff RG.

Would you trust your loved ones to this trainee? Certification decisions in postgraduate anaesthesia training.

Br J Anaesth. 2020; 125 (5): e408-e410. doi: 10.1016/j.bja.2020.07.009. 



\section{INTRODUCTION}

Postgraduate medical education culminates in the certification of trainees as medical specialists. Certification is a profession's self-regulation process to assure the public that specialists are qualified to deliver safe, high-quality care [1].

The high-stakes decision to certify a trainee entails the credentialing of training and its assessment [1]. We recently observed considerable variation in assessment procedures and certification in postgraduate anesthesia training across Europe [2]. With the aim to better understand the variation in certification processes and the basis of certification decisions, we performed an interview study and explored whether programs meet the requirement of public accountability to deliver competent specialists. Ahead of a full report, the focus of this letter is on the competence of trainee anesthetists at completion of training, framed as entrustment of care for patients close to the supervisor, summarized as "Would you trust your loved ones to each trainee you certify?".

\section{METHODS}

This qualitative study used constructivist Grounded theory principles and followed standards for reporting qualitative research $[3,4]$.

Following approval by the ethical review board of the Netherlands Association for Medical Education (NERB file 847, March 2017) and informed consent, we conducted semi-structured interviews with 26 senior anesthetists from 21 European countries. Each of the participants was directly involved in certification decisions, e.g. as program director. We purposively sampled participants to represent the different assessment and certification practices, identified previously [2], to ascertain divergent perspectives from a range of countries. Between June 2017 and December 2018, two anesthetists $(G J, A P M)$ and one trainee (AO), conducted the interviews. The initial interview guide reflected our research questions and the literature. A professional service transcribed the audio-recorded interviews. Two authors (GJ and AO) performed open coding individually and axial coding through several discussions. Subsequently, GJ and AO independently established respondents' position with regards to readiness of trainees to be entrusted with the care of loved ones at completion of training, and resolved any discrepancies through discussion. A web-based application (www.dedoose.com) facilitated collaborative analysis. In several iterations of data collection and constant comparative analysis we achieved saturation after 26 interviews. Findings from our prior study [2] helped to maintain reflexivity regarding our presuppositions. 


\section{RESULTS}

Questions on the theme "Would you trust your loved ones to each trainee you certify?" equally evoked affirmative, irresolute and negative responses (see Table 1 for quotes).

TABLE 1: Sample quotes of responses to questions on the theme "Would you trust your loved ones to each one of them?"

\begin{tabular}{|c|c|}
\hline Response & Quote (participant no.) \\
\hline \multirow[t]{3}{*}{ Affirmative } & I would absolutely have no qualms about them anesthetizing me or my children (12) \\
\hline & $\begin{array}{l}\text { The exams are particularly challenging. If somebody is not up to the job, they will not get through the } \\
\text { exams. I have got a lot of faith in the examination system. (13) }\end{array}$ \\
\hline & $\begin{array}{l}\text { He has been assessed for five years, so we can say: he's safe. [...] We can put our hands on our heart and } \\
\text { say he's ready, for sure. (16) }\end{array}$ \\
\hline \multirow[t]{3}{*}{ Irresolute } & I cannot guarantee you $100 \%$ that everyone who passes this final exam will be $100 \%$ in their practice. (18) \\
\hline & $\begin{array}{l}\text { Although we have run national courses for supervisors, it might be that we don't have the same idea of } \\
\text { the level needed. (11) }\end{array}$ \\
\hline & $\begin{array}{l}\text { I think in standard deviations. The certification cut-off is not the mean, but at }-2 \text { standard deviations. We } \\
\text { always try to bring you to the middle. (23) }\end{array}$ \\
\hline \multirow[t]{6}{*}{ Negative } & $\begin{array}{l}\text { There are some strict criteria. If they meet those they pass. Even if I would not like to have them treat me. } \\
\text { (7) }\end{array}$ \\
\hline & $\begin{array}{l}\text { We don't have a bedside evaluation. The examination is just theory. We don't evaluate formally the way of } \\
\text { thinking, the way of doing. (6) }\end{array}$ \\
\hline & $\begin{array}{l}\text { She's a problematic person. We know she'll be a very problematic anesthesiologist after the exam [...], but } \\
\text { the only criterion is knowledge. (22) }\end{array}$ \\
\hline & $\begin{array}{l}\text { I have no right to forbid a trainee to go to the board exam; pass the oral after five years, and then you're } \\
\text { certified. (8) }\end{array}$ \\
\hline & $\begin{array}{l}\text { The main weakness is the detection of problems with trainees; in other words, to ensure that they are } \\
\text { ready is very difficult (25) }\end{array}$ \\
\hline & My chief advises me to be lenient. Because if I am too strict, my institution will get less money. (5) \\
\hline
\end{tabular}

Participants who answered affirmatively labelled it the most vital issue in certification. They expressed confidence in their assessment processes to establish competence, relying on 'big hurdle' exams or longitudinal holistic assessment.

Some participants, however, were hesitant to answer this question affirmatively for all trainees and felt unsure whether some trainees met competence standards.

Ten interviewees admitted having certified trainees they did not deem competent enough to anesthetize their relatives. They blamed deficient evaluation criteria (e.g. assessment focusing solely on knowledge), ignoring important aspects such as clinical competence or professionalism. Other reasons included an inability to stop trainees from getting certified, poor methods to detect underperforming trainees, staff shortages, and the financial consequences to the department of failing a trainee. 


\section{DISCUSSION}

So, although decision-makers were satisfied with the competence level of most trainees they had certified, many indicated to have certified trainees they would not entrust with the unsupervised care of their loved ones.

Such "false positive" certification decisions - certified, but not truly competent - are an alarming finding and suggest flawed assessment systems that fail to consider all facets of competence. Failure to take aspects such as professionalism into account may jeopardize professional collaboration and patient safety [5].

A limitation of our qualitative research approach is that we are not able to quantify the incidence of such "false positive" certifications, nor can we pinpoint the problem to countries or curricular systems. Nevertheless, it is concerning that this experience appears to be common among anesthetists certifying trainees across Europe. Another limitation is that we have not specifically investigated individual or local tendencies to entrust residents at completion of training with care for loved ones. Furthermore, our interview study was in anesthesia only, but we suspect that this finding will resonate with colleagues responsible for certification in both surgical and non-surgical specialties. Finally, although we did apply researcher triangulation, we did not triangulate with data from other sources. A future study could build on our findings with data from surveys or focus groups.

To fulfil the profession's promise of societal accountability, the assessment and certification processes should be optimized, to ensure adequate competence of all trainees at the time of certification. All patients, including our own loved ones, deserve to justifiably trust every new medical specialists that our training programs deliver. 


\section{REFERENCES}

1. Boulet J, van Zanten M. Ensuring high-quality patient care: the role of accreditation, licensure, specialty certification and revalidation in medicine. Med Educ 2014; 48:75-86.

2. Jonker G, Manders LA, Marty AP, et al. Variations in assessment and certification in postgraduate anaesthesia training: a European survey. Br J Anaesth 2017; 119:1009-14.

3. Watling CJ, Lingard L. Grounded theory in medical education research. AMEE Guide No. 70. Med Teach 2012; 34:850-61.

4. O'Brien BC, Harris IB, Beckman TJ, Reed DA, Cook DA. Standards for reporting qualitative research: a synthesis of recommendations. Acad Med 2014; 89:1245-51.

5. Cooper WO, Spain DA, Guillamondegui O, et al. Association of coworker reports about unprofessional behavior by surgeons with surgical complications in their patients. JAMA Surg 2019; 154:828-34. 



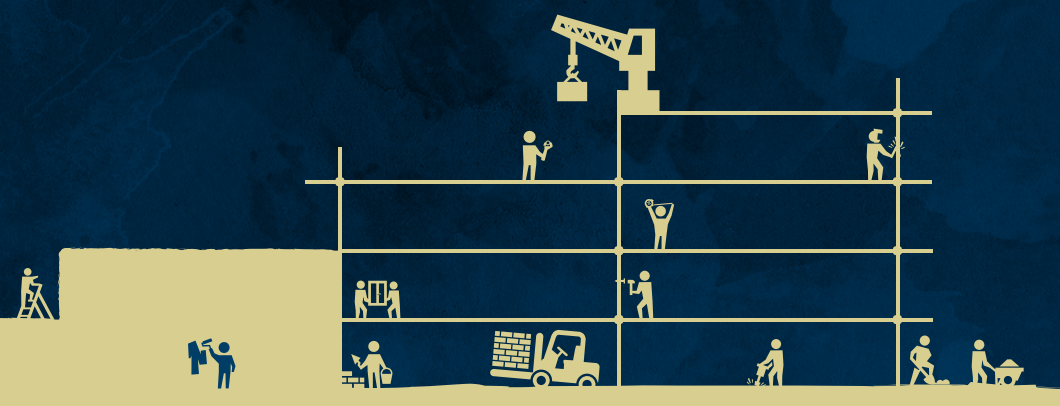




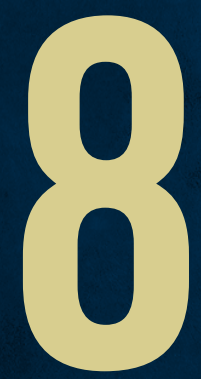

\section{A CASE FOR COMPETENCY-BASED ANESTHESIOLOGY TRAINING WITH ENTRUSTABLE PROFESSIONALACTIVITIES}

AN AGENDA FOR DEVELOPMENT AND RESEARCH

Published as:

Jonker G, Hoff RG, ten Cate O.

A case for competency-based anaesthesiology training with entrustable professional activities. An agenda for development and research.

Eur J Anaesthesiol. 2015;32(2):71-6. doi: 10.1097/EJA.0000000000000109. 


\begin{abstract}
Competency frameworks are based on what are considered to be the general essential qualities of a doctor. Competencies, being behavioral descriptors, need a strong link to clinical practice to allow trainers to observe and then use them in assessing trainees' performance. The emerging concept of entrustable professional activities (EPA) may serve as such a link. An EPA is a description of an essential clinical task that frames competencies in the context of clinical practice. A full set of EPA defines a specialty and constitutes the curriculum of specialty training. After observation of satisfactory performance on an EPA, the resident should be permitted to perform that activity without direct supervision. The terms of this should allow a trainer to provide justification for this decision. This makes graded assumption of responsibilities possible. We describe the potential benefits of working with EPA in anesthesiology training and set an agenda for curriculum development and research in this area.
\end{abstract}




\section{INTRODUCTION}

Every day, attending anesthesiologists delegate clinical tasks to residents. Most decisions to delegate are made informally and implicitly, often based on limited personal impressions of knowledge, skills, attitudes and trustworthiness of the trainee. Attending anesthesiologists should be able to justify these decisions. Such justification is of prime importance in the guarantee of quality of care, patient safety, supervisor's liability and educational appropriateness. Justification becomes even more important as society increasingly expects the medical profession to account for the quality of its members, including that of residents and graduates [1,2]. Demands are made on specialty-training programs to demonstrate that their graduates have mastered all desirable abilities, or competencies, at completion of training $[3,4]$. In addition, clear end-points in specialtytraining make benchmarking and comparison of training programs on a national or international level possible.

This is what competency-based education is aimed at [5]. However, competencies that set out the desirable traits of a doctor in general terms are difficult to observe and assess in day-to-day clinical practice [6-11], making proof of mastery of competencies and comparison of training programs difficult. In this article, we discuss competencybased training, its problems and move towards a potential solution: the emerging concept of entrustable professional activities (EPAs) [12]. We will describe how EPAs link competencies to clinical tasks and how EPAs allow justification of decisions to delegate by attention to observation of clinical performance. Lastly, we will set an agenda for curriculum development and research on this topic.

\section{COMPETENCY-BASED TRAINING}

For more than a decade, training in medical specialties has been based around competency frameworks, such as that of the Accreditation Council for Graduate Medical Education (ACGME) in the United States or the CanMEDS of the Royal College of Physicians and Surgeons of Canada [13]. These frameworks set out for several competency domains what are considered to be the critical abilities needed for professional practice [3]. With competency-based training, a shift from knowledge acquisition to knowledge application is intended [14], with attained competence rather than time-in-training being the key [15]. Competency-based training has its limitations. A potential pitfall is that the art of medicine is broken down into a detailed list of competencies taken out of context $[12,15-17]$. Often behavioral descriptors are formulated in universal terms that are not designed for a specific specialty [18]. Many clinical educators see current 
competency frameworks as theoretical and somewhat detached from day-to-day practice [6-9]. Competencies are difficult to assess as separate entities while supervising residents $[10,11]$. The true goal of training should not be to attain competencies, but rather to become a doctor with expertise, who is ready to bear professional responsibility and who can be entrusted with the care of patients $[1,12,16,18]$.

A possible way to link competencies to clinical activities is the concept of EPAs [19]. When the performance of daily clinical activities is evaluated well, it is possible to draw inferences about the attainment of predefined competencies $[12,18]$.

\section{ENTRUSTABLE PROFESSIONAL ACTIVITIES}

An EPA is a task or responsibility, essential to the practice of a specialty. It can be executed individually by a trained professional within a circumscriptive time frame and it requires specific knowledge, skills and attitudes. Each EPA encompasses competencies from different domains and can be observed and assessed by a supervisor. Supervisors can entrust a resident with an EPA, once an adequate level of performance has been obtained, to execute a task without direct supervision [18-21]. EPAs remove competencies from a theoretical framework by attaching them to the familiar context of clinical practice $[16,22]$. They clarify the learning objectives of a program or rotation by displaying the training opportunities that exist in daily work, and offering guidance to assessors on what they should assess [19-21, 23, 24].

Examples of EPAs in anesthesiology are general anesthesia in an American Society of Anesthesiologists (ASA) I to II day surgery patient, handover of a patient to the recovery room, epidural analgesia for labor, admitting a critically ill patient to an ICU, anesthesia for a common procedure in an ASA I to II infant, and trauma life support (Appendix 1). One could think of approximately 5 to 10 EPAs per year of training, with the complete set of EPAs covering the breadth and depth of the specialty.

A practical procedure such as inserting a central venous line, would not, on its own, be considered an EPA, but would be incorporated as an item (skill) in several EPAs across several subspecialties, that in this case might include intensive care, cardiac anesthesia and neuro-anesthesia. The same holds true for clinical knowledge, wherein for example, use of inotropes might feature as an item in several EPAs from different subspecialties, but would not stand alone as an EPA. Also, competencies such as participating in an interprofessional healthcare team may be observed in many EPAs such as trauma life support, but would not constitute an independent EPA. 
Competency domains and EPAs can be seen as two dimensions of a grid, the competencies-activities matrix (Table 1) [18, 20]. By observing performance of an EPA, one implicitly observes several domains of competence [20]. Typically, for each EPA, multiple domains of competence are explicitly relevant, whereas other domains of competence weigh more heavily for other EPAs. If a resident is unable to perform an EPA, deficits in competencies that underpin this activity can be found and used for feedback and further learning [16, 21, 22].

TABLE 1: The competencies-activities matrix

\begin{tabular}{|c|c|c|c|c|c|c|c|}
\hline & \multicolumn{7}{|c|}{ CanMEDS roles of competence } \\
\hline & $\begin{array}{c}\text { Medical } \\
\text { Expert }\end{array}$ & Communicator & Collaborator & Manager & $\begin{array}{c}\text { Health } \\
\text { Advocate }\end{array}$ & Scholar & Professional \\
\hline $\begin{array}{l}\text { Entrustable } \\
\text { Professional } \\
\text { Activity } 1\end{array}$ & $\bullet$ & $\bullet$ & & & $\bullet$ & & \\
\hline $\begin{array}{l}\text { Entrustable } \\
\text { Professional } \\
\text { Activity } 2\end{array}$ & $\bullet$ & $\bullet$ & $\bullet$ & & & $\bullet$ & \\
\hline $\begin{array}{l}\text { Entrustable } \\
\text { Professional } \\
\text { Activity } 3\end{array}$ & $\bullet$ & & & $\bullet$ & $\bullet$ & & \\
\hline $\begin{array}{l}\text { Entrustable } \\
\text { Professional } \\
\text { Activity } 4\end{array}$ & $\bullet$ & $\bullet$ & $\bullet$ & & & & $\bullet$ \\
\hline $\begin{array}{l}\text { Entrustable } \\
\text { Professional } \\
\text { Activity } 5\end{array}$ & & $\bullet$ & & $\bullet$ & & $\bullet$ & • \\
\hline
\end{tabular}

There may be both intra-individual and inter-individual differences in learning curves for EPAs, and residents may vary in the sequence in which they master them (Figure 1) [20]. In a developmental trajectory, junior residents will master simple EPAs whilst only more advanced trainees will master complex EPAs.

EPAs clarify the level of proficiency by indicating the resident's responsibilities and the necessary level of supervision. For any EPA, five levels of proficiency can be distinguished, which translate into the levels of supervision to be provided (Table 2) [18, 20, 25, 26]. This level of proficiency should be recorded in the resident's portfolio. 
A

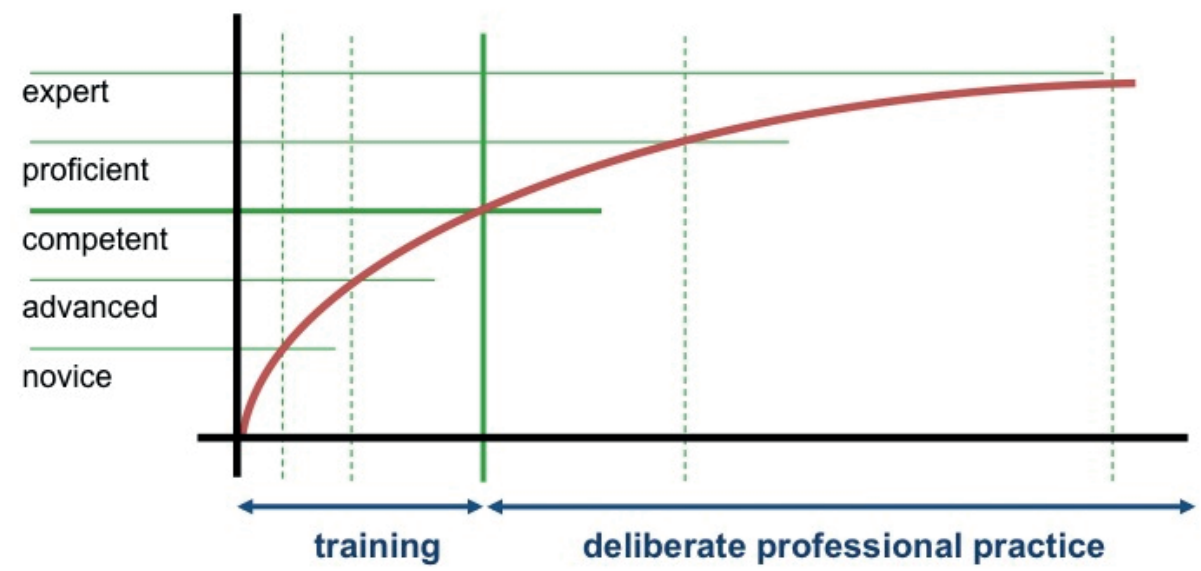

B

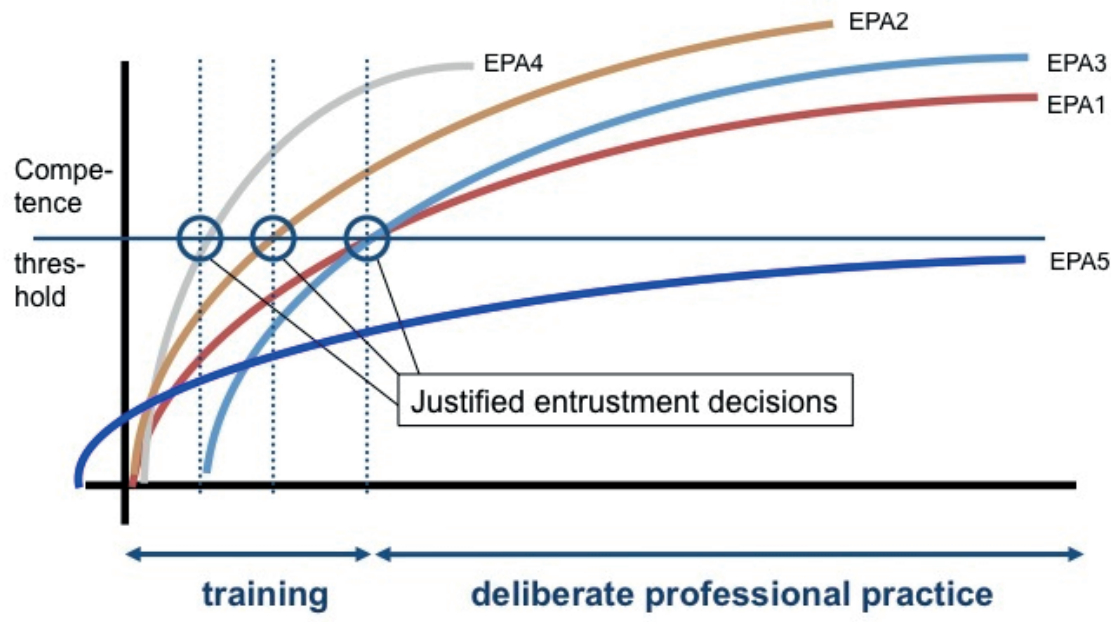

FIGURE 1: Acquisition of competence.

(a) Acquisition of competence, showing the competence threshold (corresponding to proficiency level IV) and continuing growth of expertise after delegation of a clinical activity.

(b) Acquisition of competence for 5 different EPAs. At reaching the competence threshold, an informed and justified delegation decision can be made.

Adapted with permission from [20]. 
TABLE 2: Levels of proficiency for an EPA $[20,25,26]$

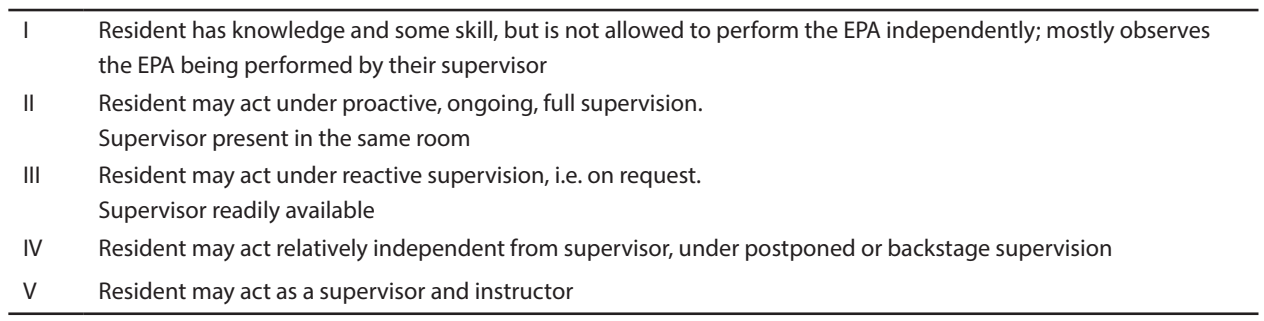

At reaching level IV, a formal decision is to be made to delegate an EPA to a resident to carry out without close supervision $[18,20]$. This decision to delegate should be made after assessment of the performance of that particular EPA, and based on several assessments by a number of assessors. It should be recorded in the resident's portfolio. Decisions to delegate may be designated as STARs (Statement of Awarded Responsibility) [18] or digital badges [27]. This method is in sharp contrast to the traditional situation, which is characterized by implicit, informal and uninformed delegation.

Although a resident may be viewed as competent after reaching level IV, the proficiency of this trainee is likely to further increase with added experience (Figure 1) [20]. After the removal of close supervision, the resident should still be able to ask for help and assistance from someone more experienced if necessary, just as permanent staff might do.

Premature, unsupervised care provided by residents adversely influences patient safety, healthcare costs and liability of supervisors [28]. Conversely, an overprotective approach until the completion of training means that junior attending specialists will not have learned to bear critical clinical responsibilities. With the use of EPA, deliberate decisions to delegate based on many assessments by multiple assessors can be made for specific tasks. This makes graded assumption of responsibility during residency training possible[16] and enhances learning [19, 24, 28].

For a training program, a vision of a developmental timeline of levels of supervision is possible (Table 3). The timeline indicates which level of proficiency (Table 2) a resident would be expected to have at specified stages in training. In addition, it would show the expected timing of decisions to dispense with close supervision. 
TABLE 3: Expected level of supervision by training stage

\begin{tabular}{lcccccc}
\hline & & \multicolumn{4}{c}{ Expected level of supervision } \\
\cline { 3 - 7 } & & $\begin{array}{c}\text { Training } \\
\text { year 1 }\end{array}$ & $\begin{array}{c}\text { Training } \\
\text { year 2 }\end{array}$ & $\begin{array}{c}\text { Training } \\
\text { year 3 }\end{array}$ & $\begin{array}{c}\text { Training } \\
\text { year 4 }\end{array}$ & $\begin{array}{c}\text { Post-training sub- } \\
\text { specialization }\end{array}$ \\
\hline Professional & EPA1 & III & IV & V & V & V \\
activities & EPA2 & III & IV & IV & IV & V \\
& EPA3 & II & III & IV & V & V \\
& EPA4 & II & III & IV & V & V \\
\hline
\end{tabular}

\section{FUTURE STEPS IN ANESTHESIOLOGY TRAINING: AN AGENDA FOR DEVELOPMENT AND RESEARCH}

Training programs based on EPAs are being explored and developed, across the world and across specialties, such as in psychiatry in New Zealand and Australia [21, 29], internal medicine [30], family medicine [31], and pediatrics in the USA, orthopedic surgery in Canada, obstetrics and gynecology [32], and physician assistant training [33] in the Netherlands. Anesthesiology training programs throughout the world are organized in an outcome and competency-based way [34-36] but, to our knowledge, to date, none have been based on EPAs. To build a training program with EPAs, consensus should be sought locally, nationally or even internationally on which essential clinical tasks define the specialty $[12,21,26,30]$.

For each EPA, the task content and context should be set out. Each EPA should be mapped to the relevant competencies in a competencies-activities matrix (Table 1) [12]. These competencies must be set out in an observable behavior format to make them implicitly assessable by observing the EPA.

How to best assess complex tasks robustly and accurately remains the central question [23]. Currently, there is no single tool for assessing performance of EPAs; what is needed is the development of assessment systems that incorporate both quantitative and qualitative tools $[1,37,38]$. Different EPAs may use different sets of tools, such as high and low fidelity simulation, Objective Structured Assessment of Technical Skills (OSATS), Direct Observation of Procedural Skills (DOPS), Mini Clinical Evaluation Exercise (MiniCEX) [38-40] and Multisource feedback procedures. These or other instruments should cover the competencies that have been identified as crucial for the particular EPA being assessed. The role of different tools within an EPA assessment system needs to be established and tested in practice for validity, reliability, generalizability and educational 
outcome [40]. Moreover, standards of good performance have to be defined [37], and judges should be trained and 'calibrated' with examples of performance levels for an EPA $[1,23]$.

Progress in mastery of EPAs together with reports, records and comments can be kept in a digital portfolio and used to assist formal decisions to delegate. Learning analytics technology can be used to inform learners about their progress and to establish benchmarks for justified delegation. Learning analytics may provide insight into training performance at the institutional or (inter-) national level, and can make comparison of institutions possible.

Finally, apart from knowledge and skill, factors affecting trustworthiness of a resident need further investigation [18, 28]. Trustworthiness is difficult to quantify, but incorporates understanding of one's limitations, conscientiousness and truthfulness [16, 41]. Although resident proficiency might be the central issue, trustworthiness remains a significant factor in delegation, but its exact role needs to be elucidated.

A research and development agenda (Table 4) should therefore include the identification and sharing of essential EPAs for anesthesiology training, the identification or construction of instruments to allow for justification of delegation and the adaptation of training programs, gearing them to qualify anesthesiologists with established high levels of competence.

Directly linked to the development of an EPA-based training program are the challenges that come with the implementation of any new training system. There may be resistance at the introductory level before residents and supervisors accept the proposed changes [42]. Organizational challenges might include dealing with allowing a variable time spent in training and problems with subsequent enrolment planning in subspecialty training posts [42]. Residents' acceptance depends on clear expectations of the program and explicit learning objectives.

Also, program directors need to have a well-defined view on stimulating and rewarding advancement in training [42]. It is essential that supervisors are convinced of the advantages of the new system and are well instructed in its use [42]. 


\section{CONCLUSION}

The concept of EPAs attaches competencies to clinical practice in anesthesiology. It appears to be a promising approach to demonstrating that the graduating resident has obtained the abilities that the profession, regulatory bodies and society expect. The EPA approach centers on observation of performance of essential professional tasks in different contexts from which the attainment of competencies can be inferred. EPAs may be a good way to make progress in meeting learning objectives transparent. They may also make possible justified, formal and informed delegation of clinical tasks to trainees. The mark of quality of training is demonstrable expertise in performance. A program for research and development is necessary to elicit the effects of the use of EPAs in anesthesiology training. The goal is to link quality of training with the ultimate outcome of training: quality of patient care.

TABLE 4: Development and research

\begin{tabular}{ll}
\hline Development & Research \\
\hline Determine consensus set of EPAs & $\begin{array}{l}\text { Compare local, national and international consensus sets of EPAs in } \\
\text { anesthesiology } \\
\text { Does set of EPAs comprise everything to be assessed in residents? }\end{array}$ \\
$\begin{array}{l}\text { Describe all EPAs } \\
\text { Map to competencies and Milestones } \\
\text { Create sets of assessment tools }\end{array}$ & $\begin{array}{l}\text { Test (sets of) assessment tools for validity, fairness, reliability } \\
\text { Establish role of simulation in skill and performance assessment } \\
\text { Define performance standards }\end{array}$ \\
$\begin{array}{l}\text { Train raters in use of assessment tools } \\
\text { Calibrate raters with examples of performance } \\
\text { standards }\end{array}$ & $\begin{array}{l}\text { Evaluate effect of rater training and calibration } \\
\text { Develop portfolio } \\
\text { Use learning analytics to benchmark trainees and } \\
\text { institutions }\end{array}$ \\
$\begin{array}{l}\text { Use learning analytics to monitor effects of working with EPAs } \\
\text { (duration of training, satisfaction) }\end{array}$ \\
\hline
\end{tabular}




\section{REFERENCES}

1. Holmboe ES, Sherbino J, Long DM, Swing SR, Frank JR. The role of assessment in competencybased medical education. Med Teach 2010; 32:676-82.

2. Nasca TJ, Philibert I, Brigham T, Flynn TC. The Next GME Accreditation System - rationale and benefits. N Engl J Med 2012; 366:1051-6.

3. lobst WF, Sherbino J, ten Cate O, et al. Competency-based medical education in postgraduate medical education. Med Teach 2010; 32:651-6.

4. Schartel SA, Metro DG. Evaluation: measuring performance, ensuring competence, achieving long-term excellence. Anesthesiology 2010; 112:519-20.

5. Frank JR, Snell LS, ten Cate O, et al. Competency-based medical education: theory to practice. Med Teach 2010; 32:638-45.

6. Grant J. The incapacitating effects of competence: a critique. Adv Health Sci Educ Theory Pract 1999; 4:271-7.

7. Talbot M. Monkey see, monkey do: a critique of the competency model in graduate medical education. Med Educ 2004; 38:587-92.

8. Norman GR. Outcomes, objectives and the seductive appeal of simple solutions. Adv Health Sci Educ Theory Pract 2006; 11:217-20.

9. Brightwell A, Grant J. Competency-based training: who benefits? Postgrad Med J 2013; 89:107-10.

10. Lurie SJ, Mooney CJ, Lyness JM. Measurement of the general competencies of the accreditation council for graduate medical education: a systematic review. Acad Med 2009; 84:301-9.

11. Lurie SJ, Mooney CJ, Lyness JM. Pitfalls in assessment of competency-based educational objectives. Acad Med 2011; 86:412-4.

12. Ten Cate O. Trust, competence, and the supervisor's role in postgraduate training. BMJ 2006; 333: 748-51.

13. Frank JR. The CanMEDS 2005 physician competency framework: better standards, better physicians, better care. 2005, Ottawa: Royal College of Physicians and Surgeons in Canada.

14. Carraccio C, Wolfsthal SD, Englander R, Ferentz K, Martin C. Shifting paradigms: from Flexner to competencies. Acad Med 2002; 77:361-7.

15. Frank JR, Mungroo R, Ahmad Y, et al. Toward a definition of competency-based education in medicine: a systematic review of published definitions. Med Teach 2010; 32:631-7.

16. Jones MD, Rosenberg A, Gilhooly JT, Carraccio CL. Perspective: competencies, outcomes, and controversy - linking professional activities to competencies to improve resident education and practice. Acad Med 2011; 86:161-5.

17. Pangaro $L$, ten Cate O. Frameworks for learner assessment in medicine: AMEE Guide no. 78. Med Teach 2013; 35:e1-14.

18. Ten Cate O, Scheele F. Competency-based postgraduate training: can we bridge the gap between theory and clinical practice? Acad Med 2007; 82:542-7. 
19. Ten Cate O. Entrustability of professional activities and competency-based training. Med Educ 2005; 39:1176-7.

20. Ten Cate O, Snell L, Carraccio C. Medical competence: the interplay between individual ability and the health care environment. Med Teach 2010; 32:669-75.

21. Boyce P, Spratt C, Davies M, McEvoy P. Using entrustable professional activities to guide curriculum development in psychiatry training. BMC Medical Education 2011; 11:96.

22. Carraccio $C$, Burke AE. Beyond competencies and milestones: adding meaning through context. J Grad Med Educ 2010; 2:419-22.

23. Hicks PJ, Englander R, Schumacher DJ, et al. Pediatrics milestone project: next steps toward meaningful outcomes assessment. J Grad Med Educ 2010; 2:577-84.

24. Babbott $\mathrm{S}$. Watching closely at a distance: key tensions in supervising resident physicians. Acad Med 2010; 85:1399-1400.

25. Ten Cate O. Nuts and bolts of entrustable professional activities. J Grad Med Educ 2013; 5:1578.

26. Chang A, Bowen JL, Buranosky RA, et al. Transforming primary care training - patientcentered medical home entrustable professional activities for internal medicine residents. $J$ Gen Int Med 2013; 28:801-9.

27. Mehta NB, Hull AL, Young JB, Stoller JK. Just imagine: new paradigms for medical education. Acad Med 2013; 88:1-6.

28. Sterkenburg A, Barach P, Kalkman C, Gielen M, ten Cate O. When do supervising physicians decide to entrust residents with unsupervised tasks? Acad Med 2010; 85:1408-17.

29. Royal Australia \& New Zealand College of Psychiatrists. EPA Handbook. http://www.ranzcp. org/Files/ranzcp-attachments/PreFellowship/2012-Fellowship-Program/EPA-handbook. aspx [accessed 25 March 2014]

30. Hauer KE, Kohlwes J, Cornett P, Hollander H, Ranji S. Identifying entrustable professional activities in internal medicine training. $J$ Grad Med Educ 2013; 5:54-9.

31. Shaughnessy AF, Sparks J, Cohen-Osher M, et al. Entrustable professional activities in family medicine. J Grad Med Educ 2013; 5:112-8.

32. Scheele F, Teunissen $P$, van Luijk $S$, et al. Introducing competency-based postgraduate medical education in the Netherlands. Med Teach 2008; 30:248-53.

33. Mulder $\mathrm{H}$, ten Cate $\mathrm{O}$, Daalder R, Berkvens J. Building a competency-based workplace curriculum around entrustable professional activities: the case of physician assistant training. Med Teach 2010; 32:e453-9.

34. Ringsted C, Østergaard D, Van der Vleuten CPM. Implementation of a formal in-training assessment programme in anaesthesiology and preliminary results of acceptability. Acta Anaesthesiol Scand 2003; 47:1 196-1203.

35. Van Gessel E, Mellin-Olsen J, Østergard HT, et al. Postgraduate training in anaesthesiology, pain and intensive care: the new European competence-based guidelines. Eur J Anaesthesiol 2012; 29:165-8. 
36. The Accreditation Council for Graduate Medical Education, The American Board of Anesthesiology. The Anesthesiology Milestone Project. http://www.acgme.org/acgmeweb/ Portals/0/PDFs/Milestones/AnesthesiologyMilestones.pdf [accessed 25 March 2014]

37. Govaerts MJB, van der Vleuten CPM, Schuwirth LWT, Muijtjens AMM. Broadening perspectives on clinical performance assessment: rethinking the nature of in-training assessment. Adv Health Sci Ed Theory Pract 2007; 12:239-60.

38. Swing SR, Clyman SG, Holmboe ES, Williams RG. Advancing resident assessment in graduate medical education. J Grad Med Educ 2009; 1:278-86.

39. Norcini J, Burch V. Workplace-based assessment as an educational tool. AMEE Guide No 31. Med Teach 2007; 29:855-71.

40. Kogan JR, Holmboe ES, Hauer KE. Tools for direct observation and assessment of clinical skills of medical trainees: a systematic review. JAMA 2009; 302:1316-26.

41. Kennedy TJT, Regehr G, Baker R, Lingard L. Point-of-care assessment of medical trainee competence for independent clinical work. Acad Med 2008; 83:589-92.

42. Ebert TJ, Fox CA. Competency-based education in anesthesiology. Anesthesiology 2014; 120:24-31. 


\section{APPENDIX 1. AN EXAMPLE OF AN EPA IN ANESTHESIOLOGY}

TABLE 1. Trauma life support EPA

\begin{tabular}{|c|c|}
\hline Title EPA & Resuscitation of the multiple trauma patient in the Emergency Room \\
\hline $\begin{array}{l}\text { Detailed description } \\
\text { (including limitation of the EPA to } \\
\text { specific patient groups and/or context) } \\
\text { Which specific knowledge, skills and } \\
\text { attitudes are necessary to perform the } \\
\text { EPA at an adequate level? }\end{array}$ & $\begin{array}{l}\text { Resuscitation of trauma patients, of all age groups, in the Emergency Room. } \\
\text { Active participation in the trauma team. Assessment and control of vital organ } \\
\text { systems. Pain management in trauma patients. } \\
\text { 1. Trauma mechanisms \& pathophysiology } \\
\text { 2. Organization of trauma care } \\
\text { 3. Collaboration in the trauma team } \\
\text { 4. Trauma diagnoses \& treatment } \\
\text { 5. Primary \& secondary survey } \\
\text { 6. Trauma airway management } \\
\text { 7. Emergency IV \& IO access } \\
\text { 8. Emergency thoracostomy } \\
\text { 9. Hemorrhage / massive transfusion } \\
\text { 10. } \quad \text { Emergency Room registration procedures }\end{array}$ \\
\hline $\begin{array}{l}\text { Which CanMEDs competency } \\
\text { domains are mostly addressed in this } \\
\text { EPA? }\end{array}$ & $\begin{array}{l}\varnothing \text { Medical expert } \\
\varnothing \text { Communicator } \\
\varnothing \text { Collaborator } \\
\text { O Manager } \\
\text { O Scholar } \\
\text { O Health advocate } \\
\varnothing \text { Professional }\end{array}$ \\
\hline $\begin{array}{l}\text { How can progression of the resident in } \\
\text { this EPA be assessed? }\end{array}$ & $\begin{array}{l}\text { 1. Trauma Mini-CEX } \\
\text { 2. OSATS on trauma airway management } \\
\text { 3. OSATS on emergency IV \& IO access } \\
\text { 4. OSATS on emergency thoracostomy } \\
\text { 5. Multi-source feedback } \\
\text { 6. Trauma case-based discussions } \\
\text { 7. Participation in trauma Simulator Sessions }\end{array}$ \\
\hline $\begin{array}{l}\text { Which criteria must be met by the } \\
\text { resident to fulfil the EPA satisfactory } \\
\text { with proficiency level IV } \\
\text { (resident may act with postponed or } \\
\text { backstage supervision) }\end{array}$ & $\begin{array}{l}\text { 1. Completion of two-month rotation Anesthesia in the Emergency Room } \\
\text { 2. ATLS certification } \\
\text { 3. APLS certification } \\
\text { 4. Positive result (pass) on (at least) five trauma Mini-CEX, on different days, by } \\
\text { different assessors in different contexts } \\
\text { 5. Positive result (pass) on (at least) two case-based discussions on trauma, on } \\
\text { different days, by different assessors in different contexts } \\
\text { 6. Positive result (pass) on OSATS on trauma airway management, emergency } \\
\text { IV \& IO access and emergency thoracostomy } \\
\text { 7. Positive result (pass) on two trauma Simulator Sessions, in different contexts } \\
\text { 8. Positive result (pass) on the judgment of the EPA by (at least) } 3 \text { different } \\
\text { assessors }\end{array}$ \\
\hline
\end{tabular}

IV = Intra Venous, IO = Intra Osseous, Mini-CEX = Mini Clinical Evaluation Exercise, OSATS = Objective Structured Assessment of Technical Skills, ATLS = Advanced Trauma Life Support ${ }^{\oplus}$, APLS = Advanced Pediatric Life Support ${ }^{\circledR}$ 
An Entrustable Professional Activity (EPA)

- is an identifiable part of clinical work in the local context,

- requires a specific level of knowledge, skills and attitude,

- is part of regular work of the medical specialty,

- reflects one or more items from the CanMeds competency framework

- can be performed separately from other tasks,

- can be executed within a limited timeframe,

- can be observed and assessed. 


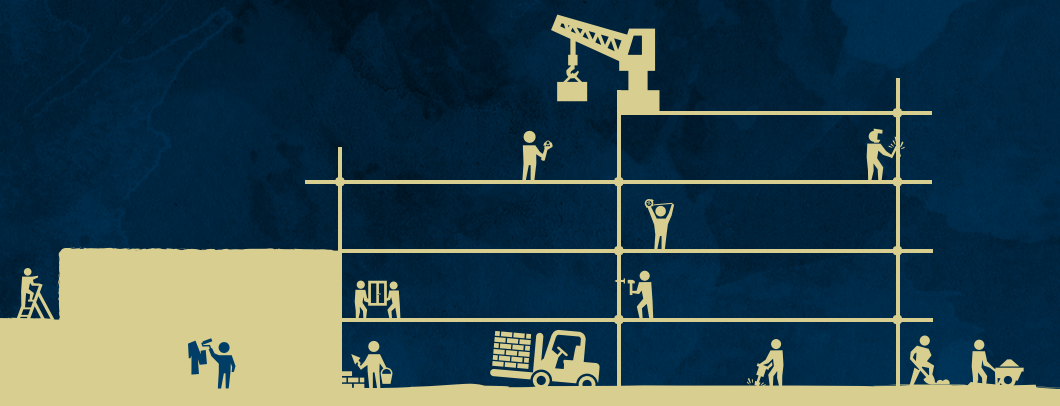




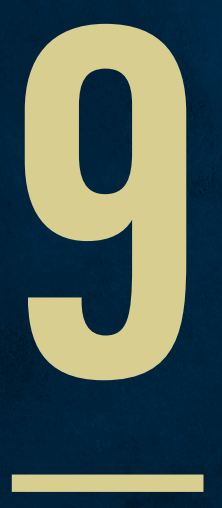

\section{GENERAL DISCUSSION}



Medical education consists of a series of associated but detached stages [1]. The stages contribute to a collective ultimate goal: the training of doctors able to provide safe, effective patient-centered care [2]. However, the stages are usually not aligned to create a collective effort to reach this ultimate goal. Each stage concentrates on interim goals and falls short of optimally preparing learners for the subsequent stage. Therefore, the educational trajectory to medical specialist is riddled with transitions that learners experience as difficult. If learners arrive well-prepared, the transitions are no threat or problem, but rather an opportunity that may catalyze development [3].

If the various stages are well aligned and form a coherent whole, they could shape a developmental pathway across a seamless continuum from medical student to medical specialist $[4,5]$. It could strengthen the relation between basic sciences and clinical medicine, between medical education and patient care, and concomitantly improve the training of doctors [4].

Competency-based medical education (CBME) is well-suited to build an education continuum with its ultimate goal of providing society with professionals who have met predefined outcomes to be able to deliver safe and effective care [1, 2, 6-10]. CBME can be powerfully linked to clinical practice with entrustable professional activities [11, 12]. Entrustable professional activities (EPAs) are essential tasks of a discipline that can be entrusted to an individual to perform without direct supervision once competence has been demonstrated [11-13]. A set of EPAs describes the scope of practice of a discipline and therefore also describes the outcomes a learner within that discipline should attain [11]. A learner gradually develops to become a medical specialist by attaining the EPAs that cover her specialty.

We set out to study the facilitation of competence development by forging a continuum by use of CBME and EPAs and phrased our research questions in Chapter 1 as:

- Does an elective final year focused on acute care have a beneficial effect on the development of competence and preparedness for the next stage, i.e. working as a doctor in an acute care specialty?

- If the innovation has effect, can its effect be understood by looking at learning theory, like Communities of practice, and motivational theory, such as Selfdetermination theory? And if the innovation does not sort effects, do these theories require adaptation?

- What is the psychosocial and educational effect on students of simulation pretesting beyond the competence level of graduates? 
- What is the structure, or are the structures, of European postgraduate anesthesiology training and to what degree have training programs transitioned to CBME and to EPAs?

- What is the foundation or justification of the ultimate entrustment decision of certification granted to trainees at completion of training in anesthesiology in Europe?

- How can CBME, operationalized with EPAs, be applied to postgraduate anesthesiology training, and what research is required to assist competency-based anesthesiology training with EPAs?

\section{MAJOR FINDINGS}

The thesis describes an elective final year of medical school focused on the domain of acute care (Chapter 2). This track has a beneficial effect on competence development and preparedness for work in acute care, as its graduates score higher on performance tests and resemble junior doctors better than other graduates (Chapter 5 ).

Students' sense of belonging to a learning community and their agency are important determinants of the relative success of the innovation, although an incomplete implementation confronts students with little affordances in the workplace (Chapter 3). In addition, a simulation pre-test beyond the competence level of graduates instills their motivation for learning (Chapter 4).

The thesis then turns to current postgraduate anesthesiology training, finding substantial variation in European approaches to assessment and certification (Chapter 6). The certification systems do not always offer a solid foundation for the decision to certify, which leads to the certification of trainees who are not fully competent (Chapter 7). EPAs may offer a solution, but further research is needed (Chapter 8).

\section{THE BENEFICIAL EFFECT OF A FINAL YEAR DEVOTED TO ACUTE CARE ON COMPETENCE AND PREPAREDNESS}

At UMC Utrecht, students choose clinical rotations and a research block to compile an individual program for the final year of medical school. This year is called a transitional year, which means that students are being prepared to work as a doctor by bearing increasing responsibilities in patient care under appropriate supervision [14]. Chapter 
2 discusses an optional variant of the individual transitional year: an elective track with a multidisciplinary approach to the theme of acute care, that we came to call the Acute Care Transitional Year (ACTY). The ACTY aims to enhance competence development and prepare learners for work as a doctor, and postgraduate training, in the domain of acute care.

Chapter 5 shows that graduating ACTY students did better on performance test modalities, i.e. skills and simulations, than non-ACTY students, but junior doctors did better on simulations than ACTY students. In addition, ACTY students had higher odds than non-ACTY students of meeting postgraduate acute care expectations, expressed as global rating scores in the multimodal assessment (Chapter 5). Taken together, the ACTY meets its aims as its graduates resemble doctors with clinical experience better than other graduates, suggesting better preparedness for work in acute care jobs.

There is a paucity of literature on interventions comparable to the ACTY track. One study described a postgraduate longitudinal simulation course to prepare junior trainees for calls to acutely deteriorated inpatients, which was valued highly by participants and used summative simulation assessment to establish that outcomes were met [15]. Instead, there is a body of literature on preparatory bootcamp courses, operated by over half of the US medical schools to ease the transition to postgraduate work [16], including a meta-analysis finding increased short-term post-course knowledge and skill levels, and self-reported confidence [17].

\section{COHERENCE, MOTIVATION, AND EXPERIENTIAL LEARNING EXPLAIN THE ACTY'S BENEFICIAL EFFECT}

The beneficial effect of the ACTY can be explained referring to learning theory and motivational theory. The ACTY supported competence development through coherence, augmentation of motivation, and a degree of experiential learning in subinternships.

First, coherence stimulated focused learning. Coherence was created by clearly articulated learning objectives that covered tasks that junior doctors in acute care will face, multimodal pre-testing of those objectives, and a learning community with teaching sessions (Chapters 2 and 3). The multidisciplinary approach to the theme of acute care horizontally integrated learning [4] while students did rotations in various clinical specialties to develop competence [5]. 
Second, the ACTY augmented motivation. The interaction with congenial peers in a learning community, personal formative feedback on the pre-test, and mentor support boosted motivation (Chapters 3 and 4). The three basic psychological needs to be satisfied for intrinsic motivation, according to Self-determination theory [18], further explained in Chapter 3, are the needs for relatedness, competence, and autonomy. The supportive learning environment seems to satisfy the need for relatedness, and partly the needs for competence and autonomy, stimulating students' motivation and natural tendency to develop (Chapter 3). The importance of a supportive learning environment was underlined by the way accommodating factors relieved stress in the postgraduatelevel simulation pre-test of performance in managing critically-ill patients, bending it into a motivating educational experience (Chapter 4). From the perceived merit of debriefing and the identification of personal assets and deficits, as expressed in the interviews, we infer a learning goal-orientation in the participants, meaning that they are inclined to learn from mistakes at the edge of their capability [19-21]. As elaborated in chapter 4, this echoes Vygotsky's theory of the zone of proximal development, which states that growth toward the next level requires teacher support [22, 23]. Leaving the comfort zone and engaging in guided completion of a task generates constructive friction between teaching and learning $[24,25]$. Psychological safety is indispensable to make students "embrace being uncomfortable" in simulations [26, 27]. With the accommodating prerequisites, challenging simulations at the far edge of the zone of proximal development are safe and motivate students to develop their competence (Chapter 4). This major finding diverges from current recommendations to tailor simulation tasks difficulty closer to a learner's level of development [28].

The third way the ACTY supported competence development was constituted by three subinternships with acute care learning objectives. Graduates generally rate subinternships as highly valuable [29], improving their perceived preparedness to perform tasks of a doctor, although reports on readiness to deal with emergencies are conflicting [30-32]. UK students reported having had only one to two hands-on acute care experiences in their final year student-assistantships (subinternships) [33, 34]. Although the studies in this thesis do not detail actual numbers of participations in acute situations, ACTY students and graduates experienced limited active opportunity for competence development in acute clinical care (Chapter 3). They encountered insufficient adoption into a community of practice at workplaces with limited affordances for participation [35, 36].

An explanation for limited hands-on acute care experience lies in the imperfect implementation of the ACTY. Not only the departments involved in the design, but many departments in various hospitals hosted ACTY students, often simultaneously 
with non-ACTY students in the same rotations. This led to heterogeneity in local understanding of the ACTY track, variation in workplace uptake, and disparity in supervisor commitment (Chapter 3 ). As a result, ACTY rotation content did not differ from the normal rotation, despite the intended emphasis on acute care learning. In addition, the ACTY's EPA-based approach preceded the local introduction of EPAs in undergraduate and postgraduate education. Faculty involved in supervising students were insufficiently instructed and prepared to deliver the ACTY. Faculty development is critical for the successful implementation of innovative clinical teaching and requires planning, preparation, and enduring commitment [37-41].

The imperfect implementation may have curtailed the ACTY's potential for student competence development. An improved implementation should focus on increasing ACTY student participation in acute care in welcoming communities of practice with extended affordances. Combined with the high learner agency (Chapter 3), the needs for competence and autonomy could be satisfied and, consequently, competence development could be enhanced. A strengthened implementation could amplify the ACTY's beneficial effect on the competence level of graduates.

\section{DEVELOPING A CONTINUUM FRAMEWORK OF ACUTE CARE EPAS}

The ACTY has learning objectives, framed as three interdisciplinary EPAs, to guide acute care competence development to make graduates meet the workplace expectations of the junior doctor workforce (Box 1).

BOX 1: The three EPAs of the ACTY with a summary description *

1. Recognition and initial treatment of patients with vital instability

Includes: Evaluating patient with the $A B C D$ approach; Measuring and interpreting vital signs; Arriving at a clinical evaluation; Initiating Basic Life Support (including bag-mask-ventilation and airway maneuvers and starting intravenous fluid therapy).

\section{Evaluation and initial management of patients with respiratory insufficiency}

Includes: Rapid evaluation with the ABCD approach; Performing a focused history of a patient with respiratory insufficiency in an Emergency Room, Coronary Care Unit, ward or urgent outpatient clinic; Performing a physical exam (including $A B C D$ and vital signs); Ordering and interpreting basic diagnostic tests (blood, chest X-ray, ECG); Drafting a differential diagnosis; Start initial management and treatment plans.

3. Evaluation and initial management of patients with circulatory insufficiency

[This includes the same components as for patients with respiratory insufficiency]

*The fully elaborated descriptions are provided in Chapter 2. 
Undergraduate EPAs may be categorized as core, specialty-specific, and elective EPAs [42]. Core EPAs are activities to be entrusted to all graduates on postgraduate day one in any junior doctor job, such as 'Gather a history and perform a physical examination' $[43,44]$. Specialty-specific undergraduate EPAs are tasks to be entrusted on day one of postgraduate jobs in a certain specialty, could feature as outcomes for final year electives, and thus pertain to a subset of learners. Elective undergraduate EPAs are optional, advanced EPAs at postgraduate training level [42]. The interdisciplinary ACTY EPAs (Box 1) fall in the latter category. In the Netherlands, these acute care tasks are regularly delegated to junior doctors in the participating specialties without deliberate entrustment decision and this led the designers of the ACTY to designate them learning objectives of the track. However, the ACTY EPAs did not build on a core undergraduate EPA, were incorrectly gauged as specialty-specific EPAs, and did not connect to postgraduate EPAs (Figure 1).

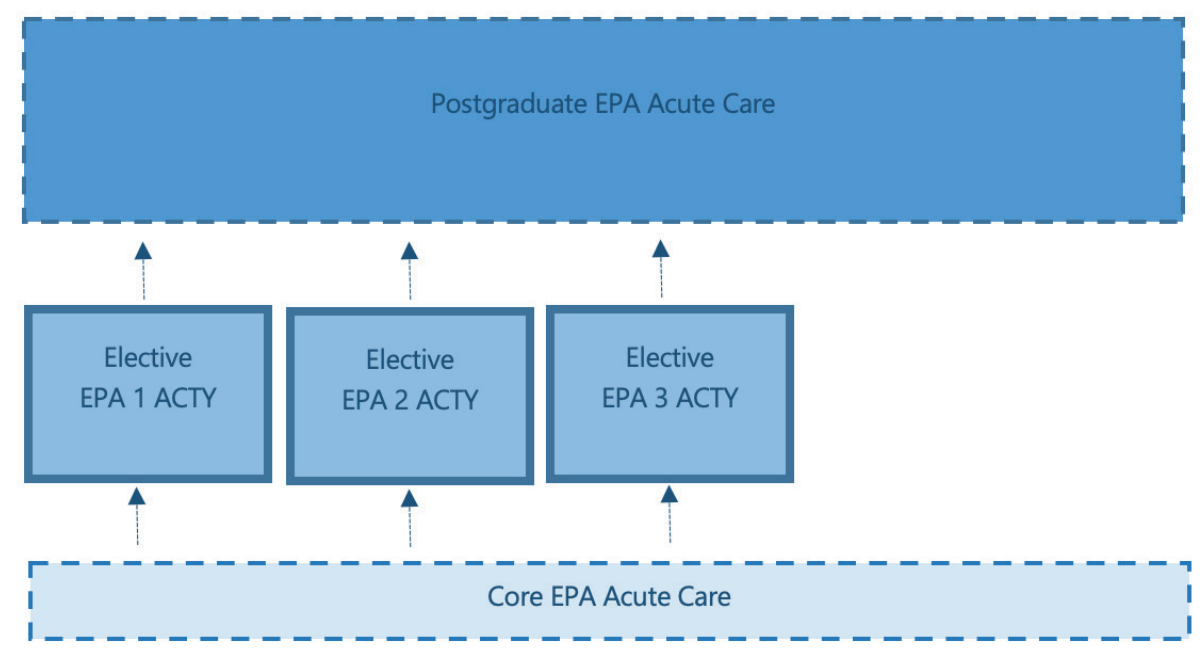

FIGURE 1: Lack of relationship between core, ACTY, and postgraduate acute care EPAs. ACTYEPAs 1-3 are the EPAs'Recognition and initial treatment of patients with vital instability', 'Evaluation and initial management of patients with respiratory insufficiency', and 'Evaluation and initial management of patients with circulatory insufficiency', as described in Table 1. At the time, they were neither supported by a core undergraduate EPA (lower light blue box), nor were they connected to postgraduate EPAs (upper dark blue box) as they did not yet exist.

In retrospect, the ACTY EPAs could have been designed at specialty-specific undergraduate EPA levels, describing smaller tasks that are entrusted on day one of a job in the domain of ACTY specialties. Specialty-specific EPAs are meant to improve preparedness and to inform specialty advice [42]. The "domain-specific" interdisciplinary 
undergraduate EPAs could prepare ACTY students for work in a range of specialties and could integrate into a larger acute care elective EPA. Elective EPAs help the student to identify capabilities and learning needs [45], motivate to work on those learning needs (Chapter 3), and aid to determine preparedness to transition into a specific postgraduate direction [46].

This would result in a relation between acute care EPAs as shown in Figure 2, fostering a continuum in competence development. The acute care undergraduate core EPA would be 'Being first responder to patients with acute deterioration and mobilizing capable help', akin to the acute care EPA in the core undergraduate set developed in Berlin [47] and somewhat broader than 'Providing basic life support', an Utrecht core undergraduate EPA regarding acute care [48]. Domain-specific interdisciplinary undergraduate EPAs, the redesigned ACTY objectives, would build on the core EPA by extending responsibilities to initiating diagnostic tests and first steps in management, e.g. 'Being first responder, initiating diagnostic tests and first steps in management for patients with respiratory compromise'. One or more specialty-specific EPAs could flank the domain-specific EPAs to optimally prepare for the elective EPA. An example could be 'Being first responder, initiating diagnostic tests and first steps in management for patients with altered consciousness', which would also be a final year EPA for different students, aspiring postgraduate training in neurology or neurosurgery. The core EPA and the domain-specific and specialty-specific extensions could nest up into larger postgraduate advanced life support EPAs, e.g. 'Manage a high-acuity patient with a welldefined presentation, illness, or injury' from emergency medicine [49] or 'Resuscitation and admission of the adult patient in need of intensive care' from anesthesiology [50].

A hierarchy of core, specialty-specific, domain-specific, and elective undergraduate EPAs, as depicted in Figure 2, better maps acute care competence development to prepare for work in this domain. The stepwise increase in difficulty resonates with the zone of proximal development in that learners can carry out tasks just beyond the current level that cause constructive friction necessary for competence development [22-25]. Supposedly, the stepwise model will increase hands-on experiences under appropriate guidance as it better fits with workplace affordances [36]. It will facilitate meaningful participation in the work of the community of practice [35], and improve the preparatory effect of the ACTY. 


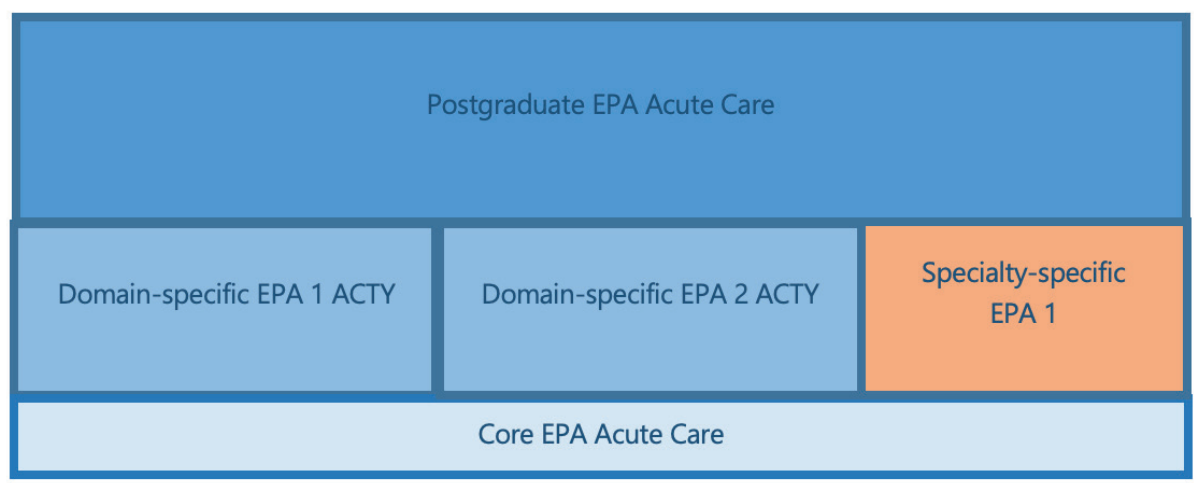

FIGURE 2: Hierarchical relation of undergraduate and postgraduate acute care EPAs. At the base is core EPA 'Being first responder to patients with acute deterioration and mobilizing capable help'. For students preparing for work in acute care this EPA is extended with (middle, blue) domain-specific EPA 1 and 2 'Being first responder, initiating diagnostic tests and first steps in management for patients with respiratory compromise' and 'Being first responder, initiating diagnostic tests and first steps in management for patients with circulatory compromise'. Together with a related specialty-specific EPA 'Being first responder, initiating diagnostic tests and first steps in management for patients with altered consciousness' (middle, amber), the domain-specific EPAs integrate into, but are not necessary equal to, elective EPAs (i.e. postgraduate EPAs) such as 'Manage a high-acuity patient with a well-defined presentation, illness, or injury' [49] or 'Resuscitation and admission of the adult patient in need of intensive care' [50] (top). These postgraduate EPAs need further postgraduate expertise.

A hierarchy of EPAs could be the unifying framework that leads to far-reaching vertical integration and shaping of a continuum [42]. The appropriate degree of supervision, i.e. the degree of independence granted, could be tailored to the development of the student with a granular entrustment-supervision scale [51-54]. However, the implementation of assessment leading to entrustment decisions in undergraduate medical education is work in progress and is challenging $[55,56]$. Emergency physicians suggest to resort to simulation-assessment for the evaluation of acute care EPAs, alluding to the lack of opportunities and concern for patient safety in the workplace, as well as the benefit of standardization and realistic portrayal of (classic) presentations [57]. The tension that exists between quality of care and student learning is omnipresent in medical education, but very salient in acute care and supervisors must negotiate this tension in ad hoc and summative entrustment decisions [58]. From a community of practice perspective, it requires commitment of supervising faculty to reconcile experiential learning and patient safety [59]. 


\section{A THEMATIC TRANSITIONAL YEAR TRANSFORMS STUDENTS INTO DOCTORS}

The ACTY embodies a track that balances breadth and depth by graduating broadlytrained physicians with a profile of competence in acute care. This profile represents useful preparatory competence for a variety of specialties without cutting off opportunities in other specialties by being overly focused. The ACTY attracted $7 \%$ of the annual cohort (Chapter 2) and offered a moderate form of pre-specialization. Prespecialization has the supposed benefits of shortening the developmental trajectory, augmenting learning curves, and make students stand out from the crowd of graduates [60].

A limitation is that the ACTY is a single medical school initiative pertaining to one domain of medicine. The ACTY principles of thematic coherence with horizontal integration and interdisciplinary learning objectives, and a supportive motivating environment could be easily transferred to tracks aiming to optimize preparedness of a subset of learners for a selection of specialties in a particular domain of medicine, facilitating the "remarkable transformation of students to doctors" [61].

\section{POSTGRADUATE ANESTHESIOLOGY TRAINING IS INTERNATIONALLY FAR FROM UNIFORM}

Just as in other medical specialties, CBME has been making an advance in postgraduate anesthesiology training. In 2003 Ringsted and colleagues described a changeover to competency-based training in anesthesiology in Denmark, including a shift to workplace assessment of competencies and tasks $[62,63]$. Since then, and especially in the last decade, many publications have addressed CBME in anesthesiology (e.g. [64-66]). A recent systematic review of the literature on CBME in anesthesiology [67] noticed that the evidence on achieving outcomes was limited to improved procedural skills, rather than overall competence. However, the improved procedural performance resulted in improved patient outcomes and cost-effectiveness [68]. The review concluded that the existing research provides a base to address the many identified gaps in knowledge about CBME in anesthesiology [67].

The studies in the second part of the thesis add to this base. Chapter 6 provides a complete overview of current anesthesiology training programs in Europe with respect to assessment and certification processes. Chapter 6 shows that there is no uniform approach to assessment and certification and the adoption of CBME is far from 
complete. Time-and-rotation based apprenticeship models were ubiquitous and had an underlying traditional focus on either acquisition and assessment of knowledge or required numbers of exposures (Chapter 6). However, some countries adopted CBME totally or adopted elements, such as assessment tools. Outside of Europe, variation between countries in training duration and assessment exists as well [69]. Countries like the USA, Japan, and Brazil have a focus on required numbers of exposures [69], similar to a substantial number of European countries (Chapter 6), while Canada has a longstanding orientation on CBME.

The actual implementation of CBME in Europe lags behind with the Union of European Medical Specialists / European Board of Anesthesiology training guidelines (Chapter 6). The guidelines had a procedural orientation in 2001, started adopting CBME principles in 2008, embraced CBME in 2012, and committed to CBME wholeheartedly in 2020 [7073]. The latest guidelines warn against minor adaptations of existing traditional timebased structures [73], which seems to have been occurring in several countries (Chapter 6). The guidelines do acknowledge that heterogeneity in programs is inevitable because of differences in rate of change, laws and regulations, scope of practice, and available resources [73].

CBME can create more conformity among training programs across countries with comparable healthcare needs [67]. Harmonization of training outcomes facilitates the transferability of medical specialists between countries [67]. In the European Union, member states are obliged by law to recognize equivalent qualifications across. However, because of the importance to serve local demands [74] and differences in local clinical practices there will be no universal European training program [73]. Nevertheless, as noted in Chapter 6, a degree of harmonization with clear outcomes of training makes programs and graduates more readily comparable [73]. Chapter 6 also notes that the CBME frameworks provide the language that facilitates comparability and helps in safeguarding a minimal level of training of all European anesthesiologists [73].

Learning from shared best practices is a way to foster harmonization and to implement modern approaches to training. Whereas Chapter 6 provides an overview of current assessment and certification practice, the goal of the grounded theory study, of which Chapter 7 describes initial results, is to evaluate the quality of these practices and identify crucial elements of a robust assessment and certification system. Full analysis is to result in increased understanding of the certification process and in a model for assessment and certification, grounded in the data, on which to build further research on the implementation of improvements. 
Current assessment and certification practices fail to include all facets of competence and fail to prevent underperforming trainees to get certified (Chapter 7). The systems do not always satisfactorily justify the certification decision. This means that also trainees, whom anesthesiologists directly involved in certification decisions would not entrust with the unsupervised care of their loved ones, are getting certified. This minority of newly certified specialists can be seen as "false positives" of the system: certified but not fully competent (Chapter 7). There are no reports of the prevalence of false-positives, but it is estimated that up to $10 \%$ of trainees have "questionable competence" at certification [75]. A study among newly licensed veterinarians, graduating from vet medical school into practice, found that many graduates did not feel fully competent to independently perform commonly occurring professional activities at day one of practice [76]. The prevalence ranged from $26 \%$ for 'obtaining a diagnostic blood sample and interpret the results' to $98 \%$ for 'performing minor surgical procedures'. Apparently, veterinary education did not prepare sufficiently, or did not intend to prepare, for unsupervised practice of these activities. The authors argued that a curriculum with EPAs might have better exposed the gap between education and practice requirements, and they also emphasized that learning continues after graduation [76].

The certification decision is the ultimate entrustment decision in postgraduate training: to entrust the trainee with the adequate and independent performance of the specialty. Failure of the assessment and certification system to take all aspects of competence into account is a major issue (Chapter 7). Ignoring inadequate professionalism competencies leads to specialists who collaborate inadequately and have higher complications rates, endangering patient safety [77]. In a postgraduate training program with early adoption of EPAs, portfolio entries showed an inappropriate emphasis on technical aspects of medical care and amount of exposure, neglecting competency domains such as collaboration and communication [78, 79]. Educators in anesthesiology identified five areas where trainees who have not achieved minimum competence level at certification are lacking, indicating the importance of assessing these areas [80, 81]. The areas are: synthesis of information into a clear anesthetic plan, adaptation of an anesthetic plan to changing conditions, effective interpersonal skills and communication with patients and staff, identification of opportunities to improve performance, and discernment of own limits [80]. The development of an assessment and certification system that minimizes the risk of certifying trainees who are not yet competent (false-positives) is of great importance for the quality and safety of healthcare. This development starts with the completion of data analysis from the study leading to Chapter 7. 


\section{EPAS IN POSTGRADUATE ANESTHESIOLOGY TRAINING}

This thesis includes the first paper that directly links EPAs to the context of anesthesiology (Chapter 8). It charted an agenda for curriculum development and research, identifying research opportunities like obtaining consensus on sets of EPAs, comparing (inter-) national programs, validating assessment tools, establishing the role of simulation assessment, identification of markers of professional development, application of performance standards, the use of learning analytics in monitoring effects of EPAs on training, and the process of entrustment decisions.

A set of EPAs should cover the breadth of the specialty and determine the outcomes required of a postgraduate trainee graduating as a medical specialist [11, 12, 52, 82]. Therefore, reaching a consensus on a set of EPAs that covers the anesthetic specialty was high on the agenda. In anesthesiology, an EPA-based program was first mentioned in two Canadian papers $[66,83]$ and Wisman and colleagues were the first to publish a set of EPAs based on a consensus at a national level [50]. In a modified Delphi study Dutch program directors arrived at a consensus on 45 EPAs. From this set, the EPAs of the national training program were derived, which are in use since 2019.

In one canton of Switzerland, junior trainees, senior trainees, and supervising anesthesiologists agreed on 7 EPAs to be entrusted in the first year of postgraduate training [84]. The seven EPAs are attainable because of their reasonably small scope pertaining to the steps in perioperative care of relatively healthy patients for low-risk surgery $[84,85]$. The Dutch program, in accord with the Delphi consensus set [50], chose to nest the seven tasks within one larger EPA.

A single center Delphi process in Germany resulted in a consensus set of 39 EPAs to cover the local anesthesiology curriculum [86]. The set agreed strongly with the Dutch set, but included fewer EPAs for pain and intensive care medicine. Of interest, risks of surgical procedures, risks due to patient co-morbidity, and age-related risks in children featured in both sets to differentiate levels of complexity in similar activities, requiring distinct entrustment decisions. This led, however, to higher granularity of the German EPA set with for example several EPAs around abdominal procedures, which can be considered observable index cases within a single EPA of the Dutch set. Index cases are archetypical for an EPA, represent layers of complexity within an EPA, and may be of key importance in entrustment of the EPA.

A major difference was the inclusion of subspecialty EPAs, e.g. "providing anesthetic care for patients undergoing heart transplantation", in the German set [86], which were voted 
out in the Dutch Delphi since they were not relevant for all trainees graduating from the program [50]. Until now, there are no studies comparing EPA-based anesthesiology programs internationally. Certainly, many EPAs would look similar globally, but how cultural context and local healthcare needs affect EPA design, granularity, sequencing, and assessment is an area for future research.

A systematic review of the 2011-2018 literature on EPAs in postgraduate training showed that $76 \%$ of papers reported on EPA development, while $20 \%$ addressed implementation and/or assessment of EPAs, and 4\% reported both [87]. Implementation of CBME with or without EPAs is challenging $[88,89]$, and within anesthesiology training no studies reported on the implementation or assessment of EPAs. Thus, returning to the agenda in Chapter 8, there is a research gap regarding implementation and assessment.

\section{FUTURE RESEARCH}

This thesis offers multiple starting points for further research. A selection of possible studies is suggested below.

\section{Thematic transitional year}

The role of undergraduate EPAs in preparing for postgraduate work needs further elucidation, including the role of workplace assessments and entrustment decisions [56]. In 2016, UMC Utrecht medical school started implementing core undergraduate EPAs $[48,90]$. Consequently, supervisors are familiarizing with the concept of EPAs and this makes foregrounding of EPAs in the ACTY feasible. A strengthened implementation of the ACTY in the workplace warrants a replication of the assessment study (Chapter 5) to detect further enhancement of competence development. In addition, a realist evaluation study could elucidate by which mechanisms and in which circumstances the intervention generates its outcome [91, 92]. Furthermore, similar effects from other thematic transitional years could triangulate our findings and support the idea of specialty streaming [93-96].

The 'intercurricular' period between undergraduate and postgraduate education, in which recent graduates work as a physician-not-in-training, has importance for professional identity formation and career orientation [97]. Currently, a follow-up study of ACTY graduates is conducted to illuminate their specialty choices and career paths toward the attainment of postgraduate training posts, as enhanced preparedness and competence in the ACTY could shorten the 'intercurricular' period. Additional research could concentrate on how supervisors and the clinical environment support learning in 
this period to optimize the development of physicians-not-in-training. The effect of the use of EPAs in this period on individualization of content and duration of time-variable postgraduate specialty training is of interest.

\section{Postgraduate training}

Future studies could look at the prevalence of false-positives with the certification of trainees, illuminate what aspects of competence are lacking, and what is needed to timely diagnose and remediate deficiencies. The grounded theory study, of which Chapter 7 reported preliminary results, offers a starting point.

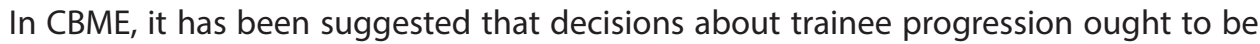
team decisions $[7,98]$. There is a growing body of literature on how clinical competence committees collate information from multiple sources and make such judgments [99101]. Promotion to a next training phase, e.g. the transition to senior trainee, poses a decision that involves portfolio data and team deliberations. Low-stakes assessments add up to a complete, valid, and reliable holistic picture of trainee competence that allows high-stakes summative decisions [102-108]. Of interest, clinical performance data not obtained via workplace assessments [109] also find ways into decisions on trainees [110]; a controversial topic that needs illumination. Summative judgments require not only solid assessment data but also a standard or criterion for performance that defines the entrustment decision [108] and takes potential risks of incompetent task performance into account [82]. How a standard is determined and a decision comes about requires further attention of researchers. Comparing certification, as the ultimate entrustment decision, with in-training entrustment decisions sheds light on the decision-making processes and may inform the design of certification processes.

While a trainee is making progress in attaining competence in a set of EPAs, she should transform into a medical specialist. This calls for attention to markers of professional development. Recently, Ten Cate \& Chen identified the entrustment-enabling factors agency, reliability, integrity, capability, and humility [111]. These factors are presumably difficult to assess in single observations, but demand longstanding relationships between trainee and supervisor. How these factors can be taken aboard in end-ofrotation evaluations, promotion decisions, and entrustment decisions is an area of further investigation.

Currently, formative workplace assessments rarely pinpoint performance gaps and seldom provide an action plan for improvement [112], whereas this would provide guidance to navigate the zone of proximal development. Further research could study the effect of an EPA-program on quality and quantity of feedback. A portfolio 
equipped with learning analytic technology helps individual learners to get meaningful information on their performance and progress [113], but can also be used to compare workplace assessments before and after the introduction of an EPA curriculum [114]. This strain of research provides insight in the role of the learning environment and supervision in instruction and sequencing of activities, which may be used to optimize the efficiency of CBME. Programmatic assessment relies on frequent, subjective, lowstakes expert observations in the clinical workplace with quantitative and qualitative measures on all aspects of competence [7, 102-104, 106, 107, 115-117]. However, there is a tension between single workplace assessment's formative purpose and summative feeling to trainees [118-120]. This tension may influence feedback and assessment seeking behavior as well as effect of formative assessments, and requires further attention.

The psychometric tradition in assessment, emphasizing numeric data and reliability of measurements, has been dominant in anesthesiology [80,81, 121-124]. Such quantitative assessments often focus on one procedural skill, whereas qualitative assessments are valued in holistic workplace performance evaluation [114]. The context-dependence of competence, the dynamics of clinical practice, the subjectivity of supervisors' judgments, and the failure to capture all aspects of performance in numbers are at odds with the strong tradition to objectively assess learners $[98,125,126]$. Recent studies in anesthesiology aim to reconcile both worlds [127-131]. For example, adding an entrustment-supervision scale increased the reliability of workplace assessments [128], as asking supervisors a prospective judgment on the supervision level is aligned with the provision and delegation of care [132]. Workplace assessment tools have different purposes and different reliabilities; a clever combination of tools needs to be sought that assesses all important facets of competence and adds up to a reliable summative judgment [130]. Additional research must establish the role of simulation-training and simulation-based assessment $[67,123]$ in preparing for and sequencing of clinical tasks. Research in this area should explore the relation between simulation and workplace learning and assessment.

Much research aims at how to achieve the competence level that permits unsupervised practice. Less is known about how expertise continues to develop after entrustment and the role of remote or delayed supervision (and assessment) of activities entrusted to trainees. Entrustment decisions do not only confirm a level of competence, but also the right to act with a decreased level of supervision [133]. Whether this leads to privileging of trainees to act with less supervision in practice remains to be determined. 
Since 2019 the Dutch national curriculum for anesthesiology training is EPA-based. A curriculum evaluation might contain a replication of the Delphi study [50], to confirm or adapt the set of EPAs now in use. Such work could include the evaluation of the quality of the EPAs $[82,114,134,135]$.

Comparing local implementations of the national curriculum may reveal differences in interpretation, sequencing, and assessment practices. Portfolio learning analytics can assist the comparison of programs for benchmarking and allows review of assessment data from entire programs. An easy example for the use of learning analytics is provided by the evaluation of the impact of the Covid-19 pandemic on workplace assessment and feedback of anesthesiology trainees [136]. Database analysis revealed that trainees requested 1 to 2 fewer assessments per month, with a shift from perioperative to acute care EPAs, but completion rates were unchanged. In addition, both direct observations and case-based discussions were employed and quality remained stable with timely rich feedback [136].

Comparing EPA-based anesthesiology curricula internationally may reveal influences of context, culture, and regulations on EPA descriptions and sequencing. Furthermore, a formal comparison with EPA-based training curricula in other specialties may provide insights in the issue of granularity of EPAs and size of sets in serving as attainable goals during training.

\section{FUTURE DIRECTIONS: BUILDING AN EDUCATION CONTINUUM}

Presently, the training of doctors consists of a series of independent silos "haphazardly pieced together" $[1,5]$. In the future, a seamless continuum of aligned CBME stages, with EPAs as a unifying framework, can be envisioned [1, 2, 5, 42, 61, 73, 137, 138], that leads to improved healthcare quality and safety by ensuring that graduates of undergraduate and postgraduate education meet the delineated standards of competence.

A continuum can be built adhering to the five key components of CBME implementation: clearly articulated competencies for practice as outcome, sequenced progression in a path of expertise development, tailored learning experiences to facilitate the developmental acquisition of competence, competency-focused instruction to promote the acquisition of competence, and programmatic assessment to support and document development [139]. 


\section{Clearly articulated competencies for practice as outcome}

Core EPAs in undergraduate education cover the outcomes that all learners need in the early postgraduate stage. Specialty-specific EPAs add what learners need in specific fields of medicine. Demonstrable competence in these EPAs are taken into account in the individualization and shortening of postgraduate training time [140].

Postgraduate EPAs describe the demands of specialists at certification. Predefined outcomes as a central aim of CBME does not imply that graduates are all the same. All trainees need to achieve competence in the core set of EPAs of the program. In addition trainees can develop and demonstrate competence for elective EPAs belonging to an area of interest such as a subspecialty [138], for example in fellowship training.

EPAs need to be explicitly defined and designed according to guidelines [82] and be based on adequate consensus to allow widespread application and implementation.

\section{Sequenced progression on a path of expertise development}

Core EPAs in undergraduate education are expanded with specialty-specific EPAs that fit with the specialty orientation of the learner. Rather than specialty-specific, these EPAs may well be domain-specific, serving as preparation for work in a range of related specialties. Gaining domain-specific competence can be perceived as a fork in the path of development.

Longitudinal clerkships, because of continuity in supervision and patient care, optimize the use of EPAs and forming of trust [4, 141-143]. A coherent thematic transitional year must provide longitudinal learning objectives, rotations, and supervision.

The undergraduate EPAs are foundational building blocks of larger postgraduate EPAs, which means that a learner expands her accumulated expertise with growth in patient care responsibilities. Learners develop at individual rates in different EPAs. The variable training time model will replace the current model of fixed duration [108, 144146]. Issues around workforce planning, professional identity formation, regulatory minimum time requirements, and the traditional emphasis on numbers of exposures need to be addressed. For example, with the focus on outcomes, assured by proper assessment, flexible timing of graduation from undergraduate education is possible - and is occasionally an urgent requirement, such as during the Covid-19 pandemic [147]. Adding to the variation in time are the increased flexibility required by part-time working trainees, individualized training opportunities, and differences in experience prior to commencing postgraduate training. Nonetheless, time is a factor in the growing of trust and entrustment of tasks which are central to assessment around EPAs [142, 
144]. This requires sustained relationships with supervisors, in undergraduate education and postgraduate training, in more longitudinal horizontally integrated attachments. Entrustment leads to a change in trainee responsibilities, i.e. in the right to act [133].

The continuum of competence development persists after certification at completion of postgraduate training. Generally, the largest part of a doctor's career is after certification as a medical specialist. Competence is not permanent, it may decay with disuse and grow further with continued usage [148, 149]. Longer-term competence requires continuing deliberate practice, an attitude of self-regulated lifelong learning, including reflexivity $[138,148,150]$. Recertification as a specialist based on continuing professional development can be competency-based if activities and their appraisal are authentic [73, 150], and may well be linked to EPAs. Multisource feedback [151], peer observation [152], and simulations [153-156] can have a role in recertification. Similar activities can be used for re-entry into the field or into a subspecialty.

\section{Tailored learning experiences to facilitate development}

Instead of specialty-oriented rotations, clinical learning experiences are sequenced primarily from an educational perspective to facilitate development. Learnercenteredness applied to the active participation in provision of patient care increases opportunities for meaningful learning experiences [157]. It eases transitions and exploits the transformative potential of experiential learning $[3,45,157,158]$ to boost the development of competence and professional identity formation [159]. With the restricted working hours, no trainee time can be wasted on inappropriate tasks, but all effort goes into tailored experiences to efficiently navigate the zone of proximal development.

\section{Competency-focused instruction}

Faculty development is critical in successfully implementing CBME programs [37-40]. It includes teaching faculty how to teach, how to assess [107], but also how to coach and support trainee development, reflective practice, and wellbeing.

Workplace learning across the continuum is supported by formative assessment and constructive feedback. Supervisors and learners are ready to exploit the learning benefit of each day in clinical work. The choice of activities may alter the balance between training and service provision. Workplace instruction can occur in high-intensity settings with a team of interprofessional learners and supervisors. Workplace instruction also includes debriefing of situations, ad hoc bedside teaching, and case-based discussions. 
Outside the clinical workplace, learning is supported by teaching and simulation training. Intensive simulation training for complex procedural skills according to mastery learning principles, with structured assessments, detailed feedback and repeated exercise is an effective and patient-safe way to build initial expertise [27], prior to patient exposure and the accumulation of experience to reach proficiency. Simulation training and assessment is also used in undergraduate [15] and postgraduate stages of training to practice and evaluate the management of rare but critical situations and crisis resource management competencies, e.g. communicating around clinical deterioration of patients [160].

\section{Programmatic assessment}

The observation and evaluation of performance with a diversity of tools in a developmental model of assessment is at the heart of a program of assessment in CBME. To foster continuity and increase applicability of faculty development, the same or highly similar assessment tools are to be used across the continuum [5]. Longstanding relationships are helpful in establishing mutual trust; both in the trainee to carry out tasks with an appropriate level of supervision, as in the supervisor as an acceptable source of feedback.

Programmatic assessment requires quantitative and qualitative data from multiple assessors with multiple complementary tools at multiple time points and wants all individual assessments to be low-stakes and supportive of learning. In addition to live observation in direct supervision situations, video-recorded cases can be retrospectively reviewed when indirect supervision is applied. Furthermore, a case-based discussion, i.e. chart-based recall, with the application of what-if questions, assesses readiness for unfamiliar situations and anticipation of risks and complications, making it an entrustment-based discussion [161]. A user-friendly electronic portfolio with learning analytic features makes development visible and supports decisions to withdraw supervision. After the group entrustment or promotion decision, trainees continue to receive feedback on their performance. 


\section{CONCLUSION}

This thesis aimed to contribute to the evolution toward a medical education continuum from student to specialist and increased the understanding of competency-based medical education and entrustable professional activities as tools for building that continuum.

The thesis described an elective track in the final year of medical school to enhance competence development and prepare learners for work as a doctor in the domain of acute care. This variant of a transitional year delivered graduates who scored higher than a comparison group on performance tests and resembled junior doctors better, indicating better preparedness for work in acute care. Even while the implementation of this track could have been more complete with more affordances to practice acute care, students' sense of belonging to a learning community and their agency proved important determinants of the success of the innovation. In addition, a simulation pre-test exceeding the competence level of graduates instilled their determination for learning.

The thesis then turned to current postgraduate anesthesiology training, finding substantial variation in European approaches to assessment and certification. The existing certification systems did not always offer a solid foundation for the decision to certify, which may have led to the certification of trainees who are not fully competent.

A continuum is envisioned with students graduating well-prepared for work in the area of their preference and for further training to become a lifelong learning specialist who meets the requirements to provide safe and high quality patient care. Entrustable professional activities are promising building blocks for such a continuum. 


\section{REFERENCES}

1. lobst WF, Holmboe ES. Building the continuum of competency-based medical education. Perspect Med Educ 2015; 4(4):165-7.

2. Aschenbrener CA, Ast C, Kirch DG. Graduate medical education: its role in achieving a true medical education continuum. Acad Med 2015; 90(9):1203-9.

3. Westerman M. Mind the gap. The transition to hospital consultant [thesis]. 2012, Vrije Universiteit Amsterdam.

4. Hirsh D, Ogur B, Thibault GE, Cox M. "Continuity" as an organizing principle for clinical education reform. N Engl J Med 2007; 356(8):858-66.

5. Englander R, Carraccio C. A lack of continuity in education, training, and practice violates the "Do no harm" principle. Acad Med 2018; 93(3S Competency-Based, Time-Variable Education in the Health Professions):S12-6.

6. lobst WF, Sherbino J, ten Cate O, et al. Competency-based medical education in postgraduate medical education. Med Teach 2010; 32(8):651-6.

7. Holmboe ES, Sherbino J, Long DM, Swing SR, Frank JR. The role of assessment in competencybased medical education. Med Teach 2010; 32(8):676-82.

8. Frank JR, Snell LS, ten Cate $\mathrm{O}$, et al. Competency-based medical education: theory to practice. Med Teach 2010; 32(8):638-45.

9. Hodges $\mathrm{BD}$. The shifting discourses of competence, in The question of competence. Reconsidering medical education in the twenty-first century, Hodges BD, Lingard L, Editors. 2012, Ithaca, NY: Cornell University Press. 14-41.

10. Nasca TJ, Philibert I, Brigham T, Flynn TC. The Next GME Accreditation System - Rationale and Benefits. N Engl J Med 2012; 366(11):1051-6.

11. Ten Cate O. Entrustability of professional activities and competency-based training. Med Educ 2005; 39(12):1176-7.

12. Ten Cate O, Scheele F. Competency-based postgraduate training: can we bridge the gap between theory and clinical practice? Acad Med 2007; 82(6):542-7.

13. Englander R, Frank JR, Carraccio C, et al. Toward a shared language for competency-based medical education. Med Teach 2017; 39(6):582-7.

14. Ten Cate O. Medical education in the Netherlands. Med Teach 2007; 29(8):752-7.

15. McMurray L, Hall AK, Rich J, Merchant S, Chaplin T. The Nightmares Course: a longitudinal, multidisciplinary, simulation-based curriculum to train and assess resident competence in resuscitation. J Grad Med Educ 2017; 9(4):503-8.

16. Elnicki DM, Gallagher S, Willett L, et al. Course offerings in the fourth year of medical school: how U.S. medical schools are preparing students for internship. Acad Med 2015; 90(10):132430.

17. Blackmore C, Austin J, Lopushinsky SR, Donnon T. Effects of postgraduate medical education "boot camps" on clinical skills, knowledge, and confidence: a meta-analysis. J Grad Med Educ 2014; 6(4):643-52. 
18. Ryan RM, Deci EL. Self-determination theory and the facilitation of intrinsic motivation, social development, and well-being. Am Psychol 2000; 55(1):68-78.

19. Dweck CS. Self-Theories: Their Role in Motivation, Personality, and Development. 2000, New York, NY: Psychology Press.

20. Yeager DS, Dweck CS. Mindsets that promote resilience: when students believe that personal characteristics can be developed. Educ Psychol 2012; 47(4):302-14.

21. Cook DA, Artino AR. Motivation to learn: an overview of contemporary theories. Med Educ 2016; 50(10):997-1014.

22. Chaiklin S. The Zone of proximal development in Vygotsky's analysis of learning and instruction, in Vygotsky's educational theory in cultural context, A. Kozulin, et al., Editors. 2003, Cambridge: Cambridge University Press. 39-64.

23. Vygotsky L. Mind in society. The development of higher psychological processes. 1978, Cambridge, MA: Harvard University Press.

24. Ten Cate O, Snell L, Mann K, Vermunt J. Orienting teaching toward the learning process. Acad Med 2004; 79(3):219-28.

25. Vermunt J, Verloop N. Congruence and friction between learning and teaching. Learning \& Instruction 1999; 9:257-80.

26. Rudolph JW, Raemer DB, Simon R. Establishing a safe container for learning in simulation: the role of the presimulation briefing. Simul Healthc 2014; 9(6):339-49.

27. Kneebone R. Evaluating clinical simulations for learning procedural skills: a theory-based approach. Acad Med 2005; 80(6):549-53.

28. Issenberg SB, McGaghie WC, Petrusa ER, Lee Gordon D, Scalese RJ. Features and uses of highfidelity medical simulations that lead to effective learning: a BEME systematic review. Med Teach 2005; 27(1):10-28.

29. Pereira AG, Harrell HE, Weissman A, et al. Important skills for internship and the fourth-year medical school courses to acquire them: a national survey of internal medicine residents. Acad Med 2016; 91(6):821-6.

30. Illing JC, Morrow GM, Rothwell CR, et al. Perceptions of UK medical graduates' preparedness for practice: a multi-centre qualitative study reflecting the importance of learning on the job. BMC Med Educ 2013; 13:34.

31. Minter RM, Amos KD, Bentz ML, et al. Transition to surgical residency: a multi-institutional study of perceived intern preparedness and the effect of a formal residency preparatory course in the fourth year of medical school. Acad Med 2015; 90(8):1116-24.

32. Braniff C, Spence RA, Stevenson M, Boohan M, Watson P. Assistantship improves medical students' perception of their preparedness for starting work. Med Teach 2016; 38(1):51-8.

33. Lempp H, Seabrook M, Cochrane M, Rees J. The transition from medical student to doctor: perceptions of final year students and preregistration house officers related to expected learning outcomes. J Clin Pract 2005; 59(3):324-9.

34. Burford B, Ellis E, Williamson A, Forest I, Vance G. Learning opportunities in student assistantships. The Clin Teacher 2015; 12(2):121-7. 
35. Lave J, Wenger E. Situated Learning: Legitimate Peripheral Participation. 1991, Cambridge: Cambridge University Press.

36. Billett S. Workplace participatory practices. J Workp/ Learning 2004; 16(6):312-24.

37. Dath $\mathrm{D}$, lobst $\mathrm{W}$. The importance of faculty development in the transition to competencybased medical education. Med Teach 2010; 32(8):683-6.

38. Holmboe ES, Ward DS, Reznick RK, et al. Faculty development in assessment: the missing link in competency-based medical education. Acad Med 2011; 86(4):460-7.

39. Fraser AB, Stodel EJ, Jee R, Dubois DA, Chaput AJ. Preparing anesthesiology faculty for competency-based medical education. Can J Anaesth 2016; 63(12):1364-73.

40. Walsh A, Koppula S, Antao V, et al. Preparing teachers for competency-based medical education: fundamental teaching activities. Med Teach 2018; 40(1):80-5.

41. Albanese MA, Mejicano G, Anderson WM, Gruppen L. Building a competency-based curriculum: the agony and the ecstasy. Adv Health Sci Educ Theory Pract 2010; 15(3):439-54.

42. Chen $\mathrm{HC}$, van den Broek WE, ten Cate $\mathrm{O}$. The case for use of entrustable professional activities in undergraduate medical education. Acad Med 2015; 90(4):431-6.

43. Englander R, Flynn T, Call S, et al. Toward defining the foundation of the MD degree: core entrustable professional activities for entering residency. Acad Med 2016; 91(10):1352-8.

44. AAMC. Core Entrustable Professional Activities for Entering Residency: Toolkits for the 13 Core EPAs - Abridged 2017 [Available from: https://www.aamc.org/system/files/c/2/484778epa13toolkit.pdf].

45. O'Brien BC. What to do about the transition to residency? Exploring problems and solutions from three perspectives. Acad Med 2018; 93(5):681-4.

46. Murray KE, Lane JL, Carraccio C, et al. Crossing the gap: using competency-based assessment to determine whether learners are ready for the undergraduate-to-graduate transition. Acad Med 2019; 94(3):338-45.

47. Holzhausen Y, Maaz A, Bosch J, Peters H. Development of entrustable professional activities for entry into residency at the Charité Berlin. GMS J Med Educ 2019; 36(1):Doc5.

48. Ten Cate O, Graafmans L, Posthumus I, Welink L, van Dijk M. The EPA-based Utrecht undergraduate clinical curriculum: development and implementation. Med Teach 2018; 40(5):506-13.

49. Hart $D$, Franzen $D$, Beeson $M$, et al. Integration of entrustable professional activities with the milestones for emergency medicine residents. West J Emerg Med 2019; 20(1):35-42.

50. Wisman-Zwarter N, van der Schaaf M, ten Cate O, et al. Transforming the learning outcomes of anaesthesiology training into entrustable professional activities: A Delphi study. Eur J Anaesthesiol 2016; 33(8):559-67.

51. Ten Cate O, Snell L, Carraccio C. Medical competence: the interplay between individual

52. Ten Cate O, Chen HC, Hoff RG, et al. Curriculum development for the workplace using Entrustable Professional Activities (EPAs). AMEE Guide No. 99. Med Teach 2015; 37(11):9831002. 
53. Rekman J, Gofton W, Dudek N, Gofton T, Hamstra SJ. Entrustability scales: outlining their usefulness for competency-based clinical assessment. Acad Med 2016; 91(2):186-90.

54. Ten Cate $\mathrm{O}, \mathrm{Sch}$ wartz $\mathrm{A}$, Chen $\mathrm{HC}$. Assessing trainees and making entrustment decisions: on the nature and use of entrustment-supervision scales. Acad Med 2020; 95(11):1662-9.

55. Lomis K, Amiel JM, Ryan MS, et al. Implementing an entrustable professional activities framework in undergraduate medical education: early lessons from the AAMC core entrustable professional activities for entering residency pilot. Acad Med 2017; 92(6):765-70.

56. Meyer EG, Chen HC, Uijtdehaage S, Durning SJ, Maggio LA. Scoping review of entrustable professional activities in undergraduate medical education. Acad Med 2019; 94(7):1040-9.

57. Thompson LR, Leung CG, Green B, et al. Development of an assessment for entrustable professional activity (EPA) 10: emergent patient management. West J Emerg Med 2017; 18(1):35-42.

58. Ten Cate O. Entrustment decisions: bringing the patient into the assessment equation. Acad Med 2017; 92(6):736-8.

59. Yardley S, Teunissen PW, Dornan T. Experiential learning. AMEE Guide No. 63. Med Teach 2012; 34(2):e102-15.

60. Han JJ, Vapiwala N. Pre-specialization - considerations for more focused and personalized educational modules in the twenty-first century. Med Teach 2019; 41(2):190-4.

61. Sklar DP. Creating a medical education continuum with competencies and entrustable professional activities. Acad Med 2019; 94(9):1257-60.

62. Ringsted C, Østergaard D, Scherpbier A. Embracing the new paradigm of assessment in residency training: an assessment programme for first-year residency training in anaesthesiology. Med Teach 2003; 25(1):54-62.

63. Ringsted C, Østergaard D, van der Vleuten CPM. Implementation of a formal in-training assessment programme in anaesthesiology and preliminary results of acceptability. Acta Anaesthesiol Scand 2003; 47(10):1196-203.

64. Bould MD, Naik VN, Hamstra SJ. Review article: new directions in medical education related to anesthesiology and perioperative medicine. Can J Anaesth 2012; 59(2):136-50.

65. Ebert TJ, Fox CA. Competency-based education in anesthesiology. History and challenges. Anesthesiology 2014; 120(1):24-31.

66. Fraser AB, Stodel EJ, Chaput AJ. Curriculum reform for residency training: competence, change, and opportunities for leadership. Can J Anaesth 2016; 63(7):875-84.

67. Weller JM, Naik VN, San Diego RJ. Systematic review and narrative synthesis of competencybased medical education in anaesthesia. Br J Anaesth 2020; 124(6):748-60.

68. Bisgaard CH, Rubak SLM, Rodt SA, Petersen JAK, Musaeus P. The effects of graduate competency-based education and mastery learning on patient care and return on investment: a narrative review of basic anesthetic procedures. BMCMed Educ 2018; 18(1):154.

69. Yamamoto S, Tanaka P, Madsen MV, Macario A. Comparing anesthesiology residency training structure and requirements in seven different countries on three continents. Cureus 2017; 9(2):e1060. 
70. Van Gessel E, Goldik Z, Mellin-Olsen J, et al. Postgraduate training in anaesthesiology, resuscitation and intensive care: state-of-the-art for trainee evaluation and assessment in Europe. Eur J Anaesthesiol 2010; 27(8):673-5.

71. Van Gessel E, Mellin-Olsen J, Østergard HT, et al. Postgraduate training in anaesthesiology, pain and intensive care: the new European competence-based guidelines. Eur J Anaesthesiol 2012; 29(4):165-8.

72. Van Gessel EF, Østergard HT, Niemi-Murola L. Harmonisation of anaesthesiology training in Europe. Best Pract Res Clin Anaesthesiol 2012; 26(1):55-67.

73. Shorten GD, De Robertis E, Goldik Z, et al. European Section/Board of Anaesthesiology/ European Society of Anaesthesiology consensus statement on competency-based education and training in anaesthesiology. Eur J Anaesthesiol 2020; 37(6):421-34.

74. Frank JR, Mungroo R, Ahmad Y, et al. Toward a definition of competency-based education in medicine: a systematic review of published definitions. Med Teach 2010; 32(8):631-7.

75. Long DM. Competency-based training in neurosurgery: the next revolution in medical education. Surg Neurol 2004; 61(1):5-14.

76. Duijn C, Bok H, ten Cate O, Kremer W. Qualified but not yet fully competent: perceptions of recent veterinary graduates on their day-one skills. Vet Rec 2020; 186:216.

77. Cooper WO, Spain DA, Guillamondegui O, et al. Association of coworker reports about unprofessional behavior by surgeons with surgical complications in their patients. JAMA Surg 2019; 154(9):828-34.

78. Van Loon KA, Teunissen PW, Driessen EW, Scheele F. The role of generic competencies in the entrustment of professional activities: a nationwide competency-based curriculum assessed. J Grad Med Educ 2016; 8(4):546-52.

79. Van Loon KA, Teunissen PW, Driessen EW, Scheele F. Formal versus informal judgments: faculty experiences with entrustment in graduate medical education. J Grad Med Educ 2018; 10(5):537-42.

80. Blum RH, Boulet JR, Cooper JB, et al. Simulation-based assessment to identify critical gaps in safe anesthesia resident performance. Anesthesiology 2014; 120(1):129-41.

81. Blum $\mathrm{RH}$, Muret-Wagstaff $\mathrm{SL}$, Boulet $\mathrm{JR}$, et al. Simulation-based assessment to reliably identify key resident performance attributes. Anesthesiology 2018;128(4):821-31.

82. Ten Cate O, Taylor DR. The recommended description of an entrustable professional activity. AMEE Guide No. 140. Med Teach 2020; Online ahead of print.

83. Stodel EJ, Wyand A, Crooks S, et al. Designing and implementing a competency-based training program for anesthesiology residents at the University of Ottawa. Anesthesiol Res Pract 2015; 2015:713038.

84. Marty AP, Schmelzer S, Thomasin RA, et al. Agreement between trainees and supervisors on first-year entrustable professional activities for anaesthesia training. Br J Anaesth 2020; 125(1):98-103.

85. Breckwoldt J, Beckers SK, Breuer G, Marty A. Entrustable professional activities : Promising concept in postgraduate medical education [in German]. Anaesthesist 2018; 67(6):452-7. 
86. Moll-Khosrawi P, Ganzhorn A, Zöllner C, Schulte-Uentrop L. Development and validation of a postgraduate anaesthesiology core curriculum based on entrustable professional activities: a Delphi study. GMS J Med Educ 2020; 37(5):1-23.

87. O'Dowd E, Lydon S, O'Connor P, Madden C, Byrne D. A systematic review of 7 years of research on entrustable professional activities in graduate medical education, $2011-2018$. Med Educ 2019; 53(3):234-49.

88. Caverzagie KJ, Nousiainen MT, Ferguson PC, et al. Overarching challenges to the implementation of competency-based medical education. Med Teach 2017; 39(6):588-93.

89. Nousiainen MT, Caverzagie KJ, Ferguson PC, Frank JR. Implementing competency-based medical education: What changes in curricular structure and processes are needed? Med Teach 2017; 39(6):594-8.

90. Ten Cate O, Borleffs J, van Dijk M, Westerveld T. Training medical students for the twentyfirst century: Rationale and development of the Utrecht curriculum "CRU+". Med Teach 2018; 40(5):461-6.

91. Wong G, Greenhalgh T, Westhorp G, Pawson R. Realist methods in medical education research: what are they and what can they contribute? Med Educ 2012; 46(1):89-96.

92. Haji F, Morin MP, Parker K. Rethinking programme evaluation in health professions education: beyond 'did it work?'. Med Educ 2013; 47(4):342-51.

93. Benbassat J, Baumal R. Expected benefits of streamlining undergraduate medical education by early commitment to specific medical specialties. Adv Health Sci Educ Theory Pract 2012; 17(1):145-55.

94. Andrew SE, Oswald A, Stobart K. Bridging the continuum: Analysis of the alignment of undergraduate and postgraduate accreditation standards. Med Teach 2014; 36(9):804-11.

95. Aagaard E, Abaza M. The residency application process - burden and consequences. N Engl J Med 2016; 374(4):303-5.

96. Andrews JS, Bale JF, Soep JB, et al. Education in pediatrics across the continuum (EPAC): first steps toward realizing the dream of competency-based education. Acad Med 2018; 93(3):414-20.

97. Querido S, de Rond M, Wigersma L, van den Broek S, ten Cate O. The significance of experiencing clinical responsibilities for specialty career choice. Med Sci Educ 2020; 30:16371.

98. Hodges B. Assessment in the post-psychometric era: learning to love the subjective and collective. Med Teach 2013; 35(7):564-8.

99. Hauer KE, ten Cate O, Boscardin CK, et al. Ensuring resident competence: a narrative review of the literature on group decision making to inform the work of clinical competency committees. J Grad Med Educ 2016; 8(2):156-64.

100. Duitsman ME, Fluit C, van Alfen-van der Velden J, et al. Design and evaluation of a clinical competency committee. Perspect Med Educ 2019; 8(1):1-8.

101. Duitsman $M E$, Fluit $C$, van der Goot WE, et al. Judging residents' performance: a qualitative study using grounded theory. BMC Med Educ 2019; 19(1):13. 
102. Govaerts MJ, van der Vleuten CP, Schuwirth LW, Muijtjens AM. Broadening perspectives on clinical performance assessment: rethinking the nature of in-training assessment. $A d v$ Health Sci Educ Theory Pract 2007; 12(2):239-60.

103. Schuwirth LW, van der Vleuten CP. Programmatic assessment: from assessment of learning to assessment for learning. Med Teach 2011; 33(6):478-85.

104. Van der Vleuten CP, Schuwirth LW, Driessen EW, Dijkstra J, Tigelaar D, Baartman LK, et al. A model for programmatic assessment fit for purpose. Med Teach 2012; 34(3):205-14.

105. Schuwirth LW, van der Vleuten CP. Programmatic assessment and Kane's validity perspective. Med Educ 2012; 46(1):38-48.

106. Bok HGJ, Teunissen PW, Favier RP, et al. Programmatic assessment of competency-based workplace learning: when theory meets practice. BMC Med Educ 2013; 13:123.

107. Lockyer J, Carraccio C, Chan MK, et al. Core principles of assessment in competency-based medical education. Med Teach 2017; 39(6):609-16.

108. Gruppen LD, ten Cate O, Lingard LA, Teunissen PW, Kogan JR. Enhanced requirements for assessment in a competency-based, time-variable medical education system. Acad Med 2018; 93(3S Competency-Based, Time-Variable Education in the Health Professions):S17-21.

109. Castanelli DJ, Weller JM, Molloy E, Bearman M. Shadow systems in assessment: how supervisors make progress decisions in practice. Adv Health Sci Educ Theory Pract 2020; 25(1):131-47.

110. Tam J, Wadhwa A, Martimianakis MA, Fernando O, Regehr G. The role of previously undocumented data in the assessment of medical trainees in clinical competency committees. Perspect Med Educ 2020; 9(5):286-93.

111. Ten Cate O, Chen HC. The ingredients of a rich entrustment decision. Med Teach 2021; Online ahead of print.

112. Gauthier S, Cavalcanti R, Goguen J, Sibbald M. Deliberate practice as a framework for evaluating feedback in residency training. Med Teach 2015; 37(6):551-7.

113. Van der Schaaf M, Donkers J, Slof B, et al. Improving workplace-based assessment and feedback by an e-portfolio enhanced with learning analytics. Educ Technol Res Dev 2016; 65(2):359-80.

114. Schultz K, Griffiths J, Lacasse M. The application of entrustable professional activities to inform competency decisions in a family medicine residency program. Acad Med 2015; 90(7):888-97.

115. Swing SR, Clyman SG, Holmboe ES, Williams RG. Advancing resident assessment in graduate medical education. J Grad Med Educ 2009; 1(2):278-86.

116. Kogan JR, Holmboe ES, Hauer KE. Tools for direct observation and assessment of clinical skills of medical trainees. JAMA 2009; 302(12):1316-26.

117. Griffiths J, Dalgarno N, Schultz K, Han H, van Melle E. Competency-based medical education implementation: are we transforming the culture of assessment? Med Teach 2019; 41(7):8118.

118. Castanelli DJ, Jowsey T, Chen Y, Weller JM. Perceptions of purpose, value, and process of the mini-Clinical Evaluation Exercise in anesthesia training. Can J Anaesth 2016; 63(12):1345-56. 
119. Watling C. The uneasy alliance of assessment and feedback. Perspect Med Educ 2016; 5(5):2624.

120. Watling CJ, Ginsburg S. Assessment, feedback and the alchemy of learning. Med Educ 2019; 53(1):76-85.

121. Bould MD, Crabtree NA, Naik VN. Assessment of procedural skills in anaesthesia. Br J Anaesth 2009; 103(4):472-83.

122. Baker K. Determining resident clinical performance. Getting beyond the noise. Anesthesiology 2011; 115(4):862-78.

123. Chiu M, Tarshis J, Antoniou A, et al. Simulation-based assessment of anesthesiology residents' competence: development and implementation of the Canadian National Anesthesiology Simulation Curriculum (CanNASC). Can J Anaesth 2016; 63(12):1357-63.

124. Wanderer JP, de Oliveira Filho GR, Rothman BS, Sandberg WS, McEvoy MD. Implementation and evaluation of the Z-Score system for normalizing residency evaluations. Anesthesiology 2018; 128(1):144-58.

125. Cook DA, Kuper A, Hatala R, Ginsburg S. When assessment data are words: validity evidence for qualitative educational assessments. Acad Med 2016; 91(10):1359-69.

126. Ten Cate O, Regehr G. The power of subjectivity in the assessment of medical trainees. Acad Med 2019; 94(3):333-7.

127. Boulet JR, Murray D. Review article: assessment in anesthesiology education. Can J Anaesth 2012; 59(2):182-92.

128. Weller JM, Misur M, Nicolson S, et al. Can I leave the theatre? A key to more reliable workplacebased assessment. Br J Anaesth 2014; 112(6):1083-91.

129. Weller JM, Castanelli DJ, Chen Y, Jolly B. Making robust assessments of specialist trainees' workplace performance. Br J Anaesth 2017; 118(2):207-14.

130. Castanelli DJ, Moonen-van Loon JMW, Jolly B, Weller JM. The reliability of a portfolio of workplace-based assessments in anesthesia training. Can J Anaesth 2019; 66(2):193-200.

131. Dubois DG, Lingley AJ, Ghatalia J, McConnell MM. Validity of entrustment scales within anesthesiology residency training. Can J Anaesth 2021; 68(1):53-63.

132. Crossley J, Jolly B. Making sense of work-based assessment: ask the right questions, in the right way, about the right things, of the right people. Med Educ 2012; 46(1):28-37.

133. Ten Cate $O$. Entrustment as assessment: recognizing the ability, the right, and the duty to act. J Grad Med Educ 2016; 8(2):261-2.

134. Post JA, Wittich CM, Thomas KG, et al. Rating the quality of entrustable professional activities: content validation and associations with the clinical context. $J$ Gen Intern Med 2016; 31(5):518-23.

135. Taylor DR, Park YS, Egan R, et al. EQual, a novel rubric to evaluate entrustable professional activities for quality and structure. Acad Med 2017; 92(11S AAMC Proceedings of the 56th Annual Research in Medical Education Sessions):S110-7.

136. Kealey A, Alam F, McCreath G, et al. Real-world impact of the COVID-19 pandemic on the assessment of anaesthesiology residents. Br J Anaesth 2020; 125(5):e430-e2. 
137. Carraccio C, Englander R, Gilhooly J, et al. Building a framework of entrustable professional activities, supported by competencies and milestones, to bridge the educational continuum. Acad Med 2017; 92(3):324-30.

138. Ten Cate O, Carraccio C. Envisioning a true continuum of competency-based medical education, training, and practice. Acad Med 2019; 94(9):1283-8.

139. Van Melle E, Frank JR, Holmboe ES, Dagnone D, Stockley D, Sherbino J. A core components framework for evaluating implementation of competency-based medical education programs. Acad Med 2019; 94(7):1002-9.

140. Hoff RG, Frenkel J, Imhof SM, ten Cate O. Flexibility in postgraduate medical training in the Netherlands. Acad Med 2018; 93(3S Competency-Based, Time-Variable Education in the Health Professions):S32-6.

141. Hirsh D, Walters L, Poncelet AN. Better learning, better doctors, better delivery system: possibilities from a case study of longitudinal integrated clerkships. Med Teach 2012; 34(7):548-54.

142. Hirsh DA, Holmboe ES, ten Cate O. Time to trust: longitudinal integrated clerkships and entrustable professional activities. Acad Med 2014; 89(2):201-4.

143. Evans DB, Henschen BL, Poncelet AN, Wilkerson L, Ogur B. Continuity in undergraduate medical education: mission not accomplished. J Gen Intern Med 2019; 34(10):2254-9.

144. Ten Cate O, Gruppen LD, Kogan JR, Lingard LA, Teunissen PW. Time-variable training in medicine. Acad Med 2018; 93(3S):S6-11.

145. Kogan JR, Whelan AJ, Gruppen LD, et al. What regulatory requirements and existing structures must change if competency-based, time-variable training is introduced into the continuum of medical education in the United States? Acad Med 2018; 93(3S):S27-31.

146. Teunissen PW, Kogan JR, ten Cate O, Gruppen LD, Lingard LA. Learning in practice: a valuation of context in time-variable medical training. Acad Med 2018; 93(3S):S22-6.

147. Hauer KE, Lockspeiser TM, Chen HC. The COVID-19 pandemic as an imperative to advance medical student assessment. Acad Med 2021;96(2):182-185.

148. Campbell C, Silver I, Sherbino J, ten Cate O, Holmboe ES. Competency-based continuing professional development. Med Teach 2010; 32(8):657-62.

149. Gruppen L, Frank JR, Lockyer J, et al. Toward a research agenda for competency-based medical education. Med Teach 2017; 39(6):623-30.

150. Sehlbach C, Govaerts MJB, Mitchell S, et al. Box-ticking and Olympic high jumping physicians' perceptions and acceptance of national physician validation systems. Med Teach 2018; 40(9):886-91.

151. Overeem K, Wollersheim H, Driessen E, et al. Doctors' perceptions of why 360-degree feedback does (not) work: a qualitative study. Med Educ 2009; 43(9):874-82.

152. Overeem K, Driessen EW, Arah OA, et al. Peer mentoring in doctor performance assessment: strategies, obstacles and benefits. Med Educ 2010; 44(2):140-7.

153. Steadman $\mathrm{RH}$, Huang $\mathrm{YM}$. Simulation for quality assurance in training, credentialing and maintenance of certification. Best Pract Res Clin Anaesth 2012; 26(1):3-15. 
154. Steadman RH, Burden AR, Huang YM, Gaba DM, Cooper JB. Practice improvements based on participation in simulation for the maintenance of certification in anesthesiology program. Anesthesiology 2015; 122(5):1154-69.

155. Weinger MB, Banerjee A, Burden AR, et al. Simulation-based assessment of the management of critical events by board-certified anesthesiologists. Anesthesiology 2017; 127(3):475-89.

156. Banerjee A, Burden A, Slagle JM, et al. Key performance gaps of practicing anesthesiologists. Int Anesth Clin 2020; 58(1):13-20.

157. Van Schalkwyk SC, Hafler J, Brewer TF, et al. Transformative learning as pedagogy for the health professions: a scoping review. Med Educ 2019; 53(6):547-58.

158. Keeley MG, Gusic ME, Morgan HK, Aagaard EM, Santen SA. Moving toward summative competency assessment to individualize the postclerkship phase. Acad Med 2019; 94(12):1858-64.

159. Van den Broek WES, Wijnen-Meijer M, ten Cate O, van Dijk M. Medical students'preparation for the transition tot postgraduate training through final year elective rotations. GMS J Med Educ 2017; 34(5):Doc65.

160. Breen D, O'Brien S, McCarthy N, Gallagher A, Walshe N. Effect of a proficiency-based progression simulation programme on clinical communication for the deteriorating patient: a randomised controlled trial. BMJ Open 2019; 9(7): e025992.

161. Ten Cate O, Hoff RG. From case-based to entrustment-based discussions. The Clin Teach 2017; 14(6):385-9. 



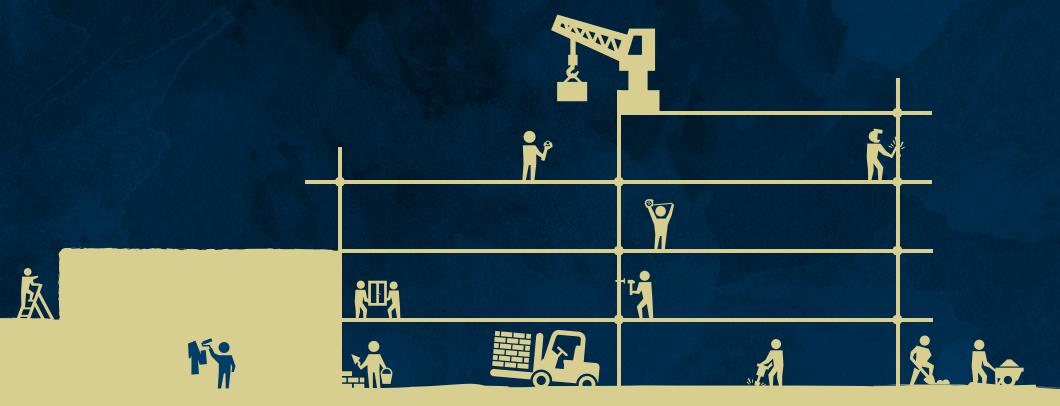




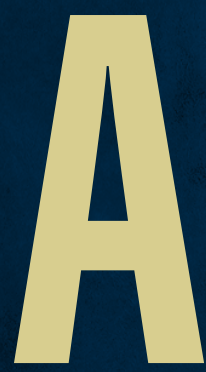

\section{APPENDICES}

SUMMARY

SAMENVATTING IN HET NEDERLANDS

DANKWOORD

CURRICULUM VIAEE 



\section{SUMMARY}

The main objective of the thesis is to explore the role of competency-based medical education (CBME) and entrustable professional activities (EPAs) in forging an educational continuum that fosters the development of competence.

Chapter 1 is a general introduction to the thesis. It describes how learners develop through a series of stages with challenging transitions into doctors. A pathway that spans the continuum from student to medical specialist would improve learners' development. CBME, applied to both undergraduate and postgraduate stages of the trajectory, is a promising approach to build a continuum. Chapter 1 takes a closer look at the development of competence from a theoretical perspective. The purpose of the thesis is elaborated and framed in research questions.

The first part of the thesis concerns the role of a thematic transitional year of medical school in forging an educational continuum. The research questions pertaining to this part are: Does an elective transitional year, dedicated to acute care, have a beneficial effect on the development of competence and preparedness for the next stage, i.e. working as a doctor in an acute care specialty? If the innovation has effect, can its effect be understood by looking at learning theory, like Communities of practice, and motivational theory, such as Self-determination theory? And if the innovation does not sort effects, do these theories require adaptation? What is the psychosocial and educational effect on students of simulation pre-testing beyond the competence level of graduates?

The second part of the thesis is involved with CBME in postgraduate anesthesiology training. The research questions related to this part of the thesis are: What is the structure, or are the structures, of European postgraduate anesthesiology training and to what degree have training programs transitioned to CBME and to EPAs? What is the foundation or justification of the ultimate entrustment decision of certification, granted to trainees at completion of training in anesthesiology in Europe? How can CBME, operationalized with EPAs, be applied to postgraduate anesthesiology training, and what research is required to assist competency-based anesthesiology training with EPAs?

Chapter 2 lays out the idea of a multidisciplinary elective thematic final year. Anesthesiology, cardiology, emergency medicine, intensive care medicine, and pulmonology collaborated in the design of a coherent track that balances breadth with depth and graduates generalist doctors with a useful profile of acute care competence, 
prepared for work as a doctor in a selection of specialties. The Acute Care Transitional Year (ACTY) has clearly articulated, advanced level learning objectives formulated as three EPAs on the evaluation and initial management of critically compromised patients. The ACTY elective profile EPAs offer directed preparation for authentic tasks that junior doctors face in a range of specialties. The thematic orientation and the learning objectives provide coherence in a year that normally consists of a personal selection of elective rotations. The ACTY, introduced in a preliminary form in 2014/2015 and in full form in 2015/2016 attracts approximately 24 students per year (7\% of the annual cohort). Of these students, $92 \%$ aim for a specialty that takes part in the ACTY, but only $16 \%$ are determined which specialty. Moreover, $68 \%$ also consider a career outside of the ACTY specialties.

The ACTY is object of study in the research described in Chapters 3, 4, and 5.

After the implementation of the ACTY, we gathered information from students, graduates, and faculty about successes and challenges of the new track (Chapter 3 ). In an explorative qualitative study with Appreciative inquiry as a method, we spoke to endusers of the ACTY in individual interviews and focus groups, using Self-determination theory as an interpretive lens. End-users saw three strengths: 1) the ACTY focuses learning in a coherent program with clear learning objectives, 2) the teaching sessions contribute to the coherence and focus of learning, but above all create a congenial learning community, 3) the ACTY attracts highly motivated and proactive students. As opportunities for change and improvement participants named: 1) heterogeneity in involvement of clinical supervisors, 2) subordinate position of the EPAs, and 3) limited hands-on experience in acute care.

Heterogeneity in local understanding of the ACTY track, variation in workplace uptake, and disparity in supervisor commitment are signs of an imperfect implementation. Participants suggest just-in-time information, faculty development and creating a supervisor network as improvement strategies. Participants feel that EPAs could be positioned more central in the ACTY curriculum, by making EPAs the focal point of workplace assessment and student evaluation, and by working toward entrustment. The advent of the new EPA-based core clinical curriculum will likely ease the adoption of ACTY EPAs. Fundamental is providing sufficient hands-on engagement in actual acute care situations by affording legitimate workplace roles, supported by bedside teaching, case-based discussions and simulation training, participants propose.

Self-determination theory provides insight in how the ACTY produces effect. The coherent curriculum with EPAs and the pre-test yielding explicit personal feedback are 
elements that satisfy the psychological need for competence. The learning community of congenial peers fulfils the need for relatedness. By creating a supportive environment, with peers, teachers and mentors, the need for autonomy is partly met. With the needs largely satisfied students' natural tendency for growth is stimulated.

Chapter 4 takes a closer look at the simulation pre-test at the start of the ACTY.Vygotsky's Zone of proximal development (ZPD) refers to the space between what learners have mastered and what they should master in the next developmental stage. Did the solo management of critically ill cases in the simulation pre-test, at the far edge of their ZPD, cause destructive friction and demoralization? The phenomenological study aims to understand the psychosocial and educational effect of the simulation pre-test by indepth interviewing of individual ACTY students on their simulation experience. The essence of the students' experience is that they struggled to deal with the simulated acute care situations, leading to stress, stirred up by uncertainty about medical management, deterioration of the simulation patients, and disappointment about their performance. The stress impeded cognitive functioning. However, the formative practice setting, anticipation of poor performance, debriefing, a safe environment, and the prospect of training opportunities regulated the emotional response to stress, turning a tense simulation into a motivating educational experience.

The main finding of the study is that in a safe formative pre-test setting, simulations at the far edge of the ZPD do not cause demoralization and destructive friction, but rather cause constructive friction and instill motivation to develop. The finding implies that simulation pre-testing at the far edge of the ZPD, which represents simulation beyond traditional borders, can be used safely.

Chapter 5 appraises the effect of the ACTY on learning and preparedness for practice, i.e. whether graduates meet postgraduate acute care expectations. The chapter describes a quasi-experimental study with a pre-test \& post-test design in which participants took part in a multimodal assessment of acute care knowledge, clinical reasoning and casemanagement, practical skills, and performance in simulations.

The study compares ACTY students' test results with those of non-track students - with an interest in acute care - and with junior doctors with six months of clinical acute care experience. The test consisted of a written knowledge exam, case-based discussions, Objective Structured Clinical Examinations of skills, and high-fidelity simulations of critically ill patients requiring urgent care. Each assessment element yielded a checklist score, calculated as the awarded points as percentage of the maximum points. In addition, assessors reported a gestalt, expert evaluation of overall participant 
performance on their station on a three-point global rating scale (GRS), in answer to the question "How did the participant's performance compare to the expected level of a junior doctor with six months of clinical experience?" (does not meet expectations borderline - meets expectations).

The study demonstrates, that students graduating from the ACTY perform better in the assessment than non-ACTY students, especially on skills and simulations. Junior doctors did better on simulations than ACTY graduates. Moreover, ACTY students have higher odds than non-ACTY students of meeting the postgraduate expectations of a junior doctor, as determined by GRS.

In pursuit of a better transition to postgraduate expectations, the study finds that graduates from this program resemble junior doctors with clinical experience better than other graduates, suggesting they are better prepared for junior doctor acute care challenges.

This final year dedicated to acute care enhances learning and preparedness for work in this domain. Other transitional years, offering multidisciplinary perspectives on different themes, could similarly enhance learning and preparedness to enter residency or start to work in those areas.

Postgraduate anesthesiology training stems from a traditional time-and-rotation based apprenticeship model. Competency-based medical education principles may have led to evolution of this model in varying ways, but the extent of similarities and disparities is unknown. The aim of an international survey study is to compare European postgraduate anesthesiology training programs regarding assessment and certification processes (Chapter 6). National representatives of all member countries of the Union of European Medical Specialists/European Board of Anaesthesiology completed an online questionnaire with constructed response and selected response format questions, producing quantitative and qualitative data on assessment and certification processes. Not only the duration of training differs substantially (median of 5 years, range $2.75-7$ ), there is also difference in the number of assessment tools used.

The study categorizes European training programs according to approach to assessment and certification in a triangular model. Two main orientations were present, both stemming from the traditional apprenticeship model. One had an underlying knowledge orientation, with assessment focusing on securing an adequate level of knowledge, evaluated with an exam. The other had an underlying procedural orientation, evidencing trainee expertise with the completion of specified numbers of 
procedures, assessed with a logbook. Countries within these orientations displayed, to different extents, the adoption of elements of a third orientation, i.e. a competencybased approach to training. This spectrum of diversity and evolution is depicted graphically by positioning countries along two sides of a triangle.

Whereas UEMS/EBA training guidelines have moved from a procedural to a competencybased orientation, current training in Europe is changing at varying speed toward competency-based training. The move to competency-based training is accompanied by the use of a larger number of assessment tools to support an ultimate summative decision on trainees' competence.

There is no uniform certification practice in Europe. The diversity in learning outcomes, assessment, and certification makes international comparison of training standards difficult.

While Chapter 6 provides a complete overview of current assessment and certification practices, it does not address the quality of these processes. Chapter 7 deals with the quality of assessment and certification processes in European postgraduate anesthesiology training and aims to improve understanding of the basis of certification decisions. The chapter is a short report - preceding a full report - from an interview study using a constructivist Grounded theory approach. The chapter focuses on whether decision-makers think that trainees have reached the competence level of a medical specialist, framed as entrustment of care for the supervisor's loved ones. Participants were 26 anesthesiologists directly involved in certification decisions, purposively sampled from the different approaches to assessment and certification established in Chapter 6. The study finds that decision-makers' answers to the question "Would you trust your loved ones to the trainees you certify?" were, disconcertingly, equally affirmative, irresolute, and negative. Some participants labelled it as the most important question around certification. Participants expressed varying levels of confidence in their assessment systems. Ten participants disclosed to have certified trainees they would not entrust with the unsupervised care of their loved ones, blaming deficiencies in the assessment system, impossibilities in regulations, and incentives to pass trainees.

Flawed assessment and certification systems, that fail to consider all facets of competence, lead to "false positives": certified but not fully competent.

Chapter 8 starts with declaring the importance of justified decisions in delegating tasks to trainees for reasons of quality of care, patient safety, supervisor liability, and educational appropriateness. It continues to describe the role of competency-based 
training with its focus on outcomes of training in meeting the goal of accountability. It subsequently describes the concept of EPAs to operationalize competency-based anesthesiology training and overcome some of the problems with competency-based training by linking competencies to essential tasks in clinical practice. With its attention to observation of clinical performance, EPAs may be helpful in making learner progress visible. EPAs allow deliberate, informed, justified decisions on delegation of tasks to trainees. Consequently, EPAs present a way to demonstrate that graduating trainees have the capabilities that the profession, regulatory bodies, and society expect.

The chapter concludes with setting an agenda for curriculum development and research. The development of an EPA-based curriculum starts with identifying a consensus set of EPAs. Then a toolbox of assessment instruments is compiled for robust evaluation of trainee performance and justified entrustment decisions. Raters need to be trained and calibrated. A portfolio should be designed. This portfolio should be approachable by learning analytic technology to display learner progress, compare learners and institutions, and evaluate implementation and effects of EPA-based anesthesiology training. Research opportunities closely link to curriculum development. Examples are: obtaining consensus on sets of EPAs, comparing (inter-)national programs, validating assessment tools, establishing the role of simulation assessment, identification of markers of professional development, application of performance standards, the use of learning analytics in monitoring effects of EPAs on training, and the process of entrustment decisions.

The thesis concludes with a general discussion (Chapter 9). This chapter highlights the major findings of the thesis and puts them into perspective of the literature. It discusses how coherence, motivation, and experiential learning explain the ACTY's beneficial effect. The chapter proposes a continuum framework of acute care EPAs, It also describes how international postgraduate anesthesiology training is far from uniform and describes current literature on EPAs in anesthesiology. The chapter suggests avenues for further research and concludes with the vision of an education continuum that consists of aligned CBME stages, operationalized with EPAs. 


\section{SAMENVATTING IN HET NEDERLANDS}

Het doel van dit proefschrift is om de rol van competentiegericht opleiden en entrustable professional activities (EPAs) te onderzoeken in het smeden van een opleidingscontinuüm dat competentieontwikkeling faciliteert.

Hoofdstuk 1 is de algemene inleiding van het proefschrift en beschrijft hoe studenten zich via een serie van fases, met uitdagende transities, ontwikkelen tot dokters. Een traject dat het continuüm omvat van student tot medisch specialist kan de ontwikkeling van de lerende verbeteren. Competentiegericht opleiden, toegepast in de fases zowel vóór als na het afstuderen als arts, is een veelbelovende aanpak om zo'n continuüm mee te bouwen. Hoofdstuk 1 beschouwt competentieontwikkeling vanuit een theoretisch kader. Het doel van het proefschrift wordt benoemd en in onderzoeksvragen vervat.

Het eerste deel van het proefschrift behandelt de rol van een thematisch schakeljaar in de studie geneeskunde in het smeden van een opleidingscontinuüm. De onderzoeksvragen die horen bij dit deel zijn: heeft een optionele invulling van het schakeljaar, gewijd aan acute zorg, een gunstig effect op competentieontwikkeling en voorbereiding voor de volgende fase, dat wil zeggen werken als dokter in het acute zorg domein? Als de innovatie effect heeft, kan dit worden begrepen door het betrekken van leertheorieën zoals Communities of practice en motivatie theorie zoals Self-determination theory? Wat is het psychosociale en onderwijskundige effect op studenten van pre-test simulaties van een hogere moeilijkheidsgraad dan passend bij het competentie niveau van afstudeerders?

Hettweededeel van het proefschrifthoudtzich bezig metcompetentiegerichtopleiden in de medische vervolgopleiding tot anesthesioloog. De bijbehorende onderzoeksvragen zijn: wat is de structuur, of structuren, van de medische vervolgopleiding anesthesiologie in Europa en in welke mate hebben opleidingsprogramma's de transitie naar competentiegericht opleiden gemaakt? Wat is de onderbouwing of rechtvaardiging voor de ultieme bekwaamverklaring, die van certificering als specialist, die aan artsen in opleiding tot specialist (aios) wordt gegeven na voltooien van de opleiding anesthesiologie in Europa? Hoe kan competentiegericht opleiden, geoperationaliseerd middels EPAs, worden toegepast op de opleiding anesthesiologie en welk onderzoek is benodigd om die toepassing te ondersteunen?

Hoofdstuk 2 beschrijft het idee van een multidisciplinaire thematische invulling van het laatste studiejaar. De specialismen anesthesiologie, cardiologie, intensive care geneeskunde, longziekten en spoedeisende geneeskunde ontwierpen in 
samenwerking een coherent programma, met balans tussen breedte en verdieping, waardoor generalistische artsen afstuderen met een bruikbaar competentieprofiel in acute zorg, voorbereid om te gaan werken in diverse vakken. Het schakeljaar acute zorg (Acute Care Transitional Year, ACTY) heeft duidelijk omschreven leerdoelen van hoog niveau, geformuleerd als drie EPAs aangaande evaluatie en eerste behandeling van kritisch bedreigde patiënten. De electieve profiel-EPAs van het ACTY bieden gerichte voorbereiding op authentieke taken die jonge artsen tegenkomen in een scala aan specialismen. De thematische invulling en de leerdoelen bieden coherentie in een jaar dat normaliter is opgebouwd uit een persoonlijke selectie van stages. Het ACTY, in preliminaire vorm geïntroduceerd in 2014/2015 en in volledige vorm uitgerold in 2015/2016, trekt ongeveer 24 studenten per jaar (7\% van een jaarcohort). Van deze studenten richt $92 \%$ zich op een specialisme dat deelneemt aan het ACTY, maar slechts $16 \%$ is zeker van welk specialisme. Daarnaast overweegt $68 \%$ een carrière buiten de specialismen die deelnemen aan het ACTY.

Het ACTY is object van studie in het onderzoek dat wordt beschreven in de Hoofdstukken 3,4 en 5.

Na de implementatie van het ACTY, hebben we informatie verzameld bij studenten, afgestudeerden en supervisors over de successen en uitdagingen van dit nieuwe programma (Hoofdstuk 3). In een exploratief kwalitatief onderzoek met Appreciative inquiry als methode, spraken we eindgebruikers van het ACTY in individuele interviews en focus groepen, waarbij we Self-determination theory als interpretatieve lens gebruikten. Eindgebruikers zagen drie sterktes: 1 ) het ACTY geeft richting aan het leren in een coherent programma met heldere leerdoelen, 2) de lesmiddagen dragen bij aan de coherentie en het focussen van leren, maar biedt bovenal een leergemeenschap van gelijkgestemden, 3) het ACTY trekt zeer gemotiveerde en proactieve studenten. Als mogelijkheden voor verandering en verbetering zagen de deelnemers: 1 ) heterogeniteit in mate van ingevoerd zijn van klinische supervisors, 2) een weinig prominente positie van de EPAs en 3) beperkte gelegenheid voor hands-on ervaring in acute zorg.

Heterogeniteit in plaatselijk begrip van het ACTY programma, variatie in invoering op de werkplek en verschillen in mate van verbintenis van supervisors zijn tekenen van een imperfecte implementatie. Deelnemers opperen juist getimede informatie verstrekking, training van supervisors en het creëren van een netwerk van supervisors als verbeterstrategieën. Deelnemers vinden dat de EPAs een centrale positie in het ACTY curriculum dienen te krijgen, door de werkplekevaluatie en beoordeling van studenten rond de EPAs vorm te geven en te werken richting bekwaamverklaringen. De komst van het nieuwe curriculum voor de studie geneeskunde, gebaseerd op EPAs, vereenvoudigt 
de invoering van de ACTY EPAs waarschijnlijk. Essentieel is, volgens de deelnemers, het voorzien in voldoende hands-on betrokkenheid bij acute zorgverlening door middel van toekennen van een legitieme rol op de werkplek, ondersteund door instructie aan bed, discussies aan de hand van casuïstiek en simulatie training.

Self-determination theory helpt het ACTY effect te begrijpen. Met het coherente programma, de EPAs en de pre-test met zijn persoonlijke feedback wordt voldaan aan de psychologische behoefte aan competentie. De leergemeenschap van gelijkgestemde studenten vervult de behoefte aan betrokkenheid. Door het neerzetten van een ondersteunende omgeving met peers, begeleiders en mentoren wordt deels voldaan aan de behoefte tot autonomie. Met de behoeften goeddeels vervuld, wordt de natuurlijke geneigdheid om te ontwikkelen gestimuleerd.

Hoofdstuk 4 beschouwt de simulatie pre-test aan het begin van het ACTY nader. Vygotsky's Zone van naaste ontwikkeling (Zone of proximal development, ZPD) refereert aan de ruimte tussen wat een lerende beheerst en wat ze moet beheersen in het volgende ontwikkelingsstadium. Heeft het zelfstandig behandelen van kritiek zieke "patiënten" in de simulatie pre-test, aan de buitengrens van de ZPD, geleid tot destructieve frictie en ontmoediging? Het fenomenologisch onderzoek beoogt het psychosociale en onderwijskundige effect van de simulatie pre-test te doorgronden door diepte-interviews met individuele ACTY studenten over hun simulatie ervaring. De essentie van hun ervaring is dat ze worstelden met de gesimuleerde acute zorg situaties, hetgeen leidde tot stress, aangewakkerd door onzekerheid over de behandeling, verslechtering van de simulatie patiënt en teleurstelling over hun optreden. De stress verminderde het cognitief functioneren. Echter, de formatieve oefen-setting, anticipatie op een matig optreden, debriefing, een veilige omgeving en het vooruitzicht van trainingsgelegenheden reguleerden de emotionele respons op stress en maakten van een gespannen simulatie een motiverend onderwijsmoment.

De belangrijkste bevinding van het onderzoek is dat in een veilige, formatieve pre-test setting, simulaties aan de buitengrens van de ZPD niet leiden tot ontmoediging en destructieve frictie, maar juist tot constructieve frictie en motivatie om te groeien. Deze bevinding impliceert dat een simulatie pre-test aan de buitengrens van de ZPD, voorbij traditionele grenzen, veilig kan worden toegepast.

Hoofdstuk 5 evalueert het effect van het ACTY op het leren en de voorbereiding voor de praktijk, dat wil zeggen in welke mate afstudeerders aan de verwachtingen voldoen die in de acute zorg aan hen zullen worden gesteld. Het hoofdstuk beschrijft een quasi- 
experimenteel onderzoek met een pre-test \& post-test design, waarin deelnemers een multimodale toets aflegden van kennis, klinisch redeneren en behandelplan maken, praktische vaardigheden en optreden in simulaties op het gebied van acute zorg.

De studie vergelijkt de test resultaten van ACTY studenten met die van studenten die niet aan het programma deelnamen - maar wel interesse in acute zorg hadden en met die van jonge dokters met zes maanden klinische ervaring in de acute zorg. De toets bestond uit een schriftelijke kennistest, case-based discussions, Objective Structured Clinical Examination vaardighedenstations en high-fidelity simulaties van kritiek zieke patiënten die met spoed zorg nodig hadden. Elk station in de toets leverde een checklist score op, berekend als het behaalde aantal punten als percentage van het maximum aantal punten. Daarnaast rapporteerden examinatoren een gestalt, expert oordeel van overall optreden in dat station op een driepunts globaal oordeel schaal (global rating scale, GRS) in antwoord op de vraag "hoe verhoudt het optreden van de deelnemer zich tot het te verwachten niveau van een jonge dokter met zes maanden klinische ervaring?" (voldoet niet aan de gestelde verwachting - voldoet krap aan de verwachting - voldoet aan de verwachting).

De studie toont aan dat studenten die via het ACTY afstuderen beter scoren in de toets dan andere studenten, met name op vaardigheden en simulaties. Jonge dokters scoorden beter dan ACTY afstudeerders. Daarnaast hadden ACTY studenten een hogere kans dan andere studenten om te voldoen aan het verwachte niveau van een jonge dokter met zes maanden ervaring, zoals gemeten op de GRS.

Zoekend naar een betere transitie naar het werk na afstuderen, vindt deze studie dat afstudeerders uit het ACTY beter op jonge dokters met klinische ervaring lijken dan andere afstudeerders, hetgeen suggereert dat ACTY afstudeerders beter voorbereid zijn op de acute zorg uitdagingen die de jonge dokter het hoofd moet bieden.

Dit laatste studiejaar, gewijd aan acute zorg, verbetert leren en geeft een betere voorbereiding op werken in dit domein. Andere schakeljaren, met multidisciplinair perspectief op een ander thema, zouden op gelijke wijze het leren kunnen verbeteren en beter kunnen voorbereiden op werk of vervolgopleiding binnen een gebied.

De medische vervolgopleiding anesthesiologie komt voort uit het traditionele meestergezel-model dat is gebaseerd op tijdsduur en stages. Principes van competentiegericht opleiden hebben mogelijkerwijs geleid tot evolutie van dit model in verschillende richtingen, maar de mate van overeenkomsten en verschillen is onbekend. Het doel van een internationale survey studie is om de Europese vervolgopleidingen anesthesiologie 
in Europa te vergelijken aangaande toetsings- en certificeringsprocedures (Hoofdstuk 6). Nationale vertegenwoordigers van alle lidstaten van de Union of European Medical Specialists/European Board of Anaesthesiology vulden een online questionnaire in met vragen in zowel open als gesloten format, leidend tot kwantitatieve en kwalitatieve data over de toetsings- en certificeringsprocedures. Niet alleen de duur van de opleiding varieert substantieel (mediaan 5 jaar, range 2.75 - 7), ook het aantal toetsinstrumenten loopt uiteen.

De studie categoriseert Europese opleidingsprogramma's volgens hun benadering van toetsing en certificering in een driehoekig model. Twee hoofd-oriëntaties waren aanwezig, die beiden hun oorsprong hebben in het traditionele meester-gezel model. Een had een onderliggende oriëntatie op kennis, met toetsing gericht op het zekerstellen van een adequaat kennisniveau, geëvalueerd middels een examen. De ander had een onderliggende procedurele oriëntatie, waarin de expertise van de aios wordt aangetoond met het voltooien van gespecificeerde aantallen procedures, getoetst middels een logboek. Landen binnen deze hoofd-oriëntaties vertoonden, in verschillende mate, de adoptie van elementen van een derde oriëntatie, te weten een competentiegerichte opleidingsaanpak. Het spectrum aan diversiteit en evolutie wordt grafisch weergegeven door de landen langs twee benen van een driehoek te positioneren.

Alhoewel de UEMS/EBA opleidingsrichtlijnen van een procedurele naar een competentiegerichte oriëntatie zijn gegaan, verandert de opleiding in Europa met wisselende snelheid in de richting van competentiegericht opleiden. De beweging richting competentiegericht opleiden gaat gepaard met het gebruik van een groter aantal toetsinstrumenten om de uiteindelijke summatieve beslissing over de bekwaamheid van de aios te maken.

Er is dus geen uniforme wijze van certificeren in Europa. De diversiteit in leerdoelen, toetsing en certificering bemoeilijkt een internationale vergelijking van training standaarden.

Hoofdstuk 6 geeft een compleet overzicht van huidige toetsings- en certificeringsprocedures, maar adresseert niet de kwaliteit van die procedures. Hoofdstuk 7 behandelt de kwaliteit van de toetsings- en certificeringsprocedures in de opleiding tot anesthesioloog in Europa en beoogt de basis die ten grondslag ligt aan de certificeringsbeslissing te doorgronden. Het hoofdstuk is een korte rapportage - voorafgaand aan een complete publicatie - van een interviewstudie die een constructivistische Grounded theory benadering gebruikt. Het hoofdstuk focust zich 
op de vraag of degenen die certificeringsbeslissingen nemen vinden dat aios aan het eind van hun opleiding het competentieniveau van medisch specialist hebben bereikt, geframed als het toevertrouwen van de zorg voor hun geliefden. Deelnemers vormden een doelgericht sample van 26 anesthesiologen die direct betrokken zijn in het maken van certificeringsbeslissingen, met verschillende toetsings- en certificeringsprocedures zoals vastgesteld in Hoofdstuk 6. Dit onderzoek stelt verontrustend vast dat zij die dergelijke beslissingen maken de vraag"Zou u uw geliefden aan de aios die je certificeert toevertrouwen?" gelijkelijk bevestigend, twijfelend, of negatief beantwoordden. Sommige deelnemers bestempelden deze kwestie als de belangrijkste vraag rond certificering. Deelnemers gaven uitdrukking aan wisselende mate van vertrouwen in hun toetsingssysteem. Tien deelnemers onthulden dat ze aios hadden gecertificeerd die ze de ongesuperviseerde zorg voor hun geliefden niet zouden toevertrouwen, waarbij ze de schuld gaven aan een deficiënt toetsingssysteem, aan onmogelijkheden door wet- en regelgeving of aan prikkels om aios te laten slagen.

Gebrekkige toetsings- en certificeringssystemen, die nalaten alle facetten van competentie mee te wegen, leiden tot "vals positieven": gecertificeerd maar niet volledig competent.

Hoofdstuk 8 begint met het onderstrepen van het belang van gerechtvaardigde besluiten om taken aan aios te delegeren vanwege kwaliteit van zorg, aansprakelijkheid van de supervisor en onderwijskundige gepastheid. Vervolgens beschrijft het de rol van competentiegericht opleiden, met haar focus op opleidings-uitkomsten, in het voldoen aan de eis van maatschappelijke verantwoording. Daaropvolgend beschrijft het hoofdstuk het EPA concept om competentiegericht opleiden in de anesthesiologie te operationaliseren en enkele problemen van competentiegericht opleiden te verhelpen door competenties te verbinden met essentiële taken in de klinische praktijk. Door de nadruk op observatie van klinisch functioneren kunnen EPAs behulpzaam zijn in het zichtbaar maken van voortgang van de aios. EPAs maken bewuste, geïnformeerde, gerechtvaardigde besluiten mogelijk over het delegeren van taken aan aios. Dientengevolge, hebben EPAs potentie om inzichtelijk te maken dat aios ten tijde van certificering de bekwaamheid hebben die de beroepsgroep, controlerende instanties en de maatschappij van hen verwachten.

Tot besluit stelt het hoofdstuk een agenda op voor curriculumontwikkeling en onderzoek. De ontwikkeling van een op EPAs gebouwd curriculum begint met het bereiken van consensus over een set EPAs. Daarna wordt een gereedschapskist met toetsinstrumenten samengesteld voor robuuste beoordeling van het functioneren van de aios en onderbouwde bekwaamverklaringen. Beoordelaars behoeven training en kalibratie. Een portfolio moet worden gebouwd dat benaderbaar is met learning analytics technologie om voortgang weer te geven, aios en opleidingsinstituten te vergelijken 
en om de effecten van de implementatie van EPAs in de opleiding anesthesiologie te evalueren. Onderzoeksmogelijkheden zijn hier nauw aan gerelateerd. Voorbeelden zijn: het verkrijgen van consensus over een set EPAs, (inter-)nationaal vergelijken van opleidingen, validatie van toetsinstrumenten, het vaststellen van de rol van simulatietoetsen, identificatie van markers van professionele ontwikkeling, gebruiken van standaarden als cesuur, het gebruik van learning analytics voor het monitoren van de effecten van EPAs op de opleiding en tot slot het proces van bekwaam verklaren.

Dit proefschrift sluit af met een algemene discussie (Hoofdstuk 9). Het hoofdstuk markeert de belangrijkste bevindingen van het proefschrift en plaatst ze in perspectief van de literatuur. Het behandelt hoe coherentie, motivatie en werkplekleren het gunstige effect van het ACTY verklaren. Het hoofdstuk stelt een raamwerk voor van een continuüm in acute zorg EPAs. Verder beschrijft Hoofdstuk 9 hoe de opleiding tot anesthesioloog internationaal gezien verre van uniform is en behandelt de literatuur over EPAs in de anesthesiologie. Het hoofdstuk doet suggesties ten aanzien van vervolgonderzoek en eindigt met een visie op een opleidingscontinuüm dat bestaat uit afgestemde competentiegerichte fases, geoperationaliseerd met EPAs. 



\section{DANKWOORD}

De best gelezen bladzijden van dit boek. Graag moedig ik de lezer hier aan om ook de minder clichématige delen van dit boek te bekijken.

En ik laat hier ook de kans niet onbenut om u iets mee te geven: als ik één ding geleerd heb in dit traject is het wel dat leren een sociaal gebeuren is. Leren doe je niet alleen, maar samen met anderen, gesteund door anderen, reflecterend met anderen, opgepept of geïnspireerd door anderen; kortom leren vindt plaats in een interpersoonlijke context. Om werkelijk iedereen persoonlijk te bedanken voor zijn of haar rol in deze sociale omgeving gaat niet lukken, maar weet dat ik dankbaar ben voor de context waarin dit (ons!) leren mocht plaats hebben en plaats heeft.

Professor Ten Cate, beste Olle. "You're so privileged to have Olle as your supervisor", werd me meer dan eens verteld. Ik weet niet of je dat voorrecht als wederkerig hebt ervaren. Soms was ik lastig, ongrijpbaar, langzaam als buitenpromovendus van het slag medisch specialist. Veel dank voor je persistentie en je onuitputtelijke bron van ideeën en medische onderwijskundige kennis!

Professor Hoff, beste Reinier. Begonnen als mijn co-promotor, heb je die rol feitelijk vastgehouden toen je tweede promotor werd. Al coachend hielp je me het doel voor ogen houden, te relativeren, de ambitie dáár te houden. Als er een opleiding tot promotor was zou ik je wel een EPA beoordeling op niveau 4 willen geven. Veel dank in ieder geval!

Professor Kalkman, beste Cor. Mooi dat je, na de stap opzij voor Reinier, betrokken bleef bij mijn traject. Dank voor alle academische input, en je voorbeeld in de skill'academisch schrijven en schaven'.

Voor het onderzoek rondom het Dedicated Schakeljaar gaat mijn dank uit naar de medeontwikkelaars van het DSJ, medewerkers van de afdeling KVO, van het Simulatiecentrum Rijnstate, en iedereen die deelnam aan de studies of als examinator optrad en aan student onderwijskunde Mirja voor het validiteitsargument. Speciale dank aan de co-auteurs voor het verzette werk: Stefan, Eveline, studenten onderwijskunde Rhodé \& Charissa, Fedde (kwalitatief onderzoek, met jouw achtergrond: blijft gaaf), Myra en Jacqueline.

Beste Eveline, speciale dank aan jou voor het meedenken over de opzet en voor het runnen van de toets, je optimisme en natuurlijk de uurtjes achter mappen en computer om de dataset loepzuiver te krijgen. 
Dr Reitsma, beste Hans, heel veel dank voor de statistische hulp. Jouw focus op 'Welk verhaal kun je vertellen met deze data?' was een groot inzicht.

Voor de studies over de opleiding tot anesthesioloog gaat mijn dank uit naar de deelnemers en de co-auteurs Lieke (natuurlijk ook voor de driehoek), Adi, Elisabeth (and thanks for motivating EBA reps to partcipate!) en Annelot (interviewen was mooi: "Look, that apartmentbuilding is on fire!") en onderwijskunde student Frederique voor het meedenken over onderzoeksmogelijkheden.

Dank aan alle mede-promovendi in het 'klasje van Olle' voor het samen leren over onderwijskunde in de health professions. Nienke, dank voor de samenwerking, voordat het pad van je opleidingscontinuüm een andere richting nam. Prof Van der Schaaf, beste Marieke, dank voor je support aan mijn onderzoek en activiteiten!

Beste Marcella, dank voor je steun, begrip en geduld, maar niet te vergeten het'protecten' van onderzoekstijd. Dank ook aan alle anesthesiologen en aios voor het accepteren van mijn letterlijke of figuurlijke afwezigheid. Professor Buhre, beste Wolfgang, professor Van Klei, beste Wilton en beste Desiree, Bas, Yorick \& Francesca, dank voor het gestelde vertrouwen en geven van ruimte aan mijn ontwikkeling. Professor Knape, beste Hans, "overal 'nee' op zeggen, dat moet je doen om zo'n traject te volbrengen", dat stuk voor de komma is mislukt, maar het volbrengen is gelukt. Dank voor je support.

Raymond, ik ben vereerd dat ik jou, 25 jaar na onze ontmoeting op de Schuit, als een van de eersten kon vertellen dat het af was. Dank voor het actieve meedenken over de voorkant en top dat je mijn paranimf bent (kunnen we weer eens een rokkostuum aan)!

Lieber Adi, in den sechs Jahren seit Du mich ein Email geschickt hast infolge des EJA Artikels (das jetzige Kapitel 8) hat sich nicht nur ein schöner Seinesgleichenkontakt (Du der Schweizer Gersten und ich der Niederländische Adi) sondern auch eine sehr wertvolle Freundschaft entwickelt. Danke daß Du mein Paranimf bist!

Lieve pa en ma, lieve schoonouders, dank voor de erkenning en herkenning van dit wetenschappelijke werk; dat was echt van steun. Beste vrienden, lieve familie, dank voor jullie trouw. Ik weet vast nog de weg naar jullie van onder mijn steen vandaan.

Lieve Benjamin, bedankt voor je interesse in en verwondering over deze klus. Lieve Jonathan, zonder klagen accepteerde jij als ik weer aan de bak moest: zo ben je. Dankjewel. Lieve Victorine, dit project is ongeveer zo oud als jij. Love you omgevallen acht. 
Lieve Emilie, aan jou ben ik vanzelfsprekend de allermeeste dank verschuldigd. Ontdaan van alle clichés komt het neer op: ik hou van jou. 



\section{CURRICULUM VITAE}

Gersten Jonker, geboren op 4 november 1976 in Leek, studeerde Geneeskunde aan de Rijksuniversiteit Groningen (1995 - 2002). Hij richtte zich in de keuzeruimte op de diverse facetten van de anesthesiologie, inclusief een keuze co-assistentschap in het Universitair Medisch Centrum Utrecht (prof. Knape). Alvorens te starten met de medische vervolgopleiding tot anesthesioloog (2003 - 2008, Sint Antonius Ziekenhuis, Nieuwegein, opleiders dr. Leusink, dr. Van Dongen en dr. Bruins) werkte hij een klein jaar als arts-assistent niet in opleiding op de Intensive Care Volwassenen van het Academisch Medisch Centrum in Amsterdam (2002 - 2003, prof. Vroom). Gersten's enthousiasme voor de perioperatieve zorg voor kinderen mondde na voltooiing van de opleiding uit in een fellowship kinderanesthesiologie in het Wilhelmina Kinderziekenhuis (2008 - 2009, drs. Van der Werff, prof. Knape) en een fellowship paediatric intensive care \& anaesthesia in het Royal Hospital for Sick Children in Glasgow, Schotland (2009 - 2011, dr. Bolton). Sinds 2011 is hij als anesthesioloog verbonden aan het Wilhelmina Kinderziekenhuis en het UMC Utrecht en heeft hij zich vanaf 2013 toegelegd op medisch onderwijskunde, waarvan een Basis en Senior Kwalificatie Onderwijs (UMC Utrecht), twee postgraduate certificates (University of Dundee, UMC Utrecht) en dit proefschrift getuigen. Sinds 2018 is hij plaatsvervangend opleider anesthesiologie in het UMC Utrecht.

Gersten woont in Utrecht met zijn vrouw Emilie. Samen hebben ze drie kinderen: Benjamin, Jonathan en Victorine. 



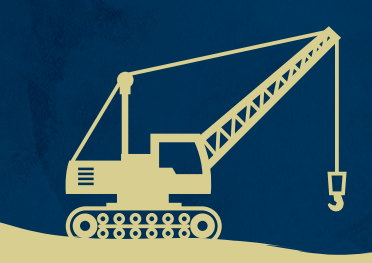

